Con motivo de completar 100 números de Estudios Internacionales, en esta ocasión hemos querido hacer una publicación especial que incluye un índice general de la revista.

Realizado conjuntamente con la Biblioteca del Instituto de Estudios Internacionales, este índice ha sido clasificado en forma cronológica, por autores, por descriptores y secuencial. Este último ordenamiento tiene por finalidad el poder usar el índice de descriptores, ya que cada articulo se ha identificado con un número especial que no necesariamente es correlativo.

Esperamos que este índice sea de gran utilidad para nuestros suscriptores y los lectores en general. 


\title{
Indice Cronologico
}

\author{
Estudios Internacionales \\ Nos. 1-99
}

\section{$N^{0} 1$, abril 1967, año I}

02284 Véliz, Claudio "El Instituto de Estudios Internacionales", pp. 3-7.

02291 Toynbee, Arnold "El estudio de la historia contemporánea", pp. 8-20.

02238 Herrera Lane, Felipe "Viabilidad de una comunidad latinoamericana", pp. 21-42.

02316 Sunkel, Osvaldo "Política nacional de desarrollo y dependencia externa", pp. 43-75.

02208 Gittings, John "iTiene China una política exterior?", pp. 76-94.

02237 Gott, Richard "El sur de Africa y el fin de la guerra fría", pp. 95-109.

02289 Texto de la Declaración Conjunta emitida por los Presidentes de Chile, Don Eduardo Frei, y de Zambia, señor Kenneth Kaunda, Santiago, 30 de noviembre de 1966; pp. 115-118.

\section{$\mathrm{N}^{0} 2$, jửio 1967, año I}

02315 Vernant, Jacques "El mundo, Europa y Francia", pp. 123-136.

02314 Younger, Kenneth "El papel de Gran Bretaña en la política internacional", pp. 137-155.

02233 Joxe, Alain "Hacia una nueva concepción de la seguridad europea", pp. 156-188. 
02301 Wallis, Víctor "La experiencia del Brasil con una política exterior independiente", pp. 189-211.

02206 Gittings, John "Ultimos libros sobre Vietnam", pp. 212-226.

02290 Acta de los Acuerdos de la Reunión de Presidentes (Punta del Este, Uruguay, 14 de abril de 1967), pp. 252-271.

02288 Carta enviada por Ernesto "Che" Guevara al Secretario Ejecutivo de la Organización de Solidaridad de los Pueblos de Africa, Asia y América Latina (OSPAAAL), La Habana, abril de 1967; pp. 272-282.

\section{No3-4, octubre-marzo 1967-1968, año I}

02201 Frondizi, Arturo "El problema nacional de América Latina y ciertos esquemas de integración regional", pp. 285-303.

02225 Gurley, John G. "El desarrollo económico de China comunista", pp. 304-322.

02203 Furtado, Celso "La concentración del poder económico en los Estados Unidos y sus proyecciones en América Latina", pp. 323-336.

02300 Wertheim, W. F. "Indonesia antes y después del Golpe de Untung", pp. 357-352.

02212 García, Antonio "Proceso y frustración de las reformas agrarias en América Latina", pp. 353-410.

02299 Lowenthal, Richard "Alemania y el fin del sistema bipolar en la política internacional", pp. 411-426.

02177 Almeyda, Clodomiro "La OLAS y la crisis política en América Latina", pp. 427-442.

02226 Gott, Richard "El Congo a partir de Mobutu", pp. 443-489.

02241 Parte final de la Declaración General de la Primera Conferencia de la Organización Latinoamericana de Solidaridad, La Habana, agosto 1967; pp. 440-442.

$02287 \mathrm{El}$ acuerdo entre GECOMIN y la Société Générale des Minerais, Kinshasa, 15 de febrero de 1967; pp. 485-487.

\section{$N^{0} 5$, abril-junio 1968, año II}

02207 Gittings, John "El Ejército Popular de Liberación y la Revolución Cultural", pp. 3-37.

02223 Herrera Amílcar O. "La ciencia en el desarrollo de América Latina", pp. 38-63.

02222 Kolkowicz, Roman "Una herejía santificada: Idea y realidad del Ejército Rojo", pp. 64-84.

02363 Gott, Richard "La experiencia guerrillera en Bolivia", pp. 85-114. 
02298 Joxe, Alain "Cohetes anticohetes: Regreso a las estrategias defensivas", pp. 115-137.

02755 Véliz, Claudio; García, Antonio; Vernant, Jacques "El seminario de Arica", pp. 138-150.

02221 Barraclough, Solon Z. "Integración en América Central", pp. 151157.

\section{$N^{\circ} 6$, julio-septiembre 1968, año II}

02218 Kaplan, Marcos "Estado, dependencia externa y desarrollo en América Latina", pp. 179-213.

02194 Devillers, Philippe "Francia y la Segunda Guerra del Vietnam", pp. 214-241.

02195 Díaz Alejandro, Carlos "El Grupo Andino en el proceso de integración latinoamericana", pp. 242-257.

02322 Hirschman, Albert O. "Liderazgo, percepción del cambio y subdesarrollo", pp. 258-270.

02345 Naudon, Carlos "Cinco libros sobre Israel", pp. 271-275.

02297 Joxe, Alain "Doctrina estratégica y guerras de intervención", pp. 276-286.

02240 Convenio Constitutivo de la Corporación Andina de Fomento; pp. 295-312.

\section{$N^{0} 7$, octubre-diciembre 1968, año II}

02344 Ortíx, Eduardo "Jaime Eyzaguirre", pp. 315-316.

02296 Thomson, James C. "Vietnam: un caso clásico", pp. 317-331.

02295 Sábato, Jorge A. "Energía atómica en Argentina", pp. 332-357.

02196 End, Heinrich "La política exterior del gobierno Kissinger-Brandt", pp. 358-367.

02219 Godoy, Horacio H. "La integración de América Latina y el proceso del poder mundial", pp. 368-386.

02294 Silva Castro, Raúl "Juan Egaña, precursor de la integración latinoamericana", pp. 387-405.

02182 Bambirra, Vania "La revolución cultural y el marxismo", pp. 406416.

02220 Feder, Ernest "Desarrollo agrícola y crecimiento económico", pp. 417-422. 


\section{$N^{0} 8$, enero-marzo 1969; año II}

02180 Baltra, Alberto "América Latina y la Segunda UNCTAD", pp. 449460.

02293 O'Brien, Philip "La Alianza para el Progreso y los préstamos por programa a Chile", pp. 461-489.

02814 Petras, James "Estados Unidos y el nuevo equilibrio en América Latina", pp. 490-518.

02292 Sunkel, Osvaldo "La tarea política y teórica del planificador en América Latina", pp. 519-529.

02189 Ciria, Alberto "La comunicación política en América Latina: algunos de sus problemas", pp. 530-542.

02217 Kaiser, Karl "Una nueva política oriental en Alemania", pp. 543-564.

02176 Acosta, Mercedes; Vilas, Carlos María "Santo Domingo y Checoslovaquia en la Política de Bloques", pp. 565-576.

\section{$N^{0} 9$, abril-junio 1969, año III}

02282 Véliz, Claudio "Centralismo, nacionalismo e integración", pp. 3-22.

02281 Sunkel, Osvaldo "Esperando a Godot: América Latina antela nueva administración republicana de los Estados Unidos", pp. 23-31.

02187 Burton, J. W. "No-alineación y política mundial contemporánea", pp. 32- 17 .

02257 Hoffmann, Stanley "El estilo norteamericano: su pasado, sus principios", pp. 48-62.

02280 Ortíx, Eduardo "Las grandes potencias y la crisis de Nigeria", pp. 63-76.

\section{$N^{0} 10$, julio-septiembre 1969, año III}

02185 Bognar, Jozsef "Reforma económica en Hungría", pp. 107-123.

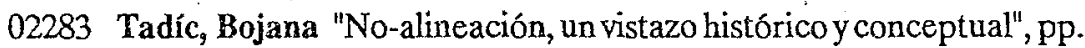
124-143.

02279 Wátkins, Melville H. "Canadá: industria y propiedad extranjera", pp. 144-157.

02278 Martins, Luciano "Mayo de 1968: una revolución nueva e intransitiva", pp. 158-185.

02277 Kaplan, Marcos "Corporaciones públicas multinacionales para el desarrollo y la integración", pp. 186-230.

02275 Mensaje de los Estados signatarios del Tratado de Varsovia à los paises europeos; pp. 231-235. 
02276 Discurso del Presidente Nixon en la sesión conmemorativa del Tratado de la Organización del Atlántico Norte; pp. 236-242.

\section{$N^{0} 11$, octubre-diciembre 1969, año III}

02423 Joxe, Alain "¿Fin de la preponderancia estratégica norteamericana?", pp. 273-320.

02815 Millar, T. B. "Los océanos Indico y Pacífico: algunas consideraciones estratégicas", pp. 321-351.

02273 Orrego Vicuña, Francisco "Dilemas en el Grupo Andino", pp. 352371.

02213 Faúndez, Julio "El sistema interamericano de seguridad en la política exterior de Estados Unidos", pp. 372-392.

02286 Mensaje a la Nación del Presidente de la República del Perú, General Juan Velasco Alvarado sobre la Reforma Agraria, Lima, 24 de junio de 1969; pp. 393-402.

02285 Consenso Latinoamericano de Viña del Mar; pp. 403-418.

\section{$N^{0} 12$, enero-marzo 1970, año III}

02729 Cotler, Julio "Crisis política y populismo militar en el Perú", pp. 439-488.

02726 Torres-Rivas, Edelberto "Desarrollo, integración y dependencia en Centroamérica", pp. 489-511.

02727 Tomassini, Luciano "La misión imposible del presidente Nixon", pp. 512-543.

02728 Bodenheimer, Susanne "La crisis del Movimiento Socialdemócrata en América Latina", pp. 544567.

\section{No13, abril-junio 1970, año IV}

02216 Mirski, Gueorgui "El papel político del ejército de los países en Asia y Africa", pp. 3-20.

02272 Oldfelt, Carin "Estudio comparativo sobre zonas pesqueras en el mundo", pp. 21-37.

02324 Teitelboin, Sergio "Los países del Pacífico Sur y el mar territorial", pp. 38-59.

02271 Sunkel, Osvaldo "La Universidad Latinoamericana ante el avance científico y técnico; algunas reflexiones", pp. 60-89.

02343 Petras, James; Rimensnyder, Nelson "Los militares y la modernización del Perú", pp. 90-123. 
02211 Mattelart, Marcel "La dependencia de los medios de comunicación de masas en Chile", pp. 124-154.

\section{$\mathrm{N}^{0} 14$, julio-septiembre 1970 , año IV}

02215 Joxe, Alain; Cadena, Cecilia "El armamentismo de los países dependientes: el caso latinoamericano", pp. 3-81.

02262 Murphy, Cornelius F, "Coacción económica y tratados desiguales", pp. 82-103.

02242 Gittings, John "La nueva guerra de Indochina", pp. 104-116.

02214 Croner, Claes "Estudios sobre el subdesarrollo colombiano: comentario crítico", pp. 117-132.

02210 Luna, Julio "El desarrollo pesquero y la integración regional", pp. 133-149.

\section{No15, octubre-diciembre 1970, año IV}

02270 Sathyamurthy, x. V. "Las relaciones internacionales asiáticas: perspectivas contemporáneas", pp. 3-41.

02269 Petras, James "Venezuela: una década de democracia capitalista", pp. $42-59$.

02197 Faúndez, Julio "El Presidente de Estados Unidos y la facultad para hacer la guerra", pp. 60-83.

02268 Kalecki, Michal; Kula, Marcin "Notas sobre los aspectos sociales y económicos de los 'regímenes intermedios': el caso de Bolivia", pp. 84-96.

02267 Sepúlveda, Alberto "El militarismo desarrollista en América Latina", pp. 97-124.

\section{$N^{0} 16$, enero-marzo 1971, año IV}

02261 Sunkel, Osvaldo "Capitalismo transnacional y desintegración nacional en América Latina", pp. 3-61.

02260 Véliz, Claudio "Cambio y continuidad: El Pacto Andino en la historia contemporánea", pp. 62-92.

02259 Ribeiro, Darcy "El desafío de la marginalidad", pp. 93-125.

02323 Thomas, Hugh "Cuba: la revolución y sus raíces históricas", pp. 126157.

02258 Kadar, Bela "Los países pequeños en la economía mundial", pp. 158-188.

02342 Discurso pronunciado por el Ministro de Relaciones Exteriores de 
Chile, señor Clodomiro Almeyda ante la Asamblea General de los Estados Americanos, reunida en San José de Costa Rica, el 15 de abril de 1971; pp. 189-198.

\section{$N^{0} 17$, enero-marzo 1972, año $\mathrm{V}$}

02175 Aberastury, Marcelo "Asia Oriental y Meridional y el Pacífico: Inicios de 1972", pp. 3-24.

02341 Mihaly, Eugene B. "La estrategia de los Estados Unidos en el Pacífico Occidental y el dilema de Micronesia", pp. 25-39.

02395 Grant, Bruce "Australia y el Pacífico", pp. 40-52.

02339 Holbraad, Carsten "El papel de las potencias medias en la política internacional", pp. 53-75.

02340 Merlini, Cesare "La posición internacional de Italia. Oportunidades y tentaciones", pp. 76-91.

02338 Jaguaribe, Helio "El equilibrio ecológico mundial y los países subdesarrollados", pp. 92-123.

\section{$N^{\circ} 18$, abril-junio 1972, año $V$}

02335 Ribeiro, Darcy "Nuevos caminos de la Revolución Latinoamericana", pp. 3-28.

02334 Niekerk, Arnold van "La pendiente de la dependencia: Una visión desde afuera", pp. 29-40.

02190 Clarkson, Stephen "La intelligentsia satélite: los intelectuales canadienses frente a los Estados Unidos", pp. 41-67.

02333 Ogelsby, J. C. M. "Relaciones canadiense-latinoamericanas, pasadas, presentes y futuras", pp. 68-87.

02331 Tomassini, Luciano "Implicaciones internacionales del deterioro ambiental", pp. 88-118.

02,332 Discurso pronunciado por el Presidente Constitucional de la República Mexicana, Lic. Luis Echeverría Alvarez, en la reunión plenaria del Tercer Período de Sesiones de la Conferencia de las Naciones Unidas sobre Comercio y Desarrollo, Santiago de Chile, 19 de abril de 1972; pp. 119-127.

02330 Exposición del Señor Enrique V. Iglesias, Secretario Ejecutivo de la Comisión Económica para América Latina en el Tercer Período de Sesiones de la Conferencia de las Naciones Unidas sobre Comercio y Desarrollo, Santiago, 25 de abril de 1972; pp. 128-141. 


\section{$\mathrm{N}^{0} 19$, julio-septiembre 1972, año $\mathrm{V}$}

02337 Schmitter, Philippe C. "La portugalización de Brasil", pp. 3-55.

02336 Moran, Theodore H. "Nuevo trato a las materias primas", pp. 56-70.

02205 Girvan, Norman "El conflicto de Guyana-Alcan y la nacionalización de Demba", pp. 71-90.

02191 Claverie Rodríguex, Heliodoro; Echeverría, Pedro Luis; Villalba Vera, Jovito "El tratado modificado de reciprocidad comercial entre Venezuela y los Estados Unidos", pp. 91-102.

02184 Bernstein, Enrique "Situación política en víspera de mayo de 1968", pp. 103-166.

\section{$N^{\circ} 20$, octubre-diciembre 1972, año $V$}

02178 Araujo Castro, José Augusto de "El continente americano dentro de la problemática mundial", pp. 3-39.

02181 Ball, W. MacMahon "Australia en el Pacífico"; pp. 40-52.

02266 Kojima, Kiyoshi "Un área de libre comercio del Pacífico", pp. 53-66.

02265 Snow, Peter G. "Desarrollo económico y seguridad nacional en el régimen militar argentino", pp. 67-74.

02263 Declaración conjunta constitutiva de la Comisión Andino-Argentina, establecida durante el $\mathrm{X}$ período ordinario de sesiones de la Comisión del Acuerdo de Cartagena, el 17 de noviembre de 1972; pp. 75-77.

02264 Comisión Mixta-Andino-Mexicana establecida durante el X período de sesiones ordinarias de la Comisión del Acuerdo de Cartagena, 17 de noviembre de 1972; pp. 78-84.

\section{$N^{\circ} 21$, enero-marzo 1973, año VI}

02224 Herrera Lane, Felipe "La tarea inconclusa: América Latina integrada", pp. 3-23.

02193 Delgado, Carlos "Sobre algunos problemas de la participación en la Revolución Peruana", pp. 24-43.

02192 Constantinesco, Leontin "Las relaciones Estados Unidos-Comunidad Económica Europea en la perspectiva de la Rueda Nixon", pp. 44-54.

02329 Moneta, Carlos J. "Argentina y Australia: esquemas para la cooperación", pp. 55-83.

02239 Discurso pronunciado por el Ministro de Relaciones Exteriores de Chile Clodomiro Almeyda M., en el III Período Ordinario de Sesio- 
nes de la Asamblea General de la Organización de Estados Americanos; pp. 84-96.

\section{$N^{0} 22$, abril-junio 1973, año VI}

02328 Pinto, Aníbal "Relaciones económicas entre América Latina y Estados Unidos: implicaciones y perspectivas políticas", pp. 3-31.

02327 Sunkel, Osvaldo "Relaciones económicas entre América Latina y Estados Unidos: comentarios al trabajo de Aníbal Pinto", pp. 32-43.

02326 Peña, Félix "El Grupo Andino: un nuevo enfoque de la participación internacional de los países en desarrollo", pp. 44-81.

02188 Byth, James "Niugini: una nueva nación cuprífera en el Pacífico se acerca a su independencia", pp. 82-105.

02200 Fogarty, John "Australia y el problema de las inversiones extranjeras", pp. 106-118.

02325 Discurso del Primer Ministro de Jamaica, señor Michael Manley, en la XIV Reunión de la Asamblea de Gobernadores del Banco Interamericano de Desarrollo; pp. 119-124.

\section{No23, julio-septiembre 1973, año VI}

02360 Silva Michelena, José A. "Tendencias recientes en la política mundial", pp. 3-22.

02204 Girvan, Norman "Teorías de dependencia económica en el Caribe y Latinoamérica: un estudio comparativo", pp. 23-60.

02362 Villagrán Kramer, Francisco "Mecanismos de regularización internacional de productos básicos", pp. 61-92.

02756 Niekerk, Arnold van "América Latina y las Antillas Neerlandesas", pp. 93-104.

02361 Exposición pronunciada por el Embajador del Brasil Miguel A. Ozorio de Almeida en el Vigésimoquinto Período de Sesiones de la CEPAL (Quito, marzo 27 de 1973); pp. 105-121.

\section{$N^{\circ} 24$, octubre-diciembre 1973 , año VI}

02198 Ferrer, Aldo "Relaciones económicas entre la Comunidad Económica Europea y América Latina", pp. 3-42.

02357 Pérez Llana, Carlos "América Latina y los paísts no alineados", pp. 43-65.

02358 Orrego Vicuña, Francisco "Algunos problemas de derecho internacional planteados por la nacionalización de la industria del cobre en Chile", pp. 66-88. 
02359 Discurso pronunciado por el Ministro de Relaciones Exteriores de Chile, Almirante Ismaei Huerta, ante la Asamblea de las Naciones Unidas, en Nueva York, el día 9 de octubre de 1973; pp. 89-106.

\section{$N^{\circ} 25$, enero-marzo 1974, año VII}

02365 Herrera Lane, Felipe "América Latina y el desafío internacional para la educación", pp. 3-15.

02366 Sagasti, Francisco R.; Guerrero, Mauricio "Situación de la ciencia y tecnología en América Latina", pp. 16-56.

02367 Sachs, Ignacy "Ecodesarrollo: un aporte a la definición de estilos de desarrollo para América Latina", pp. 57-77.

\section{$N^{0} 26$, abril-junio 1974, año VII}

02368 Jaguaribe, Helio "Los acontecimientos chilenos", pp. 3-19.

02369 Sigmund, Paul E. "El bloqueo invisible y la caída de Allende", pp. 20-38.

02370 Palma Vicuña, Ignacio "Aportes para un análisis de la crisis chilena", pp. 39-67.

02371 Declaración del Episcopado chileno sobre la reconciliación en Chile, Santiago, 24 de abril de 1974; pp. 68-73.

\section{No27, julio-septiembre 1974, año VII}

02318 Hurtado, Héctor; Pazos, Javier; Mayobre, Eduardo "El Caribe y Venezuela: integración de la integración", pp. 3-30.

02319 Moneta, Carlos J. "Africa y los grandes actores externos", pp. 31-75.

02320 Ireland, Rowan "La Iglesia Católica del Brasil: límites del aggiornamento", pp. 76-90.

02321 "América Latina en un contexto de grandes mutaciones internacionales"; anticipo del capítulo I del Estudio Económico de América Latina, 1973, de CEPAL; pp. 91-126.

\section{$N^{0} 28$, octubre-diciembre 1974, año VII}

02256 Godoy, Horacio H. "Los acuerdos entre los Estados Unidos y la Unión de las Repúblicas Socialistas Soviéticas", pp. 3-48.

02356 Imaz, José luis, de "¿Adiós a la teoría de la dependencia? Una perspectiva desdé la Argentina", pp. 49-75.

02186 Bull, Hedley "Las relaciones internacionalés como ocupación académica", pp.76-93. 


\section{$N^{0} 29$, enero-marzo 1975, año VIII}

02372 Tomassini, Luciano "Tendencias favorables o adversas a la formación de un sistema regional latinoamericano", pp. 3-46.

02373 Pérez Llana, Carios "¿Potencias intermedias o países mayores? La política exterior de Argentina, Brasil y México", pp. 47-105.

02374 Jaguaribe, Helio "El Brasil y la América Latina", pp. 106-136.

02375 Peña, Félix "Tendencias y perspectivas de la integración económica en América Latina", pp. 137-152.

02376 Acto constitutivo del Foro Latinoamericano; pp. 153-155.

\section{$\mathrm{N}^{0} 30$, abril-junio 1975, año VIII}

02202 Furtado, Celso "Una interpretación estructuralista de la "crisis" actual del capitalismo", pp. 3-47.

02199 Ferrer, Aldo "La crisis del Sistema Monetario Internacional: un enfoque estructuralista", pp. 48-99.

02364 Grant, James P. "Las naciones de la OPEP: ¿Asociados o competidores?", pp. 100-118.

02179 Aziz, Sartaj "Los verdaderos problemas de la crisis de alimentos", pp. 119-130.

\section{$\mathrm{N}^{0} 31$, julio-septiembre 1975, año VIII}

02351 Jaguaribe, Helio "El Vietnam y los Estados Unidos", pp. 3-18.

02183 Bergsten C., Fred "Relaciones económicas entre Estados Unidos y Latinoamérica: la estructura internacional y algunos enfoques posibles", pp. 19-41.

02350 Lafer, Celso "Una redefinición del orden mundial y la Alianza Latinoamericana. Perspectivas y posibilidades", pp. 42-58.

02354 Hansen, Roger "Relaciones económicas entre los Estados Unidos y América Latina. ¿Bilaterales, regionales o globales?", pp. 59-99.

02355 Hodara, Joseph "La coyuntura internacional: cuatro versiones", pp. 100-113.

\section{$N^{0} 32$, octubre-diciembre 1975, año VIII}

02317 Orrego Vicuña, Francisco "De la crisis de la energía al concepto del patrimonio económico de la humanidad: criterios para reestructurar el sistema económico internacional", pp. 3-32.

02353 Halty Carrere, Máximo "¿Hacia un nuevo orden tecnológico?", pp. $33-50$. 
02352 Palma, Pedro A. "Análisis del Sistema Monetario Internacional", pp. 51-102.

02349 Muñoz, Heraldo; Sánchez, Walter "La détente y el sistema internacional", pp. 103-122.

No33, enero-marzo 1976, año IX

02424 Graysón; George W. "Portugal y el movimiento de las Fuerzas Armadas", pp. 3-46.

02425 Sagasti, Francisco R. "Autodependencia tecnológica y cooperación en los países del Tercer Mundo", pp. 47-61.

02426 Langlois, Juan Carlos "Una nueva dimensión para los Bancos de Desarrollo", pp. 62-70.

02427 Muñoz, Heraldo "Dependencia estratégica y no-estratégica: materias primas y relaciones internacionales en la perspectiva de la crisis petrolera", pp. 71-108.

\section{No34, abril-junio 1976, año IX}

02377 Dam, André, van "El triunfo del caballo", pp. 3-9.

02378 Diamand, Marcelo "Las posibilidades de una técnica nacional en Latinoamérica: El caso argentino", pp. 10-41.

02754 Iglesias, Enrique V. "Transferencia de recursos en el ámbito internacional", pp. 42-57.

02379 Tironi B, Ernesto "Las estrategias nacionales de desarrollo y la integración de los países andinos", pp. 58-102.

\section{No35, julio-septiembre 1976, año IX}

02380 Fagen, Richard "La política exterior de los Estados Unidos y el desarrollo del Tercer Mundo", pp. 3-37.

02381 Lowenthal, Abraham F. "Ejércitos y política en América Latina", pp. 38-64.

02382 Sánchez, Walter "El triángulo Washington-Moscú-Pekín y el proceso de distension Internacional", pp. 65-117.

02383 Diálogo entre dos Continentes: Club de Roma y Foro Latinoamericano, Roma 1976; pp. 118-122. 


\section{$N^{0} 36$, septiembre-diciembre 1976, año IX}

02384 Jaguaribe, Helio "El estudio del futuro y de la supervivencia del hombre", pp. 3-10.

02385 Furtado, Celso "El conocimiento económico de América Latina", pp. 11-23.

02386 Sábato, Jorge A. "El cambio tecnológico necesario y posible", pp. 24-41.

02387 Niekerk, Arnold van "La sociología latinoamericana: un testimonio epistemológico", pp. 42-73.

02388 Uslar Pietri, Arturo "Lo espécífico del hombre latinoamericano", pp. 74-89.

02389 Discurso del Presidente Carlos Andrés Pérez pronunciado el 3 de mayo de 1976, con ocasión de la inaguración del Seminario América Latina, conciencia y nación, organizado en Caracas por el Instituto de Altos Estudios de América Latina de la Universidad Simón Bolívar; pp. 90-96.

\section{$N^{037}$, enero-marzo 1977, año $X$}

02390 Díaz Alejandro, Carlos "Relaciones Norte - Sur: el componente económico", pp. 3-44.

02391 Lowenthal, Abraham F. "El fin de la presunción hegemónica", pp. 45-67.

02392 Pérez Llana, Carlos "El legado de Henry Kissinger: algunas implicancias de su gestión", pp. 68-91.

02393 Aftalión, Marcelo E. "La política exterior norteamericana y América Latina", pp. 92-104.

02394 Diálogo sobre integración y desarrollo; pp. 105-109.

\section{$N^{0} 38$, abril-junio 1977, año $X$}

02396 Ffrench-Davis, Ricardo "Pacto Andino y libre comercio", pp. 3-11.

02397 Tironi B., Ernesto "La Decisión 24 sobre capitales extranjeros en el Grupo Andino", pp. 12-26.

02398 Valdés Subercaseaux, Gabriel "Situación del Grupo Andino en el contexto latinoamericano e internacional", pp. 27-46.

02399 Salgado, Germánico "Integración, conciliación de políticas y diferencias de estructura económica", pp. 47-66.

02400 Wilhelmy, Manfred "La política exterior chilena y el Grupo Andino", pp. 67-87. 
02401 Sobre el.Pacto Andino. Carta dirigida por el ex Presidente de Chile, señor Eduardo Frei, al director de El Mercurio de Santiago, el 28 de agosto"de 1976; pp. 88-93.

02402 Reformas al Pacto Andino: Discurso pronunciado por el Presidente de Colombia, señor Alfonso López Michelsen, en Medellín, el 18 de septiembre de 1976; pp. 94-106.

02403 Cuarta Reunión del Foro Latinoamericano, México, D. F., 7 al 9 de mayo de 1977; pp. 107-128.

\section{No39, julio-septiembre 1977, año X}

02404 Diamand, Marcelo "Hacia el cambio del paradigma económico a través de la experiencia de los países en desarrollo", pp.3-56.

02405 Flores de la Peńa, Horacio "Un nuevo modelo de desarrollo", pp. $57-80$.

02406 Iglesias, Enrique V. "Situación y perspectivas de América Latina", pp. 81-123.

\section{$N^{\circ} 40$, octubre-diciembre 1977 , año X}

02840 Diez años de Estudios Internacionales; pp. 3-4.

02407 Véliz, Claudio "Errores y omisiones: Notas sobre la política exterior de los países de América Latina durante los últimos diez años", pp. 5-12.

02408 Herrera Lane, Felipe "América Latina y el Tercer Mundo", pp. 1332.

02753 Sunkel, Osvaldo "El desarrollo de la teoría del desarrollo", pp. 3346.

02409 Jaguaribe, Helio "El Informe Linowitzy las relaciones Estados Unidos-América", pp. 47-59.

02410 Lagos, Gustavo "El Plan Carter y 'La Guerra de la Energía", pp. 60-88.

02411 Orrego Vicuña, Francisco "Las alternativas de América Latina como clase media de las naciones", pp. 89-110.

02412 Tomassini, Luciano "Falencias y falacias: notas sobre el estudio de las relaciones Norte-Sur", pp. 111-130.

\section{$N^{\circ} 41$, enero-marzo 1978, año XI}

02413 Ward, Bárbara "Perspectivas históricas del Nuevo Orden Económico Internacional", pp. 5-15.

02414 Haq, Mahbub ul "El Diálogo Norte-Sur: la segunda fase", pp. 16-26. 
02415 Tomassini, Luciano "Intereses mutuos: las verdaderas bases del Diálogo Norte-Sur", pp. 27-50.

02416 Sampaio Malan, Pedro "Las relaciones económicas internacionales del Brasil: notas para una agenda de investigación", pp. 51-72.

02417 Sábato, Jorge A. "El plän nuclear brasileño y la bomba atómica", pp. $73-82$.

02418 Vargas Hidalgo, Rafael "Estados Unidos y América Latina bajo la presidencia de Carter", pp. 83-119.

\section{$\mathrm{N}^{0} 42$, ab̉il-junio 1978, año XI}

02752 Ferrer, Aldo "La crisis del sistema trilateral y América Latina", pp. 3-38.

02419 Sewell, John "¿Pueden prosperar los países ricos sin que progresen Ios países pobres?", pp. 39-65.

02420 Perry, Guillermo "Mercados mundiales de manufacturas, industrialización y política comercial de los países en desarrollo", pp. 66-94.

02421 Iglesias, Enrique V. "¿Va América Latina hacia la bancarrota?", pp. 95-110.

02422 Wilhelmy, Manfred "La política exterior de Estados Unidos: dinámica interna y nuevos problemas", pp. 111-134.

\section{$N^{\circ} 43$, julio-septiembre 1978 , año XI}

02429 Prebisch, Raúl "Notas sobre el desarrollo del capitalismo periférico", pp. 3-25.

02428 Herrera Lane, Felipe "El desarrollo y las políticas culturales en América Latina", pp. 26-46.

02430 Lafer, Celso "El estudio de las relaciones internacionales: necesidades y perspectivas", pp. 47-56.

02451 Cepeda Ulloa, Fernando "La influencia de las agencias internacionales en el proceso de desarrollo de Colombia 1950-1974", pp. 57-75.

02452 Andrade Lieras, Gustavo "Hacia adónde va el Japón", pp. 76-89.

02453 Díax Albónico, Rodrigo "Los elementos objetivos y subjetivos en la definición internacional de la agresión", pp. 90-107.

\section{$N^{\circ} 44$, octubre-diciembre 1978, año XI}

$02751^{\circ}$ Sunkel, Osvaldo; Fuenzálida, Edmundo "Capitalismo transnacional y desarrollo nacional", pp. 3-27. 
02454 Villamil, José J. "El futuro del Caribe: su marco institucional", pp. 28-44.

02455 Godfrey, Martin; Langdon, Steven "iSocios en el desarrollo? La tesis de la transnacionalización en el contexto keniano", pp. 45-70.

02747 Griffith-Jones, Stephany "El crecimiento de la banca multinacional, los mercados de euromonedas y los países de la periferia", pp. 71-87.

02456 Muñoz, Heraldo "Cambio y continuidad en el debate sobre la dependencia y el imperialismo", pp. 88-138.

\section{$N^{0} 45$, enero-marzo 1979, año XII}

02457 Azevedo da Silveira, Antonio "Las relaciones entre América Latina y los Estados Unidos", pp. 3-13.

02458 Iglesias, Enrique V. "Perspectivas económicas de América Latina y sus implicaciones para los Estados Unidos", pp. 14-26.

02459 Ortíz Mena, Antonio "Las relaciones económicas entre América Latina y la OECD: nuevas perspectivas", pp. 27-35.

02460 Rostow, W. W. "Cómo romper la impasse en las negociaciones económicas multilaterales Norte-Sur", pp. 36-55.

02461 Valdés Subercaseaux, Gabriel "Reflexiones sobre el futuro de América Latina", pp. 56-67.

\section{N'46, abril-junio 1979, año XII}

02748 Jaguaribe, Helio "Autonomía periférica y hegemonía céntrica", pp. 91-130.

02462 Pérez Llana, Carlos "Perspectivas de América Latina en el diálogo Norte-Sur", pp. 131-143.

02463 Russell, Roberto; Carballal, Teresa "América Latina ¿Hacia qué nuevo orden internacional?", pp. 144-176.

02464 Casanova, Manuel "La participación de América Latina en el sistema económico internacional de la postguerra", pp. 177-203.

02465 Tomassini, Luciano "El nuevo orden económico internacional: varios enfoques", pp. 204-219.

\section{N47, julio-septiembre 1979, año XII}

02749 Levine, Flavián "¿Economía o economía política?", pp. 231-246.

02466 Bergsten C, Fred "Relaciones económicas entre los Estados Unidos y América Latinan", pp. 247-257. 
02467 González, Norberto "Prioridades de América Latina en el Diálogo Norte-Sur", pp. 258-274.

02468 Orrego Vicuña, Francisco "La legislación unilateral parä la explotación de los fondos marinos: su incompatibilidad con el derecho internacional", pp. 275-292.

02469 Zegers Santa Cruz, Fernando "El sistema antártico y la cuestión del aprovechamiento de los recursos en el área", pp. 293-321.

02470 Kñakal, Jan "Las empresas transnacionales en el desarrollo contemporáneo de América Latina", pp. 322-350.

\section{$N^{0} 48$, octubre-diciembre 1979, año XII}

02750 Botero, Rodrigo "La Comisión Brandt: una perspectiva latinoamericana", pp. 361-371.

02471 Grunwald, Joseph "El comercio intraindustrial Norte-Sur: compartir la producción industrial entre los países en desarrollo y desarrollados", pp. 372-389.

02472 Lagos, Gustavo; Klaveren, Alberto van "Las relaciones interamericanas en una perspectiva global", pp. 390-418.

02473 Chaparro, Patricio "El Sistema Económico Latinoamericano (SELA), como instancia de mediación, representación y acción política, ¿destinado al fracaso?", pp. 419-439.

02474 Wilhelmy, Manfred "Hacia un análisis de la política exterior chilena contemporánea", pp, 440-471.

02475 Barros Charlín, Raymundo "La elección del Parlamento Europeo por sufragio universal directo", pp. 472-494.

\section{$N^{\circ} 49$, enero-marzo 1980, año XIII}

02476 Ferrer, Aldo "La economía internacional desde una perspectiva latinoamericana", pp. 3-37.

02477 Berrocal Soto, Fernando "América Latina en la década de los 80", pp. 38-53.

02478 Lowenthal, Abraham F.; Fishlow, Albert "Los nuevos intereses de los Estados Unidos en el hemisferio occidental", pp. 54-69.

02479 Sábato, Jorge A.; Ramesh, Jairman "Programas de energía nuclear en el mundo en desarrollo: su fundamento e impacto", pp. 70-85.

02480 Sagasti, Francisco R. "Políticas de ciencia y tecnología para el desarrollo", pp. 86-111.

02481 Gligo, Nicolo;:Morello, Jorge "Notas sobre la historia ecológica de América Latina", pp. 112-148. 


\section{No50, abril-junio 1980, año XIII}

02482 Vélix, Claudio "La tradición centralista en América Latina", pp. 151162.

02483 Sunkel, Osvaldo; Tomassini, Luciano "La crisis del sistema transnacional y el cambio en las relaciones internacionales de los países en desarrollo", pp. 163-207.

02484 Ullman, Richard "Seguridad internacional en los ochenta", pp. 208235.

02485 Lagos, Gustavo "Tendencias y perspectivas del estudio de las relaciones internacionales: tareas para América Latina", pp. 236-251.

02743 Grabendorf, Wolf "Perspectivas y polos de desarrollo en América Latina", pp. 252-278.

\section{$N^{0} 51$, julio-septiembre 1980, año XIII}

02486 Lagos, Ricardo "América Latina: algunos hechos económicos recientes y su poder de negociación"; pp. 291-308.

02487 Lafer, Celso "La política exterior brasileña: Balance y perspectivas", pp. 309-327.

02488 Muñoz, Heraldo "Los estudios internacionales en América Latina: problemas fundamentales", pp. 328-344.

02489 Díaz Albónico, Rodrigo "El sistema de seguridad interamericana y sus nuevos desarrollos a través del Tratado de Tlatelolco", pp. 345381.

02490 Marcella, Gabriel "Las relaciones militares entre los Estados Unidos y América Latina. Crisis e interrogantes futuras", pp. 382-400.

02491 Mols, Manfred "Observaciones europeas sobre la integración latinoamericana", pp. 401-412.

\section{$N^{0} 52$, octubre-diciembre 1980 , año XIII}

02492 Almeida, Rómulo "Reflexiones sobre la:integración latinoamericana", pp. 417-459.

02493 Tulchin, Joseph S. "Una perspectiva histórica de la política argentina frente al Brasil", pp. $460-480$.

02494 Moneta, Carlos J. "América Latina y el sistema internacional en la década del ochenta: ¿Hacia un nuevo orden antártico?", pp. 481-526.

02495 Green, Rosario "La importancia del estudio de las relaciones internacionales de los países latinoamericanos", pp. 527-544. 
02496 Tomassini, Luciano "Los estudios internacionales en América Latina: algunas contribuciones", pp. 545-552.

\section{No53, enero-marzo 1981, ańo XTV}

02497 Orrego Vicuña, Francisco "Europa y América Latina: ¿Hacia un rol internacional complementario?", pp. 3-16.

02499 Sábato, Jorge A.; Caputo, Dante M.; Sábato, Jorge F. "Cooperación para el desarrollo: algunas reflexiones y propuestas", pp. $17-47$.

02500 Salgado, Germánico "Discurso pronunciado con motivo de la celebración del día de las Naciones Unidas, en Santiago el día 24 de octubre de $1980^{\prime \prime}$, pp. 48-54.

02501 Russell, Roberto; Carballal, Teresa "El Nuevo Orden Económico Internacional: tendencias observables en el Norte y en los países mayores de América Latina", pp. 55-88.

02502 Drekonja Kornat, Gerhald "Aproximaciones a la política exterior latinoamericana", pp. 89-104.

02503 Alcalde Cardoza, Javier "Las relaciones económicas internacionales en la década del 80", pp. 105-135.

\section{$\mathrm{N}^{0} 54$, abril-junio 1981, año XIV}

02504 Pinto, Anibal "Guerra Fría y distensión en América Latina: a la luz de los ensayos de don José Medina Echavarría", pp. 145-165.

02505 Abdenur, Roberto; Sardenberg, Ronaldo "Notas sobre las relaciones Norte-Sur y el Informe Brandt", pp. 166-200.

02506 Wionczek, Miguel S. "¿Qué puede hacerse con el Informe Brandt?", pp. 201-223.

02507 Nitsch, Manfred "Los intereses de los países ricos y el desarrollo del Tercer Mundo: La República Federal de Alemania", pp. 224-253.

02508 Perry, Guillermo "El Informe Brandt y el comercio de productos industrializados", pp. 254-265.

02509 Los Documentos de Villa de Leyva; pp. 266-287.

\section{$N^{0} 55$, julio-septiembre 1981, año XIV}

02510 Iglesias, Enrique V. "Perspectivas del desarrollo de América Latina", pp. 311-321.

02511 Sánchez, Walter "Las relaciones internacionales de América Latina: marginalidad y autonomía", pp. 322-356. 
02512 Lafourcade, Hernán "Perspectivas del desarrollo de los recursos marinos en América Latina", pp. 357-379.

02513 Pinochet de la Barra, Oscar "Evolución política jurídica del problema antártico", pp. 380-393.

02514 María, Luis G. de "Balance político y económico de la integración andina durante 1980", pp. 394-411.

02515 Nohlen, Dieter; Fernández B., Mario "Cooperación y conflicto en la Cuenca del Plata", pp. 412-443.

\section{$N^{0} 56$, octubre-diciembre 1981, año XIV}

02516 Urquidi, Yíctor L.; Sánchez, Vicente; Terrazas, Eduardo "Perspectivas y alternativas de América Latina ante los problemas mundiales", pp. 447-473.

02517 Lagos, Gustayo "Entre la détente y la Guerra Fría: La crisis del destino manifiesto de las superpotencias", pp. 474-499.

02518 Varas, Augusto "La renserción de América Latina en el marco estratégico mundial", pp. 500-516.

02519 Roett, Riordan "iTienen los Estados Unidos algún futuro en América Latina?", pp. 517-529.

02520 Soares de Lima, M. Regina; Hirst, Mónica "Estados Unidos y América Latina: cerrando una época en descomposición", pp. 530552.

02521 Pérez Llana, Carlos "Brasil y Europa: el problema de las percepciones", pp. 553-567.

02522 Orrego Vicuña, Francisco "Hacia nuevas formas de integración. económica en América Latina: lecciones de una experiencia", pp. 568-577.

\section{$N^{0} 57$, enero-marzo 1982, año XV}

02523 Saraiva Guerreiro, Ramiro "La política latinoamericana del Brasil", pp. 3-9.

02524 Jaguaribe, Helio Brasil-Argentina: Breve análisis de las relaciones de conflicto y cooperación", pp. 9-27.

02525 Peña, Félix "Perspectivas de las relaciones entre la Argentina y el Brasil: algunos apuntes", pp. 28-38.

02526 Grabendorf, Wolf "Brasil y la República Federal de Alemania: ¿Un modelo para las relaciones entre el Primer y Tercer Mundo?", pp. 39-59. 
02527 Mesa-Lago, Carmelo "La dependencia económica externa de Cuba y su repercusión sobre su política exterior", pp. 60-87.

02528 Berríos, Rubén "La empresa transideológica y las relaciones económicas Este-Oeste-Sur", pp. 88-103.

02744 Barros Charlín, Raymundo "Notas sobre Andrés Bello y América Latina", pp. 104-124.

\section{$N^{0} 58$, abril-junio 1982, año XV}

02529 Lafer, Celso "Reflexiones sobre el tema del nuevo orden mundial en un orden internacional en transformación", pp. 127-165.

02530 Tomassini, Luciano "Interdependencia y desarrollo nacional", pp. 166-189.

02531 Orrego Vicuña, Francisco "Perspectivas de la cooperación entre América Latina y los países de ASEAN", pp. 190-204.

02532 Bitar, Sergio "América Latina y Estados Unidos: Relaciones económicas en los años setenta", pp. 205-224.

02536 Jaguaribe, Helio "El futuro de las relaciones entre el Brasil y los Estados Unidos", pp. 225-231.

02537 Grabendorff, Wolf "iDe país aislado a aliado preferido? Las relaciones entre Argentina y los Estados Unidos: 1976-1981", pp. 232239.

\section{$N^{0} 59,1982$ julio-septiembre, año XV}

02538 Saraiva Guerreiro, Ramiro "El mensaje del Brasil en la Conferencia de Cancún", pp. 243-246.

02533 Días David, Mauricio "La transnacionalización económica versus la autonomía de las políticas nacionales", pp. 247-259.

02539 Edwards, Sebastián "Deuda externa, ahorro doméstico y crecimiento económico en Chile: Una perspectiva de largo plazo: 1982-1990", pp. 260-275.

02540 Alcalde Cardoza, Javier "La crisis de las relaciones atlánticas y la formación de un centro europeo (1968-1975); un ensayo interpretativo", pp. 276-294.

02534 Dunkel, Arthur "El comercio internacional y la función del GATI", pp. 295-303.

02541 Martínez Sotomayor, Carlos "Presencia de la educación y la cultura en las relaciones internacionales de Chile ${ }^{n}$, pp. 304-323.

02542 Barros Charlín, Raymundo "En torno a una obra sobre integración latinoamericana", pp. 324-336. 
02543 Paolillo, Felipe "El impacto del nuevo derecho del mar en la evolución de la organización internacional", pp. 337-357.

\section{$N^{\circ} 60,1982$ octubre-diciembre, año XV}

02544 Moneta, Carlos J. "El conflicto de las Islas Malvinas: su papel en la política exterior argentina en el contexto mundial", pp. 361-409.

02545 Pérez Llana, Carlos "La política exterior de la Argentina post-Malvinas", pp. 410-442.

02546 Jaguaribe, Helio "Reflexiones sobre el Atlántico Sur: América Latina y el Brasil ante la desarticulación del sistema interamericano", pp.443-461.

02547 Lafer, Ceiso "La política externa brasileña y la crisis en el Atlántico Sur: una evaluación", pp. 462-472.

02548 Orrego Vicuña, Francisco "La crisis del Atlántico Sury su influencia en el sistema regional", pp. 473-498.

02535 Muñoz, Heraldo "Efectos y lecciones del conflicto de las Malvinas", pp. 499-512.

02550 Sábato, Jorge A. "¿Cómo entenderse con Estados Unidos?", pp. 513-518.

02551 Orrego Vicuña, Francisco "El elusivo entendimiento entre América Latina y los Estados Unidos", pp. 519-532.

02552 Tomassini, Luciano "Hacia un sistema latinoamericano de seguridad regional", pp. 533-541.

\section{No61, 1983 enero-marzo, año XVI}

02553 Herrera Lane, Felipe "La Banca de Fomento Latinoamericana y la empresa privada: una perspectiva internacional", pp. 3-13:

02554 Orrego Vicuña, Francisco "La definición de un régimen para los -recursos minerales antárticos: opciones básicas", pp. 14-30.

02555 Cardoso, Fernando H. "América Latina y la influencia de los modelos políticos europeos en los años 80", pp. 31-46.

02556 Mota Sardenberg, Ronaldo "Brasil-Europa y la reestructuración del poder internacional", pp. 47-57.

02557 Fendt, Roberto "Comercio exterior y políticas exteriores en Brasil: problemas y prioridades", pp. 58-76.

02558 Wionczek, Miguel S. "El futuro de las relaciones chino-soviéticas y su probable impacto global", pp. 77-89.

02559 Ness, Peter van; Raichur, Satish "Dilemas del desarrollo en China: 1949-1980", pp. 90-116. 
02560 Cousiño Cousiño, José Antonio "Tecnología y ética en el Nuevo Orden Informativo", pp. 117-133.

02561 Insulza, José Miguel "La política de la administración Reagan hacia América Latina: un primer balance", pp. 134-165.

\section{$\mathrm{N}^{0} 62,1983$ abril-junio, año XVI}

02562 Prebisch, Raúl "La crisis del capitalismo y la periferia", pp. 169-179.

02563 Galtung, Johan "Análisis del carácter de la crisis internacional actual", pp. 180-210.

02564 Iglesias, Enrique V. "La crisis económica internacional y las perspectivas de América Latina", pp. 211-231.

02565 Hager, Wolfgang "El comercio Norte-Sur y la autonomía socioeconómica: una fórmula de paz", pp. 232-246.

02566 Figueredo, Reynaldo "Hacia una nueva apreciación del sistema de comercio internacional", pp. 247-254.

02567 Spraos, John "El deterioro de la relación de intercambio: algunas perspectivas", pp. 255-280.

02568 Ffrench-Davis, Ricardo "Deuda externa y balanza de pagos de América Latina: tendencias recientes y perspectivas", pp. 281-304.

02569 Massad, Carlos "América Latina: aspectos principales del financiamiento externo", pp. 305-314.

02570 Ferrer, Aldo "La deuda externa y las políticas nacionales", pp. 315329.

02571 Urquidi, Víctor L. "La interdependencia económica global y el cambio social", pp. 330-335.

\section{$N^{0} 63,1983$ julio-septiembre, año XVI}

02572 Betancourt, Belisario "La capacidad de respuesta de América Latina ante la crisis", pp. 339-349.

02573 Tomassinị, Luciano "Las relaciones internacionales de América Latina en los escenarios posibles en el largo plazon , pp. 350-378.

02574 Lafourcade, Hernán "Hacia la reorganización del mecanismo de reciclaje financiero internacional", pp. 379-390.

02575 Orrego Vicuña, Francisco "Políticas internas e influencias externas en el debate sobre derechos humanos en América Latina", pp. 391405.

02576 Cançado Trindade, Antonio Augusto "Posiciones internacionales del Brasil al nivel unilateral", pp. 406-458. 
02577 Aleixo, José Carlos Brandi "Líneas generales de la política externa del Brasil", pp. 459-482.

02578 Grabendorff, Wolf "América Central como región de crisis internacional", pp. 483-4,97.

02579 Zorgbibe, Charles "¿Qué seguridad para Africa?: tres imágenes del kaleidoscopio africano", pp. 498-506.

\section{$N^{0} 64,1983$ octubre-diciembre, año XVI}

02580 Prebisch, Raúl "Hacia la recuperación económica y la equidad social", pp. 510-522.

02581 Urquidi, Víctor L. "La actual depresión internacional y los países en vías de desarrollo", pp. 523-533.

02582 Furtado, Celso "La crisis financiera internacional y sus consecuencias para América Latina", pp. 534-546.

02583 Deylin, Robert "La crisis del sector externo de América Latina: el origen del problema y algunas opciones para enfrentarlo", pp. 547567.

02584 Buira, Ariel "México: la crisis de divisas y el programa de ajuste", pp. 568-578.

02585 Nogueira Batista, Paulo "Análisis crítico de la programación gubernamental del sector externo en el Brasil", pp. 579-602.

02586 Ferrer, Aldo "¿Puede Argentina pagar su deuda externa?", pp. 603628.

02587 Green, Rosario "Visión y acción de Washington frente a la deuda externa latinoamericana", pp. 629-663.

02588 Reunión de personalidades sobre la crisis mundial y América Latina: conclusiones; pp. 664-668.

02589 Reunión sobre crisis y deuda en América Latina: conclusiones; pp. 669-674.

\section{$N^{\circ} 65,1984$ enero-marzo, año XVII}

02590 Jaguaribe, Helio "Reflexiones sobre la paz mundial", pp.4-15.

02591 Tomassini, Luciano "El proceso de transnacionalización y las relaciones externas de los países latinoamericanos", pp. 16-55.

02592 Varas, Augusto "De la internacionalización a la transnacionalización en América Latina", pp. 56-65.

02593 Bueno, Gerardo M. "Interdependencia económica: perspectivas desde América Latina", pp. 66-93. 
02594 Bouzas, Roberto "Estados Unidos y el proceso de transnacionalización en la postguerra", pp. 94-111.

02595 Grabendorf, Wolf "Las relaciones entre América Latina y Europa Occidental: los actores nacionales y transnacionales, sus objetivos y expectativas", pp. 112-130.

02596 Moneta, Carios J. "El factor energético (hidrocarburos), en las relaciones internacionales de América Latina", pp. 131-159

02597 Lahera, Eugenio "La internacionalización del proceso productivo", pp. 160-166.

\section{$N^{\circ} 66,1984$ abril-junio, año XVII}

02598 Russell, Roberto "Argentina y la política exterior del régimen autoritario (1976-1983): una evaluación preliminar", pp. 170-201.

02599 Soares, Glaucio Ary Dillon "El futuro de là democracia en América Latina", pp. 202-231.

02600 Orrégo Vicuña, Francisco "Políticas internas e influencias externas en el debate sobre derechos humanos en América Latina", pp. 232246.

02601 Bitar, Sergio "Los intereses económicos de EE.UU, y su política hacia América Latina", pp. 247-256.

02602 Iglesias, Enrique Y. "América Latina: crisis y opciones de desarrollo", pp. 257-292.

02603 Pardo, Arvid "El espacio oceánico y la humanidad", pp. 293-306.

\section{$N^{\circ} 67,1984$ julio-septiembre, año XVII}

02604 Ferrer, Aldo "Deuda, soberanía y democracia en América Latina", pp. 309-323.

02605 Armanet Armanet, Pilar "La seguridad regional: hacia la consolidación de la zona desnuclearizada", pp. 324-336.

02606 Infante Caffi, María Teresa "Argentina y Chile: percepciones del conflicto de la zona del Beagle", pp. 337-358.

02607 Jaksic, Iván "Puerto Rico: los dilemas del status político y el desarrollo dependiente", pp. 359-377.

02608 Barros Charlín, Raymundo "Comunidad Económica Europea: la incertidumbre compartida", pp. 378-400.

02609 Granda Alva, Germán; García y García Sánchez-Blanco, José Luis "La cooperación para el desarrollo de las comunidades europeas y sus relaciones con América Latina: un reto para España", pp. 401417 . 


\section{$N^{\circ} 68,1984$ octubre-diciembre, año XVII}

02610 Martner G., Gonzalo "América Latina dentro del orden económico mundial", pp. 420-440.

02611 Wionczek, Miguel S. "Las desventuras de la ALADI: 1980-1983", pp 441-458.

02612 Salgado, Germánico "El Grupo Andino: problemas y perspectivas", pp. 459-492.

02613 Rosenthal, Gert "Algunas lecciones de la integración económica en América Latina: el caso de Centroamérica", pp. 493-512.

02614 Klaveren, Alberto van "Las nuevas formas de concertación política en América Latina", pp. 513-536.

02615 Durán, Esperanza "La solución de Contadora para el logro de la paz en Centroamérica", pp. 537-547.

02616 Nohlen, Dieter "El cambio de régimen político en América Latina: en torno a la democratización de los regímenes autoritarios", pp. 548-575.

\section{$N^{\circ} 69,1985$ enero-maizo, año XVIII}

02617 Wionczek, Miguel S. "La economía mundial en 1984 y sus perspectivas para el resto de los años ochenta", pp. 3-31.

02618 Barros, Alexandre de S. C. "Política internacional en América Latina: seguridad en los primeros años del decenio de 1980 y después", pp. $32-50$.

02619 Russell, Roberto "El fenómeno Reagan y América Latina: visiones, obstáculos y perspectivas", pp. 51-62.

02620 Lagos, Gustavo; Plaza, Oscar "La actual política exterior norteamericana y su proyección en América Latina", pp. 63-80.

02621 Santa Cruz, Hernán "La anticooperación internacional y el retorno de las políticas de poder", pp. 81-86.

02624 Marshall, Isabel; Silva, Enrique; Mardones, José Luis "Proteccionismo y reestructuración en la industria del cobre: las políticas de los productores", pp. 87-109.

02622 Moneta, Carlos J. "Fuerzas Armadas y gobierno constitucional después de Malvinas: hacia una nueva relación civil-militar", pp.110-171.

\section{$N^{0} 70,1985$ abril-junio, año XVIII}

02623 Pérez Llana, Carlos "La crisis internacional y los países en desarro1lo", pp. 175-185. 
02625 Sideri, Sandro "Europa y América Latina en la crisis mundial", pp. 186-220.

02626 Tomassini, Luciano "La economía mundial y América Latina: reflexiones sobre el corto y el mediano plazo", pp. 221-240.

02627 Hirst, Mónica "Las relaciones de Estados Unidos con las potencias medianas en América Latina: los casos de México y Brasil", pp. 241-269.

02628 Selcher, Wayne "Relaciones entre Brasil y Argentina en la década del 80: de una cautelosa rivalidad a una competencia amistosa", pp. 270-301.

02629 Wilhelmy, Manfred "¿Es Afganistán un Vietnam para la Unión Soviética?", pp. 302-334.

\section{No71, julio-septiembre 1975, año XVIII}

02630 Jaguaribe, Helio "Los conflictos cardinales de nuestro tiempo y la posición del Brasil", pp. 337-348.

02631 Tella, Torcuato di "Los procesos políticos en América Latina", pp. 349-369.

02632 Delich, Francisco "De la democracia como necesidad a la democracia como condición", pp. 370-381.

02633 Matos Mar, José "Crisis del Estado y desborde popular en el Perú", pp. 382-388.

02634 Viñas, Angel "Coordenadas de la política de seguridad española: análisis y sugerencias", pp. 389-421.

02635 Grabendorff, Wolf "La crisis centroamericana: iTiene Europa Occidental un papel en ella?", pp. 422-439.

02636 Cepeda Ulloa, Fernando "El proceso de paz en Colombia y la politica internacional", pp. 440-450.

\section{$N^{0} 72,1985$ octubre-diciembre, año XVIII}

02637 Maira, Luis "Los márgenes de hegemonía internacional de Estados Unidos: una visión histórica", pp. 454-477.

02638 Tavares, María da Çonceiçao "La recuperación de la hegemonía norteamericana", pp. 478-505.

02639 Bitar, Sergio "El desconcertante reimpulso de la hegemonía internacional de Estados Unidosn", pp. 506-527.

02640 Bouzas, Roberto "La evolución de la economía y la política económica norteamericana en 1984/1985", pp. 528-575. 
02641 Rodríguez Mendoza, Miguel "América Latina y la nueva legislación comercial de Estados Unidos", pp. 576-592.

02642 Pelzman, Joseph; Núñez, José "El crimen más largo: los controles impuestos por los Estados Unidos a la exportación de productos textiles", pp. 593-600.

\section{$N^{0} 73,1986$ enero-marzo, año XIX}

02643 Pérez Llana, Carlos "Relaciones internacionales y transición política", pp. 3-15.

02644 Roett, Riordan "Panorama de las relaciones políticas y la seguridad del área del Atlántico, como consecuencia del trastorno económico", pp. 16-36.

02645 Paiva Abreu, Marcelo de; Fritsch, Winston "Un estudio sobre la graduación", pp. 37-75.

02646 Walker, Ignacio "Las armas nucleares y el carácter de las relaciones internacionales", pp. 76-97.

02647 Estévez, Jaime "Crisis de pagos y políticas de ajuste en América Latina", pp. 98-117.

02648 Berthelot, Ives "Perspectivas económicas para 1985-1990: algunas inquietudes", pp. 118-121.

\section{$N^{0} 74,1986$ abril-junio, año XIX}

02649 Herrera Lane, Felipe "Alianza para el Progreso: los postulados y las realizaciones", pp. 125-132.

02650 Lowenthal, Abraham F. "Las relaciones externas de América Latina en 1985", pp. 133-158.

02651 Sunkel, Osvaldo "Las empresas transnacionales en el capitalismo actual: algunos viejos y nuevos temas de reflexión", pp. 159-169.

02652 Ominami, Carlos "El Tercer Mundo y la economía mundial", pp. 170-210.

02653 Bodemer, Klaus "La política de desarrollo de la administración Reagan: fundamentos ideológicos, estrategias y perspectivas", pp. 211238.

02654 Ferguson, Yale H. "Reflexiones sobre el análisis de las políticas externas latinoamericanas", pp. 239-274.

\section{$N^{\circ} 75,1986$ julio-septiembre, año XIX}

02655 Portales, Carlos "Sudamérica: seguridad regional y relaciones con Estados Unidos", pp. 279-334. 
02656 Briones, Alvaro "El Tercer Mundo en la perspectiva latinoamericana", pp. 335-370.

02657 Arias, María Fernanda "Trilateralismo y política norteamericana en la década del 80: el caso de la administración Reagan", pp. 371-391.

02659 Irigoin, Jeannette "El espacio: ¿Patrimonio común de la humanidad?", pp. 392-404.

\section{No76, 1986 octubre-diciembre, año XIX}

02658 Ominami, Carios "América Latina y la Tercera Revolución Industrial", pp. 407-419.

02660 Pérez, Carlota "Las nuevas tecnologias: una visión de conjunto", pp. 420-459.

02661 Lorino, Philippe "La Comunidad Económica Europea en la competencia tecnológica mundial", pp. 460-486.

02662 Sagasti, Francisco R. "Perspectivas futuras de la ciencia y la tecnología en América Latina", pp.487-512.

02663 Bitar, Sergio "Las políticas económicas de los países desarrollados. Consecuencias para América Latina", pp. 513-530.

\section{$N^{\circ} 77,1987$ enero-marzo, año XX}

02664 Varas, Augusto "De la competencia a la cooperación militar en América Latina", pp. 3-18.

02665 Armanet Armanet, Pilar "La zona desnuclearizada latinoamericana en la perspectiva de la cooperación regional", pp. 19-38.

02666 Mercado Jarrín, Edgardo "Perspectivas de los acuerdos de limitación de desarme en América Latina y el Caribe", pp. 39-69.

02667 Orrego Vicuña, Francisco "La búsqueda de un nuevo papel para la Organización de los Estados Americanos: el Protocolo de Reformas de la Carta de 1985", pp. 70-87.

02668 Barros Charlín, Raymundo "Trayectoria y agenda de ALADI", pp. 88-101.

02669 Muñoz, Heraldo "Las causas del auge y la declinación del Sistema Interamericano de Seguridad: una perspectiva latinoamericana", pp. $102-113$. 


\section{No78, 1987 abril-junio, año XX}

02670 Tomassini, Luciano "Elementos para el análisis de la política exterior", pp. 125-157.

02671 Boisier, Sergio "Notas en torno al desarrollo de regiones fronterizas en América Latina", pp. 158-191.

02672 Tulchin, Joseph S. "La Guerra de las Malvinas: un conflicto inevitable que nunca debió haber ocurrido", pp. 192-209.

02673 Pinochet de la Barra, Oscar "Negociaciones antárticas de Chile en un mundo cambiante", pp. 210-222.

02674 Pomerlau, Claude "El problema de las relaciones Iglesia-Estado en México", pp. 223-241.

\section{$\mathrm{N}^{0} 79,1987$ julio-septiembre, ańo XX}

02675 Bianchi, Andrés; Devlin, Robert; Ramos, Joseph "El proceso de ajuste en América Latina 1981-1986", pp. 272-320.

02676 Iglesias, Enrique V. "Nuevas formas de cooperación entre la Comunidad Económica Europea y América Latina", pp. 321-327.

02677 Lafer, Celso "Las nuevas dimensiones de la política externa brasileña", pp. 328-341.

02678 Valdivieso Eguiguren, Sergio "El tema antártico en las Naciones Unidas", pp. 342-351.

02679 Portales, Carlos "Democracia y derechos humanos en la política exterior del Presidente Reagan", pp. 352-378.

02680 Wilhelmy, Manfred "La evolución de la multipolaridad", pp. 379401.

\section{No80, 1987 octubre-diciembre, año XX}

02681 Muñoz, heraldo "El estudio de las políticas exteriores latinoamericanas; temas y enfoques dominantes", pp. 406-434.

02682 Pardo, Rodrigo; Tokatlian, Juan Gabriel "Política internacional, paz interna e interés nacional", pp. 435-441.

02695 Russell, Roberto; Hirst, Mónica "Democracia y política exterior los casos de Argentina y Brasil", pp. 442-490.

02683 Wilhelmy, Manfred; Fermandois Huerta, Joaquín "La Cancillería en la futura política exterior de Chile", pp. 491-505.

02684 Varas, Augusto "Percepciones estratégicas del Pacífico Sur", pp. 506-519. 
02685 Grabendorff, Wolf "La política nuclear y de no proliferación de Brasil", pp. 520-568.

\section{$N^{\circ} 81,1988$ enero-marzo, año XXI}

02686 Muñoz, Heraldo "El escenario mundial hacia el año 2000", pp. 3-14.

02687 Peña, Félix "La cumbre latinoamericana de Acapulco: transformación económica, democratización y cooperación internacional", pp. 15-22.

02688 Bitar, Sergio "América Latina en el nuevo mapa de la economía mundial", pp. 23-44.

02689 Mols, Manfred "ASEAN luego de la tercera reunión cumbre", pp. 45-60.

02691 Moneta, Carlos J. "Corea del Sur y los países asiáticos de reciente industrialización (PARI) en el contexto de los cambios del sistemà económico mundial. Reflexiones para América Latina", pp. 61-93.

02690 Pardo, Rodrigo; Tokatlian, Juan Gabriel "Teoría y práctica de las relaciones internacionales: el caso de Colombia", pp. 94-135.

\section{No82, 1988 abril-junio, año XXI}

02707 Sierralta, Hernán "La estructura de poder del BID", pp. 141-156.

02708 Palmer, David Scott "Actores y factores en las relaciones contemporáneas de los Estados Unidos y América Latina", pp. 157-172.

02709 Roett, Riordan "Perspectivas para el Plan Arias en El Salvador y Guatemala", pp. 173-183.

02710 Perina; Rubén M.; Ramírez, Norma A. "La importancia de América Latina en el sistema internacional en la década de los ochenta: un ensayo bibliográfico", pp. 184-205.

02711 Edwards, Ernesto "América Latina y la economía mundial", pp. 206253.

02712 Primer Seminario Regional sobre Diplomacia Económica: las políticas económicas de los países industrializados y su impacto en América Latina: síntesis de los debates; pp. 254-281.

\section{$N^{0} 83,1988$ julio-septiembre, año XXI}

02723 Tomassini, Luciano "Introducción al estudio de las nuevas formas de concertación latinoamericana", pp. 310-326.

02745 Klaveren, Alberto van "La cooperación política europea: realidades y desafíos de un modelo de concertación externa", pp. 327-353. 
02724 Green, Rosario "Nuevas formas de concertación regional en América Latina: el Grupo de los Ocho", pp. 354-372.

02746 O'Connell, Arturo "La coordinación de los deudores latinoamericanos: el consenso de Cartagena y el Grupo de los Ocho", pp. 373-385.

02725 Peña, Félix "Concertación latinoamericana: arquitectura de integración e ingeniería de negocios", pp. 386-424.

\section{$\mathrm{N}^{\circ} 84$, octubre-diciembre 1988 , año XXI}

02718 Jaguaribe, Helio "La relación Norte-Sur", pp. 425-438.

02719 Fleixa Lima, Paulo de Tarso "Perspectivas de las relaciones entre América Latina y los países de la Liga de los Estados Arabes", pp. 439-450.

02720 Khalil, Ismael "La promoción de las relaciones entre Estados latinoamericanos y árabes", pp. 451-461.

02721 Tulchin, Joseph S. "Los Estados Unidos y América Latina en la década del 60", pp. 462-497.

02722 Tomassini, Luciane "El análisis de la política exterior", pp. 498-559.

\section{$\mathrm{N}^{\circ} 85$, enero-marzo 1989, año XXII}

00247 Wagner Tizón, Alan. "Paz, desarme y desarrollo en América del Sur", pp. 3-9.

00246 Portales, Carlos "Seguridad compartida en América Latina: desafío del siglo XXI", pp. 10-20.

00245 Thiago Cintra, José "Conflictos regionales: tendencias en un período de transición", pp. 21-41.

00244 Orrego Vicuña, Francisco El régimen de los minerales de los fondos marinos: términos y condiciones de una renegociación", pp. 42-52.

00248 Diéguez M., María Isabel "La neutralidad de Argentina durante la Segunda Guerra Mundial", pp. 53-77.

00249 Schmitter, Philippe C. "Idealismo, cambio de régimen y cooperación regional: lecciones del ConoSur de América Latina", pp. 78-130.

\section{$N^{086}$, abril-junio 1989, año XXII}

00239 Orrego Vicuña; Francisco "La cooperación en el Pacífico: una perspectiva desde América Latina", pp. 131-152.

00241 Arenal, Celestino del " $\mathrm{La}$ teoría de las relaciones internacionales hoy: debates y paradigmas", pp. 153-182. 
00242 Karl, Terry Lynn "Hegemonías y empresarios políticos: dependencia, democratización y cooperación en las Américas", pp. 183-223.

00240 Rojas Aravena, Francisco "El proceso de Esquipulas: el desarrollo *: conceptual y los mecanismos operativos", pp. 224-247.

00243 Serbin, Andrés "América Latina y la "Conexión Europea" del Caribe s. no-hispánico", pp. 248-276.

\section{No87, julio-septiembre 1989, año XXII}

00219 Moneta, Carlos J. "Los países asiáticos de reciente industrialización en la década del 90 . Elementos para un debate latinoamericano", pp. 279-297.

00220 Heine, Jorge "Latinos y antillanos: las relaciones entre América Latina y el Caribe en los noventa", pp. 298-307.

00221 Portales, Carlos "Los factores externos y el régimen autoritario. Evolución e impacto de las Relaciones Internacionales de Chile en el proceso de transición a la democracia", pp. 308-341.

00222 Klaveren, Alberto van "Las relaciones entre Europa Occidental y América Latina: una profundización esquiva", pp. 342-364.

00223 Frohmann, Alicia "De Contadora al Grupo de los Ocho: el reaprendizaje de la concertación política regional", pp. 365-427.

\section{No88, octubre-diciembre 1989, año XXII}

00234 Ferrero Costa, Eduardo "Las relaciones de América Latina con el Japón y otros países asiáticos de la Cuenca del Pacífico", pp. 439-462.

00235 Hirst, Mónica; Segre, Magdalena "La política exterior de Brasil en 1988: los avances posibles", pp. 463-488.

00236 Eguizábal, Cristina; Rojas Aravena, Francisco "Política exterior, negociación y procesos de decisión en Centroamérica: elementos para una aproximación", pp. 489-513.

00237 Ebenroth, Carsten Thomas "Internacionalización de la economía. Instituciones concurrentes, manejo de deuda externa e inversiones extranjeras", pp. 514-558.

00238 Bernal Meza, Raúl "El rol de las regiones en la política exterior: su potencial de articulación con los países limítrofes", pp. 559-587.

\section{$N^{\circ} 89$, enero-marzo 1990, año XXIII}

00415 Giner, Salvador, Moreno, Luis "La sociedad civil en Europa Occidental", pp. 3-20. 
00416 Lipietz, Alain "Hacia una nueva inserción de Europa en la economía mundial", pp. 21-44.

00417 Guimaraes, Roberto P. "El Leviatán acorralado: continuidad y cambio en el papel del Estado en América Latina", pp. 45-81.

00418 Klaveren, Alberto van "Las relaciones internacionales de América Latina en la década de 1980: cambio y continuidad", pp. 82-118.

00419 Jaworski C., Helán "Las políticas de cooperación de Europa Occidental hacia América Latina y sus posibilidades futuras", pp. 119-140.

01134 Instituto de Estudios Internacionales - Biblioteca Indice Estudios Internacionales, Año XXII, Nos. 85-88, 1989; pp. 141-151.

\section{N90, abril-junio 1990, año XXIII}

00606 Varas, Augusto "Jaque a la democracia: terrorismo y anti-terrorismo en las relaciones sociales e internacionales contemporáneas", pp. 154-165.

00605 Rojas Aravena, Francisco "Violencia política y orden internacional: el terrorismo en Centroamérica", pp. 166-186.

00601 Tokatlian, Juan Gabriel; Pardo, Rodrigo "Violencia política, paz interna y política internacional", pp. 187-220.

00600 García-Sayán, Diego "Terrorismo y pacificación en el Perú", pp. 221-239.

00602 Bustamante, Fernando "La política de Estados Unidos contra el narcotráfiço y su impacto en América Latina", pp. 240-271.

00604 Instituto de Estudios Internacionales - Biblioteca Bibliografía: Violencia política, terrorismo, guerrilla y narcotráfico en América; pp. 272-276.

\section{$N^{0} 91$, julio-septiembre 1990, año XXIII}

01135 Tomassini, Luciano "La política internacional después del muro", pp. 281-338.

01136 Tokatlian, Juan Gabriel; Pardo, Rodrigo "La teoría de la interdependencia: iun paradigma alternativo al realismo?", pp. 339-382.

01137 Pérez Llana, Carlos Los Noventa: una nueva agenda internacional para una nueva década", pp. 383-398.

01138 Sunkel, Osvaldo "Perspectivas democráticas y crisis de desarrollo", pp. 399-407.

01139 Schmied, Julie "El debate metodológico entre "clásicos" y "científi$\cos ^{n}$ en las relaciones internacionales", pp. 408-417. 
01140 Instituto de Estudios Internacionales - Biblioteca Bibliografía: Teoría y estudio de las relaciones internacionales; pp. 418-421.

\section{No92, octubre-diciembre 1990, año XXIII}

01126 Mols, Manfred "Comunidad Europea-Asean: ¿un modelo de cooperación interregional?", pp. 424-443.

01127 García Menéndez, José Ramón "Estilos de crecimiento económico periférico e inserción de América Latina en el mercado mundial", pp. 444-463.

01128 Moneta, Carlos J. "La teoría de las relaciones internacionales: el realismo y sus límites", pp. 464-498.

01129 Pinochet de la Barra, Oscar "Antártica, un continente para el tercer milenio", pp. 499-511.

01130 Hofmeister, Wilhelm "La resolución de la cuestión alemana: su dimensión nacional e internacional", pp. 512-531.

01131 Fermandois Huerta, Joaquín "Expansion of third world Navies" de: Michael A. Morris (Reseña), pp. 532-537.

01132 Tomassini, Luciano "International Relations Theory: realism, pluralism, globalism", de: Paul R. Viotti y Mark V. Kauppi (Reseña), pp. 538-539.

01133 Instituto de Estudios Internacionales - Biblioteca Bibliografía: Alemania 1988-1990; pp. 540-543.

\section{$N^{\circ} 93$, enero-marzo 1991, año XXIV}

01301 Orrego Vicuña, Francisco "Nuevas modalidades para el restablecimiento de la paz y seguridad en el derecho internacional: el Grupo de Observadores de las Naciones Unidas en Centroamérica", pp. 3-18.

01300 Mares, David R. "Escenarios de seguridad en Europa Oriental y América Latina", pp. 19-41.

01302 Fernández Estigarribia, José Félix "Perspectivas de cambio de la política exterior paraguaya", pp. 42-52.

01303 Tokatlian, Juan Gabriel; Barrera, Cristina "Geografía, desarrollo regional y política exterior: el caso de la frontera tripartita colombovenezolana-brasileña en la Intendencia del Guainia: una perspectiva desde Colombia", pp. 53-80.

01304 Gutiérrez Bermedo, Heruán "Análisis comparativo del sistema de partidos y las elecciones generales en Chile 1989", pp. 81-105. 
01305 Heine, Jorge "¿Cooperación o divergencia? Hacia una nueva agenda en las relaciones europeo-latinoamericanas", pp. 106-158.

02909 Instituto de Estudios Internacionales - Biblioteca Indice de Estudios Internacionales, Año XXIII, Ne89-92, 1990; pp. 159-173.

\section{No94, abril-junio 1991, año XXIV}

01594 Wilhelmy, Manfred "Los objetivos en la política exterior latinoamericana", pp. 176-193.

01585 Caputo, Dante M.; Sábato, Jorge F. "Perspectivas de la integración político-económica continental: la integración de las democracias pobres: oportunidades y peligros", pp. 194208.

01586 Lechner, Norbert "Condiciones socio-culturales de la transición democrática: a la búsqueda de la comunidad perdida", pp. 209-228.

01593 Nohlen, Dieter; Fernández B., Mario "Democratización y política exterior: análisis comparado en torno a tres casos: Argentina, Brasil y Uruguay", pp. 229-259.

01596 Busso, Anabella "Estados Unidos y la democratización latinoamericana: los condicionantes externos", pp. 260-289.

01595 Instituto de Estudios Internacionales - Biblioteca Bibliografía: Transición a la democracia en América Latina, pp. 291-295.

\section{No95, julio-septiembre 1991, año XXIV}

01656 González, Raimundo "Algunas reflexiones sobre una diplomacia multilateral contemporánea", pp. 303-346.

01648 Matta, Javier Eduardo "Chile y la República Popular China: 1970$1990^{\prime \prime}$, pp. 347-367.

01647 Moreno Laval, Celso "América Latina y la Cuenca del Pacífico: una visión chilena", pp. 368-383.

01646 Orrego Vicuña, Francisco "El papel de la Corte Internacional de Justicia y otros tribunales en el desarrollo del derecho de la delimitación marítima", pp. 384-407.

01645 Porto de Oliveira, Amaury "Chile y Brasil: intereses conjuntos en el Pacífico", pp. 408-418.

01644 Instituto de Estudios Internacionales-Biblioteca Bibliografía: Cuenca del Pacífico; pp. 419-424. 


\section{N96, octubre-diciembre 1991, año XXIV}

01871 Infante Caffi, María Teresa "Vigésimo quinto aniversario del Instituto de Estudios Internacionales de la Universidad de Chile", pp. 429-432.

01870 Fermandois Huerta, Joaquín "De una inserción a otra: política exterior de Chile, 1966-1991", pp. 433-455.

01869 Heine, Jorge "¿Cayó también el Tercer Mundo? El Sur ante el nuevo orden global", pp. 456-471.

01852 Gutiérrez Bermedo, Hernán; Wilhelmy, Manfred "Concepciones latinoamericanas y asiáticas sobre cooperación regional", pp. 472517.

01851 Orrego Vicuña, Francisco "El proceso de cambios en el derecho internacional de los espacios comunes", pp. 518-537.

01872 Cousiño Cousiño, José Antonio "El Instituto de Estudios Internacionales: 25 años de vinculación con la Cuenca del Pacífico", pp. 538-563.

01873 Orrego Vicuña, Francisco "Bibliografía crítica de la década 19811990: relaciones internacionales y derecho internacional", pp. 564 569.

\section{$N^{\circ} 97$, enero-marzo 1992, año XXV}

02079 Morandé Lavín, José "Chile y los Estados Unidos: distanciamiento y aproximaciones", pp. 3-22.

02080 Orrego Vicuña, Francisco "Las relaciones entre los paises de América Latina y los Estados Unidos: límites regionales y entendimientos. globales", pp. 23-40.

02082 Armanet Armanet, Pilar "Política de Chile en la Cuenca del Pacífico: perspectivas para la década del noventa", pp. 41-72.

02083 Tomassini, Luciano "Desarrollo económico e inserción externa en América Latina: un proyecto elusivo", pp. 73-116.

02084 Sunkel, Osvaldo "La consolidación de la democracia y del desarrollo en Chile: desafíos y tareas", pp. 117-135.

02081 Aguilar Mandsley, Andrés; Orrego Vicuña, Francisco; Sanguinetti, Julio María; Wilkey, Malcolm; Freeland, John "Decisión de la Comisión para la Solución de Controversias entre Chile y Estados Unidos sobre el Caso Letelier Moffit, 11 de enero de 1992", pp. 136-153.

02910 Instituto de Estudios Internacionales - Biblioteca Indice de Estudios Internacionales, Año XXIV, No93-96, 1991; pp. 154-166. 


\section{$N^{0} 98$, abril-junio 1992, año XXV}

02813 Klaveren, Alberto van "Entendiendo las políticas exteriores latinoamericanas: modelo para armar", pp. 169-216.

02812 Gomes Saraiva, Miriam "Las dos dimensiones de la política exterior de la Comunidad Europea. Sus procesos de formulación y.sus difíciles relaciones", pp. 217-257.

02811 Rehren, Alfredo J. "El liderazgo encubierto de Eisenhower", pp. 258-274.

02810 Walḋmann, Peter "Terrorismo y guerrilla: la violencia organizada contra el Estado en Europa y América Latina. Un análisis comparativo", pp. 275-313.

02809 Instituto de Estudios Internacionales - Biblioteca Bibliografía: Relaciones exteriores de América Latina; pp. 314-319.

\section{$N^{0} 99$, julio-septiembre 1992, año XXV}

02917 Iglesias, Enrique V. "Hacia una agenda económica para los años noventa", pp. 322-340.

02916. Schamis, Héctor E. "Política económica conservadora en América Latina y Europa Occidental: las fuentes políticas de la privatización", pp. 341-364.

02915 León, Francisco "Cuba: procesos y dilemas", pp. 365-377.

02914 Palmer, David Scott "Perú 1992: la sorpresa de abril de Fujimori", pp. 378-384.

02913 Durán, Roberto "Vigencia del esquema conductualista en los estudios internacionales: su viabilidad en América Latina", pp. 385-404.

02274 Sweedler, Alan "La política de seguridad de Estados Unicios en la post Guerra Fría", pp. 405-426.

02912 Infante Caffi, María Teresa "El derecho internacional como objeto de los estudios internacionales", pp. 427-436.

02911 Instituto de Estudios Internacionales - Biblioteca Bibliografía: Derecho internacional; pp. 437-445. 


\title{
INDICE DE AUTORES
}

\author{
Estudios Internacionales \\ Nos. $1-99$
}

Abdenur, Roberto

02505 Abdenur, Roberto; Sardenberg, Ronaldo. "Notas sobre las relaciones Norte-Sur y el Informe Brandt", Estudios Intemacionales, NN54, año XIV, abril-junio, 1981, pp. 166-200.

RELACIONES NORTE SUR; ECONOMIA INTERNACIONAL; POLITICA INTERNACIONAL; RELACIONES EXTERIORES.

Aberastury, Marcelo

02175 Aberastury, Marcelo. "Asia Oriental y Meridional y el Pacífico: Inicios de 1972", Estudios Internacionales, №17, año V, enero-marzo, 1972, pp. 3-24.

ASIA; POLITICA MUNDIAL; OCEANO PACIFICO.

Acosta, Mercedes

02176 Acosta, Mercedes; Vilas, Carlos María. "Santo Domingo y Checoslovaquia en la Política de Bloques", Estudios Internacionales, N8, año II, enero-marzo, 1969, pp. 565-576.

EUROPA DEL ESTE; POLITICA MUNDIAL; SOCIALISMO; AMERICA CENTRAL Y CARIBE; CHECOSLOVAQUIA; POLITICA MILITAR; INTERVENCION-DERECHO INTERNACIONAL.

Aftalión, Marcè̀ $\mathbf{E}$.

02393 Aftalión, Marcelo E. "La política exterior norteamericana y América Latina", Estudios Intemacionales, Ne37, año X, enero-marzo, 1977, pp. 92-104. 
POLITICA INTERNACIONAL; ESTADOS UNIDOS; AMERICA LATINA; AMERICA DEL NORTE; RELACIONES EXTERIORES.

\section{Aguilar Mandsley, Andrés}

02081 Aguilar Mandsley, Andrés; Orrego Vicuña, Francisco; Sanguinetti, Julio María; Wilkey, Malcolm; Freeland, John. "Decisión de la Comisión para la Solución de Controversias entre Chile y Estados Unidos sobre el Caso Letelier Moffit, 11 de enero de 1992", Estudios Interiacionales, №97, año XXV, enero-marzo, 1992, pp. 136-153. // Incluye: opinión separada concurrente del profesor Francisco Orrego Vicuña //

ESTADOS UNIDOS; AMERICA DEL NORTE; CHILE; AMERICA DEL SUR; CONTROVERSIAS, SOLUCION DE; INDEMNIZACION JUDICIAL; CASOS; DOCUMENTOS; DERECHOS HUMANOS.

\section{Alcalde Cardoza, Javier}

02540 Alcalde Cardoza, Javier. "La crisis de las relaciones atlánticas y la formación de un centro europeo 1968-1975; un ensayo interpretativo", Estudios Internacionales, N259, año XV, julio-septiembre, 1982, pp. 276-294.

POLITICA MUNDIAL; EUROPA; ECONOMIA INTERNACIONAL; RELACIONES EXTERIORES; CRISIS.

02503 Alcalde Cardoza, Javier. "Las relaciones económicas internacionales en la década del 80", Estudios Intemacionales, №53, año XIV, eneromarzo, 1981, pp. 105-135.

ECONOMIA INTERNACIONAL; POLITICA INTERNACIONAL; RELACIONES NORTE SUR; RELACIONES EXTERIORES; RELACIONES ECONOMICAS INTERNACIONALES.

\section{Aleixo, José Carlos Brandi}

02577. Aleixo, José Carlos Brandi. "Líneas generales de la política externa del Brasil", Estudios Intemacionales, №63, añoXVI, julio-septiembre, 1983, pp. 459-482.

BRASIL; AMERICA DEL SUR; POLITICA MUNOIAL; RELACIONES EXTERIORES.

Almeida, Rómulo

02492 Almeida, Rómulo. "Reflexiones sobre la integración latinoamericana", Estudios Intemacionales, №52, año XIII, octubre-diciembre, 1980, pp. 417-459.

INTEGRACION REGIONAL; INTEGRACION ECONOMICA; AMERICA LATINA: ECONOMIA INTERNACIONAL.

\section{Almeyda, Ciodomiro}

02177 Almeyda, Clodomiro. "La OLAS y la crisis política en América Latina", Estudios Intemacionales, N³-4, año I, octubre-marzo, 19671968, pp. 427-442.

AMERICA LATINA; POLITICA INTERNACIONAL; OLAS. 
Andrade Lleras, Gustavo

02452 Andrade Lleras, Gustavo. "Hacia adónde va el Japón", Estudios Internacionales, Ne43, año XI, julio-septiembre, 1978, pp. 76-89. JAPON; ASIA; POLITICA INTERNACIONAL; POLITICA Y GOBIERNO; RELACIONES EXTERIORES.

Araujo Castro, José Augusto de

02178 Araujo Castro, José Augusto de. "El continente americano dentro de la problemática mundial", Estudios Internacionales, №20, año V, octubre-diciembre, 1972 , pp. 3-39.

POLITICA MUNDIAL; AMERICA.

Arenal, Celestino del

00241 Arenal, Celestino del. "La teoría de las relaciones internacionales hoy: debates y paradigmas", Estudios Intentacionales, Ne86, año XXII, abril-junio, 1989, pp. 153-182.

RELACIONES INTERNACIONALES - TEORIA.

\section{Arias, María Fernanda}

02657 Arias, María Fernanda. "Trilateralismo y política norteamericana en la década del 80: el caso de la administración Reagan", Estudios Internacionales, №75, año XIX, julio-septiembre, 1986, pp. 371-391. ESTADOS UNIDOS; AMERICA DEL NORTE; POLITICA INTERNACIONAL; GRANDES POTENCIAS.

\section{Armanet Armanet, Pilar}

02082 Armanet Armanet, Pilar. "Política de Chile en la Cuenca del Pacífico: perspectivas para la década del noventa", Estudios Internacionales, Ne97, año XXV, enero-marzo, 1992, pp. 41-72.

CHILE; AMERICA DEL SUR; CUENCA DEL PACIFICO; RELACIONES EXTERIORES; RELACIONES ECONOMICAS INTERNACIONALES; NIC'S; ASEAN; ASIA; JAPON; ASIA PACIFICO; COMERCIO EXTERIOR; EXPORTACIONES; INVERSIONES EXTRANJERAS; GRANDES POTENCIAS; ORGANIZACIONES REGIONALES.

02605 Armanet Armanet, Pilar. "La seguridad regional: hacia la consolidación de la zona desnuclearizada", Estudios Internacionales, Ne67, año XVII, julio-septiembre, 1984, pp. 324-336.

POLITICA INTERNACIONAL; AMERICA LATINA; TRATADO DE TLATELOLCO; SEGURIDAD REGIONAL; ZONAS DESNUCLEARIZADAS.

02665 Armanet Armanet, Pilar. "La zona desnuclearizada latinoamericana en la perspectiva de la cooperación regional", Estudios Internacionales, №77, año XX, enero-marzo, 1987, pp. 19-38.

AMERICA LATINA; ARMAMENTISMO; TRATADO DE TLATELOLCO; POLITICA INTERNACIONAL; ZONAS DESNUCLEARIZADAS; COOPERACION REGIONAL.

\section{Azevedo da Silveira, Antonio}

02457 Azevedo da Silveira, Antonio. "Las relaciones entre América Latina 
y los Estados Unidos", Estudios Internacionales, №45, año XII, enero-marzo, 1979, pp. 3-13.

AMERICA LATINA; ESTADOS UNIDOS; AMERICA DEL NORTE; POLITICA INTERNACIONAL; RELACIONES EXTERIORES; BRASIL; AMERICA DEL SUR.

\section{Aziz, Sartaj}

02179 Aziz, Sartaj. "Los verdaderos problemas de la crisis de alimentos", Estudios Internacionales, №30, año VIII, abril-junio, 1975, pp. 119130.

SEGURIDAD ALIMENTARIA.

\section{Ball, W. MacMahon}

02181 Ball, W. MacMahon. "Australia en el Pacífico", Estudios Internacionales, N220, año V, octubre-diciembre, 1972, pp. 40-52. AUSTRALIA; OCEANIA; OCEANO PACIFICO.

\section{Baltra, Alberto}

02180 Baltra, Alberto. "América Latina y la Segunda UNCTAD", Estudios Internacionales, Ne8, año II, 1969 enero-marzo, pp. 449-460. AMERICA. LATINA; UNCTAD; DESARROLLO ECONOMICO.

\section{Bambirra, Vania}

02182 Bambirra, Vania. "La revolución cultural y el marxismo", Estudios Internacionales, №7, año II, octubre-diciembre, 1968, pp. 406-416. MARXISMO; SOCIALISMO; ASIA; CHINA; CULTURA.

\section{Barraclough, Solon $\mathbf{Z}$.}

02221 Barraclough, Solon Z. "Integración en América Central", Estudios Internacionales, №5, año II, abril-junio, 1968, pp. 151-157.

AMERICA CENTRAL Y CARIBE; INTEGRACION REGIONAL; INTEGRACION ECONOMICA.

\section{Barrera, Cristina}

01303 Tokatlian, Juan Gabriel; Barrera, Cristina. "Geografía, desarrollo regional y política exterior: el caso de la frontera tripartita colombovenezolana-brasileña en la Intendencia del Guainia: una perspectiva desde Colombia", Estudios Intemacionales, N²93, año XXIV, enero-' marzo, 1991, pp. 53-80.

COLOMBIA; AMERICA DEL SUR; POLITICA INTERNACIONAL; GEOPOLITICA, FRONTERAS; RELACIONES EXTERIORES; BRASIL; VENEZUELA.

\section{Barros Charlín, Raymundo}

02475 Barros Charlín, Raymundo. "La elección del Parlamento Europeo por sufragio universal directo", Estudios Internacionales, No48, año XII, octubre-diciembre, 1979, pp. 472-494.

COMUNIDAD ECONOMICA EUROPEA; EUROPA; PARLANENTO EUROPEO.

02744 Barros Charlín, Raymundo. "Notas sobre Andrés Bello y América 
Latina", Estudios Internacionales, №57, año XV, enero-marzo, 1982, pp. 104-124.

AMERICA LATINA; BELLO, ANDRES; INTEGRACION REGIONAL.

02542 Barros Charlín, Raymundo. "En torno a una obra sobre integración. latinoamericana", Estudios Intemacionales, Ne59, año XV, julio-septiembre, 1982, pp. 324-336.

AMERICA LATINA; INTEGRACION REGIONAL; INTEGRACION ECONOMICA.

02608 Barros Charlín, Raymundo. "Comunidad Económica Europea: la incertidumbre compartida", Estudios Internacionales, №67, año XVII, julio-septiembre, 1984, pp. 378-400.

COMUNIDAD ECONOMICA EUROPEA; EUROPA; INTEGRACION REGIONAL; INTEGRACION ECONOMICA.

02668 Barros Charlín, Raymundo. "Trayectoria y agenda de ALADI", Estudios Internacionales, No77, año XX, enero-marzo, 1987, pp. 88-101. ALADI; INTEGRACION REGIONAL; INTEGRACION ECONOMICA; AMERICA LATINA.

Barros, Alexandre de S. C.

02618 Barros, Alexandre de S. C. "Política internacional en América Latina: seguridad en los primeros años del decenio de 1980 y después", Estudios Internacionales, №69, año XVIII, enero-marzo, 1985, pp. 32-50.

AMERICA LATINA; POLITICA INTERNACIONAL; SEGURIDAD.

\section{Bergsten C., Fred}

02183 Bergsten C., Fred. "Relaciones económicas entre Estados Unidos y Latinoamérica: la estructura internacional y algunos enfoques posibles", Estudios Intemacionales, №31, año VIII, julio-septiembre, 1975, pp. 19-41.

ESTADOS UNIDOS; AMERICA LATINA; ECONOMIA INTERNACIONAL; RELACIONES ECONOMICAS INTERNACIONALES; AMERICA DEL NORTE.

02466 Bergsten C., Fred. "Relaciones económicas entre los Estados Unidos y América Latina", Estudios Internacionales, N\$47, año XII, julio-septiembre, 1979, pp. 247-257.

ECONOMIA INTERNACIONAL; ESTADOS UNIDOS; AMERICA DEL NORTE; AMERICA LATINA; RELACIONES ECONOMICAS INTERNACIONALES.

\section{Bernal Meza, Raúl}

00238 Bernal Meza, Raúl. "El rol de las regiones en la política exterior: su potencial de articulación con los países limítrofes", Estudios Internacionales, No88, año XXIr, octubre-diciembre, 1989, pp. 559-587.

AMERICA LATINA; INTEGRACION FRONTERIZA; INTEGRACION REGIONAL; RELACIONES EXTERIORES; POLITICA INTERNACIONAL.

\section{Bernstein, Enrique}

02184 Bernstein, Enrique. "Situación política en víspera de mayo de 1968", 
Estudios Internacionales, №19, año v, julio-septiembre, 1972, pp. 103-166.

EUROPA; FPANCIA; HISTORIA; POLITICA Y GOBIERNO.

\section{Berríos, Rubén}

02528 Berríos, Rubén: "La empresa transideológica y las relaciones económicas Este-Oeste-Sur", Estudios Intemacionales, №57, año XV, enero-marzo, 1982, pp. 88-103.

ECONOMIA INTERNACIONAL; EMPRESAS TRANSNACIONALES; RELACIONES ECONOMICAS INTERNACIONALES.

\section{Berrocal Soto, Fernando}

02477 Berrocal Soto, Fernando. "América Latina en la década de los 80", Estudios Internacionales, №49, año XIII, enero-marzo, 1980, pp. 38-53.

AMERICA LATINA; ECONOMIA INTERNACIONAL.

\section{Berthelot, Ives}

02648 Berthelot, Ives. "Perspectivas económicas para 1985-1990: algunas inquietudes", Estudios Internacionales, №73, año XIX, enero-marzo, 1986, pp. 118-121.

ECONOMIA INTERNACIONAL.

\section{Betancourt, Belisario}

02572 Betancourt, Belisario. "La capacidad de respuesta de América Latina ante la crisis", Estudios Intemacionales, №63, año XVI, julio-septiembre, 1983, pp. 339-349.

ECONOMIA INTERNACIONAL; AMERICA LATINA; CRISIS.

Bianchi, Andrés

02675 Bianchi, Andrés; Devlin, Robert; Ramos, Joseph. "El proceso de ajuste en América Latina 1981-1986", Estudios Internacionales, No79, año XX, julio-septiembre, 1987, pp. 272-320.

ECONOMIA INTERNACIONAL; AMERICA LATINA; DEUDA EXTERNA; POLITICA ECONOMICA.

\section{Bitar, Sergio}

02532 Bitar, Sergio. "América Latina y Estados Unidos: Relaciones económicas en los años setenta", Estudios Intemacionales, №58, año xV, abril-junio, 1982, pp. 205-224.

AMERICA LATINA; ESTADOS UNIDOS; AMERICA DEL NORTE; ECONOMIA INTERNACIONAL; RELACIONES ECONOMICAS INTERNACIONALES.

02601 Bitar, Sergio. "Los intereses económicos de EE.UU. y su política hacia América Latina", Estudios Internacionales, №66, año XVII, abril-junio, 1984, pp. 247-256.

ESTADOS UNIDOS; AMERICA DEL NORTE; AMERICA LATINA; ECONOMIA INTERNACIONAL; POLITICA INTERNACIONAL. 
02639 Bitar, Sergio. "El desconcertante reimpulso de la hegemonía internacional de Estados Unidos", Estudios Internacionales, N72, año XVIII, octubre-diciembre, 1985, pp. 506-527.

ESTADOS UNIDOS; AMERICA DEL NORTE; POLITICA INTERNACIONAL; POLITICA MUNDIAL; ECONOMIA INTERNACIONAL; PODER.

02663 Bitar, Sergio. "Las políticas económicas de los países desarrollados. Consecuencias para América Latina", Estudios Internacionales, NQ76, año XIX, octubre-diciembre, 1986, pp. 513-530.

ECONOMIA INTERNACIONAL; AMERICA LATINA; PAISES DESARROLLADOS; POLITICA ECONOMICA.

02688 Bitar, Sergio. "América Latina en el nuevo mapa de la economía mundial", Estudios Internacionales, No81, año XXI, enero-marzo, 1988, pp. 23-44.

ECONOMIAINTERNACIONAL; AMERICA LATINA; ESTADOS UNIDOS; AMERICA DEL NORTE; COMUNIDAD ECONOMICA EUROPEA; EUROPA; JAPON; ASIA.

\section{Bodemer, Klaus}

02653 Bodemer, Klaus. "La política de desarrollo de la administración Reagan: fundamentos ideológicos, estrategias y perspectivas", Estudios Internacionales, №74, año XIX, abril-junio, 1986, pp. 211-238. ESTADOS UNIDOS; AMERICA DEL NORTE; POLITICA INTERNACIONAL; TER-. CER MUNDO; POLITICA MUNDIAL.

\section{Bodenheimer, Susanne}

02728 Bodenheimer, Susanne. "La crisis del Movimiento Socialdemócrata en América latina", Estudios Internacionales, №12, año III, eneromarzo, 1970, pp. 544-567.

AMERICA LATINA; SOCIALDEMOCRACIA.

\section{Bognar, Jozsef}

02185 Bognar, Jozsef. "Reforma económica en Hungría", Estudios Internacionales, №10, año III, julio-septiembre, 1969, pp. 107-123. SOCIALISMO; EUROPA DEL ESTE; HUNGRIA; POLITICA ECONOMICA; REFORMAS; CONDICIONES ECONOMICAS.

\section{Boisier, Sergio}

02671 Boisier, Sergio. "Notas en torno al desarrollo de regiones fronterizas en América Latina", Estudios Internacionales, N278, año XX, abril-junio, 1987, pp. 158-191.

AMERICA LATINA; FRONTERAS; DESARROLLO; INTEGRACION REGIONAL.

\section{Botero, Rodrigo}

02750 Botero, Rodrigo. "La Comisión Brandt: una perspectiva latinoamericana", Estudios Internacionales, №48, año XII, octubre-diciembre, 1979, pp. 361-371.

AMERICA LATINA; RELACIONES NORTE SUR; POLITICA INTERNACIONAL; DIALOGO NORTE SUR. 


\section{Bouzas, Roberto}

02594 Bouzas, Roberto. "Estados Unidos y el proceso de transnacionalización en la postguerra", Estudios Intemacionales, №65, año XVII, enero-marzo, 1984, pp. 94-111.

ESTADOS UNIDOS; AMERICA DEL NORTE; POLITICA INTERNACIONAL; RELACIONES EXTERIORES.

02640 Bouzas, Roberto. "La evolución de la economía y la política económica norteamericana en 1984/1985", Estudios Internacionales, №72, año XVIII, octubre-diciembre, 1985, pp. 528-575.

ESTADOS UNIDOS; AMERICA DEL NORTE; ECONOMIA INTERNACIONAL; POLITICA ECONOMICA.

\section{Briones, Alvaro}

02656 Briones, Alvaro. "El Tercer Mundo en la perspectiva latinoamericana", Estudios Internacionales, №75, año XIX, julio-septiembre, 1986, pp. 335-370.

TERCER MUNDO; AMERICA LATINA; POLITICA INTERNACIONAL; POLITICA MUNDIAL; ECONOMIA INTERNACIONAL.

Bueno, Gerardo M.

02593 Bueno, Gerardo M. "Interdependencia económica: perspectivas desde América Latina", Estudios Intemacionales, №65, año XVII, eneromarzo, 1984, pp. 66-93.

ECONOMIA INTERNACIONAL; AMERICA LATINA; DEPENDENCIA ECONOMICA; RELACIONES ECONOMICAS INTERNACIONALES.

Buira, Ariel

02584 Buira, Ariel. "México: la crisis de divisas y el programa de ajuste", Estudios Intemacionales, №64, año XVI, octubre-diciembre, 1983, pp. 568-578.

MEXICO; AMERICA DEL NORTE; ECONOMIA INTERNACIONAL; POLTICA ECONOMICA.

\section{Bull, Hedley}

02186 Bull, Hedley. "Las relaciones internacionales como ocupación académica", Estudios Internacionales, $\mathrm{N}^{228}$, año VII, octubre-diciembre, 1974, pp. 76-93.

RELACIONES INTERNACIONALES; RELACIONES INTERNACIONALES - ESTUDIO Y ENSEÑANZA.

\section{Burton, J. W.}

02187 Burton, J. W. "No-alineación y política mundial contemporánea", Estudios Internacionales, No9, año III, abril-junio, 1969, pp. 32-47. TERCER MUNDO; POLITICA MUNDIAL; PAISES NO ALINEADOS.

\section{Busso, Anabella}

01596 Busso, Anabella. "Estados Unidos y la democratización latinoameri- 
cana: los condicionantes externos", Estudios Internacionales, No94, año XXIV, abril-junio, 1991, pp. 260-289.

ESTADOS UNIDOS; AMERICA DEL NORTE; AMERICA LATINA; DEMOCRATIZACION; AMERICA DEL SUR; RELACIONES EXTERIORES; TRANSICION DEMOCRATICA; POLITICA Y GOBIERNO; POLITICA INTERNACIONAL; AMERICA CENTRAL Y CARIBE.

\section{Bustamante, Fernando}

00602 Bustamante, Fernando. "La política de Estados Unidos contra el narcotráfico y su impacto en América Latina", Estudios Internacionales, NN90, año XXIII, abril-junio, 1990, pp. 240-271.

ESTADOS UNIDOS; AMERICA DEL NORTE; AMERICA LATINA; DROGAS; POLL TICA.

\section{Byth, James}

02188 Byth, James. "Niugini: una nueva nación cuprifera en el Pacífico se acerca a su independencia", Estudios Internacionales, №22, año VI, abril-junio, 1973, pp. 82-105.

COBRE; RECURSOS NATURALES; OCEANO PACIFICO; EMPRESAS TRANSNACIONALES; RECURSOS MINERALES; OCEANIA; PAPUA NUEVA GUINEA; INVERSIONES EXTRANJERAS.

\section{Cadena, Cecilia}

02215 Joxe, Alain; Cadena, Cecilia. "El armamentismo de los países dependientes: el caso latinoamericano", Estudios Internacionales, №14, año IV, julio-septiembre, 1970, pp. 3-81.

ARMAMENTISMO; DEPENDENCIA; AMERICA LATINA; ESTRATEGIA.

\section{Cançado Trindade, Antonio Augusto}

02576 Cançado Trindade, Antonio Augusto. "Posiciones internacionales del Brasil al nivel unilateral", Estudios Internacionales, N63, año XVI, julio-septiembre, 1983, pp. 406-458.

BRASIL; AMERICA DEL SUR; POLITICA INTERNACIONAL.

Caputo, Dante M.

02499 Sábato, Jorge A.; Caputo, Dante M.; Sábato, Jorge F. "Cooperación para el desarrollo: algunas reflexiones y propuestas", Estudios Internacionales, $\mathrm{N}^{2} 53$, año XIV, enero-marzo, 1981, pp. 17-47.

AMERICA LATINA; POLITICA INTERNACIONAL; COOPERACION INTERNACIONAL.

01585 Caputo, Dante M.; Sábato, Jorge F. "Perspectivas de la integración político-económica continental: la integración de las democracias pobres: oportunidades y peligros", Estudios Internacionales, N N94, año XXIV, abril-junio, 1991, pp. 194-208.

AMERICA LATINA; ESTADOS UNIDOS; AMERICA DEL NORTE; AMERICA DEL SUR; INTEGRACION POLITICA; INTEGRACION ECONOMICA; RELACIONES EXTERIORES; ESTADOS UNIDOS; AMERICA DEL NORTE; DEMOCRACIA. 
Carballal, Teresa

02463 Russell, Roberto; Carballal, Teresa. "América Latina ¿Hacia qué nuevo orden internacional?", Estudios Intemacionales, Ne46, año XII, abril-junio, 1979, pp. 144-176.

AMERICA LATINA; POLITICA INTERNACIONAL; RELACIONES NORTE SUR; NUEVO ORDEN ECONOMICO INTERNACIONAL.

02501 Russell, Roberto; Carballal, Teresa. "El Nuevo Orden Ecconómico Internacional: tendencias observables en el Norte y en los países mayores de América Latina", Estuidios Intemacionales, No53, año XIV, enero-marzo, 1981, pp. 55-88.

NUEVO ORDEN ECONOMICO INTERNACIONAL; RELACIONES NORTE SUR; AMERICA LATINA; ECONOMIA INTERNACIONAL; POLITICA INTERNACIONAL; RELACIONES EXTERIORES.

\section{Cardoso, Fernando $\mathrm{H}$.}

02555 Cardoso, Fernando H. "América Latina y la influencia de los modelos políticos europeos en los años 80", Estudios Intemacionales, N61, año XVI, enero-marzo, 1983, pp. 31-46.

AMERICA LATINA; ELROPA; POLITICA Y GOBIERNO; PARTIDOS POLITICOS.

\section{Casanova, Manuel}

02464 Casanova, Manuel. "La participación de América Latina en el sistemạ económico internacional de la postguerra", Estudios Intemacionales, No46, año XII, abril-junio, 1979, pp. 177-203.

AMERICA LATINA; ECONOMIA INTERNACIONAL; NUEVO ORDEN ECONOMICO INTERNACIONAL; POLITICA INTERNACIONAL.

\section{Cepeda Ulloa, Fermando}

02451 Cepeda Ulloa, Fernando. "La influencia de las agencias internacionales en el proceso de desarrollo de Colombia 1950-1974", Estudios Intemacionales, Ne43, año XI, julio-septiembre, 1978, pp. 57-75. DESARROLLO ECONOMICO; COLOMBIA; AMERICA DEL SUR; COOPERACION INTERNACIONAL; ORGANIZACIONES INTERNACIONALES.

02636 Cepeda Ulloa, Fernando. "El proceso de paz en Colombia y la política internacional", Estudios Internacionales, No71, año XVII, julio-septiembre, 1985 , pp. 440-450.

COLOMBIA; AMERICA DEL SUR; POLITICA INTERNACIONAL; POLITICA Y GOBIERNO; PAZ.

\section{Chaparro, Patricio}

02473 Chaparro, Patricio. "El Sistema Económico Latinoamericano (SELA), como instancia de mediación, representación y acción política, idestinado al fracaso?", Estudios Internacionales, N48, año XII, octubre-diciembre, 1979 , pp. 419-439.

AMERICA LATINA; SELA; INTEGRACION REGIONAL. 
Ciria, Alberto

02189 Ciria, Alberto. "La comunicación política en América Latina: algunos de sus problemas", Estudios Intemacionales, N28, año II, eneromarzo, 1969, pp. 530-542.

AMERICA LATINA; POLITICA Y GOBIERNO; CULTURA POLITICA; COMUNICACIONES.

\section{Clarkson, Stephen}

02190 Clarkson, Stephen. "La intelligentsia satélite: los intelectuales canadienses frente a los Estados Unidos", Estudios Intemacionales, №18, año V, abril-junio, 1972, pp. 41-67.

CANADA; ESTADOS UNIDOS; AMERICA DEL NORTE; CIENCIA YTECNOLOGIA.

\section{Claverie Rodríguez, Heliodoro}

02191 Claverie Rodríguez, Heliodoro; Echeverría, Pedro Luis; Villalba Vera, Jovito. "El tratado modificado de reciprocidad comercial entre Venezuela y los Estados Unidos", Estudios Internacionales, $\mathrm{N}^{\mathrm{e}} 19$, año V, julio-septiembre, 1972, pp. 91-102.

VENEZUELA; ESTADOS UNIDOS; ECONOMIA INTERNACIONAL; COMERCIO EXTERIOR; TRATADOS; COOPERACION ECONOMICA; RELACIONES ECONOMICAS INTERNACIONALES; AMERICA DEL SUR; AMERICA DEL NORTE.

\section{Constantinesco, Leontin}

02192 Constantinesco, Leontin. "Las relaciones Estados Unidos-Comunidad Económica Europea en la perspectiva de la Rueda Nixon", Estuldios Internacionales, Ne21, año VI, enero-marzo, 1973, pp. 44-54. ESTADOS UNIDOS; COMUNIDAD ECONOMICA EUROPEA; RELACIONES ECONOMICAS; COMERCIO EXTERIOR; POLITICA MUNDIAL; ECONOMIA INTERNACIONAL; GATT; AMERICA DEL NORTE; RELACIONES ECONOMICAS INTERNACIONALES; EUROPA.

\section{Cotler, Julio}

02729 Cotler, Julio. "Crisis política y populismo militar en el Perú", Estudios Internacionales, No12, año III, enero-marzo, 1970, pp. 439-488.

FUERZAS ARMADAS; PERU; MILTTARISMO; POPULISMO; POLITICA Y GOBIERNO; CRISIS; AMERICA DEL SUR.

\section{Cousiño Cousiño, José Antonio}

01872 Cousiño Cousiño, José Antonio. "El Instituto de Estudios Internacionales: 25 años de vinculación con la Cuenca del Pacífico", Estudios Internacionales, №96, año XxrV, octubre-diciembre, 1991, pp. 538563.

CHILE; AMERICA DEL SUR; INSTITUTO DE ESTUDIOS INTERNACIONALES; UNIVERSIDAD DE CHILE; CUENCA DEL PACIFICO; OCEANO PACIFICO.

02560 Cousiño Cousiño, José Antonio. "Tecnología y ética en el Nuevo 
Orden Informativo", Estudios Internacionales, №61, año XVi, eneromarzo, 1983, pp. 117-133.

CIENCIA Y TECNOLOGIA; MEDIOS DE COMUNICACION; ETICA.

\section{Croner, Claes}

02214 Croner, Claes, "Estudios sobre el subdesarrollo colombiano: comentario crítico", Estudios Intemacionales, №14, año IV, julio-septiembre, 1970, pp. 117-132.

DESARROLLO ECONOMICO; COLOMBIA; AMERICA DEL SUR.

\section{Dam, André, van}

02377 Dam, André, van. "El triunfo del caballo", Estudios Internacionales, №34, año IX, abril-junio, 1976, pp. 3-9.

ECONOMIA INTERNACIONAL; DESARROLLO ECONOMICO; CIENCIA Y TECNOLOGIA; EMPRESAS TRANSNACIONALES.

\section{Delgado, Carlos}

02193 Delgado, Carlos. "Sobre algunos problemas de la participación en la Revolución Peruana", Estudios Intemacionales, №21, año VI, eneromarzo, 1973, pp. 24-43.

PERU; FUERZAS ARMADAS; AMERICA DEL SUR; REVOLUCIONES; POLITICA Y GOBIERNO; CRISIS; PARTICIPACION POLITICA.

\section{Delich, Francisco}

02632 Delich, Francisco. "De la democracia como necesidad a la democracia como condición", Estudios Internacionales, №71, año XVIII, julioseptiembre, 1985 , pp. 370-381.

DEMOCRACIA; POLITICA Y GOBIERNO; AMERICA LATINA.

\section{Devillers, Philippe}

02194 Devillers, Philippe. "Francia y la Segunda Guerra del Vietnam", Estudios Intemacionales, N6, año II, julio-septiembre, 1968, pp. 214-241.

FRANCIA; VIETNAM; CONFLICTOS; EUROPA; POLITICA INTERNACIONAL; ASIA; GUERRA; RELACIONES EXTERIORES.

\section{Devlin, Robert}

02583 Devlin, Robert. "La crisis del sector externo de América Latina: el origen del problema y algunas opciones para enfrentarlo", Estudios Internacionales, No64, año XVI, octubre-diciembre, 1983, pp. 547-567. ECONOMIA INTERNACIONAL; AMERICA LATINA; DEUDA EXTERNA.

02675 Bianchi, Andrés; Devlin, Robert; Ramos, Joseph. "El proceso de ajuste en América Latina 1981-1986", Estudios Internacionales, No79, año $\mathrm{XX}$, julio-septiembre, 1987, pp. 272-320.

ECONOMIA. INTERNACIONAL; AMERICA LATINA; DEUDA EXTERNA; POLITICA ECONOMICA. 


\section{Diamand, Marcelo}

02378 Diamand, Marcelo. "Las posibilidades de una técnica nacional en Latinoamérica: El caso argentino", Estudios Internacionales, №34, año IX, abril-junio, 1976, pp. 10-41.

CIENCIA Y TECNOLOGIA; AMERICA LATINA; ARGENTINA; AMERICA DEL SUR.

02404 Diamand, Marcelo. "Hacia el cambio del paradigma económico a través de la experiencia de los países en desarrollo", Estudios Internacionales, $\mathrm{N}^{2} 39$, año X, julio-septiembre, 1977, pp. 3-56.

ECONOMIA INTERNAGIONAL; DESARROLLO ECONOMICO; PAISES EN DESA RROLLO.

\section{Días David, Mauricio}

02533 Días David, Mauricio. "La transnacionalización económica versus la autonomía de las políticas nacionales", Estudios Internacionales, Ne59, año XV, julio-septiembre, 1982, pp. 247-259.

ECONOMIA INTERNACIONAL; POLITICA ECONOMICA; RELACIONES ECONOMICAS INTERNACIONALES.

\section{Díaz Albónico, Rodrigo}

02453 Díaz Albónico, Rodrigo. "Los elementos objetivos y subjetivos en la definición internacional de la agresión", Estudios Intemacionales, №43, año XI, julio-septiembre, 1978, pp. 90-107.

DERECHO INTERNACIONAL; AGRESION - DERECHO INTERNACIONAL.

02489 Díaz Albónico, Rodrigo. "El sistema de seguridad interamericana y sus nuevos desarrollos a través del Tratado de Tlatelolco", Estudios Internacionales, N51, año XII, julio-septiembre, 1980, pp. 345-381. SEGURIDAD; SISTEMA INTERAMERICANO; TRATADO DE TLATELOLCO; AMERICA LATINA; POLITICA INTERNACIONAL; SEGURIDAD INTERNACIONAL.

\section{Díaz Alejandro, Carlos}

02195 Díaz Alejandro, Carlos. "El Grupo Andino en el proceso de integración latinoamericana", Estudios Intemacionales, N6, año II, julioseptiembre, 1968, pp. 242-257.

GRUPO ANDINO; INTEGRAGION ECONOMICA; AMERICA LATINA; INTEGRACION REGIONAL.

02390 Díaz Alejandro, Carlos. "Relaciones Norte-Sur: el componente económico", Estudios Internacionales, №37, año X, enero-marzo, 1977, pp. 3-44.

ECONOMIA INTERNACIONAL; RELACIONES NORTE SUR; RELACIONES ECONOMICAS INTERNACIONALES.

\section{Diéguez M., María Isabel}

00248 Diéguez M., María Isabel. "La neutralidad de Argentina durante la Segunda Guerra Mundial", Estudios Intemacionales, №85, año XXII, enero-marzo, 1989, pp. 53-77.

ARGENTINA; AMERICA DEL SUR; GUERRA MUNDIAL I; ESTADOS UNIDOS; 
AMERICA DEL NORTE; RELACIONES BILATERALES; NEUTRALIDAD; POLITICA MUNDIAL.

\section{Drekonja Kornat, Gerhald}

02502 Drekonja Kornat, Gerhald. "Aproximaciones a la política exterior latinoamericana", Estudios Internacionales; $N^{2} 53$, año XrV, eneromarzo, 1981, pp. 89-104.

AMERICA LATINA; POLITICA INTERNACIONAL; RELACIONES EXTERIORES.

\section{Dunkel, Arthur}

02534 Dunkel, Arthur. "El comercio internacional y la función del GATT", Estudios Internacionales, N259, año XV, julio-septiembre, 1982, pp. 295-303.

ECONOMIA INTERNACIONAL; COMERCIO EXTERIOR; GATT.

\section{Durán, Espéranza}

02615 Durán, Esperanza. "La solución de Contadora para el logro de la paz en Centroamérica", Estudios Intemacionales, №68, año XVII, octubre-diciembre, 1984, pp. 537-547.

AMERICA CENTRAL Y CARIBE; CONFLICTOS; GRUPO CONTADORA; PAZ.

\section{Durán, Roberto}

02913 Durán, Roberto. "Vigencia del esquema conductualista en los estudios internacionales: su viabilidad en América Latina", Estudios Intemacionales, №99, año XXV, julio-septiembre, 1992, pp. 385-404. AMERICA LATINA; RELACIONES INTERNACIONALES - ESTUDIO Y ENSENAANZA; RELACIONES INTERNACIONALES - TEORIA; METODOLOGIA.

\section{Ebenroth, Carsten Thomas}

00237 Ebenroth; Carsten Thomas. "Internacionalización de la economía. Instituciones concurrentes, manejo de deuda externa e inversiones extranjeras", Estudios Internacionales, №88, año XXII, octubre-diciembre, 1989 , pp. 514-558.

COMERCIO EXTERIOR; GATT; SISTEMA MONETARIO INTERNACIONAL; INVERSIONES EXTRANJERAS; DEUDA EXTERNA.

\section{Echeverría, Pedro Luis}

02191 Claverie Rodríguez, Heliodoro; Echeverría, Pedro Luis; Villalba Vera, Jovito. "El tratado modificado de reciprocidad comercial entre Venezuela y los Estados Unidos", Estudios Internacionales, Ne19, año $\mathrm{V}$, julio-septiembre, 1972, pp. 91-102.

VENEZUELA; ESTADOS UNIDOS; ECONOMIA INTERNACIONAL; COMERCIO EXTERIOR; TRATADOS; COOPERACION ECONOMICA; RELACIONES ECONOMICAS INTERNACIONALES; AMERICA DEL SUR; AMERICA DEL NORTE.

\section{Edwards, Ernesto}

02711 Edwards, Ernesto. "América Latina y la economía mundial", Estudios Intemacionales, Ne82, año XXI, abril-junio, 1988, pp. 206-253. 
AMERICA LATINA; ECONOMIA INTERNACIONAL; DEUDA EXTERNA; COMERCIO EXTERIOR.

\section{Edwards, Sebastián}

02539 Edwards, Sebastián. "Deuda externa, ahorro doméstico y crecimiento económico en Chile. Una perspectiva de largo plazo: 1982-1990", Estudios Internacionales, №59, año XV, julio-septiembre, 1982, pp. 260-275.

CHILE; AMERICA DEL SUR; DESARROLLO ECONOMICO; DEUDA EXTERNA; POLITICA ECONOMICA.

\section{Eguizábal, Cristina}

00236 Eguizábal, Cristina; Rojas Aravena, Francisco. "Política exterior, negociación y procesos de decisión en Centroamérica: elementos para una aproximación", Estudios Internacionales, №88, año XXII, octubre-diciembre, 1989 , pp. 489-513.

AMERICA CENTRAL Y CARIBE; RELACIONES EXTERIORES; ACTORES POLITICOS; INTEGRACION REGIONAL; POLITICA INTERNACIONAL; NEGOCIACIONES; TOMA DE DECISIONES.

\section{End, Heinrich}

02196 End, Heinrich. "La política exterior del gobierno Kissinger-Brandt", Estudios Internacionales, №7, año II, octubre-diciembre, 1968, pp. 358-367.

POLITICA INTERNACIONAL; ALEMANIA.

Estévez, Jaime

02647 Estévez, Jaime. "Crisis de pagos y políticas de ajuste en América Latina", Estudios Internacionales, №73, año XIX, enero-marzo, 1986, pp. 98-117.

AMERICA LATINA; ECONOMIA INTERNACIONAL; DEUDA EXTERNA; POLITICA ECONOMICA.

\section{Fagen, Richard}

02380 Fagen, Richard. "La política exterior de los Estados Unidos y el desarrollo del Tercer Múundo", Estudios Internacionales, №35, año IX, julio-septiembre, 1976, pp. 3-37.

POLITICA INTERNACIONAL; ESTADOS UNIDOS; TERCER MUNDO; DESARROLLO ECONOMICO; POLITICA MUNDIAL; AMERICA DEL NORTE.

\section{Faúndez, Julio}

02213 Faúndez, Julio. "El sistema interamericano de seguridad en la política exterior de Estados Unidos", Estudios Intemacionales, Ne11, año III, octubre-diciembre, 1969, pp. 372-392.

SISTEMA INTERAMERICANO; SEGURIDAD; ESTADOS UNIDOS; AMERICA LATINA; POLITICA INTERNACIONAL; AMERICA DEL NORTE.

02197 Faúndez, Julio. "El Presidente de Estados Unidos y la facultad para 
hacer la guerra", Estudios Intemacionales, №15, año IV, octubre-diciembre, 1970 , pp. 60-83.

ESTADOS UNIDOS; POLITICA INTERNACIONAL; CONSTITUCION; AMERICA DEL NORTE; PODER LEGISLATIVO; INTERVENCION - DERECHO INTERNACIONAL.

\section{Feder, Ernest}

02220 Feder, Ernest. "Desarrollo agrícola y crecimiento económico", Estudios Intemacionales, №7, año II, octubre-diciembre, 1968, pp. 417422. AGRICULTUURA; DESARROLLO ECONOMICO.

\section{Fendt, Roberto}

02557 Fendt, Roberto. "Comercio exterior y políticas exteriores en Brasil: problemas y prioridades", Estudios Internacionales, №61, año XVI, enero-marzo, 1983, pp. 58-76.

BRASIL; AMERICA DEL SUR; COMERCIO EXTERIOR; POLITICA INTERNACIONAL; ECONOMIA INTERNACIONAL; RELACIONES EXTERIORES.

Ferguson, Yale $\mathrm{H}$.

02654 Ferguson, Yale $H$. "Reflexiones sobre el análisis de las políticas externas latinoamericanas", Estudios Intemacionales, №74, año XIX, abril-junio, 1986, pp. 239-274.

POLITICA INTERNACIONAL; AMERICA LATINA; POLITICA Y GOBIERNO.

\section{Fermandois Huerta, Joaquín}

02683 Wilhelmy, Manfred; Fermandois Huerta, Joaquín. "La Cancillería en la futura política exterior de Chile", Estudios Internacionales, №80, año XX, octubre-diciembre, 1987, pp. 491-505.

CHILE; AMERICA DEL SUR; POLITICA INTERNACIONAL; DIPLOMACIA; MINISTERIO DE RELACIONES EXTERIORES.

01131 Fermandois Huerta, Joaquín. "Expansion of third world Navies", de: Michael A. Morris, Reseña, Estudios Internacionales, Ne92, año XXIII, octubre-diciembre, 1990, pp. 532-537//Reseña del libro: "Expansion of third world Navies", Morris, Michael A// RESEÑA DE LIBROS.

01870 Fermandois Huerta, Joaquín. "De una inserción a otra: política exterior de Chile, 1966-1991", Estudios Internacionales, No96, año XXIV, octubre-diciembre, 1991, pp. 433-455.

CHILE; AMERICA DEL SUR; POLITICA INTERNACIONAL; RELACIONES EXTERIORES; POLITICA Y GOBIERNO.

\section{Fernández B., Mario}

02515 Nohlen, Dieter; Fernández B., Mario. "Cooperación y conflicto en la Cuenca del Plata", Estudios Internacionales, №55, año Xrv, julio-septiembre, 1981, pp. 412-443.

INTEGRACION REGIONAL; INTEGRACION ECONOMICA; AMERICA LATINA; 
CUENCA DEL PLATA; COOPERACION REGIONAL; COOPERACION ECONOMIGA; CONFLICTOS.

01593 Nohlen, Dieter; Fernández B., Mario. "Democratización y política exterior: análisis comparado en torno a tres casos: Argentina, Brasil y Uruguay", Estudios Intemacionales, Ne94, año XXIV, abril-junio, 1991, pp. 229-259.

ARGENTINA; BRASIL; URUGUAY; AMERICA DEL SUR; POLITICA INTERNACIONAL; DEMOCRATIZACION; TRANSICION DEMOCRATICA; AMERICA LATINA; INTEGRACION; INTEGRACION ECONOMICA.

\section{Fernández Estigarribia, José Félix}

01302 Fernández Estigarribia, José Félix. "Perspectivas de cambio de la política exterior paraguaya", Estudios Intentacionales, №93, año XXIV, enero-marzo, 1991, pp. 42-52.

PARAGUAY; AMERICA DEL SUR; POLITICA INTERNACIONAL; TRANSICION DEMOCRATICA; POLITICA Y GOBIERNO.

\section{Ferrer, Aldo}

02198 Ferrer, Aldo. "Relaciones económicas entre la Comunidad Económica Europea y América Latina" Estıdios Internacionales, No24, año VI, octubre-diciembre, 1973 , pp. 3-42.

ECONOMIA INTERNACIONAL; COMUNIDAD ECONOMICA EUROPEA; AMERICA LATINA; COMERCIO EXTERIOR; COOPERACION ECONOMICA; RELACIONES ECONOMICAS INTERNACIONALES.

02199 Ferrer, Aldo. "La crisis del Sistema Monetario Internacional: un enfoque estructuralista", Estudios Intemacionales, Ne30, año VIII, abril-junio, 1975, pp. 48-99.

ECONOMIA INTERNACIONAL; SISTEMA MONETARIO INTERNACIONAL; CRISIS.

02752 Ferrer, Aldo. "La crisis del sistema trilateral y América Latina", Estudios Internacionales, Ne42, año XI, abril-junio, 1978, pp. 3-38. AMERICA LATINA; POLITICA MUNDIAL; POLITICA INTERNACIONAL; ECONOMIA INTERNACIONAL; GRANDES POTENCIAS; EUROPA OCCIDENTAL; JAPON; ASIA; ESTADOS UNIDOS; AMVERICA DEL NORTE.

02476 Ferrer, Aldo. "La economía internacional desde una perspectiva latinoamericana", Estudios Intemacionales, N49, año XIII, eneromarzo, 1980, pp. 3-37.

ECONOMIA INTERNACIONAL; AMERICA LATINA; TERCER MUNDO.

02570 Ferrer, Aldo. "La deuda externa y las políticas nacionales", Estudios Internacionales, $\mathrm{N}^{2} 62$, año XVI, abril-junio, 1983, pp. 315-329. ECONOMIA INTERNACIONAL; DEUDA EXTERNA; AMERICA LATINA; POLITICA ECONOMICA.

02586 Ferrer, Aldo. "¿Puede Argentina pagar su deuda externa?", Estudios Internacionales, N64, año XVI, octubre-diciembre, 1983, pp. 603-628. ARGENTINA; AMERICA DEL SUR; ECONOMIA INTERNACIONAL; DEUDA EXTERNA. 
02604 Ferrer, Aldo. "Deuda, soberanía y democracia en América Latina", Estudios Internacionales, №67, año XVII, julio-septiembre, 1984, pp. 309-323.

DEUDA EXTERNA; AMERICA LATINA; ECONOMIA INTERNACIONAL; DEMOCRACIA; SOBERANIA.

\section{Ferrero Costa, Eduardo}

00234 Ferrero Costa, Eduardo. "Las relaciones de América Latina con el Japón y otros paises asiáticos de la Cuenca del Pacífico", Estudios Intemacionales, Ne88, año XXII, octubre-diciembre, 1989 , pp. 439462.

AMERICA LATINA; ASIA; JAPON; CUENCA DEL PACIFICO; RELACIONES ECONOMICAS INTERNACIONALES; ASIA PACIFICO.

\section{Ffrench-Davis, Ricardo}

02396 Ffrench-Davis, Ricardo. "Pacto Andino y libre comercio", Estudios Internacionales, No38, año X, abril-junio, 1977, pp. 3-11.

INTEGRACIONECONOMICA; INTEGRACION REGIONAL; PACTO ANDINO; COMERCIO EXTERIOR; LIBRE COMERCIO.

02568 Ffrench-Davis, Ricardo. "Deuda externa y balanza de pagos de América Latina: tendencias recientes y perspectivas", Estudios Internacionales, No62, año XVI, abril-junio, 1983, pp. 281-304. ECONOMIA INTERNACIONAL; AMERICA LATINA; DEUDA EXTERNA.

\section{Figueredo, Reynaido}

02566 Figueredo, Reynaldo. "Hacia una nueva apreciación del sistema de comercio internacional", Estudios Intemacionales, No62, año XVI, abril-junio, 1983, pp. 247-254.

ECONOMIA INTERNACIONAL; COMERCIO EXTERIOR.

\section{Fishlow, Albert}

02478 Lowenthal, Abraham F.; Fishlow, Albert. "Los nuevos intereses de los Estados Unidos en el hemisferio occidental", Estudios Internacionales, №49, año XIII, enero-marzo, 1980, pp. 54-69.

ESTADOS UNIDOS; AMERICA DEL NORTE; AMERICA LATINA; POLITICA INTERNACIONAL.

\section{Fleixa Lima, Paulo de Tarso}

02719 Fleixa Lima, Paulo de Tarso. "Perspectivas de las relaciones entre América Latina y los paises de la Liga de los Estados Arabes", Estudios Internacionales, N84, año XXI, octubre-diciembre, 1988, pp. 439-450.

POLITICA INTERNACIONAL; AMERICA LATINA; RELACIONES NORTE SUR; ECONOMIA INTERNACIONAL; PAISES ARABES; RELACIONES EXTERIORES. 


\section{Flores de la Peña, Horacio}

02405 Flores de la Peña, Horacio. "Un nuevo modelo de desarrollo", Estudios Internacionates, №39, año X, julio-septiembre, 1977, pp. 57-80. DESARROLLO ECONOMICO.

\section{Fogarty, John}

02200- Fogarty, John. "Australia y el problema de las inversiones extranjeras", Estıdios Intemacionales, №22, año v1, abril-junio, 1973, pp. 106-118.

AUSTRALIA; INVERSIONES EXTRANJERAS; DEPENDENCIA; OCEANIA; EMPRESAS TRANSNACIONALES.

\section{Freeland, John}

02081 Aguilar Mandsley, Andrés; Orrego Vicuña, Francisco; Sanguinetti, Julio María; Wilkey, Malcolm; Freeland, John. "Decisión de la Comisión para la Solución de Controversias entre Chile y Estados Unidos sobre el Caso Letelier Moffit, 11 de enero de 1992", Estudios Internacionales, №97, año XXV, enero-marzo, 1992, pp. 136-153. //nncluye: opinión separada concurrente del profesor Francisco Orrego Vicuña/l.

ESTADOS UNIDOS; AMERICA DEL NORTE; CHILE; AMERICA DEL SUR; CONTROVERSIAS, SOLUCION DE; INDEMNIZACION JUDICIAL; CASOS; DOCUMENTOS; DERECHOS HUMANOS.

\section{Fritsch, Winston}

02645 Paiva Abreu, Marcelo de; Fritsch, Winston. "Un estudio sobre la graduación", Estudios Intemacionales, №73, año XIX, enero-marzo, 1986, pp. 37-75.

ECONOMIA INTERNACIONAL; GATT; BRASIL; AMERICA DEL SUR.

\section{Frohmann, Alicia}

00223 Frohmann, Alicia. "De Contadora al Grupo de los Ocho: el reaprendizaje de la concertación política regional", Estudios Internacionales, No87, año XXII, julio-septiembre, 1989, pp. 365-427.

GRUPO CONTADORA; GRUPO DE LOS OCHO; INTEGRACION REGIONAL; COOPERACION REGIONAL; AMERICA LATINA; AMERICA CENTRAL Y CARIBE; CONCERTACION POLITICA.

\section{Frondizi, Arturo}

02201 Frondizi, Arturo. "El problema nacional de América Latina y ciertos esquemas de integración regional", Estudios Internacionales, N23-4, año I, octubre-marzo, 1967-1968, pp. 285-303.

AMERICA LATINA; INTEGRACION ECONOMICA; INTEGRACION REGIONAL; POLITICA Y GOBIERNO.

\section{Fuenzalida, Edmundo}

02751 Sunkel, Osvaldo; Fuenzalida, Edmundo. "Capitalismo transnacional 
y desarrollo nacional", Estudios Internacionales, N244, año XI, octubre-diciembre, 1978, pp. 3-27.

CAPITALISMO; DESARROLLO ECONOMICO; ECONOMIA INTERNACIONAL; POLITICA INTERNACIONAL; EMPRESAS TRANSNACIONALES.

\section{Furtado, Celso}

02203 Furtado, Celso. "La concentración del poder económico en los Estados Unidos y sus proyecciones en América Latina", Estudios Internacionales, №3-4, año I, octubre-marzo, 1967-1968, pp. 323-336.

ECONOMIAINTERNACIONAL; ESTADOS UNIDOS; AMERICA LATINA; DEPENDENCIA; EMPRESAS TRANSNACIONALES; AMERICA DEL NORTE; RELACIONES ECONOMICAS INTERNACIONALES; POLITICA INTERNACIONAL.

02202 Furtado, Celso. "Una interpretación estructuralista de la "crisis" actual del capitalismo", Estudios Internacionales, №30, año VIII, abril-junio, 1975, pp. 3-47.

ECONOMIA INTERNACIONAL; CAPITALISMO; DEPENDENCIA; CRISIS.

02385 Furtado, Celso. "El conocimiento económico de América Latina", Estudios Internacionales, №36, año IX, septiembre-diciembre, 1976, pp. 11-23.

DESARROLLOECONOMICO; AMERICA LATINA; ECONOMIA INTERNACIONAL.

02582 Furtado, Celso. "La crisis financiera internacional y sus consecuencias para América Latina", Estudios Intemacionales, №64, año XVI, octubre-diciembre, 1983, pp. 534-546.

ECONOMIA INTERNACIONAL; AMERICA LATINA; DEUDA EXTERNA; CRISIS.

\section{Galtung, Johan}

02563 Galtung, Johan. "Análisis del carácter de la crisis internacional actual", Estudios Intemacionales, №62, año XVI, abril-junio, 1983, pp. 180-210.

POLITICAMUNDIAL; NUEVO ORDEN ECONOMICO INTERNACIONAL; ECONOMIA INTERNACIONAL; CRISIS.

\section{García Menéndez, José Ramón}

01127 García Menéndez, José Ramón. "Estilos de crecimiento económico periférico e inserción de América Latina en el mercado mundial", Estudios Internacionales, No92, año XXIII, octubre-diciembre, 1990, pp. 444-463.

AMERICA LATINA; CRECIMIENTO ECONOMICO; COMERCIO INTERNACIONAL; RELACIONES ECONOMICAS INTERNACIONALES.

\section{García y García Sánchez-Blanco, José Luis}

02609 Granda Alva, Germán; García y García Sánchez-Blanco, José Luis. "La cooperación para el desarrollo de las comunidades europeas y sus relaciones con América Latina: un reto para España", Estudios Internacionales, N67, año XVII, julio-septiembre, 1984, pp. 401-417. AMERICA LATINA; COMUNIDAD ECONOMICA EUROPEA; ESPANNA; EUROPA; 
COMUNIDADES EUROPEAS; COOPERACION INTERNACIONAL; RELACIONES EXTERIORES; COOPERACION REGIONAL.

\section{García, Antonio}

02212 García, Antonio. "Proceso y frustración de las reformas agrarias en América Latina", Estudios Intemacionales, N³-4, año I, octubremarzo, 1967-1968, pp. 353-410.

AMERICA LATINA; REFORMA AGRARIA.

02755 Véliz, Claudio; García, Antonio; Vernant, Jacques. "El seminario de Arica", Estudios Intentacionales, №5, año In, abril-junio, 1968, pp. 138-150.

AMERICA LATINA; INTEGRACION ECONOMICA; INTEGRACION POLITICA.

\section{García-Sayán, Diego}

00600 García-Sayán, Diego. "Terrorismo y pacificación en el Perú", Estudios Internacionales, N990, año XXIII, abril-junio, 1990, pp. 221-239. TERRORISMO; AMERICA LATINA; PERU; DEMOCRACIA; PAZ.

\section{Giner, Salvador}

00415 Giner, Salvador; Moreno, Luis. "La sociedad civil en Europa Occidental", Estudios Intemacionales, N\&89, año XXII, enero-marzo, 1990 , pp. 3-20.

EUROPA OCCIDENTAL; CLASES SOCIALES; SOCIEDAD.

\section{Girvan, Norman}

02205 Girvan, Norman. "El conflicto de Guyana-Alcan y la nacionalización de Demba", Estudios Internacionales, N¹9, año v, julio-septiembre, 1972, pp. 71-90.

AMERICA LATINA; GUYANA; NACIONALIZACION; RECURSOS NATURALES; EMPRESAS TRANSNACIONALES; AMERICA DEL SUR.

02204 Girvan, Norman. "Teorías de dependencia económica en el Caribe y Latinoamérica: un estudio comparativo", Estudios Internacionales, N²3, año VI, julio-septiembre, 1973, pp. 23-60.

AMERICA LATINA; DEPENDENCIA; DESARROLLO ECONOMICO; AMERICA CENTRAL Y CARIBE; DEPENDENCIA ECONOMICA.

\section{Gittings, John}

02208 Gittings, John. "¿Tiene China una política exterior?", Estudios Internacionales, №1, año 1, abri1, 1967, pp. 76-94.

POLITICA INTERNACIONAL; CHINA; ASIA; CULTURA; RELACIONES EXTERIORES.

02206 Gittings, John. "Ultimos libros sobre Vietnam", Estudios Intemacionales, N22, año I, julio, 1967, pp. 212-226.

VIETNAM; CONFLICTOS; POLITICA INTERNACIONAL; ASIA.

02207 Gittings, John. "El Ejército Popular de Liberación y la Revolución 
Cultural", Estudios Internacionales, №5, año II, abril-junio, 1968, pp. 3-37.

CHINA; ASIA; FUERZAS ARMADAS; CULTURA; REVOLUCIONES.

02242 Gittings, John. "La nueva guerra de Indochina", Estudios Internacionales, №14, año $\mathrm{rV}$, julio-septiembre, 1970, pp. 104-116. VIETNAN; ASIA; GUERRA.

\section{Gligo, Nicolo}

02481 Gligo, Nicolo; Morello, Jorge. "Notas sobre la historia ecológica de América Latina", Estudios Internacionales', №49, año XIII, eneromarzo, 1980, pp. 112-148.

MEDIO AMBIENTE; HISTORIA; AMERICA LATINA; ECOLOGIA.

\section{Godfrey, Martin}

02455 Godfrey, Martin; Langdon, Steven. "¿Socios en el desarrollo? La tesis de la transnacionalización en el contexto keniano", Estudios Internacionales, Ne44, año XI, octubre-diciembre, 1978, pp. 45-70.

KENIA; AFRICA; ECONOMIA INTERNACIONAL; POLITICA INTERNACIONAL; RELACIONES EXTERIORES.

\section{Godoy, Horacio H.}

02219 Godoy, Horacio H. "La integración de América Latina y el proceso del poder mundial", Estudios Internacionales, №7, año II, octubre-diciembre, 1968, pp. 368-386.

INTEGRACION REGIONAL; INTEGRACION ECONOMICA; AMERICA LATINA; POLITICA MUNDIAL.

02256 Godoy, Horacio H. "Los acuerdos entre los Estados Unidos y la Unión de las Repúblicas Socialistas Soviéticas", Estudios Intemacionales, №28, año VII, octubre-diciembre, 1974, pp. 3-48.

ESTADOS UNIDOS; POLITICAINTERNACIONAL; AMERICA DEL NORTE; EUROPA DEL ESTE; URSS.

\section{Gomes Saraiva, Miriam}

02812 Gomes Saraiva, Miriam. "Las dos dimensiones de la política exterior de la Comunidad Europea. Sus procesos de formulación y sus difíciles relaciones", Estudios Internacionales, №98, año XXV, abril-junio, 1992, pp. 217-257.

COMUNIDADES EUROPEAS; POLITICA INTERNACIONAL; RELACIONES INTERNACIONALES; DERECHO COMUNITARIO; EUROPA; COOPERACION POLITICA; COOPERACION INTERNACIONAL.

\section{González, Norberto}

02467 González, Norberto. "Prioridades de América Latina en el Diálogo Norte-Sur", Estudios Internacionales, N²47, año XII, julio-septiembre, 1979, pp. 258-274.

AMERICA LATINA; DIALOGO NORTE SUR; DESARROLLO ECONOMICO; ECONOMIA INTERNACIONAL; RELACIONES EXTERIORES. 


\section{González, Raimundo}

01656 González, Raimundo. "Algunas reflexiones sobre una diplomacia multilateral contemporánea", Estudios Internacionales, №95, año XXIV, julio-septiembre, 1991, pp. 303-346.

DIPLOMACIA; COOPERACION INTERNACIONAL; DERECHO INTERNACIONAL; SEGURIDAD INTERNACIONAL; MEDIO AMBIENTE.

\section{Gott, Richard}

02226 Gott, Richard. "El Congo a partir de Mobutu", Estudios Internacionales, N23-4, año I, octubre-marzo, 1967-1968, pp. 443-489. CONGO; AFRICA; TERCER MUNDO.

02363 Gott, Richard. "La experiencia guerrillera en Bolivia", Estudios Intemacionales, $\mathrm{N}^{25}$, año II, abril-junio, 1968, pp. 85-114.

BOLIVIA; AMERICA DEL SUR; GUERRILLAS; VIOLENCIA; POLITICA Y GOBIERNO.

02237 Gott, Richard. "El sur de Africa y el fin de la guerra fría", Estudios Internacionales, №1, año I, abril, 1967, pp. 95-109.

AFRICA; GUERRA FRIA; POLITICA MUNDIAL.

\section{Grabendorff, Wolf}

02743 Grabendorff, Wolf. "Perspectivas y polos de desarrollo en América Latina", Estudios Internacionates, №50, año XIIr, abril-junio, 1980, pp. 252-278.

DESARROLLO ECONOMICO; AMERICA LATINA; POLITICA INTERNACIONAL; ECONOMIA INTERNACIONAL.

02526 Grabendorff, Wolf. "Brasil y la República Federal de Alemania: ¿Un modelo para las relaciones entre el Primer y Tercer Mundo?", Estudios Intemacionales, №57, año XV, enero-marzo, 1982, pp. 39-59. BRASIL; AMERICA DEL SUR; EUROPA; POLITICA INTERNACIONAL; GRANDES POTENCIAS; TERCER MUNDO; ALEMANIA REP. FEDERAL; RELACIONES EXTERIORES.

02537 Grabendorff, Wolf. "¿De país aislado a aliado preferido? Las relaciones entre Argentina y los Estados Unidos: 1976-1981. "Estudios Internacionales, N58, año XV, abril-junio, 1982, pp. 232-239. ARGENTINA; AMERICA DEL SUR; ESTADOS UNIDOS; AMERICA DEL NORTE; POLITICA INTERNACIONAL; RELACIONES EXTERIORES.

02578 Grabendorff, Wolf. "América Central como región de crisis internacional", Estudios Internacionales, №63, año XV1, julio-septiembre, 1983, pp. 483-497.

AMERICA CENTRAL Y CARIBE; POLITICA INTERNACIONAL.

02595 Grabendorff, Wolf. "Las relaciones entre América Latina y Europa Occidental: los actores nacionales y transnacionales, sus objetivos y expectativas", Estudios Internacionales, N65, año XVII, enero-marzo, 1984, pp. 112-130. 
AMERICA LATINA; EUROPA; POLITICA INTERNACIONAL; COOPERACION INTERNACIONAL; EUROPA OCCIDENTAL; RELACIONES EXTERIORES.

02635 Grabendorff, Wolf. "La crisis centroamericana: ¿Tiene Europa Occidental un papel en ella?", Estudios Intemacionales, №71, año XVII, julio-septiembre, 1985 , pp. $422-439$.

AMERICA CENTRAL Y CARIBE; CONFLICTOS; POLITICA INTERNACIONAL; EUROPA; EUROPA OCCIDENTAL.

02685 Grabendorff, Wolf. "La política nuclear y de no proliferación de Brasil", Estudios Intemacionales, №80, año XX, octubre-diciembre, 1987, pp. 520-568.

BRASIL; AMERICA DEL SUR; ENERGIA NUCLEAR; ARMAMENTISMO; POLITICA INTERNACIONAL; CONTROL DE ARMAMENTOS.

\section{Granda Alva, Germán}

02609 Granda Alva, Germán; García y García Sánchez-Blanco, José Luis. "La cooperación para el desarrollo de las comunidades europeas y sus relacionés con América Latina: un reto para España", Estudios Intenacionales, N67, año XVII, julio-septiembre, 1984, pp. 401-417. AMERICA LATINA; COMUNIDAD ECONOMICA EUROPEA; ESPANA; EUROPA; COMUNIDADES EUROPEAS; COOPERACION INTERNACIONAL; RELACIONES EXTERIORES; COOPERAGION REGIONAL.

\section{Grant, Bruce}

02395 Grant, Bruce. "Australia y el Pacífico", Estudios Intemacionales, No17, año V, enero-marzo, 1972, pp. 40-52.

AUSTRALIA; OCEANIA; OCEANO PACIFICO.

Grant, James $P$.

02364 Grant, James P. "Las naciones de la OPEP: ¿Asociados o competidores?", Estudios Internacionales, Ne30, año VIII, abril-junio, 1975, pp. 100-118.

ECONOMIA INTERNACIONAL; OPEP; PETROLEO; PRODUCTOS BASICOS; COOPERACION INTERNACIONAL.

\section{Grayson, George W.}

02424 Grayson, George W. "Portugal y el movimiento de las Fuerzas Armadas", Estudios Internacionales, №33, año IX; enero-marzo, 1976, pp. 3-46.

PORTUGAL; EUROPR; FUERZAS ARMADAS; POLITICAY GOBIERNO; GOLPES DE ESTADO.

\section{Green, Rosario}

02495 Green, Rosario. "La importancia del estudio de las relaciones internacionales de los países latinoamericanos ${ }^{\prime \prime}$, Estudios Intemacionales, Ne52, año XII, octubre-diciembre, 1980, pp. 527-544.

AMERICA LATINA; RELACIONES INTERNACIONALES - ESTUDIO Y ENSEÑANZA. 
02587 Green, Rosario. "Visión y acción de Washington frente a la deuda externa latinoamericana", Estudios Internacionales, №64, año XVI, octubre-diciembre, 1983, pp. 629-663.

ECONOMIA INTERNACIONAL; DEUDA EXTERNA; AMERICA LATINA; ESTADOS UNIDOS; AMERICA DEL NORTE.

02724 Green, Rosario. "Nuevas formas de concertación regional en América Latina: el Grupo de los Ocho", Estudios Intemacionales, NN83, año XXI, julio-septiembre, 1988, pp. 354-372.

AMERICA LATINA; CONCERTACION POLITICA; GRUPO DE LOS OCHO; POLFTICA INTERNACIONAL; INTEGRACION REGIONAL.

\section{Griffith-Jones, Stephany}

02747 Griffith-Jones, Stephany. "El crecimiento de la banca multinacional, los mercados de euromonedas y los paises de la periferia", Estudios Intemacionates, Ne44, año XI, octubre-diciembre, 1978, pp. 71-87. ECONOMIA INTERNACIONAL; BANCOS; EMPRESAS TRANSNACIONALES.

\section{Grunwald, Joseph}

02471 Grunwald, Joseph. "El comercio intraindustrial Norte-Sur: compartir la producción industrial entre los países en desarrollo y desarrollados", Estudios Intemacionales, N48, año XII, octubre-diciembre, 1979, pp. 372-389.

RELACIONES NORTE SUR; ECONOMIA INTERNACIONAL; COMERCIO EXTERIOR; PAISES DESARROLLADOS; PAISES EN DESARROLLO.

\section{Guerrero, Mauricio}

02366 Sagasti, Francisco R.; Guerrero, Mauricio. "Situación de la ciencia y tecnología en América Latina", Estudios Internacionales, No25, año VII, enero-marzo, 1974, pp. 16-56.

CIENCIA Y TECNOLOGIA; AMERICA LATINA; DESARROLLO ECONOMICO.

\section{Guimaraes, Roberto P.}

00417 Guimaraes, Roberto P. "El Leviatán acorralado: continuidad y cambio en el papel del Estado en America Latina", Estudios Internacionales, No89, año XXIII, enero-marzo, 1990, pp. 45-81.

AMERICA LATINA; ESTADO; DESARROLLO ECONOMICO; DEMOCRATIZACION; DESARROLLO SOCIAL.

\section{Gurley, John G.}

02225 Gurley, John G. "El desarrollo económico de China comunista", Estudios Internacionales, No3-4, año I, octubre-marzo, 1967-1968, pp. 304-322.

DESARROLLO ECONOMICO; CHINA; ASIA.

\section{Gutiérrez Bermedo, Hernán}

01304 Gutiérrez Bermedo, Hernán. "Análisis comparativo del sistema de 
partidos y las elecciones generales en Chile 1989", Estudios Internacionales, No93, año XXIV, enero-marzo, 1991, pp. 81-105.

CHILE; AMERICA DEL SUR; TRANSICION DEMOCRATICA; PARTIDOS POLITICOS; ELECCIONES; SISTEMA ELECTORAL; AMERICA LATINA; FUERZAS ARMADAS; POLITICA Y GOBIERNO.

01852 Gutiérrez Bermedo, Hernán; Wilhelmy, Manfred. "Concepciones latinoamericanas y asiáticas sobre cooperación regional", Estudios Internacionales, Ne96, año 24, octubre-diciembre, 1991, pp. 472-517. AMERICA LATINA; ASIA; COOPERACION REGIONAL; INTEGRACION REGIONAL; DEPENDENCIA; ALALC; ALADI; ACUERDO DE CARTAGENA; SELA; CONCERTACION POLITICA; GRUPO DE RIO; GRUPO CONTADORA; ASEAN.

\section{Hager, Wolfgang}

02565 Hager, Wolfgang. "El comercio Norte-Sur y la autonomía socioeconómica: una fórmula de paz", Estudios Internacionales, N⿳62, año XVI, abril-junio, 1983, pp. 232-246.

RELACIONES NORTE SUR; COMERCIO EXTERIOR; ECONOMIA INTERNACIONAL; RELACIONES ECONOMICAS INTERNACIONALES.

\section{Halty Carrere, Máximo}

02353 Halty Carrere, Máxińo. "¿Hacia un nuevo orden tecnológico?", Estudios Internacionales, №32, año viI, octubre-diciembre, 1975, pp. 33-50.

DESARROLLO TECNOLOGICO; DEPENDENCIA; POLITICA MUNDIAL; CIENCIA Y TECNOLOGIA.

\section{Hansen, Roger}

02354 Hansen, Roger. "Relaciones económicas entre los Estados Unidos y América Latina, ¿Bilaterales, regionales o globales", Estudios Internacionales, №31, año VIII, julio-septiembre, 1975, pp. 59-99. ECONOMIAINTERNACIONAL; ESTADOS UNIDOS; AMERICA LATINA; AMERICA DEL NORTE; RELACIONES ECONOMICAS INTERNACIONALES; RELACIONES EXTERIORES.

\section{Haq, Mahbúb ul}

$02414 \mathrm{Haq}, \mathrm{Mahbub}$ ul. "El Diálogo Norte-Sur: la segunda fase", Estudios Intertacionales, N241, año XI, enero-marzo, 1978,pp. 16-26.

DIALOGO NORTE SUR; ECONOMIA INTERNACIONAL; RELACIONES NORTE SUR; RELACIONES EXTERIORES; POLITICA INTERNACIONAL.

\section{Heine, Jorge}

00220 Heine, Jorge. "Latinos y antillanos: las relaciones entre América Latina y el Caribe en los noventa", Estudios Internacionales, Ne87, año XXII, julio-septiembre, 1989, pp. 298-307.

AMERICA LATINA; AMERICA CENTRAL Y CARIBE; COOPERACION REGIONAL; RELACIONES BILATERALES; RELACIONES EXTERIORES; POLITICA INTERNACIONAL.

01305 Heine, Jorge. "¿Cooperación o divergencia? Hacia una nueva agenda 
en las relaciones europeo-latinoamericanas", Estudios Internacionales, No93, año XXIV, enero-marzo, 1991, pp. 106-158.

AMERICA LATINA; EUROPA; EUROPA OCCIDENTAL; RELACIONES EXTERIORES; COMUNIDADES EUROPEAS; COOPERACION ECONOMICA; ECONOMIA INTERNACIONAL; POLITICA INTERNACIONAL.

01869 Heine, Jorge. "¿Cayó también el Tercer Mundo? El Sur ante el nuevo orden global", Estudios Internacionales, NQ96, año XXIV, octubre-diciembre, 1991, pp. 456-471.

TERCER MUNDO; POLITICA MUNDIAL; REFORMAS; RELACIONES NORTE SUR; POLITICA INTERNACIONAL; DESARROLLO ECONOMICO; RELACIONES EXTERIORES; ECONOMIA INTERNACIONAL.

\section{Herrera, Amílcar O.}

02223 Herrera, Amílcar O. "La ciencia en el desarrollo de América Latina", Estudios Internacionales, N25, año II, abril-junio, 1968, pp. 38-63. AMERICA LATINA; CIENCIA Y TECNOLOGIA; DESARROLLO.

\section{Herrera Lane, Felipe}

02238 Herrera Lane, Felipe. "Viabilidad de una comunidad latinoamericana", Estudios Intemacionales, No1, año I, abril, 1967, pp. 21-42. INTEGRACION REGIONAL; INTEGRACION ECONOMICA; AMERICA LATINA; ECONOMIA INTERNACIONAL.

02224 Herrera Lane, Felipe. "La tarea inconclusa: América Latina integrada", Estudios Intemacionales, №21, año VI, enero-marzo, 1973, pp. 3-23.

INTEGRACION ECONOMICA; INTEGRACION REGIONAL; AMERICA LATINA; POLITICA INTERNACIONAL.

02365 Herrera Lane, Felipe. "América Latina y el desafío internacional para la educación", Estudios Intemacionales, N225, año VII, eneromarzo, 1974, pp. 3-15. EDUCACION; AMERICA LATINA.

02408 Herrera Lane, Felipe. "América Latina y el Tercer Mundo", Estudios Interinacionales, $\mathrm{N}^{2} 40$, año $\mathrm{X}$, octubre-diciembre, 1977, pp. 13-32. AMERICA LATINA; TERCER MUNDO; POLITICA INTERNACIONAL; COOPERACION ECONOMICA; RELACIONES EXTERIORES,

02428 Herrera Lane, Felipe. "El desarrollo y las políticas culturales en América Latina", Estudios Internacionales, N243, año XI, julio-septiembre, 1978, pp. 26-46. DESARROLLO ECONOMICO; AMERICA LATINA; CULTURA.

02553 Herrera Lane, Felipe. "La Banca de Fomento Latinoamericana y la empresa privada: una perspectiva internacional", Estudios Internacionales, Ne61, año XVt, enero-marzo, 1983, pp. 3-13. ECONOMIA INTERNACIONAL; AMERICA LATINA; BANCOS REGIONALES DE DESARROLLO.

02649 Herrera Lane, Felipe. "Alianza para el Progreso: los postulados y las 
realizaciones", Estudios Internacionales, №74, año XIX, abril-junio, 1986, pp. 125-132.

ALIANZA PARA EL PROGRESO; ESTADOS UNIDOS; AMERICA DEL NORTE; AMERICA LATINA; POLITICA INTERNACIONAL.

\section{Hirschman, Albert O.}

02322 Hirschman, Albert O. "Liderazgo, percepción del cambio y subdesarrollo", Estudios Internacionates, №6, año II, julio-septiembre, 1968, pp. 258-270.

DESARROLLO ECONOMICO; POLITICA MUNDIAL.

\section{Hirst, Mónica}

02520 Soares de Lima, M. Regina; Hirst, Mónica. "Estados Unidos y América Latina: cerrando una época en descomposición", Estudios Internacionales, №56, año XIV, octubre-diciembre, 1981, pp. 530-552. ESTADOS UNIDOS; AMERICA DELLNORTE; AMERICA LATINA; POLITICA INTERNACIONAL; RELACIONES EXTERIORES.

02627 Hirst, Mónica. "Las relaciones de Estados Unidos con las potencias medianas en América Latina: los casos de México y Brasil", Estudios Internacionales, №70, año XVIII, abril-junio, 1985, pp. 241-269. ESTADOS UNIDOS; AMERICA DEL NORTE; AMERICA LATINA; MEXICO; BRASIL; AMERICA DEL SUR; POLITICA INTERNACIONAL; ECONOMIA INTERNACIONAL; RELACIONES EXTERIORES.

02695 Russell, Roberto; Hirst, Mónica. "Democracia y política exterior los casos de Argentina y Brasil", Estudios Internacionales, Ne80, año XX, octubre-diciembre, 1987, pp. 442-490.

DEMOCRACIA; POLITICA INTERNACIONAL; ARGENTINA; BRASIL; AMERICA OEL SUR; POLITICA Y GOBIERNO.

00235 Hirst, Mónica; Segre, Magdalena. "La política exterior de Brasil en 1988: los avances posibles", Estudios Interinacionales, Nº88, año XXIX, octubre-diciembre, 1989, pp. 463-488.

BRASIL; AMERICA DEL SUF; RELACIONES EXTERIORES; POLITICA INTERNACIONAL.

\section{Hodara, Joseph}

02355 Hodara, Joseph. "La coyuntura internacional: cuatro versiones", Estudios Internacionales, Ne31, año vII, julio-septiembre, 1975, pp. 100-113.

ECONOMIA INTERNACIONAL; POLITICA MUNDIAL.

\section{Hoffmann, Stanley}

02257 Hoffmann, Stanley. "El estilo norteamericano: su pasado, sus principios", Estudios Internacionales, Neg, año III, abril-junio, 1969, pp. 48-62.

ESTADOS UNIDOS; POLITICA INTERNACIONAL; AMERICA DEL NORTE. 


\section{Hofmeister, Wilhelm}

01130 Hofmeister, Wilhelm. "La resolución de la cuestión alemana: su dimensión nacional e internacional", Estudios Intemacionales, №92, año XXIII, octubre-diciembre, 1990, pp. 512-531//Incluye Anexo: Cronología de los acontecimientos en el camino hacia la unidad alemana, pp. 525-531//.

EUROPA OCCIDENTAL; ALEMANIA; REUNIFICACION; RELACIONES INTERNACIONALES.

\section{Holbraad, Carsten}

02339 "El papel de las potencias medias en la política internacional", Estudios Internacionales, №17, año V, enero-marzo, 1972, pp. 53-75. POLITICA INTERNACIONAL; POLITICA MUNDIAL.

\section{Hurtado, Héctor}

02318 Hurtado, Héctor; Pazos, Javier; Mayobre, Eduardo. "El Caribe y Venezuela: integración de la integración", Estudios Internacionales, №27, año VII, julio-septiembre, 1974, pp. 3-30.

AMERICA CENTRAL Y CARIBE; VENEZUELA; INTEGRACION REGIONAL; INTEGRACION ECONOMICA; ECONOMIA INTERNACIONAL; AMERICA DEL SUR.

\section{Iglesias, Enrique V.}

02754 Iglesias, Enrique V. "Transferencia de recursos en el ámbito internacional", Estudios Internacionales, No34, año IX; abril-junio, 1976, pp. $42-57$.

ECONOMIA INTERINACIONAL; NUEVO ORDEN ECONOMICO INTERNACIONAL; TERCER MUNDO; COOPERACION ECONOMICA; RELACIONES ECONOMICAS INTERNACIONALES.

02406 Iglesias, Enrique V. "Situación y perspectivas de América Latina", Estudios Internacionales, №39, año X, julio-septiembre, 1977, pp. 81-123.

AMERICALATINA; DESARROLLO ECONOMICO; ECONOMIA INTERNACIONAL; NUEVO ORDEN ECONOMICO INTERNACIONAL; CONDICIONES ECONOMCAS.

02421 Iglesias, Enrique V. "¿Va América Latina hacia la bancarrota?", Estudios Intemacionales, N^42, año XI, abril-junio, 1978, pp. 95-110. DESARROLLO ECONOMICO; AMERICA LATINA; ECONOMIA INTERNACIONAL; CONDICIONES ECONOMICAS.

02458 Iglesias, Enrique V. "Perspectivas económicas de América Latina y sus implicaciones para los Estados Unidos", Estudios Internacionales, No45, año XII, enero-marzo, 1979, pp. 14-26.

ECONOMMIAINTERNACIONAL; AMERICA LATINA; ESTADOS UNIDOS; AMERICA DEL NORTE; RELACIONES NORTE SUR; RELACIONES ECONOMICAS INTER NACIONALES.

02510 Iglesias, Enrique V. "Perspectivas del desarrollo de América Latina", 
Estudios Internacionales, №55, año XIV, julio-septiembre, 1981, pp. 311-321.

DESARROLLO ECONOMICO; AMERICA LATINA; POUITICA INTERNACIONAL.

02564 Iglesias, Enrique V: "La crisis económica internacional y las perspectivas de Américá Latina", Estudios Internacionales, N62, año XVI, abril-junio, 1983, pp. 211-231.

ECONOMIA INTERNACIONAL; AMERICA LATINA; CRISIS.

02602 Iglesias, Enrique V. "América Latina: crisis y opciones de desarrollo", Estudios Internacionales, №66, año XVIr, enero-marzo, 1984, pp. 257-292.

DOCUMENTOS; AMERICA LATINA; DESARROLLO ECONOMICO; CEPAL; ECONOMIA INTERNACIONAL.

02676 Iglesias, Enrique V. "Nuevas formas de cooperación entre la Comunidad Económica Europea y América Latina", Estudios Intemacionales, N279, año XX, julio-septiembre, 1987, pp. 321-327.

COMUNIDAD ECONOMICA EUROPEA; EUROPA: AMERICA LATINA; ECONOMIA INTERNACIONAL; COOPERACION ECONOMICA; RELACIONES ECONOMICAS INTERNACIONALES.

02917 Iglesias, Enrique V. "Hacia una agenda económica para Ios años noventa", Estudios Intemacionales, No99, año XXV, julio-septiembre, 1992, pp. 322-340.

AMERICA LATINA; CRECIMIENTO ECONOMICO; POLITICA ECONOMICA; POLITICA SOCIAL; ESTADO; REFORMAS; INTEGRACION ECONOMICA; ECONOMIA INTERNACIONAL; DESARROLLO SUSTENTABLE; POLITICA INTERNACIONAL.

Imaz, José Luis, de

02356 Imaz, José Luis, de. "¿Adiós a la teoría de la dependencia? Una perspectiva desde la Argentina", Estudios Internacionales, N228, año VII, octubre-diciembre, 1974, pp. 49-75.

DEPENDENCIA; ARGENTINA; AMERICA DEL SUR; POUTICA MUNDIAL.

\section{Infante Caffi, Maria Teresa}

02606 Infante Caffi, María Teresa. "Argentina y Chile: percepciones del conflicto de la zona del Beagle", Estudios Internacionales, N67, año XVIr, julio-septiembre, 1984, pp. 337-358.

ARGENTINA; CHILE; AMERICA DEL SUR; CONFLICTOS; BEAGLE; POLITICA INTERNACIONAL; RELACIONES BILATERALES.

01871 Infante Caffi, María Teresa. "Vigésimo quinto aniversario del Instituto de Estudios Internacionales de la Universidad de Chile", Estudios Internacionaies, N96, año XXIV, octubre-diciembre, 1991, pp. 429-432//Palabras de la Directora del Instituto en la ceremonia de celebración de su XXV aniversario, 12 de diciembre 1991//. INSTITUTO DE ESTUDIOS INTERNACIONALES; UNIVERSIDAD DE CHILE; CHILE; AMERICA DEL SUR; DISCURSOS. 
02912 Infante Caffi, María Teresa. "El derecho internacional como objeto de los estudios internacionales", Estudios Internacionales, No99, año XXY, julio-septiembre, 1992, pp. 427-436.

DERECHO INTERNACIONAL; RELACIONES INTERNACIONALES - ESTUDIO Y ENSEÑANZA; ESTUDIO Y ENSEÑANZA.

\section{Instituto de Estudios Internacionales - Biblioteca}

01134 Instituto de Estudios Internacionales, Biblioteca. "Indice de Estudios Internacionales, Año XXII, Nos. 85-88, 1989"; Estudios Internacionales, Ne89, año XXIII, enero-marzo, 1990, pp. 141-151. INDICE.

00604 Instituto de Estudios Internacionales, Biblioteca. "Bibliografía: Violencia política, terrorismo, guerrilla y narcotráfico en América", Estudios Internacionales, №90, año XIII, abril-junio, 1990, pp. 272276.

BIBLIOGRAFIA; TERRORISMO; GUERRILLA; VIOLENCIA; DROGAS; AMERICA.

01140 Instituto de Estudios Internacionales, Biblioteca. "Bibliografía: Teoría y estudio de las relaciones internacionales", Estudios Intemacionales, No91, año XXIII, julio-septiembre, 1990, pp. 418-421.

BIBLIOGRAFIA; RELACIONES INTERNACIONALES - ESTUDIO Y ENSEÑANZA; RELACIONES INTERNACIONALES-TEORIA.

01133 Instituto de Estudios Internacionales, Biblioteca. "Bibliografía: Alemania 1988-1990", Estudios Intemacionales, №92, año XXIII, octubrediciembre, 1990 , pp. 540-543.

BIBLIOGRAFIA; ALEMANIA; REUNIFICACION; EUROPA OCCIDENTAL.

02909 Instituto de Estudios Internacionales, Biblioteca. "Indice de Estudios Internacionales, Año XXIII, N289-92, 1990", Estudios Intemacionales, №93, año XXIV, enero-marzo 1991, pp. 159-173. INDICE

01595 Instituto de Estudios Internacionales, Biblioteca. "Bibliografía: Transición a la democracia en América Latina", Estudios Internacionales, No94, año XXIV, abril-junio, 1991, pp. 291-295.

BIBLIOGRAFIA; AMERICA LATINA; TRANSICION DEMOCRATICA.

01644 Instituto de Estudios Internacionales, Biblioteca. "Bibliografía: Cuenca del Pacífico", Estudios Internacionales, Ne95, año XXrV, julio-septiembre, 1991, pp. 419-424.

BIBLIOGRAFIA; CUENCA DEL PACIFICO; ISLAS DEL PACIFICO; OCEANO PACIFICO; ASEAN.

02910 Instituto de Estudios Internacionales, Biblioteca. "Indice de Estudios Internacionales, Año XXIV, No93-96, 1991", Estudios Internacionales, No97, año XXV, enero-marzo 1992, pp. 154-166. INDICE

02809 Instituto de Estudios Internacionales, Biblioteca. "Bibliografía: Re- 
laciones exteriores de América Latina", Estudios Internacionales, Ne98, año XXV, abril-junio, 1992, pp. 314-319.

AMERICA LATINA; RELACIONES EXTERIORES; POLITICA INTERNACIONAL; BIBLIOGRAFIA.

02911 Instituto de Estudios Internacionales, Biblioteca. "Bibliografía: Derecho internacional", Estudios Internacionales, Neg9, año XXV, julio-septiembre, 1992, pp. 437-445.

DERECHO INTERNACIONAL; BIBLIOGRAFIA.

\section{Insulza, José Miguel}

02561 Insulza, José Miguel. "La política de la administración Reagan hacia América Latina: un primer balance", Estudios Internacionales, N61, año XVI, enero-marzo, 1983, pp. 134-165.

ESTADOS UNIDOS; AMERICA DEL NORTE; AMERICA LATINA; POLITICA INTERNACIONAL; RELACIONES EXTERIORES.

\section{Ireland, Rowan}

02320 Ireland, Rowan. "La Iglesia Católica del Brasil: límites del aggiornamento", Estudios Intemacionales, N227, año VII, julio-septiembre, 1974, pp. 76-90.

IGLESIA CATOLICA; BRASIL; AMERICA DEL SUR.

\section{Irigoin, Jeannette}

02659 Irigoin, Jeannette. "El espacio: ¿Patrimonio común de la humanidad?", Estudios Internacionales, №75, año XIX, julio-septiembre, 1986, pp. 392-404.

ESPACIO EXTERIOR; DERECHO ESPACIAL; CIENCIA Y TECNOLOGIA; DERECHO INTERNACIONAL.

Jaguaribe, Helio

02338 Jaguaribe, Helio. "El equilibrio ecológico mundial y los países subdesarrollados ${ }^{n}$, Estudios Internacionales, N¹7, año V; enero-marzo, 1972, pp. 92-123.

MEDIO AMBIENTE; DESARROLLO ECONOMICO; POLITICÁ MUNDIAL; PAISES EN DESARROLLO; ECOLOGIA.

02368 Jaguaribe, Helio. "Los acontecimientos chilenos", Esiudios Internacionales, NN26, año VII, abril-junio, 1974, pp. 3-19.

CHILE; AMERICA DEL SUR; POLITICA Y GOBIERNO.

02374 Jaguaribe, Helio. "El Brasil y la América Latina", Estudios Internacionales, N229, año VIII, enero-marzo, 1975, pp. 106-136.

BRASIL; AMERICA LATINA; POLITICA INTERNACIONAL; INTEGRACION REGIONAL; INTEGRACION ECONOMICA; AMERICA DEL SUR; RELACIONES EXTERIORES.

02351 Jaguaribe, Helio. "El Vietnam y los Estados Unidos", Estudios Internacionales, №31, año VTI, julio-septiembre, 1975, pp. 3-18. 
VIETNAM; ASIA; ESTADOS UNIDOS; CONFLICTOS; ESTRATEGIA; AMERICA DEL NORTE.

02384 Jaguaribe, Helio. "El estudio del futuro y de la supervivencia del hombre", Estudios Intemacionales, N³6, año IX; septiembre-diciembre, 1976, pp. 3-10.

POLITICA MUNDIAL; FUTUROLOGIA.

02409 Jaguaribe, Helio. "El Informe Linowitz y las relaciones Estados Unidos-América", Estudios Intemacionales, N40, año X, octubre-diciembre, 1977 , pp. 47-59.

ESTADOS UNIDOS; AMERICA LATINA; RELACIONES EXTERIORES; POLITICA INTERNACIONAL; AMERICA DEL NORTE.

02748 Jaguaribe, Helio. "Autonomía periférica y hegemonía céntrica", $E$ studios Internacionales, N246, año XII, abril-junio, 1979, pp. 91-130. POLITICA MUNDIAL; HISTORIA; GRANDES POTENCIAS; ESTADOS UNIDOS; AMERICA DEL NORTE; URSS; EUPIOPA DEL ESTE.

02524 Jaguaribe, Helio. "Brasil-Argentina: Breve análisis de las relaciones de conflicto y cooperación", Estudios Internacionales, N57, año XV, enero-marzo, 1982, pp. 9-27.

BRASIL; ARGENTINA; POLITICA INTERNACIONAL; AMERICA DEL SUR; RELACIONES EXTERIORES; COOPERACION REGIONAL; CONFLICTOS.

02536 Jaguaribe, Helio. "El futuro de las relaciones entre ei Brasil y los Estados Unidos", Estudios Internacionales, Ne58, año XV, abril-junio, 1982, pp. 225-231.

BRASIL; AMERICA DEL SUR; ESTADOS UNIDOS; AMERICA DEL NORTE; POLITICA INTERNACIONAL; RELACIONES EXTERIORES.

02546 Jaguaribe, Helio. "Reflexiones sobre el Atlántico Sur: América Latina y el Brasil ante la desarticulación del sistema interamericano", Estudios Intemacionales, N60, año XV, octubre-diciembre, 1982, pp. 443-461.

BRASIL; AMERICA DEL SUR; AMERICA LATINA; SISTEMA INTERAMERICANO; CONFLICTOS; ISLAS MALVINAS; POLITICA INTERNACIONAL.

02590 Jaguaribe, Helio. "Reflexiones sobre la paz mundial", Estudios Internacionales, No65, año XVII, enero-marzo, 1984, pp. $4-15$.

POLITICA MUNDIAL; ARMAMENTISMO; PAZ.

02630 Jaguaribe, Helio. "Los conflictos cardinales dè nuestro tiempo y la. posición del Brasil", Estudios Internacionales, Ne71, año XVII, julioseptiembre, 1975, pp. 337-348.

POLITICA INTERNACIONAL; BRASIL; AMERICA DEL SUR; POLTICA MUNDIAL; CONFLIGTOS.

02718 Jaguaribe, Helio. "La relación Norte-Sur", Estudios Internacionales, N`84, año XXI, octubre-diciembre, 1988, pp. 425-438.

RELACIONES NORTE SUR; TERCER MUNDO; DESARROLLO ECONOMICO. 


\section{Jaksic, Iván}

02607 Jaksic, Iván. "Puerto Rico: los dilemas del status político y el desarrollo dependiente", Estudios Internacionales, №67, año XVII, julioseptiembre, 1984, pp. 359-377.

PUERTO RICO; AMERICA CENTRAL Y CARIBE; ESTADOS UNIDOS; AMERICA DEL NORTE; HISTORIA; POLITICA INTERNACIONAL; DEPENDENCIA.

Jaworski C., Helán

00419 Jaworski C.; Helán: "Las políticas de cooperación de Europa Occidental hacia América Latina y sus posibilidades futuras", Estudios Internacionales, No89, año XXIII, enero-marzo, 1990, pp. 119-140. AMERICA LATINA; EUROPA OCCIDENTAL; COOPERACION ECONOMICA; COOPERACION TECNOLOGICA.

\section{Joxe, Alain}

02233 Joxe, Alain. "Hacia una nueva concepción de la seguridad europea", Estudios Intemacionales, N22, año I, julio, 1967, pp. 156-188. SEGURIDAD; EUROPA; POLITICA MUNDIAL.

02298 Joxe, Alain. "Cohetes anticohetes: Regreso a las estrategias defensivas", Estudios Internacionales, №5, año II, abril-junio, 1968, pp. 115137.

SEGURIDAD; ESTRATEGIA; POLITICA MUNDIAL; POLITICA INTERNACIONAL; ARMAMENTISMO.

02297 Joxe, Alain. "Doctrina estratégica y guerras de intervención", Estudios Internacionales, N6, año II, julio-septiembre, 1968, pp. 276-286. SEGURIDAD; ESTRATEGIA; VIETNAM; INTERVENCION - DERECHO INTERNACIONAL; GUERPA; ASIA.

02423 Joxe, Alain. "iFin de la preponderancia estratégica norteamericana?", Estudios Internacionales, №11, octubre-diciembre, 1969, pp. 273-320.

SEGURIDAD; ESTRATEGIA; ESTADOS UNIDOS; POLITICA MUNDIAL; POLITICA INTERNACIONAL; AMERICA DEL NORTE; GRANDES POTENCIAS.

02215 Joxe, Alain; Cadena, Cecilia. "El armamentismo de los paises dependientes: el caso latinoamericano", Estudios Intemacionales, №14, año IV, julio-septienibre, 1970, pp. 3-81.

ARMAMENTISMO; DEPENDENCIA; AMERICA LATINA; ESTRATEGIA.

\section{Kadar, Bela}

02258 Kadar, Bela. "Los países pequeños en la economía mundial", Estudios Internacionates, №16, año rv, enero-marzo, 1971, pp. 158-188. ECONOMIA INTERNACIONAL; DESARROLLO ECONOMICO; PAISES EN DESARROLLO.

\section{Kaiser, Karl}

02217 Kaiser, Karl. "Una nueva política oriental en Alemania", Estudios Internacionales, №8, año II, enero-marzo, 1969, pp. 543-564.

ALEMANIA; EUROPA; POLITICA INTERNACIONAL. 


\section{Kalecki, Michal}

02268 Kalecki, Michal; Kula, Marcin. "Notas sobre los aspectos sociales y económicos de los "regímenes intermedios": el caso de Bolivia", Estudios Internacionales, N¹5, año IV, octubre-diciembre, 1970, pp. 84-96.

BOLIVIA; AMERICA DEL SUR; DESARROLLO ECONOMICO; CONDICIONES SOCIALES; CONDICIONES ECONOMICAS.

\section{Kaplan, Marcos}

02218 Kaplan, Marcos. "Estado, dependencia externa y desarrollo en América Latina", Estudios Intemacionales, $N^{2} 6$, año II, julio-septiembre, 1968, pp. 179-213.

ESTADO; DEPENDENCIA; DESARROLLO ECONOMICO; AMERICA LATINA.

02277 Kaplan, Marcos. "Corporaciones públicas multinacionales para el desarrollo y la integración", Estudios Internacionales, Ne10, año III, julio-septiembre, 1969, pp. 186-230.

AMERICA LATINA; INTEGRACION ECONOMICA; EMPRESAS TRANSNACIONALES.

\section{Karl, Terry Lynn}

00242 Karl, Terry Lynn. "Hegemonías y empresarios políticos: dependencia, democratización y cooperación en las Américas", Estudios Internacionales, Ne86, año XXII, abril-junio, 1989, pp. 183-223.

COOPERACION REGIONAL; DEMOCRATIZACION; AMERICA LATINA; AMERICA DEL NORTE; CONCERTACION POLITICA; ESTADOS UNIDOS; DEPENDENCIA.

Khatil, Ismael

02720 Khalil, Ismael. "La promoción de las relaciones entre Estados latinoamericanos y árabes", Estudios Internacionales, No84, año XXI, octubre-diciembre, 1988, pp. 451-461.

POLITICA INTERNACIONAL; AMERICA LATINA; ECONOMIA INTERNACIONAL; PAISES ARABES; RELACIONES ECONOMICAS INTERNACIONALES; RELACIONES EXTERIORES.

\section{Klaveren, Alberto van}

02472 Lagos, Gustavo; Klaveren, Alberto van. "Las relaciones interamericanas en una perspectiva global", Estudios Internacionales, N48, año XII, octubre-diciembre, 1979, pp. 390-418.

POLITICA INTERNACIONAL; ESTADOS UNIDOS; AMERICA DEL NORTE; AMERICA LATINA; RELACIONES EXTERIORES.

02614 Klaveren, Alberto van. "Las nuevas formas de concertación política en América Latina", Estudios Intemacionales, Ne68, año XVI, octubre-diciembre, 1984, pp. 513-536.

AMERICA LATINA; INTEGRACION REGIONAL; PACTO ANDINO; ISLAS MALVINAS; CONCERTACION POLITICA; GRUPO CONTADORA. 
02745 Klaveren, Alberto van. "La cooperación política europea: realidades y desafíos de un modelo de concertación externa", Estudios Internacionales, №83, año XXI, julio-septiembre, 1988, pp. 327-353.

COMUNIDADES EUROPEAS; EUROPA; INTEGRACION REGIONAL; INTEGRACION ECONOMICA; POLITICA INTERNACIONAL; CONCERTACION POLITICA.

00222 Klaveren, Alberto van. "Las relaciones entre Europa Occidental y América Latina: una profundización esquiva", Estudios Internacionales, Ne87, año XXII, julio-septiembre, 1989, pp. 342-364.

AMERICA LATINA; EUROPA OCCIDENTAL; COMUNIDADES EUROPEAS; RELACIONES BILATERALES; COMUNIDAD ECONOMICA EUROPEA; POLITICA INTERNACIONAL.

00418 Klaveren, Alberto van. "Las relaciones internacionales de América Latina en la década de 1980: cambio y continuidad", Estudios Internacionales, Ne89, año XXIII, enero-marzo, 1990, pp. 82-118.

AMERICA LATINA; RELACIONES EXTERIORES; ESTADOS UNIDOS; EUROPA OCCIDENTAAL; ASIA; JAPON; AMERICA DEL NORTE; TERCER MUNNDO; COOPERACION REGIONAL.

02813 Klaveren, Alberto van. "Entendiendo las políticas exteriores latinoamericanas: modelo para armar", Estudios Intemacionales, №98, año XXY, abril-junio, 1992, pp. 169-216.

AMERICA LATINA; POLITICA INTERNACIONAL; RELACIONES EXTERIORES; RELACIONES INTERNACIONALES - ESTUDIO Y ENSENAANZA; DEPENDENCIA; ECONOMIA INTERNACIONAL.

\section{Kñakal, Jan}

02470 Kñakal, Jan. "Las empresas transnacionales en el desarrollo contemporáneo de América Latina", Estudios Intemacionales, №47, año XII, julio-septiembre, 1979 , pp. 322-350.

DESARROLLO ECONOMICO; AMERICA LATINA; ECONOMIA INTERNACIONAL; EMPRESAS TRANSNACIONALES.

\section{Kojima, Kiyoshi}

02266 Kojima, Kiyoshi. "Un área de libre comercio del Pacífico", Estudios Internacionales, N220, año V, octubre-diciembre, 1972, pp. 53-66. COMERCIO EXTERIOR; OCEANO PACIFICO; INTEGRACION ECONOMICA; LIBRE COMERCIO.

\section{Kolkowicz, Roman}

02222 Kolkowicz, Roman. "Una herejía santificada: Idea y realidad del Ejército Rojo", Estudios Internacionaies, N5, año II, abril-junio, 1968, pp. 64-84.

FUERZAS ARMADAS; URSS; EUROPA DEL ESTE.

\section{Kula, Marcin}

02268 Kalecki, Michal; Kula, Marcin. "Notas sobre los aspectos sociales y económicos de los "regímenes intermedios": el caso de Bolivia", 
Estudios Intemacionales, №15, año IV, octubre-diciembre, 1970, pp. 84-96.

BOLIVIA; AMERICA DEL SUR; DESARROLLO ECONOMICO; CONDICIONES SOCIALES; CONDICIONES ECONOMICAS.

\section{Lafer, Celso}

02350 Lafer, Celso. "Una redefinición del orden mundial y la Alianza Latinoamericana. Perspectivas y posibilidades", Estudios Internacionales, №31, año VIII, julio-septiembre, 1975, pp. 42-58.

POLITICA MUNDIAL; AMERICA LATINA; INTEGRACION REGIONAL; ORDEN MUNDIAL.

02430 Lafer, Celso. "El estudio de las relaciones internacionales: necesidades y perspectivas", Estudios Intemacionales, No43, año XI, julio-septiembre, 1978, pp. 47-56.

RELACIONES INTERNACIONALES - ESTUDIO Y ENSEÑANZA.

02487 Lafer, Celso. "La política exterior brasileña: Balance y perspectivas", Estudios Internacionales, №51, año XIII, julio-septiembre, 1980, pp. 309-327.

POLITICA INTERNACIONAL; BRASIL; AMERICA DEL SUR; ECONOMIA INTERNACIONAL; RELACIONES EXTERIORES.

02529 Lafer, Celso. "Reflexiones sobre el tema del nuevo orden mundial en un orden internacional en transformación", Estudios Internacionales, N258, año XV, abril-junio, 1982, pp. 127-165. POLTICA MUNDIAL; RELACIONES NORTE SUR; ORDEN MUNOIAL.

02547 Lafer, Celso. "La política externa brasileña y la crisis en el Atlántico Sur: una evaluación", Estudios Internacionales, №60, año XV, octubre-diciembre, 1982, pp. 462-472.

BRASIL; AMERICA DEL SUR; ISLAS MALVINAS; CONFLICTOS; POLITICA INTERNACIONAL; RELACIONES EXTERIORES.

. 02677 Lafer, Celso. "Las nuevas dimensiones de la política externa brasileña", Estudios Internacionales, №79, año XX, julio-septiembre, 1987, pp. 328-341.

BRASIL; AMERICA DEL SUR; POUTICA INTERNACIONAL; POLITICA Y GOBIERNO; RELACIONES EXTERIORES.

\section{Lafourcade, Hernán}

02512 Lafourcade, Hernán. "Perspectivas del desarrollo de los recursos marinos en América Latina" Estudios Internacionales, №55, año XIV, julio-septiembre, 1981, pp. 357-379.

AMERICA LATINA; DERECHO DEL MAR; RECURSOS MARINOS.

02574 Lafourcade, Hernán. "Hacia la reorganización del mecanismo de reciclaje financiero internacional", Estudios Internacionales, Ne63, año XVI, julio-septiembre, 1983, pp. 379-390.

ECONOMIA INTERNACIONAL; DEUDA EXTERNA; AMERICA LATINA. 
Lagos, Gustavo

02410 Lagos, Gustavo. "El Plan Carter y 'La Guerra de la Energía", Estudios Internacionales, N40, año X, octubre-diciembre, 1977, pp. 60-88. ESTADOS UNIDOS; POLITICA Y GOBIERNO; ENERGIA; AMERICA DEL NORTE; PETROLEO.

02472 Lagos, Gustavo; Klaveren, Alberto van. "Las relaciones interamericanas en una perspectiva global", Estudios Internacionales, Ne48, año XII, octubre-diciembre, 1979 , pp. 390-418.

POLITICA INTERNACIONAL; ESTADOS UNIDOS; AMERICA DEL NORTE; AMERICA LATINA; RELACIONES EXTERIORES.

02485 Lagos, Gustavo. "Tendencias y' perspectivas del estudio de las relaciones internacionales: tareas para América Latina", Estudios Internacionales, Ne50, àno XIII, abril-junio, 1980, pp. 236-251.

AMERICA LATINA; RELACIONES INTERNACIONALES; RELACIONES INTERNACIONALES - ESTUDIO Y ENSEÑANZA.

02517 Lagos, Gustavo. "Entre la détente y la Guerra Fría: La crisis del destino manifiesto de las superpotencias", Estudios Intemacionales, №56, año XIV, octubre-diciembre, 1981, pp. 474-499.

POLITICA MUNDIAL; GUERRA FRIA; DISTENSION; GRANDES POTENCIAS; CRISIS.

02620 Lagos, Gustavo; Plaza, Oscar. "La actual política exterior norteamerıcana y su proyección en América Latina", Estudios Intemacionales, №69, año XVIII, enero-marzo, 1985, pp. 63-80.

ESTADOS UNIDOS; AMERICA DEL NORTE; AMERICA LATINA; POLITICA INTERNACIONAL; RELACIONES EXTERIORES.

\section{Lagos, Ricardo}

02486 Lagos, Ricardo. "América Latina: algunos hechos económicos recientes y su poder de negociación", Estudios Internacionales, N51, año XIII, julio-septiembre, 1980, pp. 291-308.

AMERICA LATINA; ECONOMIA INTERNACIONAL; DESARROLLO ECONOMICO; NEGOCIACIONES.

\section{Lahera, Eugenio}

02597 Lahera, Eugenio. "La internacionalización del proceso productivo", Estudios Internacionales, N65, año XVII, enero-marzo, 1984, pp. 160-166. ECONOMIA INTERNACIONAL; EMPRESAS TRANSNACIONALES.

\section{Langdon, Steven}

02455 Godfrey, Martin; Langdon, Steven. "¿Socios en el desarrollo? La tesis de la transnacionalización en el contexto keniano", Estudios Internacionales, N44, año XI, octubre-diciembre, 1978, pp. 45-70.

KENIA; AFRICA; ECONOMIA INTERNACIONAL; POLITICA INTERNACIONAL; RELACIONES EXTERIORES. 
Langlois, Juan Carlos

02426 Langlois, Juan Carlos. "Una nueva dimensión para los Bancos de Desarrollo", Estudios Internacionales, Ne33, año IX; enero-marzo, 1976, pp. 62-70.

ECONOMIA INTERNACIONAL; DESARROLLO ECONOMICO; BANCOS REGIONALES DE DESARROLLO.

\section{Lechner, Norbert}

01586 Lechner, Norbert. "Condiciones socio-culturales de la transición democrática: a la búsqueda de la comunidad perdida", Estudios Internacionales, Ne94, año XXIV, abril-junio, 1991, pp. 209-228.

TRANSICION DEMOCRATICA; DEMOCRACIA; DEMOCRATIZACION; AMERICA LATINA; AMERICA DEL SUR; REFORMAS; CONDICIONES SOCIALES; CONDICIONES ECONOMICAS.

\section{León, Francisco}

02915 León, Francisco. "Cuba: procesos y dilemas", Estudios Intemacionales, Neg9, año XXV, julio-septiembre, 1992, pp. 365-377.

CUBA; AMERICA CENTRAL Y CARIBE; POLITICA Y GOBIERNO; DEUDA EXTERNA; ECONOMIA INTERNACIONAL; REFORMAS; DEMOCRATIZACION; DESARROLLO SOCIAL; POLITICA ECONOMICA.

\section{Levine, Flavián}

02749 Levine, Flavián. "¿Economía o economía política?", Estudios Internacionales, Ne47, año XII, julio-septiembre, 1979, pp. 231-246.

CIENCIAS SOCIALES; ECONOMIA; TEORIA ECONOMICA.

\section{Lipietz, Alain}

00416 Lipietz, Alain. "Hacia una nueva inserción de Europa en la economía mundial", Estudios Intentacionales, Ne89, año XXII, enero-marzo, 1990 , pp. $21-44$.

EUROPA; ECONOMIA INTERNACIONAL; COMERCIO EXTERIOR; COMUNIDAD ECONOMICA EUROPEA.

\section{Lorino, Philippe}

02661 Lorino, Philippe. "La Comunidad Económica Europea en la competencia tecnológica mundial", Estudios Intemacionales, №76, año XIX, octubre-diciembre, 1986 , pp. 460-486.

COMUNIDAD ECONOMICA EUROPEA; EUROPA; CIENCIA Y TECNOLOGIA; POLITICA INTERNACIONAL; TECNOLOGIA.

\section{Lowenthal, Abraham F.}

02381 Lowenthal, Abraham F. "Ejércitos y política en América Latina", Estudios Internacionales, N³5, año IX, julio-septiembre, 1976, pp. 38-64.

FUERZAS ARMADAS; AMERICA LATINA; POLITICA Y GOBIERNO. 
02391 Lowenthal, Abraham F. "El fin de la presunción hegemónica", Estidios Internacionales, №37, año X, enero-marzo, 1977, pp. 45-67.

ESTADOS UNIDOS; AMERICA LATINA; POLITICA INTERNACIONAL; AMERICA DEL NORTE; RELACIONES EXTERIORES; DEPENDENCIA.

02478 Lowenthal, Abraham F.; Fishlow, Albert. "Los nuevos intereses de los Estados Unidos en el hemisferio occidental", Estudios Internacionales, NQ49, año XIII, enero-marzo, 1980, pp. 54-69.

ESTADOS UNIDOS; AMERICA DEL NORTE; AMERICA LATINA; POLITICAINTERNACIONAL.

02650 Lowenthal, Abraham F. "Las relaciones externas de América Latina en 1985", Estudios Internacionales, N274, año XIX, abril-junio, 1986, pp. 133-158.

POLITICA INTERNACIONAL; AMERICA LATINA; ESTADOS UNIDOS; AMERICA DEL NORTE; ECONOMIA INTERNACIONAL; RELACIONES EXTERIORES.

\section{Lowenthal, Richard}

02299 Lowenthal, Richard. "Alemania y el fin del sistema bipolar en la política internacional", Estudios Internacionales, №3-4, año I, octubre-marzo, 1967-1968, pp. 411-426.

ALEMANIA; EUROPA; POLITICA MUNDIAL; POLITICA INTERNACIONAL.

\section{Luna, Julio}

02210 Luna, Julio. "El desarrollo pesquero y la integración regional", Estudios Internacionales, No14, año IV, julio-septiembre, 1970, pp. 133149.

INTEGRACION REGIONAL; INTEGRACION ECONOMICA; PESCA; AMERICA LATINA; RECURSOS NATURALES; RECURSOS MARINOS.

Maira, Luis

02637 Maira, Luis. "Los márgenes de hegemonía internacional de Estados Unidos: una visión histórica", Estudios Internacionales, №72, año XVIII, octubre-diciembre, 1985, pp. 454-477.

ESTADOS UNIDOS; AMERICA DEL NORTE; POLITICA INTERNACIONAL; HISTORIA; AMERICA LATINA; POLITICA MUNDIAL; PODER.

\section{Marcella, Gabriel}

02490 Marcella, Gabriel. "Las relaciones militares entre los Estados Unidos y America Latina. Crisis e interrogantes futuras", Estudios Internacionales, N251, año XIm, julio-septiembre, 1980, pp. 382-400.

FUERZAS ARMADAS; ESTADOS UNIDOS; AMERICA LATINA; POLITICA INTERNACIONAL; AMERICA DEL NORTE; RELACIONES EXTERIORES.

\section{Mardones, José Luis}

02624 Marshall, Isabel; Silva, Enrique; Mardones, José Luis. "Proteccionismo y reestructuración en la industria del cobre: las políticas de los productores", Estudios Internacionales, №69, año XVIII, enero-marzo, 1985, pp. 87-109. 
ECONOMIA INTERNACIONAL; COBRE; PROTECCIONISMO; ESTADOS UNIDOS; AMERICA DEL NORTE.

\section{Mares, David R.}

01300 Mares, David R. "Escenarios de seguridad en Europa Oriental y América Latina", Estudios Internacionales, №93, año 24, enero-marzo, 1991, pp. 19-41.

AMERICA LATINA; EUROPA DEL ESTE; SEGURIDAD; TRATADOS.

María, Luis G. de

02514 María, Luis G. de. "Balance político y económico de la integración andina durante 1980", Estudios Internacionales, №55, año XIV, julioseptiembre, 1981, pp. 394-411.

INTEGRACION REGIONAL; INTEGRACION ECONOMICA; PACTO ANOINO; GRUPO ANDINO; ECONOMIA INTERNACIONAL; AMERICA DEL SUR.

Marshall, Isabel

02624 Marshall, Isabel; Silva, Enrique; Mardones, José Luis. "Proteccionismo y reestructuración en la industria del cobre: las políticas de los productores", Estudios Internacionales, №69, año XVIII, enero-marzo, 1985, pp. 87-109.

ECONOMIA INTERNACIONAL; COBRE; PROTECCIONISMO; ESTADOS UNIDOS; AMERICA DEL NORTE.

\section{Martínez Sotomayor, Carlos}

02541 Martínez Sotomayor, Carlos. "Presencia de la educación y la cultura en las relaciones internacionales de Chile", Estudios Internacionales, NN59, año XV, julio-septiembre, 1982, pp. 304-323.

CHILE; AMERICA DEL SUR; CULTUPA; EDUCACION; FOLITICA INTERNACIONAL; RELACIONES INTERNACIONALES.

\section{Martins, Luciano}

02278 Martins, Luciano. "Mayo de 1968: una revolución nueva e intransitiva", Estudios Internacionales, №10, año III, julio-septiembre, 1969, pp. 158-185.

EUROPA; SOGIEDAD; CAMBIO SOCIAL; FRANCIA.

\section{Martner G., Gonzalo}

02610 Martner G., Gonzalo. "América Latina dentro del orden económico mundial", Estudios Internacionales, Ne68, año XVII, octubre-diciembre, 1984, pp. 420-440.

AMERICA LATINA; ECONOMIA INTERNACIONAL; NUEVO ORDEN ECONOMICO INTERNACIONAL.

\section{Massad, Carlos}

02569 Massad, Carlos. "América Latina: aspectos principales del financia- 
miento externo", Estudios Internacionales, №62, àño XVI, abril-junio 1983, pp. 305-314.

AMERICA LATINA; ECONOMIA INTERNACIONAL; DEUDA EXTERNA.

\section{Matos Mar, José}

02633 Matos Mar, José. "Crisis del Estado y desborde popular en el Perú", Estudios Intemacionales, №71, año XVIII, julio-septiembre 1985, pp. 382-388.

PERU; AMERICA DEL SUR; POLITICA Y GOBIERNO; CRISIS; MOVIMIENTOS SOCIALES.

\section{Matta, Javier Eduardo}

01648 Matta, Javier Eduardo. "Chile y la República Popular' China:19701990", Estudios Intemacionales, N295, año XXTV, julio-septiembre 1991, pp. 347-367.

CHILE; AMERICA DEL SUR; CHINA; RELACIONES BILATERALES; POLITICA INTERNACIONAL; RELACIONES EXTERIORES.

\section{Mattelart, Marcel}

02211 Mattelart, Marcel. "Là dependencia de los medios de comunicación de masas en Chile", Estudios Internacionales, №13, año IV, abril-junio 1970, pp. 124-154.

DEPENDENCIA; CHILE;; AMERICA DEL SUR; MEDIOS DE COMUNICACION.

Mayobre, Eduardo

02318 Hurtado, Héctor; Pazos, Javier; Mayobre, Eduardo. "El Caribe y Venezuela: integración de la integración", Estudios Internacionales, No27, año VIr, julio-septiembre, 1974, pp. 3-30.

AMERICA CENTRAL Y CARIBE; VENEZUELA; INTEGRACION REGIONAL; INTEGRACION ECONOMICA; ECONOMIA INTERNACIONAL; AMERICA DEL SUR.

\section{Mercado Jarrín, Edgardo}

02666 Mercado Jarrín, Edgardo. "Perspectivas de los acuerdos de limitación de desarme en América Latina y el Caribe", Estudios Internacionales, $\mathrm{N}^{2} 77$, año XX, enero-marzo, 1987, pp. 39-69.

ARMAMENTISMO; SEGURIDAD; AMERICA LATINA; POLITICA INTERNACIONAL; PERU; AMERICA DEL SUR; AMERICA CENTRAL Y CARIBE; DESARME.

\section{Merlini, Cesare}

02340 Merlini, Cesare. "La posición internacional de Italia. "Oportunidades y tentaciones", Estudios Internacionales, Ne17, año V, enero-marzo, 1972, pp. 76-91.

ITALIA; EUROPA; POLITICA INTERNACIONAL; RELACIONES EXTERIORES.

\section{Mesa-Lago, Carmelo}

02527 Mesa-Lago, Carmelo. "La dependencia económica externa de Cuba y su repercusión sobre su política exterior", Estudios Intemacionales, No57, año XV, enero-marzo, 1982, pp. 60-87. 
CUBA; AMERICA CENTRAL Y CARIBE; POLITICA INTERNACIONAL; ECONOMIA INTERNACIONAL; DEPENDENCIA ECONOMICA; RELACIONES EXTERIORES.

\section{Mihaly, Eugene B.}

02341 Mihaly, Eugene B. "La estrategia de los Estados Unidos en el Pacífico Occidental y el dilema de Micronesia", Estudios Intemacionales, Ne17, año V, enero-marzo, 1972, pp. 25-39.

ESTADOS UNIDOS; OCEANO PACIFICO; OCEANIA; SEGURIDAD; ESTRATEGIA; AMERICA DEL NORTE; MICRONESIA.

Millar, T. B.

02815 Millar, T. B. "Los océanos Indico y Pacífico: algunas consideraciones estratégicas", Estudios Internacionales, N²11, año III, octubre-diciembre, 1969 , pp. 321-351.

OCEANO PACIFICO; OCEANO INDICO; OCEANOPOLITICA; MAR; ESTRATEGIA; SEGURIDAD; POLITICA INTERNACIONAL; POLITICA MUNDIAL.

\section{Mirski, Gueorgui}

02216 Mirski, Gueorgui. "El papel político del ejército de los países en Asia y Africa", Estudios Internacionales, Ne13, año IV, abril-junio, 1970, pp. 3-20.

FUERZAS ARMADAS; ASIA; AFRICA; POLITICA Y GOBIERNO.

\section{Mols, Manfred}

02491 Mols, Manfred. "Observaciones europeas sobre la integración latinoamericana", Estudios Intemacionales, Ne51, año XIII, julio-septiembre, 1980 , pp. 401-412.

EUROPA; AMERICA LATINA; INTEGRACION REGIONAL; INTEGRACION ECONOMICA.

02689 Mols, Manfred. "ASEAN; luego de la tercera reunión cumbre", Estudios Internacionales, Ne81, año XXI, enero-marzo, 1988, pp. 45-60.

ASEAN; POLITICA INTERNACIONAL; INTEGRACION ECONOMICA; INTEGRACION REGIONAL.

01126 Mols, Manfred. "Comunidad Europea-Asean: ¿un modelo de cooperación interregional?", Estudios Internacionales, N92, año XXII, octubre-diciembre, 1990, pp. 424-443.

ASEAN; ASIA; COMUNIDAD ECONOMICA EUROPEA; EUROPA OCCIDENTAL; COOPERACION ECONOMICA; RELACIONES ECONOMICAS INTERNACIONA LES.

\section{Moneta, Carlos J.}

02329 Moneta, Carlos J. "Argentina y Australia: esquemas para la cooperación", Estudios Intemacionales, N²1, año VI, enero-marzo, 1973, pp. 55-83.

ARGENTINA; AMERICA DEL SUR; AUSTRALIA; COOPERACION ECONOMICA; POLITICA INTERNACIONAL; OCEANIA. 
02319 Moneta, Carlos J. "Africa y los grandes actores externos", Estudios Internacionales, N227, año VII, julio-septiembre, 1974, pp. 31-75.

AFRICA; POLITICA MUNDIAL; ECONOMIA INTERNACIONAL; RELACIONES EXTERIORES.

02494 Moneta, Carlos J. "América Latina y el sistema internacional en la década del ochenta: ¿Hacia un nuevo orden antártico?", Estudios Internacionales, NN52, año XIII, octubre-diciembre, 1980, pp. 481-526. AMERICA LATINA; POLITICA INTERNACIONAL; ANTARTICA.

02544 Moneta, Carlos J. "El conflicto de las Islas Malvinas: su papel en la política exterior argentina en el contexto mundial", Estudios Internacionales, №60, año XV, octubre-diciembre, 1982, pp. 361-409.

ISLAS MALVINAS; ARGENTINA; AMERICA DEL SUR; POLITICA INTERNACIONAL; POLITICA MUNDIAL; POLITICA Y GOBIERNO; AMERICA LATINA; CONFLICTOS.

02596 Moneta, Carlos J. "El factor energético (hidrocarburos), en las relaciones internacionales de América Latina", Estudios Internacionales, №65, año XVII, enero-marzo, 1984, pp. 131-159.

AMERICA LATINA; POLITICA INTERNACIONAL; ECONOMIA INTERNACIONAL; RECURSOS ENERGETICOS; PETROLEO; COOPERACION INTERNACIONAL; ENERGIA; RELACIONES EXTERIORES.

02622 Moneta, Carlos J. "Fuerzas Armadas y gobierno constitucional después de Malvinas: hacia una nueva relación civil-militar", Estudios Internacionales, №69, año XVIII, enero-marzo, 1985, pp. 110-171. ARGENTINA; AMERICA DEL SUR; FUERZAS ARMADAS; POLITICA Y GOBIERNO; ISLAS MALVINAS; POLITICA INTERNACIONAL.

02691 Moneta, Carlos J. "Corea del Sur y los países asiáticos de reciente industrialización (PARI) en el contexto de los cambios del sistema económico mundial. Reflexiones para América Latina", Estudios Internacionales, Ne81, año XXI, enero-marzo, 1988, pp. 61-93.

ASIA; ECONOMIA INTERNACIONAL; AMERICA LATINA; REFORMAS; COREA, REPUBLICA DE; NIC's.

00219 Moneta, Carlos J. "Los países asiáticos de reciente industrialización en la década del 90 . Elementos para un debate latinoamericano", Estudios Internacionales, N287, año XXIr, julio-septiembre, 1989, pp. 279-297.

ASIA; INDUSTRIALIZACION; AMERICA LATINA; COMERCIO EXTERIOR; NIC's.

01128 Moneta, Carlos J. "La teoría de las relaciones internacionales: el realismo y sus límites", Estudios Internacionales, No92, año XXII, octubre-diciembre, 1990 , pp. 464-498.

RELACIONES INTERNACIONALES-TEORIA.

\section{Moran, Theodore $\mathbf{H}$.}

02336 Moran, Theodore H. "Nuevo trato a las materias primas", Estudios Internacionales, №19, año V, julio-septiembre, 1972, pp. 56-70. 
RECURSOS NATURALES; EMPRESAS TRANSNACIONALES; PRODUCTOS BASICOS.

\section{Morandé Lavín, José}

02079 Morandé Lavín, José. "Chile y los Estados Unidos: distanciamiento y aproximaciones", Estudios Internacionales, N997, año XXV, eneromarzo, 1992, pp. 3-22.

CHILE; AMERICA DEL SUR; ESTADOS UNIDOS; AMERICA DEL NORTE; RELACIONES BILATERALES; RELACIONES EXTERIORES; RELACIONES ECONOMICAS INTERNACIONALES; HISTORIA; POLITICA INTERNACIONAL; INICIATIVA PARA LAS AMERICAS.

\section{Morello, Jorge}

02481 Gligo, Nicolo; Morello, Jorge. "Notas sobre la historia ecológica de América Latina", Estudios Intemacionales, N49, año XIII, eneromarzo, 1980, pp. 112-148.

MEDIO AMBIENTE; HISTORIA; AMERICA LATINA; ECOLOGIA.

\section{Moreno Laval, Celso}

01647 Moreno Laval, Celso. "América Latina y la Cuenca del Pacífico: una visión chilena", Estudios Intemacionales, N295, año XXIV, julio-septiembre, 1991, pp. 368-383.

AMERICA LATINA; CHILE; AMERICA DEL SUR; CUENCA DEL PACIFICO; RELACIONES INTERNACIONALES; INTEGRACION REGIONAL; COOPERACION REGIONAL.

Moreno, Luis

00415 Giner, Salvador; Moreno, Luis. "La sociedad civil en Europa Occidental", Estudios Internacionales, Ne89, año XxiIl, enero-marzo, 1990, pp. 3-20.

EUROPA OCCIDENTAL; CLASES SOCIALES; SOCIEDAD.

\section{Mota Sardenberg, Ronaldo}

02556 Mota Sardenberg, Ronaldo. "Brasil-Europa y la reestructuración del poder internacional", Estudios Internacionales, Ne61, año XVI, enero-marzo, 1983, pp. 47-57.

BRASIL; AMERICA DEL SUR; EUROPA; POLITICA INTERNACIONAL; POLITICA MUNDIAL; RELACIONES EXTERIORES.

\section{Muñoz, Heraldo}

02349 Muñoz, Heraldo; Sánchez, Walter. "La détente y el sistema internacional", Estudios Intemacionales, N³2, año VII, octubre-diciembre, 1975, pp. 103-122.

POLITICA INTERNACIONAL; POLITICA MUNDIAL; TERCER MUNDO; DISTEN SION.

02427 Muñoz, Heraldo. "Dependencia estratégica y no-estratégica: materias primas y relaciones internacionales en la perspectiva de la crisis 
petrolera", Estudios Internacionales, №33, año IX; enero-marzo, 1976, pp. 71-108.

DEPENDENCIA; POLITICA INTERNACIONAL; PETROLEO; CRISIS; PRODUCTOS BASICOS; RELACIONES EXTERIORES.

02456 Muñoz, Heraldo. "Cambio y continuidad en el debate sobre la dependencia y el imperialismo", Estudios Intemacionales, N44, año XI, octubre-diciembre, 1978, pp. 88-138.

DEPENDENCIA; IMPERIALISMO; AMERICA LATINA.

02488 Muñoz, Heraldo. "Los estudios internacionales en América Latina: problemas fundamentales", Estudios Internacionales, №51, año XIII, julio-septiembre, 1980, pp. 328-344.

AMERICA LATINA; RELACIONES INTERNACIONALES - ESTUDIO Y ENSEÑANZA.

02535 Muñoz, Heraldo. "Efectos y lecciones del conflicto de las Malvinas", Estudios Internacionales, №60, año XV, octubre-diciembre, 1982, pp. 499-512.

ISLAS MALVINAS; SISTEMA. INTERAMERICANO; AMERICA LATINA; ARGENTINA; AMERICA DEL SUR; ESTADOS UNIDOS; AMERICA DEL NORTE; CONFLICTOS; POLITICA INTERNACIONAL.

02669 Muñoz, Heraldo. "Las causas del auge y la declinación del Sistema Interamericano de Seguridad: una perspectiva latinoamericana", Estudios Internacionales, $\mathrm{N}^{2} 77$, año XX, enero-marzo, 1987, pp. 102-113. SISTEMA INTERAMERICANO; SEGURIDAD; AMERICA LATINA; ESTADOS UNIDOS; AMERICA DEL NORTE.

02681 Muñoz, Heraldo. "El estudio de las políticas exteriores latinoamericanas: temas y enfoques dominantes", Estudios Intemacionales, Ne80, año XX, octubre-diciembre, 1987, pp. 406-434.

AMERICA LATINA; POLITICA INTERNACIONAL; RELACIONES INTERNACIONALES.

02686 Muñoz, Heraldo. "El escenario mundial hacia el año 2000", Estudios Internacionales, Ne81, año XXI, enero-marzo, 1988, pp. 3-14. POLITICA MUNDIAL; FUTUROLOGIA.

\section{Murphy, Cornelius F.}

02262 Murphy, Cornelius F. "Coacción económica y tratados desiguales", Estudios Intemacionales, №14, año IV, julio-septiembre, 1970, pp. 82-103.

DERECHO INTERNACIONAL; ECONOMIA INTERNACIONAL.

\section{Naudon, Carlos}

02345 Naudon, Carlos. "Cinco libros sobre Israel", Estudios Internacionales, N²6, año II, julio-septiembre, 1968, pp. 271-275.

ISRAEL; POLITICA MUNDIAL; POLITICA INTERNACIONAL; MEDIO ORIENTE. 


\section{Ness, Peter van}

02559 Ness, Peter van; Raichur, Satish. "Dilemas del desarrollo en China: 1949-1980", Estudios Internacionales, №61, año XVI, enero-marzo, 1983, pp. 90-116.

CHINA; ASIA; DESARROLLLO ECONOMICO; SOCIALISMO.

\section{Niekerk, Arnold van}

02334 Niekerk, Arnold van. "La pendiente de la dependencia: Una visión desde afuera", Estudios Internacionales, №18, año v, abril-junio, 1972, pp. $29-40$.

DEPENDENCIA; AMERICA LATINA.

02756 Niekerk, Arnold van. "América Latina y las Antillas Neerlandesas", Estudios Intemacionales, №23, año VI, julio-septiembre, 1973, pp. 93-104.

AMERICA LATINA; POLITICA INTERNACIONAL; ANTILLAS NEERLANDESAS; RELACIONES EXTERIORES; AMERICA CENTRAL Y CARIBE.

02387 Niekerk, Arnold van. "La sociología latinoamericana: un testimonio epistemológico", Estudios Internacionales, №36, año IX; septiembrediciembre, 1976, pp. $42-73$.

AMERICA LATINA; SOCIOLOGIA; CIENCIAS SOCIALES.

\section{Nitsch, Manfred}

02507 Nitsch, Manfred. "Los intereses de los países ricos y el desarrollo del Tercer Mundo: La República Federal de Alemania", Estudios Internacionales, Ne54, año XIV, abril-junio, 1981, pp. 224-253.

TERCER MUUNDO; DESARROLLO ECONOMICO; EUROPA; ECONOMIA INTERNACIONAL; POLITICA INTERNACIONAL; ALEMANIA REP. FEDERAL.

\section{Nogueira Batista, Paulo}

02585 Nogueira Batista, Paulo. "Análisis crítico de la programación gubernamental del sector externo en el Brasil", Estudios Intemacionales, NN64, año XVl, octubre-diciembre, 1983, pp. 579-602.

BRASIL; AMERICA DEL SUR; ECONOMIA INTERNACIONAL; DEUDA EXTERNA.

\section{Nohlen, Dieter}

02515 Nohlen, Dieter; Fernández B., Mario: "Cooperación y conflicto en la Cuenca del Plata", Estudios Internacionales, N55, año XIV, julio-septiembre, 1981, pp. 412-443.

INTEGRACION REGIONAL; INTEGRACION ECONOMICA; AMERICA LATINA; CUENCA DEL PLATA; COOPERACION REGIONAL; COOPERACION ECONOM! CA; CONFLICTOS.

02616 Nohlen, Dieter. "El cambio de régimen político en América Latina: en torno a la democratización de los regímenes autoritarios", Estudios Intemacionales, №68, año XVII, octubre-diciembre, 1984, pp. 548-575.

AMERICA LATINA; POLITICA Y GOBIERNO; DEMOCRATIZACION; AUTORITARISMO. 
01593 Nohlen, Dieter; Fernández B., Mario. "Democratización y política exterior: análisis comparado en torno a tres casos: Argentina, Brasil y Uruguay", Estudios Intemacionales, №94, año XXIV, 1991 abril-junio, pp. 229-259.

ARGENTINA; BRASIL; URUGUAY; AMERICA DEL SUR; POLITICA INTERNACIONAL; DEMOCRATIZACION; TRANSICION DEMOCRATICA; AMIERICA LATINA; INTEGRACION; INTEGRACION ECONOMICA.

\section{Núñez, José}

02642 Pelzman, Joseph; Núñez, José. "El crimen más largo: los controles impuestos por los Estados Unidos a la exportación de productos textiles", Estudios Intemacionales, №72, año XVIII, octubre-diciembre, 1985 , pp. 593-600.

ESTADOS UNIDOS; AMERICA DEL NORTE; ECONOMIA INTERNACIONAL; CO. MERCIO EXTERIOR; EXPORTACIONES.

\section{O'Brien, Philip}

02293 O'Brien, Philip. "La Alianza para el Progreso y los préstamos por programa a Chile", Estudios Internacionales, №8, año II, enero-marzo, 1969, pp. 461-489.

CHILE; AMERICA DEL SUR; ALIANZA PARA EL PROGRESO; DESARROLLO ECONOMICO.

\section{O'Connell, Arturo}

02746 O'Connell, Arturo. "La coordinación de los deudores latinoamericanos: el consenso de Cartagena y el Grupo de los Ocho", Estudios Internacionales, №83, año XXI, julio-septiembre, 1988, pp. 373-385. DEUDA EXTERNA; ECONOMIA INTERNACIONAL; AMERICA LATINA; GRUPO DELOS OCHO; CONCERTACION POLITICA.

Ogelsby, J. C. M.

02333 Ogelsby, J. C. M. "Relaciones canadiense-latinoamericanas, pasadas, presentes y futuras", Estudios Intemacionales, N¹8, año v, abril-junio, 1972, pp. 68-87.

CANADA; AMERICA LATINA; POLITICA INTERNACIONAL; RELACIONES EXTERIORES; AMERICA DEL NORTE.

\section{Oldfeit, Carin}

02272 Oldfelt, Carin. "Estudio comparativo sobre zonas pesqueras en el mundo", Estudios Internacionales, №13, año IV, abril-junio, 1970, pp. 21-37.

PESCA; ReCuRSOS NATURALES; DERECHO Del MAR; RECURSOS MARINOS.

\section{Ominami, Carlos}

02652 Ominami, Carlos. "El Tercer Mundo y la economía mundial", Estudios Internacionales, N74, año XIX, abril-junio, 1986, pp. 170-210. 
ECONOMIA INTERNACIONAL; TERCER MUNDO; RELACIONES NORTE SUR; RELACIONES EXTERIORES.

02658 Ominami, Carlos. "América Latina y la Tercera Revolución Industrial", Estudios Intemacionales, №76, año XIX, octubre-diciembre, 1986, pp. 407-419.

AMERICA LATINA; CIENCIA Y TECNOLOGIA; ECONOMIA INTERNAGIONAL.

\section{Orrego Vicuña, Francisco}

02273 Orrego Vicuña, Francisco. "Dilemas en el Grupo Andino", Estudios Intemacionales, №11, año II, octubre-diciembre, 1969, pp. 352-371. PACTO ANDINO; INTEGRACION ECONOMICA; INTEGRACION REGIONAL; GRUPO ANDINO.

02358 Orrego Vicuña, Francisco. "Algunos problemas de derecho internacional planteados por la nacionalización de la industria del cobre en Chile", Estudios Internacionales, $\mathrm{N}^{2} 24$, año VI, octubre-diciembre, 1973, pp. 66-88.

DERECHO INTERNACIONAL; NACIONALIZACION; COBRE; CHILE; AMERICA DEL SUR; EMPRESAS TRANSNACIONALES.

02317 Orrego Vicuña, Francisco. "De la crisis de la energía al concepto del patrimonio económico de la humanidad: criterios para reestructurar el sistema económico internacional", Estudios Internacionales, No32, año VIII, octubre-diciembre, 1975, pp. 3-32.

ECONOMIA INTERNACIONAL; ENERGIA; PETROLEO; EMPRESAS TRANSNACIONALES; COMERCIO EXTERIOR.

02411 Orrego Vicuña, Francisco. "Las alternativas de América Latina como clase media de las naciones", Estudios Intemacionales, Ne40, año X, octubre-diciembre, 1977, pp. 89-110.

AMERICA LATINA; DESARROLLO ECONOMICO; TERCER MUNDO.

02468 Orrego Vicuña, Francisco. "La legislación unilateral para la explotación de los fondos marinos: su incompatibilidad con el derecho internacional", Estudios Internacionales, N47, año XII, julio-septiembre, 1979 , pp. 275-292.

DERECHO INTERNACIONAL; DERECHO DEL MAR; RECURSOS MINERALES; FONDOS MARINOS; RECURSOS MARINOS; LEGISLACION.

02497 Orrego Vicuña, Francisco. "Europa y América Latina: ¿Hacia un rol internacional complementario?", Estudios Internacionales, Ne53, año XIV, 1981 enero-marzo, pp. 3-16.

EUROPA; AMERICA LATINA; POLITICA INTERNAGIONAL; RELACIONES EXTERIORES; COOPERACION INTERNACIONAL.

02522 Orrego Vicuña, Francisco. "Hacia nuevas formas de integración económica en América Latina: lecciones de una experiencia" ${ }^{\prime}$ Estudios Internacionales, Ne56, año XIV, octubre-diciembre, 1981; pp. 568-577. 
INTEGRACION ECONOMICA; INTEGRACION REGIONAL; AMERICA LATINA; POLITICA INTERNACIONAL; RELACIONES EXTERIORES.

02531 Orrego Vicuña, Francisco. "Perspectivas de la cooperación entre América Latina y los países de ASEAN", Estudios Intemacionales, Ne58, año XV, abril-junio, 1982, pp. 190-204.

POLITICA INTERNACIONAL; AMERICA LATINA; ASEAN; OCEANO PACIFICO; ECONOMIA INTERNACIONAL; COOPERACION ECONOMICA; COOPERACION INTERNACIONAL.

02548 Orrego Vicuña, Francisco. "La crisis del Atlántico Sur y su influencia en el sistema regional", Estudios Intemacionales, $\mathrm{N}^{2} 60$, año XV, octubre-diciembre, 1982 , pp. 473-498.

ISLAS MALVINAS; SISTEMAINTERAMERICANO; CONFLICTOS; AMERICA LATINA; ESTADOS UNIDOS; AMERICA DEL NORTE; POLITICA INTERNACIONAL.

02551 Orrego Vicuña, Francisco. "El elusivo entendimiento entre América Latina y los Estados Unidos", Estudios Internacionales, $N^{2} 60$, año XV, octubre-diciembre, 1982, pp. 519-532.

AMERICA LATINA; ESTADOS UNIDOS; AMERICA DEL NORTE; POLITICA INTERNACIONAL; ISLAS MALVINAS; RELACIONES EXTERIORES.

02554 Orrego Vicuña, Francisco. "La definición de un régimen para los recursos minerales antárticos: opciones básicas", Estudios Internacionales, Ní61, año XVI, enero-marzo, 1983, pp. 14-30. ANTARTICA; RECLRSOS MINERALES.

02575 Orrego Vicuña, Francisco. "Políticas internas e influencias externas en el debate sobre derechos humanos en América Latina", Estudios Intemacionales, No63, año XVI, julio-septiembre, 1983, pp. 391-405. AMERICA LATINA; DERECHOS HUMANOS; POLITICA INTERNACIONAL; POLITICA Y GOBIERNO.

02600 Orrego Vicuña, Francisco. "Políticas internas e influencias externas en el debate sobre derechos humanos en América Latina", Estudios Intemacionales, $\mathrm{N}^{2} 66$; año XVII, abril-junio, 1984, pp. 232-246.

AMERICA LATINA; DERECHOS HUMANOS; POLITICA INTERNACIONAL; POLITIGA Y GOBIERNO.

02667 Orrego Vicuña, Francisco. "La búsqueda de un nuevo papel para la Organización de los Estados Americanos: el Protocolo de Reformas de la Carta de 1985", Estuidios Internacionales, NQ77, año XX, eneromarzo, 1987, pp. 70-87.

OEA; SISTEMA INTERAMERICANO; REFORMAS.

00244 Orrego Vicuña, Francisco. "El régimen de los minerales de los fondos marinos: términos y condiciones de una renegociacion", Estudios Internacionales, Ne85, año XXII, enero-marzo, 1989, pp. 42-52. FONDOS MARINOS; DERECHO DEL MAR; RECURSOS MINERALES.

00239 Orrego Vicuña, Francisco. "La cooperación en el Pacífico: una perspectiva desde América Latina", Estudios Intemacionales, No86, año XXII, abril-junio, 1989 , pp. 131-152. 
COOPERACION ECONOMICA; CUENCA DEL PACIFICO; AMERICA LATINA; OCEANO PACIFICO.

01301 Orrego Vicuña, Francisco. "Nuevas modalidades para el restablecimiento de la paz y seguridad en el derecho internacional:el Grupo de Observadores de las Naciones Unidas en Centroamérica", Estu' dios Internacionales, Ne93, año XXIV, enero-marzo, 1991, pp. 3-18. AMERICA CENTRAL Y CARIBE; PAZ; ONUCA; SEGURIDAD; DERECHO INTERNACIONAL.

01646 Orrego Vicuña, Francisco. "El papel de la Corte Internacional de Justicia y otros tribunales en el desarrollo del derecho de la delimitación marítima", Estudios Intemacionales, Ne95, año XXIV, julio-septiembre, 1991, pp. 384-407.

CIJ; DELIMITACION MARITIMA; DERECHO DEL MAR; DERECHO INTERNACIONAL; ZONA ECONOMICA EXCLUSIVA.

01851 Orrego Vicuña, Francisco. "El proceso de cambios en el derecho internacional de los espacios comunes", Estudios Intemacionales, N296, año XXIV, octubre-diciembre, 1991, pp. 518-537.

DERECHO INTERNACIONAL; DERECHO DEL MAR; ANTARTICA; MEDIO AMBIENTE; PROTECCION AMBIENTAL; TRATADO ANTARTICO.

01873 Orrego Vicuña, Francisco. "Bibliografía crítica de la década 19811990: relaciones internacionales y derecho internacional", Estudios Intemacionales, Ne96, año XXIV, octubre-diciembre, 1991, pp. 564569.

RELACIONES INTERNACIONALES; DERECHO INTERNACIONAL; BIBLIOGRAFIA.

02080 Orrego Vicuña, Francisco. "Las relaciones entre los países de América Latina y los Estados Unidos: límites regionales y entendimientos globales", Estudios Internacionales, N997, año XXV, enero-marzo, 1992, pp. 23-40.

AMERICA LATINA; ESTADOS UNIDOS; AMERICA DEL NORTE; RELACIONES BILATERALES; RELACIONES EXTERIORES; HISTORIA; LIBRE COMERCIO; IN. TEGRACION REGIONAL; INTEGRACION ECONOMICA; COMERCIO EXTERIOR; DEUDA EXTERNA; INVERSIONES EXTRANJERAS; CUENCA DEL PACIFICO; ASIA; JAPON; DEMOCRACIA; DROGAS; PROTECCION AMBIENTAL.

02081 Aguilar Mandsley, Andrés; Orrego Vicuña, Francisco; Sanguinetti, Julio María; Wilkey, Malcolm; Freeland, John. "Decisión de la Comisión para la Solución de Controversias entre Chile y Estados Unidos sobre el Caso Letelier Moffit, 11 de enero de 1992", Estudios Internacionales, Ne97, año XXV, enero-marzo, 1992, pp. 136-153 //Incluye:opinión separada concurrente del profesor Francisco Orrego Vicuña/l.

ESTADOS UNIDOS; AMERICA DEL NORTE; CHILE; AMERICA DEL SUR; CONTROVERSIAS, SOLUCION DE; INDEMNIZACION JUDICIAL; CASOS; DOCUMENTOS; DERECHOS HUMANOS. 


\section{Ortíz Mena, Antonio}

02459 Ortíz Mena, Antonio. "Las relaciones económicas entre América Latina y la OECD: nuevas perspectivas", Estudios Internacionales, №45, año XII; enero-marzo, 1979, pp. 27-35. ECONOMIAINTERNACIONAL; AMERICA LATINA; OECD; COOPERACION ECONOMICA; RELACIONES ECONOMICAS INTERNACIONALES.

\section{Ortíz, Eduardo}

02280 Ortíz, Eduardo. "Las grandes potencias y la crisis de Nigeria", Estutdios Intemacionales, Ne9, año III, abril-junio, 1969, pp. 63-76. POLITICA MUNDIAL; AFRICA; NIGERIA; GRANDES POTENCIAS; CRISIS.

02344. Ortíz, Eduardo. "Jaime Eyzaguirre", Estudios Internacionales, NN7, año II, octubre-diciembre, 1968, pp. 315-316.

EYZAGUIRRE, JAIME; CHILE; AMERICA DEL SUR; BIOGRAFIAS.

Paiva Abreu, Marcelo de

02645 Paiva Abreu, Marcelo de; Fritsch, Winston. "Un estudio sobre la graduación", Estudios Intemacionales, №73, año XIX, enero-marzo, 1986, pp. 37-75.

ECONOMIA INTERNACIONAL; GATT; BRASIL; AMERICA DEL SUR.

\section{Palma Yicuña, Ignacio}

02370 Palma Vicuña, Ignacio. "Aportes para un análisis de la crisis chilena", Estudios Internacionales, N226, año VII, abril-junio, 1974, pp. 39-67. CHILE; AMERICA DEL SUR; POLITICA Y GOBIERNO; CRISIS.

\section{Palma, Pedro A.}

02352 Palma, Pedro A. "Análisis del Sistema Monetario Internacional", Estudios Intemacionales, Ne32, año VIII, octubre-diciembre, 1975, pp. 51-102.

ECONOMIA INTERNACIONAL; SISTEMA MONETARIO INTERNACIONAL.

\section{Palmer, David Scott}

02708 Palmer, David Scott. "Actores y factores en las relaciones contemporáneas de los Estados Unidos y América Latina", Estudios Internacionales, N282, año XXI, abril-junio, 1988, pp. 157-172.

ESTADOS UNIDOS; AMERICA LATINA; AMERICA DEL NORTE; POLITICAINTERNACIONAL; RELACIONES EXTERIORES.

02914 Palmer, David Scott. "Perú 1992: la sorpresa de abril de Fujimori", Estudios Internacionales, No99, año XXV, julio-septiembre, 1992, pp. 378-384:

PERU; AMERIGA DEL SUR; GOLPES DE ESTADO; POLITICA Y GOBIERNO.

\section{Paolillo, Felipe}

02543 Paolillo, Felipe. "El impacto del nuevo derecho del mar en la evolu- 
ción de la organización internacional", Estudios Internacionales, №59, año XV, julio-septiembre, 1982, pp. 337-357.

DERECHO DEL MAR; POLITICA MUNDIAL.

\section{Pardo, Arvid}

02603 Pardo, Arvid. "El espacio oceánico y la humanidad", Estudios Internacionales, №66, año XVII, abril-junio, 1984, pp. 293-306. DERECHO DEL MAR; ESPACIOS MAPITIMOS.

\section{Pardo, Rodrigo}

02682 Pardo, Rodrigo; Tokatlian, Juan Gabriel. "Política internacional, paz interna e interés nacional", Estudios Intemacionales, №80, año XX, octubre-diciembre, 1987, pp. 435-441.

POLITICA INTERNACIONAL; ESTADO; POLITICA Y GOBIERNO; PAZ.

02690 Pardo, Rodrigo; Tokatlian, Juan Gabriel. "Teoría y práctica de las relaciones internacionales: el caso de Colombia", Estudios Intemacionales, Ne81, año XXI, enero-marzo, 1988, pp. 94-135.

COLOMBIA; AMERICA DEL SUR; RELACIONES INTERNACIONALES; POLITICA INTERNACIONAL; RELACIONES EXTERIORES.

00601 Tokatlian, Juan Gabricl; Pardo, Rodrigo. "Violencia política, paz interna y política internacional", Estudios Internacionales, №90, año XXIII, abril-junio, 1990, pp. 187-220.

VIOLENCIA; COLOMBIA; AMERICA. LATINA; POLITICA Y GOBIERNO; PAZ; POLITICA INTERNACIONAL.

01136 Tokatlian, Juan Gabriel; Pardo, Rodrigo. "La teoría de la interdependencia: Gun paradigma alternativo al realismo", Estudios Intemacionales, №1, año XXIII, julio-septiembre, 1990, pp. 339-382. RELACIONES INTERNACIONALES-TEORIA.

\section{Pazos, Javier}

02318 Hurtado, Héctor; Pazos, Javier; Mayobre, Eduardo. "El Caribe y Venezuela: integración de la integración", Estudios Intemacionales, No27, año VII, julio-septiembre, 1974, pp. 3-30.

AMERICA CENTRAL Y CARIBE; VENEZUELA; INTEGRACION REGIONAL; INTEGRACION ECONOMICA; ECONOMIA INTERNACIONAL; AMERICA DEL SUR.

\section{Pelzman, Joseph}

02642 Pelzman, Joseph; Núñez, José. "El crimen más largo: los controles impuestos por los Estados Unidos a la exportación de productos textiles", Estudios Intemacionales, No72, año XVIII, octubre-diciembre, 1985, pp. 593-600.

ESTADOS UNIDOS; AMERICA DEL NORTE; ECONOMIA INTERNACIONAL; COMERCIO EXTERIOR; EXPORTACIONES.

\section{Peña, Félix}

02326 Peña, Félix. "El Grupo Andino: un nuevo enfoque de la participación 
internacional de los países en desarrollo", Estudios Internacionales, №22, año VI, abril-junio, 1973, pp, 44-81.

GRUPO ANDINO; INTEGRACION REGIONAL; INTEGRACION ECONOMICA; AMERICA CENTRAL; PAISES EN DESARROLLLO.

02375 Peña, Félix. "Tendencias y perspectivas de la integración económica en América Latina", Estudios Intemacionales, №29, año vill, eneromarzo, 1975, pp. 137-152.

INTEGRACION ECONOMICA; INTEGRACION REGIONAL; AMERICA LATINA.

02525 Peña, Félix. "Perspectivas de las relaciones entre la Argentina y el Brasil: algunos apuntes", Estudios Internacionales, №57, año XV, enero-marzo, 1982, pp. 28-38.

ARGENTINA; BRASIL; AMERICA DEL SUR; POLITICA INTERNACIONAL; RELACIONES BILATERALES.

02687 Peña, Félix. "La cumbre latinoamericana de Acapulco: transformación económica, democratización y cooperación internacional", Estudios Internacionales, №81, año XXI, enero-marzo, 1988, pp. 15-22. AMERICA LATINA; POLITICA INTERNACIONAL; GRUPO DE LOS OCHO; COOPERACION INTERNACIONAL; DEMOCRATIZACION; REUNIONES CUMBRES; POLITICA ECONOMICA.

02725 Peña, Félix. "Concertación latinoamericana: arquitectura de integración e ingeniería de negocios", Estudios Internacionales, №83, año XXI, julio-septiembre, 1988, pp. 386-424.

AMERICA LATINA; INTEGRACION REGIONAL; INTEGRACION ECONOMICA; CONCERTACION POLITICA; POLITICA INTERNACIONAL.

\section{Pérez Llana, Carlos}

02357 Pérez Llana, Carlos. "América Latina y los países no alineados", Estudios Intemacionales, №24, año vi, octubre-diciembre, 1973, pp. 43-65.

AMERICA LATINA; PAISES NO ALINEADOS; POLITICA MUNDIAL; TERCER MUNDO.

02373 Pérez Llana, Carlos. "¿Potencias intermedias o países mayores? La política exterior de Argentina; Brasil y México", Estudios Intemacionales, N²9, año VIII, enero-marzo, 1975, pp. 47-105.

POLITICA INTERNACIONAL; ARGENTINA; BRASIL; MEXICO; AMERICA LATINA; AMERICA DEL NORTE; AMERICA DEL SUR.

02392 Pérez Llana, Carlos. "El legado de Henry Kissinger: algunas implicancias de su gestión", Estudios Internacionales, Ne37, año X, eneromarzo, 1977, pp. 68-91.

POLITICA INTERNACIONAL; ESTADOS UNIDOS; AMERICA DEL NORTE; KISSINGER, HENRY.

02462 Pérez Llana, Carlos. "Perspectivas de América Latina en el diálogo Norte-Sur", Estudios Internacionales, N46, año XII, abril-junio, 1979, pp. 131-143. 
AMERICA LATINA; DIALOGO NORTE SUR; RELACIONES NORTE SUR; POLITICA INTERNACIONAL; RELACIONES EXTERIORES.

02521 Pérez Llana, Carlos. "Brasily Europa: el problema de las percepciones", Estudios Intemacionales, Ne56, año Xiv, octubre-diciembre, 1981, pp. 553-567.

BRASIL; AMERICA DEL SUR; EUROPA; POLITICA INTERNACIONAL; RELACIONES EXTERIORES.

02545 Pérez Llana, Carlos. "La política exterior de la Argentina post-Malvinas", Estudios Internacionales, N60, año XV, octubre-diciembre, 1982, pp. 410-442.

ARGENTINA; ISLAS MALVINAS; AMERICA DEL SUR; POLITICA INTERNACIONAL; CONFLICTOS.

02623 Pérez Llana, Carlos. "La crisis internacional y los países en desarro1lo", Estudios Internacionales, No70, año XVII, abril-junio, 1985, pp. 175-185.

POLITICA INTERNACIONAL; AFRICA; AMERICA LATINA; ASIA; PAISES EN DESARROLLO; POLITICA MUNDIAL; CRISIS.

02643 Pérez Llana, Carlos. "Relaciones internacionales y transición política", Estudios Intemacionales, Ne73, año XIX, enero-marzo, 1986, pp. 3-15.

POLITICA INTERNACIONAL; POLITICA Y GOBIERNO; TRANSICION DEMOCRATICA.

01137 Pérez Llana, Carlos. "Los Noventa: una nueva agenda internacional para una nueva década", Estudios Internacionales, No91, año XXIIr, julio-septiembre, 1990, pp. 383-398.

ORDEN MUNDIAL; RELACIONES INTERNACIONALES; POLITICA MUNDIAL; RELACIONES INTERNACIONALES-TEORIA.

Pérez, Carlota

02660 Pérez, Carlota. "Las nuevas tecnologías: una visión de conjunto", Estudios Intemacionales, Ne76, año XIX, octubre-diciembre, 1986, pp. $420-459$.

CIENCIA Y TECNOLOGIA; TECNOLOGIA.

\section{Perina, Rubén M.}

02710 Perina, Rubén M; Ramírez, Norma A. "La importancia de América Latina en el sistema internacional en la década de los ochenta: un ensayo bibliográfico", Estudios Internacionales, Ne82, año XXI, abriljunio, 1988, pp. 184-205.

AMERICA LATINA; POLITICA INTERNACIONAL; BIBLIOGRAFIA.

\section{Perry, Guillermo}

02420 Perry, Guillermo. "Mercados mundiales de manufacturas, industrialización y política comercial de los países en desarrollo", Estudios Intemacionales, $\mathrm{N}^{2} 42$, año XI, abril-junio, 1978, pp. 66-94. 
DESARROLLO ECONOMICO; ECONOMIA INTERNACIONAL; INDUSTRIALIZACION; PAISES EN DESARROLLO.

02508 Perry, Guillermo. "El Informe Brandt y el comercio de productos industrializados", Estudios Intemacionales, N254, año XIV, abril-junio, 1981, pp. 254-265.

COMERCIO EXTERIOR; ECONOMIA INTERNACIONAL; RELACIONES NORTE SUR; RELACIONES ECONOMICAS INTERNACIONALES.

Petras, James

02814 Petras, James. "Estados Unidos y el nuevo equilibrio en América Latina", Estudios Intemacionales, No8, año Il, enero-marzo, 1969; pp. 490-518.

AMERICA LATINA; ESTADOS UNIDOS; AMERICA DEL NORTE; POLITICA Y GOBIERNO; POLITICA INTERNACIONAL; INTERVENCION - DERECHO INTERNACIONAL; CONFLICTOS; DEPENDENCIA; ALIANZA PARA EL PROGRESO.

02343 Petras, James; Rimensnyder, Nelson. "Los militares y la modernización del Perú", Estudios Internacionales, Nº13, año IV, abril-junio, 1970, pp. 90-123.

FUERZAS ARMADAS; MODERNIZACION; PERU; AMERICA DEL SUR; POLITICA $Y$ GOBIERNO.

02269 Petras, James. "Venezuela: una década de democracia capitalista", Estudios Intemacionales, №15, año IV, octubre-diciembre, 1970, pp. 42-59.

VENEZUELA; AMERICA DEL SUR; POLITICA Y GOBIERNO; DEMOCRACIA.

\section{Pinochet de la Barra, Oscar}

02513 Pinochet de la Barra, Oscar. "Evolución política jurídica del problema antártico", Estudios Intemacionales, N55, año XIV, julio-septiembre, 1981, pp. 380-393.

ANTARTICA; HISTORIA; POLITIGA INTERNACIONAL; TRATADO ANTARTICO; DERECHO INTERNACIONAL.

02673 Pinochet de la Barra, Oscar. "Negociaciones antárticas de Chile en un mundo cambiante ${ }^{\mathrm{H}}$, Estudios Intemacionales, Ne78, año XX, abriljunio, 1987, pp. 210-222.

ANTARTICA; CHILE; AMERICA DEL SUR; NEGOCIACIONES; POLITICA MUNDIAL.

01129 Pinochet de la Barra, Oscar. "Antártica, un continente para el tercer milenio", Estudios Intemacionales, No92, año XXIII, octubre-diciembre, 1990 , pp. $499-511$.

ANTARTICA; RECURSOS NATURALES; PROTECCION AMBIENTAL:

\section{Pinto, Anibal}

02328 Pinto, Aníbal. "Relaciones económicas entre América Latina y Estados Unidos: implicaciones y perspectivas políticas", Estudios Internácionales, $\mathrm{N}^{222}$, año VI, abril-junio, 1973, pp. 3-31.

ECONOMIA INTERNACIONAL; RELACIONES ECONOMICAS; ESTADOS UNI- 
DOS; AMERICA LATINA; DEPENDENCIA; RELACIONES ECONOMICAS INTERNACIONALES; AMERICA DEL NORTE; DEPENDENCIA ECONOMICA.

02504 Pinto, Aníbal. "Guerra Fría y distensión en América Latina: a la luz de los ensayos de don José Medina Echavarría", Estudios Intemacionales, №54, año XIV, abril-junio, 1981, pp. 145-165.

POLITICA MUNDIAL; AMERICA LATINA; GUERRA FRIA; DISTENSION.

\section{Plaza, Oscar}

02620 Lagos, Gustavo; Plaza, Oscar. "La actual política exterior norteamericana y su proyección en América Latina", Estudios Internacionales, No69, año XVII, enero-marzo, 1985, pp. 63-80.

ESTADOS UNIDOS; AMERICA DEL NORTE; AMERICA LATINA; POLITICAINTERNACIONAL; RELACIONES EXTERIORES.

\section{Pomerlau, Claude}

02674 Pomerlau, Claude. "El problema de las relaciones Iglesia-Estado en México", Estudios Intemacionales, Nº78, año XX, abril-junio, 1987, pp. 223-241.

MEXICO; AMERICA DEL NORTE; IGLESIA CATOLICA; POLITICA Y GOBIERNO.

\section{Portales, Carlos}

02655 Portales, Carlos. "Sudamérica: seguridad regional y relaciones con Estados Unidos", Estudios Internacionales, No75, año XIX, julio-septiembre, 1986, pp. 279-334.

AMERICA DEL SUR; ESTADOS UNIDOS; AMERICA DEL NORTE; POLITICA INTERNACIONAL; SEGURIDAD REGIONAL; RELACIONES EXTERIORES.

02679 Portales, Carlos. "Democracia y derechos humanos en la política exterior del Presidente Reagan", Estudios Internacionales, N79, año XX, julio-septiembre, 1987, pp. 352-378.

ESTADOS UNIDOS; AMERICA DEL NORTE; DEMOCRACIA; DERECHOS HUMANOS; POLITICA INTERNACIONAL.

00246 Portales, Carlos. "Seguridad compartida en América Latina: desafío del siglo XXI", Estudios Internacionales, N85, año XXII, enero-marzo, 1989, pp. 10-20.

SEGURIDAD REGIONAL; AMERICA LATINA; FUERZAS ARMADAS.

00221 Portales, Carlos. "Los factores externos y el régimen autoritario. Evolución e impacto de las Relaciones Internacionales de Chile en el proceso de transición a la democracia", Estudios Internacionales, Ne87, año XXIr, julio-septiembre, 1989, pp. 308-341.

CHILE; AMERICA DEL SUR; RELACIONES EXTERIORES; AUTORITARISMO; DEMOCRATIZACION; TRANSICION DEMOCRATICA; POLITICA Y GOBIERNO.

\section{Porto de Oliveira, Amaury}

01645 Porto de Oliveira, Amaury. "Chile y Brasil: intereses conjuntos en el Pacífico" ${ }^{\mathrm{H}}$ Estudios Internacionales, N95, año XXIV, julio-septiembre, 1991, pp. 408-418. 
CHILE; BRASIL; AMERICA DEL SUR; CUENCA DEL PACIFICO; ASIA; NIC'S; ASEAN; INTEGRACION REGIONAL; DESARROLLO ECONOMICO; COOPERACION ECONOMICA; INDUSTRIALIZACION; ECONOMIA INTERNACIONAL.

\section{Prebisch, Raúl}

02429 Prebisch, Raúl. "Notas sobre el desarrollo del capitalismo periférico", Estudios Intemacionales, N243, año XI, julio-septiembre, 1978, pp. 3-25.

ECONOMIA INTERNACIONAL; CAPITALISMO; DEPENDENCIA; DEPEINDENCIA ECONOMICA.

02562 Prebisch, Raúl. "La crisis del capitalismo y la periferia", Estudios Internacionales, N62, año XVI, abril-junio, 1983, pp. 169-179.

CAPITALISMO; AMERICA LATINA; ECONOMIAINTERNACIONAL; CRISIS; POLITICA MUNDIAL.

02580 Prebisch, Raúl. "Hacia la recuperación económica y la equidad social", Estudios Internacionales, N64, año XVI, octubre-diciembre, 1983, pp. 510-522.

ECONOMIA INTERNACIONAL; AMERICA LATINA; DEUDA EXTER̈NA; POLITICA SOCIAL; POLITICA ECONOMICA.

\section{Raichur, Satish}

02559 'Ness, Peter van; Raichur, Satish. "Dilemas del desarrollo en China: 1949-1980", Estudios Intemacionales, N61, año XVI, enero-marzo, 1983, pp. 90-116.

CHINA; ASIA; DESARROLLO ECONOMICO; SOCIALISMO.

\section{Ramesh, Jairman}

02479 Sábato, Jorge A.; Ramesh, Jairman. "Programas de energía nuclear en el mundo en desarrollo: su fundamento e impacto", Estudios Internacionales, №49, año XIII, 1980 enero-marzo, pp. 70-85.

ENERGIA NUCLEAR; DESARROLLO ECONOMICO; POLITICA MUNDIAL.

\section{Ramírez, Norma A.}

02710 Perina, Rubén M.; Ramírez, Norma A. "La importancia de América Latina en el sistema internacional en la década de los ochenta: un ensayo bibliográfico", Estudios Internacionales, N82, año XXI, abriljunio, 1988, pp. 184-205.

AMERICA LATINA; POLITICA INTERNACIONAL; BIBLIOGRAFIA.

\section{Ramos, Joseph}

02675 Bianchi, Andrés; Devlin, Robert; Ramos, Joseph. "El proceso de ajuste en América Latina 1981-1986", Estudios Internacionales, No79, año XX, julio-septiembre, 1987, pp. 272-320.

ECONOMIA INTERNACIONAL; AMERICA LATINA; DEUDA EXTERNA; POLITICA ECONOMICA. 
Rehren, Alfredo J.

02811 Rehren, Alfredo J. "El liderazgo encubierto de Eisenhower", Estudios Internacionales, №98, año XXV, abril-junio, 1992, pp. 258-274. ESTADOS UNIDOS; AMERICA DEL NORTE; CHILE; AMERICA DEL SUR; RELACIONES BILATERALES; POLITICA INTERNACIONAL; LIDERES; INTERVENCION - DERECHO INTERNACIONAL; CUBA; AMERICA CENTRAL Y CARIBE; POLITICA Y GOBIERNO.

Ribeiro, Darcy

02259 Ribeiro, Darcy. "El desafío de la marginalidad", Estudios Internacionales, N216, año IV, enero-marzo, 1971, pp. 93-125.

DESARROLLO ECONOMICO; SOCIEDAD; AMERICA LATINA; DESARROLLO SOCIAL; MARGINALIDAD.

02335 Ribeiro, Darcy. "Nuevos caminos de la Revolución Latinoamericana", Estudios Intemacionales, №18, año v, abril-junio, 1972, pp. 3-28. AMERICA LATINA; REVOLUCIONES; PERU; CHILE; AMERICA DEL SUR; POLITICA Y GOBIERNO.

\section{Rimensnyder, Nelson}

02343 Petras, James; Rimensnyder, Nelson. "Los militares y la modernización del Perú", Estudios Internacionales, №13, año IV, abril-junio, 1970, pp. 90-123.

FUERZAS ARMADAS; MODERNIZACION; PERU; AMERICA DEL SUR; POLITICA Y GOBIERNO.

\section{Rodríguez Mendoza, Miguel}

02641 Rodríguez Mendoza, Miguel. "América Latina y la nueva legislación comercial de Estados Unidos", Estudios Intemacionales, №72, año XVIII, octubre-diciembre, 1985, pp. 576-592.

ESTADOS UNIDOS; AMERICA DEL NORTE; AMERICA LATINA; ECONOMIA INTERNACIONAL; COMERCIO EXTERIOR.

\section{Roett, Riordan}

02519 Roett, Riordan. "¿Tienen los Estados Unidos algún futuro en América Latina?", Estudios Intemacionales, No56, año XIV, octubre-diciembre, 1981, pp. 517-529.

ESTADOS UNIDOS; AMERICA DEL NORTE; AMERICA LATINA; POUITICA INTERNACIONAL; RELACIONES EXTERIORES.

02644 Roett, Riordan. "Panorama de las relaciones políticas y la seguridad del área del Atlántico, como consecuencia del trastorno económico", Estudios Internacionales, N73, año XIX, enero-marzo, 1986, pp. 16-36.

SEGURIDAD; ECONOMIA INTERNACIONAL; DEUDA EXTERNA; EUROPA; ESTADOS UNIDOS; AMERICA DEL NORTE; AMERICA DEL SUR; RELACIONES EXTERIORES.

02709 Roett, Riordan. "Perspectivas para el Plan Arias en El Salvador y 
Guatemala", Estudios Internacionales, №82, año XXI, abril-junio, 1988, pp. 173-183.

AMERICA CENTRAL Y CARIBE; EL SALVADOR; GUATEMALA; CONFLICTOS; POLITICA Y GOBIERNO.

\section{Rojas Aravena, Francisco}

00240 Rojas Aravena, Francisco. "El proceso de Esquipulas: el desarrollo conceptual y los mecanismos operativos", Estudios Intemacionales, №86, año XXII, abril-junio, 1989, pp. 224-247.

ESQUIPULAS; AMERICA CENTRAL Y CARIBE; REUNIONES CUMBRES; GRUPO DE LOS OCHO.

00236 Eguizábal, Cristina; Rojas Aravena, Francisco. "Política exterior, negociación y procesos de decisión en Centroamérica: elementos para una aproximación", Estudios Intemacionales, N88, año XXII, octubre-dicie hobre, 1989, pp. 489-513.

AMERICA CENTRAL Y CARIBE; RELACIONES EXTERIORES; ACTORES POLITICOS; INTEGRACION REGIONAL; POLITICA INTERNACIONAL; NEGOCIACIONES; TOMA DE DECISIONES.

00605 Rojas Aravena, Francisco. "Violencia política y orden internacional: el terrorismo en Centroamérica", Estudios Intemacionales, №90, año XXIII, abril-junio, 1990, pp. 166-186.

VIOLENCIA; TERRORISMO; AMERICA CENTRAL Y CARIBE; ORDEN MUNDIAL; ESQUIPULAS.

\section{Rosenthal, Gert}

02613 Rosenthal, Gert, "Algunas lecciones de la integración económica en América Latina: el caso de Centroamérica", Estudios Intemacionales, Ne68, año XVII, octubre-diciembre, 1984, pp. 493-512.

AMERICA LATINA; AMERICA CENTRAL Y CARIBE; INTEGRACION ECONOMICA; ECONOMIA INTERNACIONAL.

Rostow, W. W.

02460 Rostow, W. W. "Cómo romper la impasse en las negociaciones económicas multilaterales Norte-Sur", Estudios Internacionales, Ne45, año XII, enero-marzo, 1979, pp. 36-55.

ECONOMIA INTERNACIONAL; RELACIONES NORTE SUR; NEGOCIACIONES; RELACIONES ECONOMICAS INTERNACIONALES.

\section{Russell, Roberto}

02463 Russell, Roberto; Carballal, Teresa. "América Latina ¿Hacia qué nuevo orden internacional?", Estudios Intemacionales, $\mathrm{N}^{2} 46$, año XII, abril-junio, 1979, pp. 144-176.

AMERICA LATINA; POLITICA INTERNACIONAL; RELACIONES NORTE SUR; NUEVO ORDEN ECONOMICO INTERNACIONAL.

02501 Russell, Roberto; Carballal, Teresa. "El Nuevo Orden Económico Internacional: tendencias observables en el Norte y en los países 
mayores de América Latina", Estudios Internacionales, №53, año XIV, enero-marzo, 1981, pp. 55-88.

NUEVO ORDEN ECONOMICO INTERNACIONAL; RELACIONES NORTE SUR; AMERICA LATINA; ECONOMIA INTERNACIONAL; POLITICA INTERNACIONAL; RELACIONES EXTERIORES.

02598 Russell, Roberto. "Argentina y la política exterior del régimen autoritario 1976-1983: una evaluación preliminar", Estudios Internacionales, №66, año XVII, abril-junio, 1984, pp. 170-201.

ARGENTINA; AMERICA DEL SUR; POLITICA INTERNACIONAL; POLITICA $Y$ GOBIERNO; RELACIONES EXTERIORES.

02619 Russell, Roberto. "El fenómeno Reagan y América Latina: visiones, obstáculos y perspectivas", Estudios Intemacionales, N69, año XVIII, enero-marzo, 1985, pp. 51-62.

AMERICA LATINA; ESTADOS UNIDOS; AMERICA DEL NORTE; POLITICA INTERNACIONAL; RELACIONES EXTERIORES.

02695 Russell, Roberto; Hirst, Mónica. "Democracia y política exterior los casos de Argentina y Brasil", Estudios Internacionales, N280, año XX, octubre-diciembre, 1987, pp. 442-490.

DEMOCRACIA; POLITICA INTERNACIONAL; ARGENTINA; BRASIL; AMERICA DEL SUR; POLITICA Y GOBIERNO.

Sábato, Jorge A.

02295 Sábato, Jorge A. "Energía atómica en Argentina", Estudios Internacionales, №7, año II, octubre-diciembre, 1968, pp. 332-357. ARGENTINA; AMERICA DEL SUR; ENERGIA NUCLEAR.

02386 Sábato, Jorge A. "El cambio tecnológico necesario y posible", Estudios Internacionales, №36, año IX; septiembre-diciembre, 1976, pp. 24-41.

CIENCIAY TECNOLOGIA; DESARROLLO ECONOMICO; DEPENDENCIA; AMERICA LATINA; TRANSFERENCIA DE TECNOLOGIA.

02417 Sábato, Jorge A. "El plan nuclear brasileño y la bomba atómica", Estudios Internacionales, $N^{\mathbf{e} 41}$, año XI, enero-marzo, 1978, pp. 73-82. ENERGIA NUCLEAR; BRASIL; AMERICA DEL SUR; ARMAS NUCLEARES.

02479 Sábato, Jorge A.; Ramesh, Jairman. "Programas de energía nuclear en el mundo en desarrollo: su fundamento e impacto ${ }^{n}$, Estudios Internacionales, №49, año XIII, enero-marzo, 1980, pp. 70-85. ENERGIA NUCLEAR; OESARROLLO ECONOMICO; POLITICA MUNDIAL.

02499 Sábato, Jorge A.; Caputo, Dante M.; Sábato, Jorge F. "Cooperación para el desarrollo: algunas reflexiones y propuestas", Estudios Internacionales, N253, año XIV, enero-marzo, 1981, pp. 17-47. AMERICA LATINA; POLITICA INTERNACIONAL; COOPERACION INTERNACIONAL.

02550 Sábato, Jorge A. "¿Cómo entenderse con Estados Unidos?", Estudios -Internacionales, $\mathrm{N}^{6} 60$, año XV, octubre-diciembre, 1982, pp. 513-518. 
ESTADOS UNIDOS; AMERICA DEL NORTE; ISLAS MALVINAS; CONFLICTOS; AMERICA LATINA; POLITICA INTERNACIONAL.

Sábato, Jorge $\mathrm{F}$.

02499 Sábato, Jorge A.; Caputo, Dante M.; Sábato, Jorge F. "Cooperación para el desarrollo: algunas reflexiones y propuestas", Estudios Internacionales, Ne53, año XIV, enero-marzo, 1981, pp. 17-47.

AMERICA LATINA; POLITICA INTERNACIONAL; COOPERACION INTERNACIONAL.

01585 Caputo, Dante M.; Sábato, Jorge F. "Perspectivas de la integración político-económica continental: la integración de las democracias pobres: oportunidades y peligros", Estudios Intemacionales, No94, año XXIV, abril-junio, 1991, pp. 194-208.

AMERICA LATINA; ESTADOS UNIDOS; AMERICA DEL NORTE; AMERICA DEL. SUR; INTEGRACION POLITICA; INTEGRACION EGONOMICA; RELACIONES EXTERIORES; ESTADOS UNIDOS; AMERICA DEL NORTE; DEMOCRACIA.

\section{Sachs, Ignacy}

02367 Sachs, Ignacy. "Ecodesarrolio: un aporte a la definición de estilos de desarrollo para América Latina", Estudios Intemacionales, №25, año VII, enero-marzo, 1974, pp. 57-77.

MEDIO AMBIENTE; DESARROLLO ECONOMICO; AMERICA LATINA; ECOLOGIA.

Sagasti, Francisco $R$.

02366 Sagasti, Francisco R.; Guerrero, Mauricio. "Situación de la ciencia y tecnología en América Latina", Estudios Intemacionales, №25, año VII, enero-marzo, 1974, pp. 16-56.

CIENCIA Y TECNOLOGIA; AMERICA LATINA; DESARROLLO ECONOMICO.

02425 Sagasti, Francisco R. "Autodependencia tecnológica y cooperación en los países del Tercer Mundo", Estudios Intemacionales, Ne33, año IX; enero-marzo, 1976, pp. 47-61.

CIENCIA Y TECNOLOGIA; TERCER MUNDO; COOPERACION TECNOLOGICA.

02480 Sagasti, Francisco R. "Políticas de ciencia y tecnología para el desarrollo", Estudios Intemacionales, N49, año XIII, enero-marzo, 1980, pp. 86-111.

CIENCIA Y TECNOLOGLA; DESARROLLO ECONOMICO.

02662 Sagasti, Francisco R. "Perspectivas futuras de la ciencia y la tecnología en América Latina", Estudios Intemacionales, №\%6, año XIX, octubre-diciembre, 1986, pp. 487-512.

CIENCIA $Y$ TECNOLOGIA; AMERICA LATINA; POLITICA INTERNACIONAL.

\section{Salgado, Germánico}

02399 Salgado, Germánico. "Integración, conciliación de políticas y diferencias de estructura económica", Estudios Intemacionales, No38, año $X$, abril-junio, 1977, pp. 47-66. 
INTEGRACION REGIONAL; INTEGRACION ECONOMICA; ECONOMIA INTERNACIONAL; GRUPO ANDINO; AMERICA DEL SUR; AMERICA LATINA.

02500 Salgado, Germánico. "Discurso pronunciado con motivo de la celebración del día de las Naciones Unidas, en Santiago el día 24 de octubre de 1980", Estudios Intemacionales, No53, año XIV, eneromarzo, 1981, pp. 48-54.

NACIONES UNIDAS; POLITICA MUNDIAL; DISCURSOS; CHILE; AMERICA DEL SUR.

02612 Salgado, Germánico. "El Grupo Andino: problemas y perspectivas", Estudios Intemacionales, №68, año XVII, octubre-diciembre, 1984, pp. 459-492.

GRUPO ANDINO; INTEGRACION ECONOMICA; INTEGRACION REGIONAL; ECONOMIA INTERNACIONAL; AMERICA DEL SUR; PACTO ANDINO.

\section{Sampaio Malan, Pedro}

02416 Sampaio Malan, Pedro. "Las relaciones económicas internacionales del Brasil: notas para una agenda de investigación", Estudios Intemacionales, N241, año XI, enero-marzo, 1978, pp. 51-72.

ECONOMIA INTERNACIONAL; BRASIL; AMERICA DEL SUR; RELACIONES ECONOMICAS INTERNACIONALES.

\section{Sánchez, Vicente}

02516 Urquidi, Víctor L.; Sánchez, Vicente; Terrazas, Eduardo. "Perspectivas y alternativas de América Latina ante los problemas mundiales", Estudios Intemacionales, №56, año XIV, octubre-diciembre, 1981, pp. 447-473.

AMERICA LATINA; POLITICA MUNDIAL; SOCIEDAD; ECONOMIA INTERNACIONAL; CAMBIO SOCIAL.

\section{Sánchez, Waiter}

02349 Muñoz, Heraldo; Sánchez, Walter. "La détente y el sistema internacional", Estudios Intemacionales, N³2, año vil, octubre-diciembre, 1975, pp. 103-122.

POLITICA INTERNACIONAL; POLITICA MUNDIAL; TERCER MUNDO; DISTENSION.

02382 Sánchez, Walter. "El triángulo Washington-Moscú-Pekín y el proceso de distensión Internacional", Estudios internacionales, N³5, año IX; julio-septiembre, 1976 , pp. 65-117.

POLITICA MUNDIAL; ESTADOS UNIDOS; CHINA; POLITICA INTERNACIONAL; AMERICA DEL NORTE; ASIA; URSS; EUROPA DEL ESTE; DISTENSION; SEGURIDAD INTERNACIONAL.

02511 Sánchez, Walter. "Las relaciones internacionales de América Latina: marginalidad y autonomía", Estudios Internacionales, №55, año XrV, julio-septiembre, 1981, pp. 322-356.

POLITIGA INTERNACIONAL; AMERICA LATINA; HISTORIA; RELACIONES EXTERIORES. 


\section{Sanguinetti, Julio María}

02081 Aguilar Mandsley, Andrés; Orrego Vicuña, Francisco; Sanguinetti, Julio María; Wilkey, Malcolm; Freeland, John. "Decisión de la Comisión para la Solución de Controversias entre Chile y Estados Unidos sobre el Caso Letelier Moffit, 11 de enero de 1992"', Estudios Internacionales, №97, año XXV, enero-marzo, 1992, pp: 136-153 //ncluye:opinión separada concurrente del profesor Francisco Orrego Vicuña//.

ESTADOS UNIDOS; AMERICA DEL NORTE; CHILE; AMERICA DEL SUR; CONTROVERSIAS, SOLUCION DE; INDEMNIZACION JUDICIAL; CASOS; DOCUMENTOS; DERECHOS HUMANOS.

\section{Santa Cruz, Hernán}

02621 Santa Cruz, Hernán. "La anticooperación internacional y el retorno de las políticas de poder", Estudios Intemacionales, No69, año XVIII, enero-marzo, 1985, pp. 81-86.

POLITICA MUNDIAL; COOPERACION INTERNACIONAL; PODER.

\section{Saraiva Guerreiro, Ramiro}

02523 Saraiva Guerreiro, Ramiro. "La política latinoamericana del Brasil", Estudios Intemacionales, Ne57, año XV, enero-marzo, 1982, pp. 3-9. BRASIL; AMERICA DEL SUR; POLITICA INTERNACIONAL; AMERICA LATINA; RELACIONES EXTERIORES.

02538 Saraiva Guerreiro, Ramiro. "El mensaje del Brasil en la Conferencia de Cancún", Estudios Internacionales, №59, año XV, julio-septiembre, 1982, pp. 243-246.

BRASIL; AMERICA DEL SUR; DISCURSOS; RELACIONES NORTE SUR; MEXICO; AMERICA DEL NORTE.

\section{Sardenberg, Ronaldo}

02505 Abdenur, Roberto; Sardenberg, Ronaldo. "Notas sobre las relaciones Norte-Sur y el Informe Brandt", Estudios Intemacionales, N254, año XIV, abril-junio, 1981, pp. 166-200.

RELACIONES NORTE SUR; ECONOMIAINTERNACIONAL; POLITICA INTERNACIONAL; RELACIONES EXTERIORES.

Sathyamurthy, T. V:

02270 Sathyamurthy, T. V.:Las relaciones internacionales asiáticas: perspectivas contemporáneas", Estudios Intemacionales, Ne15, año IV, octubre-diciembre, 1970 , pp. 3-41.

ASIA; POLITICA INTERNACIONAL; RELACIONES EXTERIORES.

\section{Schamis, Héctor $\mathbf{E}$.}

02916 Schamis, Héctor E. "Política económica conservadora en América Latina y Europa Occidental: las fuentes políticas de la privatización", 
Estudios Intemacionales, No99, año XXV, julio-septiembre, 1992, pp. 341-364.

AMERICA LATINA; EUROPA OCCIDENTAL; POLITICA ECONOMICA; CHILE; AMERICA DEL SUR; GRAN BRETAÑA; PRIVATIZACIONES.

\section{Schmied, Julie}

01139 Schmied, Julie. "El debate metodológico entre 'clásicos'y 'científicos' en las relaciones internacionales", Estudios Intemacionales, №91, año XXIII, julio-septiembre, 1990 , pp. 408-417. RELACIONES INTERNACIONALES-TEORIA; METODOLOGIA.

\section{Schmitter, Philippe C.}

02337 Schmitter, Philippe C. "La portugalización de Brasil", Estudios Internacionales, Ne19, año $\mathrm{V}$, julio-septiembre, 1972, pp. 3-55. BRASIL; AMERICA DEL SUR; POLITICA Y GOBIERNO; FUERZAS ARMADAS.

00249 Schmitter, Philippe C. "Idealismo; cambio de régimen y cooperación regional: lecciones del Cono Sur de América Latina", Estudios Internacionales, No85, año XXII, enero-marzo, 1989, pp. 78-130.

AMERICA DEL SUR; CONO SUR; COOPERACION REGIONAL; DEMOCRATIZACION; INTEGRACION REGIONAL; INTEGRACION ECONOMICA; TRANSICION DEMOCRATICA.

\section{Segre, Magdalena}

00235 Hirst, Mónica; Segre, Magdalena. "La política exterior de Brasil en 1988: los avances posibles", Estudios Internacionales, №88, año XXII, octubre-diciembre, 1989 , pp. 463-488.

BRASIL; AMERICA DEL SUR; RELACIONES EXTERIORES; POLITICA INTERNACIONAL.

\section{Selcher, Wayne}

02628 Selcher, Wayne. "Relaciones entre Brasil y Argentina en la década del 80: de una cautelosa rivalidad a una competencia amistosa", Estudios Internacionales, N270, año XVII, abril-junio, 1985, pp. 270301.

BRASIL; ARGENTINA; AMERICA DEL SUR; POLITICA INTERNACIONAL; ECONOMIA INTERNACIONAL; RELACIONES BILATERALES; RELACIONES ECONOMICAS INTERNACIONALES.

\section{Sepúlveda, Alberto}

02267 Sepúlveda, Alberto. "El militarismo desarrollista en América Latina", Estudios Intemacionales, N¹5, año IV, octubre-diciembre, 1970, pp. 97-124.

AMERICA LATINA; FUERZAS ARMADAS; SISTEMA POLITICO; MILTTARISMO.

\section{Serbin, Andrés}

00243 Serbin, Andrés. "América Latina y la 'Conexión Europea' del Caribe 
no-hispánico", Estudios Internacionales, No86, año XXII, abril-junio, 1989, pp. 248-276.

AMERICA LATINA; AMERICA CENTRAL Y Y CARIBE; EUROPA; RELACIONES EXTERIORES; POLITICA INTERNACIONAL.

Sewell, John

02419 Sewell, John. "¿Pueden prosperar los países ricos sin que progresen los países pobres?", Estudios Internacionales, N42, año XI, abril-junio, 1978, pp. 39-65.

ECONOMIA INTERNACIONAL; COMERCIO EXTERIOR; RELACIONES NORTE SUR; POLITICA INTERNACIONAL; RELACIONES EXTERIORES.

\section{Sideri, Sandro}

02625 Sideri, Sandro. "Europa y América Latina en la crisis mundial", Estudios: Intemacionales, №70, año XVIII, abril-junio, 1985, pp. 186220.

EUROPA; AMERICA LATINA; ECONOMIA INTERNACIONAL; CRISIS.

\section{Sierralta, Hernán}

02707 Sierralta, Hèrnán. "La estructura de poder del BID", Estudios Internacionales, №82, año XXI, abril-junio, 1988, pp. 141-156.

ECONOMIA INTERNACIONAL; BID; AMERICA LATINA.

\section{Sigmund, Paul E.}

02369 Sigmund, Paul E. "El bloqueo invisible y la caída de Allende", Estudios Internacionales, N226, año VII, abril-junio, 1974, pp. 20-38.

CHILE; AMERICA DEL SUR; POLITICA Y GOBIERNO; ESTADOS UNIDOS; AMERICA DEL NORTE; GOLPES DE ESTADO; INTERVENCION - DERECHO INTERNACIONAL.

\section{Silva Castro, Raúl}

02294 Silva Castro, Raúl. "Juan Egaña, precursor de la integración latinoamericana", Estudios Intemacionales, №7, año II, octubre-diciembre, 1968, pp. 387-405.

INTEGRACION REGIONAL; INTEGRACION ECONOMICA; AMERICA LATINA; HISTORIA; INTEGRACION.

\section{Silva Michelena, José A.}

02360 Silva Michelena, José A. "Tendencias recientes en la política mundial", Estudios Intemacionales, №23, año VI, julio-septiembre, 1973, pp. 3-22.

POLTICA MUNDIAL; AMERICA LATINA.

\section{Silva, Enrique}

02624 Marshall, Isabel; Silva, Enrique; Mardones, José Luis. "Proteccionismo y reestructuración en la industria del cobre: las políticas de los productores", Estudios Internacionales, №69, año XviII, enero-marzo, 1985, pp. 87-109. 
ECONOMIA INTERNACIONAL; COBRE; PROTECCIONISMO; ESTADOS UNIDOS; AMERICA DEL NORTE.

\section{Snow, Peter G.}

02265 Snow, Peter G. "Desarrollo económico y seguridad nacional en el régimen militar argentino", Estudios Intemacionales, $\mathrm{N}^{2} 20$, año V, octubre-diciembre, 1972 , pp. 67-74.

DESARROLLO ECONOMICO; FUERZAS ARMADAS; SEGURIDAD NACIONAL; ARGENTINA; AMERICA DEL SUR.

\section{Soares de Lima, M. Regina.}

02520 Soares de Lima, M. Regina; Hirst, Mónica. "Estados Unidos y América Latina: cerrando una época en descomposición", Estudios Internacionales, N56, año XIV, octubre-diciembre, 1981, pp. 530-552. ESTADOS UNIDOS; AMERICA DEL NORTE; AMERICA LATINA; POLITICAINTERNACIONAL; RELACIONES EXTERIOFES.

\section{Soares, Glaucio Ary Dillon}

02599 Soares, Glaucio Ary Dillon. "El futuro de la democracia en América Latina", Estudios Intemacionales, №66, año XVII, abril-junio, 1984, pp. 202-231.

AMERICA LATINA; DEMOCRACIA; POLITICA Y GOBIERNO.

Spraos, John

02567 Spraos, John. "El deterioro de la relación de intercambio: algunas perspectivas", Estudios Intemacionales, Ne62, año XVI, abril-junio, 1983, pp. 255-280.

ECONOMIA INTERNACIONAL; RELACIONES ECONOMICAS INTERINACIONALES.

\section{Sunkel, Osvaldo}

02316 Sunkel, Osvaldo. "Política nacional de desarrollo y dependencia externa", Estudios Internacionales, No1, año 1, abril, 1967, pp. 43-75. DEPENDENCIA; DESARROLLO ECONOMICO; AMERICA LATINA;:DEPENDENCIA ECONOMICA.

02292 Sunkel, Osvaldo. "La tarea política y teórica del planificador en América Latina", Estudios Intentacionales, Ne8, año II, enero-marzo, 1969, pp. 519-529.

DESARROLLO ECONOMICO; AMERICA LATINA.

02281 Sunkel, Osvaldo. "Esperando a Godot: América Latina ante la nueva administración republicana de los Estados Unidos", Estudios Internacionales, Ne9, año III, abril-junio, 1969, pp. 23-31.

AMERICA LATINA; POLITICA INTERNACIONAL; ESTADOS UNIDOS; DEPENDENCIA; AMERICA DEL NORTE.

02271 Sunkel, Osvaldo. "La Universidad Latinoamericana ante el avance 
científico y técnico; algunas reflexiones", Estudios Internacionales, №13, año IV, abril-junio, 1970, pp. 60-89.

AMERICA LATINA; CIENCIA Y TECNOLOGIA; UNIVERSIDADES.

02261 Sunkel, Osvaldo. "Capitalismo transnacional y desintegración nacional en América Latina", Estiudios Internacionales, No16, año IV, enero-marzo; 1971, p’p. 3-61.

CAPITALISMO; ECONOMIA INTERNACIONAL; POLITICA INTEFNACIONAL; POLITICA MUNDIAL; AMERICA LATINA; DEPENDENCIA; EMPRESAS TRANSNACIONALES.

02327 Sunkel, Osvaldo. "Relaciones económicas entre América Latina y Estados Unidos: comentarios al trabajo de Aníbal Pinto", Estudios Internacionales, №22, año VI, abril-junio, 1973, pp. 32-43.

AMERICA LATINÄ; ESTADOS UNIDOS; DEPENDENCIA; RELACIONES ECONOMICAS; ECONOMIA INTERNACIONAL; AMERICA DEL NORTE; DEPENDENCIA ECONOMICA.

02753 Sunkel, Osvaldo. "El desarrollo de la teoría del desarrollo", Estudios Intemacionales, N40, año X, octubre-diciembre, 1977, pp. 33-46." DESARROLLO ECONOMICO; TEORIA ECONOMICA; ECONOMIA INTERNACIONAL; DEPENDENCIA.

02751 Sunkel, Osvaldo; Fuenzalida, Edmundo. "Capitalismo transnacional y desarrollo nacional", Estudios Intemacionales, №44, año XI, octubre-diciembre, 1978, pp. 3-27.

CAPITALISMO; DESARROLLO ECONOMICO; ECONOMIA INTERNACIONAL; POLITICA INTERNACIONAL; EMPRESAS TRANSNACIONALES.

02483 Sunkel, Osvaldo; Tomassini, Luciano. "La crisis del sistema transnacional y el cambio en las relaciones internacionales de los países en desarrollo", Estudios Intemacionales, №50, año XIII, abril-junio, 1980, pp. 163-207.

ECONOMIA INTERNACIONAL; DESARROLLO ECONOMICO; RELACIONES EXTERIORES; POLITICA INTERNACIONAL; PAISES EN DESARROLLO.

02651 Sunkel, Osvaldo. "Las empresas transnacionales en el capitalismo actual: algunos viejos y nuevos temas de reflexión", Estudios Internacionales, N274, año xIX, abril-junio, 1986, pp. 159-169.

ECONOMIA INTERNACIONAL; EMPRESAS TRANSNACIONALES; CAPITALISMO.

01138 Sunkel, Osvaldo. "Perspectivas democráticas y crisis de desarrollo", Estudios Intemacionales, №91, año XXII, julio-septiembre, 1990, pp. 399-407.

AMERICA LATINA; DEMOCRATIZACION; DESARROLLO SOCIAL; DESARROLLO ECONOMICO.

02084 Sunkel, Osvaldo. "La consolidación de la democracia y del desarrollo en Chile: desafíos y tareas", Estudios Internacionales, No97, año XXV, enero-marzo, 1992, pp. 117-135.

GHILE; AMERICA DEL SUR; DEMOCRACIA; AMERICA LATINA; TRANSICION 
DEMOCRATICA; CONDICIONES ECONOMICAS; DESARROLLO ECONOMICO; POLITICA ECONOMICA; DISCURSOS; POLITICA SOCIAL.

\section{Sweedler, Alan}

02274 Sweedler, Alan. "La política de seguridad de Estados Unidos en la post Guerra Fría", Estudios Intemacionales, No99, año XXV, julioseptiembre, 1992, pp. 405-426.

ESTADOS UNIDOS; AMERICA DEL NORTE; SEGURIDAD; POLITICA MILITAR; GUERRA FRIA; URSS; EUROPA DEL ESTE; POLITICA INTERNACIONAL; ESTRATEGIA.

\section{Tadíc, Bojana}

02283 Tadíc, Bojana. "No-alineación, un vistazo histórico y conceptual", Estudios Intemacionales, №10, año III, julio-septiembre, 1969, pp. 124-143.

POLITICA MUNDIAL; PAISES NO ALINEADOS.

Tavares, María da Çonceiçao

02638 Tavares, María da Çonceiçao. "La recuperación đe la hegemonía norteamericana", Estudios Internacionales, №72, año XVIII, octubrediciembre, 1985, pp. 478-505.

ESTADOS UNIDOS; AMERICA DEL NORTE; PODER; ECONOMIA INTERNACIONAL; POLITICA INTERNACIONAL.

\section{Teitelboin, Sergio}

02324 Teitelboin, Sergio. "Los países del Pacífico Sur y el mar territorial", Estudios Internacionales, №13, año IV, abril-junio, 1970, pp. 38-59. OCEANO PACIFICO; DERECHO DEL MAR.

\section{Tella, Torcuato di}

02631 Tella, Torcuato di. "Los procesos políticos en América Latina", Estudios Intemacionales, №71, año XVIII, julio-septiembre, 1985, pp. 349-369. AMERICA LATINA; POLITICA Y GOBIERNO.

\section{Terrazas, Eduardo}

02516 Urquidi, Víctor L.; Sánchez, Vicente; Terrazas, Eduardo. "Perspectivas y alternativas de América Latina ante los problemas mundiales", Estudios Intemacionales, №56, año XIV, octubre-diciembre, 1981, pp. 447-473.

AMERICA LATINA; POLITICA MUNDIAL; SOCIEDAD; ECONOMIA INTERNACIONAL; CAMBIO SOCIAL.

\section{Thiago Cintra, José}

00245 Thiago Cintra, José. "Conflictos regionales: tendencias en un período de transición", Estudios Internacionales, N85, año XXII, enero-marzo, 1989, pp. 21-41. 
CONFLICTOS; GRANDES POTENCIAS; TERCER MUNDO; RELACIONES NORTE SUR; AMERICA LATINA; POLITICA MUNDIAL.

Thomas, Hugh

02323 Thomas, Hugh. "Cuba: la revolución y sus raices históricas", Estudios Internacionales, №16, año IV, enero-marzo, 1971, pp. 126-157.

CUBA; AMERICA CENTRAL Y CARIBE; REVOLUCIONES.

Thomson, James C.

02296 Thomson, James C. "Vietnam: un caso clásico", Estudios Intemacionales, №7, año II, octubre-diciembre, 1968, pp. 317-331.

VIETNAM; ASIA; ESTADOS UNIDOS; GUERRA; INTERVENCION - DERECHO INTERNACIONAL.

Tironi B., Ernesto

02379 Tironi B., Ernesto. "Las estrategias nacionales de desarrollo y la integración de los países andinos", Estudios Internacionales, N³4, año IX; abril-junio, 1976, pp. 58-102.

DESARROLLO ECONOMICO; INTEGRACION REGIONAL; INTEGRACION ECONOMICA; ECONOMIA INTERNACIONAL; AMERICA DEL SUR.

02397 Tironi B., Ernesto. "La Decisión 24 sobre capitales extranjeros en el Grupo Andino", Estudios Intemacionales, N³8, año X, abril-junio, 1977, pp. 12-26.

INVERSIONES EXTRANJERAS; GRUPO ANDINO; INTEGRACION ECONOMICA; INTEGRACION REGIONAL; AMERICA DEL SUR; PACTO ANDINO.

\section{Tokatlian, Juan Gabrie!}

02682 Pardo, Rodrigo; Tokatlian, Juan Gabriel. "Política internacional, paz interna e interés nacional", Estudios Intemacionales, №80, año XX, octubre-diciembre, 1987, pp. 435-441.

POLITICA INTERNACIONAL; ESTADO; POLITICA Y GOBIERNO; FAZ.

02690 Pardo, Rodrigo; Tokatlian, Juan Gabriel. "Teoría y práctica de las relaciones internacionales: el caso de Colombia", Estudios Intemacionales, N81, año XXI, enero-marzo, 1988, pp. 94-135.

COLOMBIA; AMERICA DEL SUR; RELACIONES INTERNACIONALES; POLITICA INTERNACIONAL; RELACIONES EXTERIORES.

00601 Tokatlian, Juan Gabriel; Pardo, Rodrigo. "Violencia política, paz interna y política internacional", Estudios Internacionales, No90, año XXIII, abril-junio, 1990, pp. 187-220.

VIOLENCIA; COLOMBIA; AMERICA LATINA; POLITICA Y GOBIERNO; PAZ; POLITICA INTERNACIONAL.

01136 Tokatlian, Juan Gabriel; Pardo, Rodrigo. "La teoría de la interde-

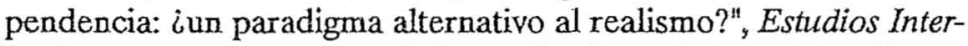
nacionales, Ne91, año XXIII, julio-septiembre, 1990, pp. 339-382. RELACIONES INTERNACIONALES-TEORIA.

01303 Tokatlian, Juan Gabriel; Barrera, Cristina. "Geografía, desarrollo 
regional y política exterior: el caso de la frontera tripartita colombovenezolana-brasileña en la Intendencia del Guainia: una perspectiva desde Colombia", Estudios Intemacionales, №93, año XXIV, eneromarzo, 1991, pp. 53-80.

COLOMBIA; AMERICA DEL SUR; POLITICA INTERNACIONAL; GEOPOLITICA; FRONTERAS; RELACIONES EXTERIORES; BRASIL; VENEZUELA.

\section{Tomassini, Luciano}

02727 Tomassini, Luciano. "La misión imposible del presidente Nixon", Estudios Intemacionales, №12, año III, enero-marzo, 1970, pp. 512543.

ESTADOS UNIDOS; POLITICA MUNDIAL; AMERICA DEL NORTE.

02331 Tomassini, Luciano. "Implicaciones internacionales del deterioro ambiental", Estudios Intemacionales, №18, año V, abril-junio, 1972, pp. 88-118.

MEDIO AMBIENTE; POLITICA MUNDIAL; DESARROLLO ECONOMICO; ECOLOGIA.

02372 Tomassini, Luciano. "Tendencias favorables o adversas a la formación de un sistema regional latinoamericano", Estudios Internacionales, N229, año VIII, enero-marzo, 1975, pp. 3-46.

AMERICA LATINA; INTEGRACION REGIONAL; INTEGRACION ECONOMICA; POLITICA INTERNACIONAL; RELACIONES EXTERIORES.

02412 Tomassini, Luciano. "Falencias y falacias: notas sobre el estudio de las relaciones Norte-Sur", Estudios Internacionales, №40, año X, octubre-diciembre, 1977, pp. 111-130.

NUEVO ORDEN ECONOMICO INTERNACIONAL; AMERICA LATINA; POLITICA INTERNACIONAL; TERCER MUNDO; DIALOGO NORTE SUR; RELACIONES NORTE SUR; RELACIONES EXTERIORES; POLITICA INTERNACIONAL,

02415 Tomassini, Luciano. "Intereses mutuos: las verdaderas bases del Diálogo Norte-Sur", Estudios Internacionales, N41, año XI, eneromarzo, 1978, pp. 27-50.

DIALOGO NORTE SUR; ECONOMIA INTERNACIONAL; RELACIONES NORTE SUR; RELACIONES ECONOMICAS INTERNACIONALES.

02465 Tomassini, Luciano. "El nuevo orden económico internacional: varios enfoques", Estıdios Intemacionales, №46, año XII, abril-junio, 1979, pp. 204-219.

NUEVO ORDEN ECONOMICO INTERNACIONAL; POLITICA INTERNACIONAL; ECONOMIA INTERNACIONAL.

02483 Sunkel, Osvaldo; Tomassini, Luciano. "La crisis del sistema transnacional y el cambio en las relaciones internacionales de los países en desarrollo", Estudios Internacionales, Ne50, año XII, abril-junio, 1980, pp. 163-207.

ECONOMIA INTERNACIONAL; DESARROLLO ECONOMICO; RELACIONES EXTERIORES; POLITICA INTERNACIONAL; PAISES EN DESARROLLO. 
02496 Tomassini, Luciano. "Los estudios internacionales en América Latina: algunas contribuciones", Estudios Internacionales, №52, año XIII, octubre-diciembre, 1980, pp. 545-552.

AMERICA LATINA; RELACIONES INTERNACIONALES - ESTUDIO Y ENSEÑANZA.

02530 Tomassini, Luciano. "Interdependencia y desarrollo nacional", Estudios Internacionales, №58, año XV, abril-junio 1982, pp. 166-189. AMERICA LATINA; POLITICA INTERNACIONAL; DEPENDENCIA; COOPERAGION REGIONAL.

02552 Tomassini, Luciano. "Hacia un sistema latinoamericano de seguridad regional", Estudios Internacionales, N260, año XV, octubre-diciembre, 1982, pp. 533-541.

AMERICA LATINA; SEGURIDAD; SISTEMA INTERAMERICANO; CONFLICTOS; POLITICA INTERNACIONAL; SEGURIDAD REGIONAL.

02573 Tomassini, Luciano. "Las relaciones internacionales de América Latina en los escenarios posibles en el largo plazo", Estudios Intemacionales, №63, año XVI, julio-septiembre, 1983, pp. 350-378.

AMERICA LATINA; POLITICA INTERNACIONAL; POLITICA MUNDIAL; INTEGRACION REGIONAL; RELACIONES EXTERIORES.

02591 Tomassini, Luciano. "El proceso de transnacionalización y las relaciones externas de los países latinoamericanos" Estudios Internacionales, №65, año XVII, enero-marzo, 1984, pp. 16-55.

AMERICA LATINA; POLITICA INTERNACIONAL; POLITICA MUNDIAL; RELACIONES EXTERIORES.

02626 Tomassini, Luciano. "La economía mundial y América Latina: reflexiones sobre el corto y el mediano plazo", Estudios Internacionales, №70, año XVIII, abril-junio, 1985, pp. 221-240.

ECONOMIA INTERNACIONAL; AMERICA LATINA; DESARROLLO ECONOMICO.

02670 Tomassini, Luciano. "Elementos para el análisis de la política exterior", Estudios Intemacionales, №78, año XX, abril-junio, 1987, pp. 1.25-157.

POLITICA INTERNACIONAL; RELACIONES INTERNACIONALES.

02723 Tomassini, Luciano. "Introducción al estudio de las nuevas formas de concertación latinoamericana", Estudios Internacionales, №83, año XXI, julio-septiembre, 1988, pp. 310-326.

AMERICA LATINA; CONCERTACION POLITICA; INTEGRACION REGIONAL; GRUPO DE LOS OCHO; GRUPO CONTADORA.

02722 Tomassini, Luciano. "El análisis de la política exterior", Estudios Internacionales, №84, año XXI, octubre-diciembre, 1988, pp. 498-559. AMERICA LATINA; POLITICA INTERNACIONAL; RELACIONES EXTERIORES.

01135 Tomassini, Luciano. "La política internacional después del muro", Estudios Internacionales, №91, año XXII, julio-septiembre, 1990, pp. 281-338. 
RELACIONES INTERNACIONALES-TEORIA; POLITICA INTERNACIONAL; POLITICA MUNDIAL; RELACIONES INTERNACIONALES; ORDEN MUNDIAL.

01132 Tomassini, Luciano. "International Relations Theory: realism, pluralism, globalism", de: Paul R. Viotti y Mark V. Kauppi, Reseña, Estudios Intemacionales, No92, año XXIII, octubre-diciembre, 1990, pp. 538-539//Reseña del libro: "International Relations Theory: realism, pluralism, globalism, Viotti, Paul R. y Mark V. Kauppi//. RESEÑA DE LIBROS.

02083 Tomassini, Luciano. "Desarrollo económico e inserción externa en América Latina: un proyecto elusivo", Estudios Intentacionales, N997, año XXV, enero-marzo, 1992, pp. 73-116.

AMERICA LATINA; DESARROLLO ECONOMICO; POLITICA INTERNACIONAL; RELACIONES EXTERIORES; CRECIMIENTO ECONOMICO; TEORIAECONOMICA; CEPAL.

\section{Torres-Rivas, Edelberto}

02726 Torres-Rivas, Edelberto. "Desarrollo, integración y dependencia en Centroamérica", Estudios Intemacionales, No12, año III, enero-marzo, 1970, pp. 489-511.

DESARROLLO ECONOMICO; INTEGRACION REGIONAL; DEPENDENCIA; AMERICA CENTRAL $Y$ CARIBE; INTEGRACION ECONOMICA.

\section{Toynbee, Arnold}

02291 Toynbee, Arnold. "El estudio de la historia contemporánea", Estudios Intemacionales, No1, año I, abril, 1967, pp. 8-20.

HISTORIA; METODOLOGIA.

\section{Tulchin, Joseph S.}

02493 Tulchin, Joseph S. "Una perspectiva histórica de la política argentina frente al Brasi"", Estudios Internacionales, N²52, año XIII, octubre-diciembre, 1980 , pp. 460-480.

POLITICA INTERNACIONAL; ARGENTINA; BRASIL; AMERICA DEL SUR; RELACIONES EXTERIORES.

02672 Tulchin, Joseph S. "La Guerra de las Malvinas: un conflicto inevitable que nunca debió haber ocurrido", Estudios Internacionales; N278, año XX, abril-junio, 1987, pp. 192-209.

ISLAS MALVINAS; AMERICA DEL SUR; CONFLICTOS; ARGENTINA; SEGURFDAD; ESTRATEGIA; GUERPA.

02721 Tulchin, Joseph S. "Los Estados Unidos y América Latina en la década del 60", Estudios Internacionales, N84, año XXI, octubre-diciembre, 1988 , pp. 462-497.

ESTADOS UNIDOS; AMERICA DEL NORTE; AMERICA LATINA; POLITICA INTERNACIONAL; RELACIOFNES EXTERIORES.

\section{Ullman, Richard}

02484 Ullman, Richard. "Seguridad internacional en los ochenta", Estudios Intemacionales, №50, año XIII, abril-junio, 1980, pp:208-235. 
POLITICA INTERNACIONAL; POLITICA MUNDIAL; SEGURIDAD INTERNACIONAL.

\section{Urquidi, Víctor L.}

02516 Urquidi, Víctor L; Sánchez, Vicente; Terrazas, Eduardo. "Perspectivas y alternativas de América Latina ante los problemas mundiales", Estudios Internacionales, №56, año XIV, octubre-diciembre, 1981, pp. 447-473.

AMERICA LATINA; POLITICA MUNDIAL; SOCIEDAD; ECONOMIA INTERNACIONALi CAMBIO SOCIAL.

02571 Urquidi, Víctor L. "La interdependencia económica global y el cambio social", Estudios Intemacionales, NN262, año XVI, abril-junio, 1983, pp. 330-335.

ECONOMIAINTERNACIONAL; DEPENDENCIA ECONOMICA; CAMBIO SOCIAL.

02581 Urquidi, Vícior L. "La actual depresión internacional y los países en vías de desarrollo", Estudios Intemacionates, №64, año XVI, octubrediciembre, 1983, pp. 523-533.

ECONOMIA INTERNACIONAL; TERCER MUNDO; PAISES EN DESARROLLO; CRISIS.

\section{Uslar Pietri, Arturo}

02388 Uslar Pietri, Arturo. "Lo específico del hombre latinoamericano", Estudios Intemacionales, №36, año IX; septiembre-diciembre, 1976, pp. 74-89.

SOCIEDAD; AMERICA LATINA.

\section{Valdés Subercaseaux, Gabriel}

02398 Valdés Subercaseaux, Gabriel. "Situación del Grupo Andino en el contexto latinoamericano e internacional", Estudios Intemacionales, №38, año X, abril-junio, 1977, pp. 27-46.

GRUPO ANDINO; AMERICA LATINA; POLITICA INTERNACIONAL; INTEGRACION ECONOMICA; INTEGRACION REGIONAL; AMERICA DEL SUR; ECONOMIA INTERNACIONAL.

02461 Valdés Subercaseaux, Gabriel. "Reflexiones sobre el futuro de América Latina", Estudios Intemacionales, №45, año XII, enero-marzo, 1979, pp. 56-67.

AMERICA LATINA; SOCIEDAD; DESARROLLLO ECONOMICO.

\section{Valdivieso Eguiguren, Sergio}

02678 Valdivieso Eguiguren, Sergio. "El tema antártico en las Naciones Unidas", Estudios Internacionales, No79, año XX, julio-septiembre, 1987, pp. 342-351.

ANTARTICA; NACIONES UNIDAS.

\section{Varas, Augusto}

02518 Varas, Augusto. "La reinserción de América Latina en el marco 
estratégico mundial", Estudios Internacionales, №56, año XN, octubre-diciembre, 1981, pp. 500-516.

AMERICA LATINA; SEGURIDAD; ESTRATEGIA; POLITICA MUNDIAL; FUERZAS ARMADAS; ESTADOS UNIDOS; AMERICA DEL NORTE; RELACIONES EXTERIORES; POLITICA INTERNACIONAL.

02592 Varas, Augusto."De la internacionalización a la transnacionalización en América Latina", Estudios Internacionales, №65, año XVII, eneromarzo, 1984, pp. 56-65.

AMERICA LATINA; POLITICA INTERNACIONAL; RELACIONES EXTERIORES.

02664 Varas, Augusto. "De la competencia a la cooperación militar en América Latina", Estudios Intemacionales, №77, año XX, enero-marzo, 1987, pp. 3-18.

FUERZAS ARMADAS; AMERICA LATINA; POLITICA INTERNACIONAL; SEGURIDAD; COOPERACION REGIONAL; POLITICA MILITAR,

02684 Varas, Augusto. "Percepciones estratégicas del Pacífico Sur", Estudios Internacionales, №80, año XX, octubre-diciembre, 1987, pp. 506-519.

SEGURIDAD; ESTRATEGIA; ESTADOS UNIDOS; AMERICA DEL NORTE; URSS; AMERICA LATINA; OCEANO PACIFICO; EUROPA DEL ESTE.

00606 Varas, Augusto. "Jaque a la democracia: terrorismo y anti-terrorismo en las relaciones sociales e internacionales contemporáneas", Estutdios Intermacionales, N N990, año XXIII, abril-junio, 1990, pp. 154-165. TERRORISMO; RELACIONES INTERNACIONALES; DEMOCRACIA.

\section{Vargas Hidalgo, Rafael}

02418 Vargas Hidalgo, Rafael. "Estados Unidos y América Latina bajo la presidencia de Carter", Estudios Intemacionales, N241, año XI, enero-marzo, 1978, pp. 83-119.

ESTADOS UNIDOS; AMERICA LATINA; POLITICA INTERNACIONAL; AMERICA DEL NORTE; RELACIONES EXTERIORES.

\section{Véliz, Claudio}

02284 Véliz, Claudio. "El Instituto de Estudios Internacionales", Estudios Intemacionales, $\mathrm{N}^{2} 1$, año I, abril, 1967, pp. 3-7.

INSTITUTO DE ESTUDIOS INTERNACIONALES; RELACIONES INTERNACIONALES - ESTUDIO Y ENSEÑANZA; CHILE; AMERICA DEL SUR; UNIVERSIDAD DE CHILE.

02755 Véliz, Claudio; García, Antonio; Vernant, Jacques. "El seminario de Arica", Estudios Internacionales, N5, año II, abril-junio, 1968, pp. 138-150.

AMERICA. LATINA; INTEGRACION ECONOMICA; INTEGRACION POLITICA.

02282 Véliz, Claudio. "Centralismo, nacionalismo e integración", Estudios Internacionales, Ne9, año III, abril-junio, 1969, pp. 3-22. INTEGRACION; NACIONALISMO; POLITICA MUNDIAL; HISTORIA.

02260 Véliz, Claudio. "Cambio y continuidad: El Pacto Andino en la histo- 
ria contemporánea", Estudios Internacionales, №16, año IV, eneromarzo, 1971, pp. 62-92.

PACTO ANDINO; AMERICA DEL SUR; INTEGRACION REGIONAL; POLITICA MUNDIAL; HISTORIA.

02407 Véliz, Claudio. "Errores y omisiones: Notas sobre la política exterior de los países de América Latina durante los últimos diez años", Estudios Internacionales, N40, año X, octubre-diciembre, 1977, pp. 5-12.

POLITICA INTERNACIONAL; AMERICA LATINA; RELACIONES EXTERIORES.

02482: Véliz, Claudio. "La tradición centralista en América Latina", Estudios Intemacionales, №50, año XIII, abril-junio, 1980, pp. 151-162. AMERICA LATINA; HISTORIA; POLITICA Y GOBIERNO.

\section{Vernant, Jacques}

02315 Vernant, Jacques. "El mundo, Europa y Francia", Estudios Internacionales, No2, año I, julio, 1967, pp. 123-136.

POLITICA MUNDIAL; EUROPA; FRANCIA.

02755 Véliz, Claudio; García, Antonio; Vernant, Jacques. "El seminario de Arica", Estudios Internacionales, №5, año II, abril-junio, 1968, pp. 138-150.

AMERICA LATINA; INTEGRACION ECONOMICA; INTEGRACION POLITICA.

Vilas, Carlos Maria

02176 Acosta, Mercedes; Vilas, Carlos María. "Santo Domingo y. Checoslovaquia en la Política de Bloques", Estudios Intemacionales, №8, año II, enero-marzo, 1969, pp. 565-576.

EUROPA DEL ESTE; POLITICA MUNDIAL; SOCIALISMO; AMERICA CENTRALY CARIBE; CHECOSLOVAQUIA; POLITICA MILITAR; INTERVENCION - DERECHO INTERNA.CIONAL:

\section{Villagrán Kramer, Francisco}

02362 Villagrán Kramer, Francisco. "Mecanismos de regularización internacional de productos básicos", Estudios Internacionales, №23, año VI, julio-septiembre, 1973, pp. 61-92.

PROOUCTOS BASICOS; COMERCIO EXTERIOR; TERCER MUNDO; ECONOMIA INTERNACIONAL.

\section{Villalba Vera, Jovito}

02191 Claverie Rodríguez, Heliodoro; Echeverría, Pedro Luis; Villalba Vera, Jovito. "El tratado modificado de reciprocidad comercial entre Venezuela y los Estados Unidos", Estudios Internacionales, №19, año V, julio-septiembre, 1972, pp. 91-102.

VENEZUELA; ESTADOS UNIDOS; ECONOMIA INTERNACIONAL; COMERCIO EXTERIOR; TRATADOS; COOPERACION ECONOMICA; RELACIONES ECONOMICAS INTERNACIONALES; AMERICA DEL SUR; AMERICA DEL NORTE. 
Villamil, José J.

02454 Villamil, José J. "El futuro del Caribe: su marco institucional", Estuir: dios Internacionales, №44, año XI, octubre-diciembre, 1978, pp. 28 44.

AMERICA CENTRAL Y CARIBE; POLITICA INTERNACIONAL; ECONOMIA INTERNACIONAL.

Viñas, Angel

02634 Viñas, Angel. "Coordenadas de la política de seguridad española: análisis y sugerencias", Estudios Internacionales, N271, año XVIII, julio-septiembre, 1985, pp. 389-421.

ESPAÑA; EUROPA; SEGURIDAD; POLITICA INTERNACIONAL; OTAN.

Wagner Tizón, Alan

00247 Wagner Tizón, Alan. "Paz, desarme y desarrollo en América del Sur", Estudios Intemacionales, №85, año XXII, enero-marzo, 1989, pp. 3-9. AMERICA DEL SUR; PAZ; DESARME; DESARROLLO.

\section{Waldmann, Peter}

02810 Waldmann, Peter. "Terrorismo y guerrilla: la violencia organizada contra el Estado en Europa y América Latina. Un análisis comparativo", Estudios Intemacionales, N298, año XXV, abril-junio, 1992, pp. 275-313.

TERRORISMO; GUERRILLAS; EUROPA; AMERICA LATINA; VIOLENCIA; NICARAGUA; ALEMANIA REP. FEDERAL.

\section{Walker, Ignacio}

02646 Walker, Ignacio. "Las armas nucleares y el carácter de las relaciones internacionales", Estudios Intemacionales, №73, año XIX, eneromarzo, 1986, pp. 76-97.

POLITICA INTERNACIONAL; ARMAMENTISMO; CONFLICTOS; ARMAS NUCLEARES; RELACIONES EXTERIORES.

Wallis, Víctor

02301 Wallis, Víctor. "La experiencia del Brasil con una política exterior independiente", Estudios Intemacionales, №2, año I, julio, 1967, pp. 189-211.

BRASIL; AMERICA DEL SUR; POLITICA INTERNACIONAL; RELACIONES EXTERIORES.

\section{Ward, Bárbara}

02413 Ward, Bárbara. "Perspectivas históricas del Nuevo Orden Económico Internacional", Estudios Intemacionales, Ne41, año XI, enero-marzo, 1978, pp. 5-15.

NUEVO ORDEN ECONOMICO INTERNACIONAL; ECONOMIA INTERNACIONAL. 
Watkins, Melville $\mathrm{H}$.

02279 Watkins, Melville $\mathrm{H}$. "Canadá: industria y propiedad extranjera", Estudios Internacionales, №10, año III, julio-septiembre, 1969, pp. 144-157.

CANADA; AMERICA DEL NORTE; EMPRESAS TRANGNACIONALES; INVERSIONES EXTRANJERAS.

Wertheim, W. F.

02300 Wertheim, W. F. "Indonesia antes y después del Golpe de Untung", Estudios Internacionales, №3-4, año I, octubre-marzo, 1967-1968, pp. 337-352. INDONESIA; ASIA; POLITICA Y GOBIERNO; GOLPES DE ESTADO.

Wilhelmy, Manfred

02400 Wilhelmy, Manfred. "La política exterior chilena y el Grupo Andino", Estudios Intemacionales, №38, año X, abril-junio, 1977, pp. 67-87. POLITICA INTERINACIONAL; CHILE; AMERICA DEL SUR; GRUPO ANDINO; INTEGRACION REGIONAL; INTEGRACION ECONOMICA; RELACIONES EXTERIORES.

02422 Wilhelmy, Manfred, "La política exterior de Estados Unidos: dinámica interna y nuevos problemas", Estudios Intemacionales, №42, año XI, abril-junio, 1978, pp. 111-134.

POLITICA INTERNACIONAL; ESTADOS UNIDOS; POLITICA Y GOBIERNO; AMERICA DEL NORTE; RELACIONES EXTERIORES.

02474 Wilhelmy, Manfred. "Hacia un análisis de la política exterior chilena contemporánea", Estudios Intemacionales, №48, año XIr, octubre-diciembre, 1979, pp. 440-471.

POLITICA INTERNACIONAL; CHILE; AMERICA DEL SUR; RELACIONES EXTERIORES.

02629 Wilhelmy, Manfred. "¿Es Afganistán un Vietnam para la Unión Soviética?", Estudios Internacionales, №70, año XVIII, abril-junio, 1985, pp. 302-334.

URSS; EUROPA DEL ESTE; AFGANISTAN; ASIA; POLITICA INTERNACIONAL; CONFLICTOS; RELACIONES EXTERIORES; INTERVENCION; DERECHO INTERNACIONAL.

02680 Wilhelmy, Manfred. "La evolución de la multipolaridad", Estudios Internacionales, №79, año XX, julio-septiembre, 1987, pp. 379-401. POLITICA MUNDIAL; ESTADOS UNIDOS; AMERICA DEL NORTE; EUROPA; CHINA; ASIA; JAPON; PAISES NO ALINEADOS.

02683 Wilhelmy, Manfred; Fermandois Huerta, Joaquín. "La Cancillería en la futura política exterior de Chile", Estudios Internacionales, №80, año XX, octubre-diciembre, 1987, pp. 491-505.

CHILE; AMERICA DEL SUR; POLITICA INTERNACIONAL; DIPLOMACIA; MINISTERIO DE RELACIONES EXTERIORES.

01594 Wilhelmy, Manfred. "Los objetivos en la política exterior latinoame- 
ricana", Estudios Internacionales, №94, año XXrv, abril-junio, 1991, pp. 176-193.

CHILE; AMERICA DEL SUR; POLITICA INTERNACIONAL; RELACIONES EXTERIORES.

01852 Gutiérrez Bermedo, Hernán; Wilhelmy, Manfred. "Concepciones latinoamericanas y asiáticas sobre cooperación regional", Estudios Internacionales, Ne96, año 24, octubre-diciembre, 1991, pp. 472-517. AMERICA LATINA; ASIA; COOPERACION REGIONAL; INTEGRACION REGIONAL; DEPENDENCIA; ALALC; ALADI; ACUERDO DE CARTAGENA; SELA; CONCERTACION POLITICA; GRUPO DE RIO; GRUPO CONTADORA; ASEAN.

\section{Wilkey, Malcolm}

02081 Aguilar Mandsley, Andrés; Orrego Vicuña, Francisco; Sanguinetti, Julio María; Wilkey, Malcolm; Freeland, John. "Decisión de la Comisión para la Solución de Controversias entre Chile y Estados Unidos sobre el Caso Letelier Moffit, 11 de enero de 1992, Estudios Internacionales, $\mathrm{N}^{997}$, año XXV, enero-marzo, 1992, pp. 136-153 //Incluye: opinión separada concurrente del profesor Francisco Orrego Vicuña/l.

ESTADOS UNIDOS; AMERICA DEL NORTE; CHILE; AMERICA DEL SUR; CONTROVERSIAS, SOLUCION DE; INDEMNIZACION JUDICIAL; CASOS; DOCUMENTOS; DERECHOS HUMANOS.

Wionczek, Miguel S.

02506 Wionczek, Miguel S. "¿Qué puede hacerse con el Informe Brandt?", Estudios Intemacionales, No54, año XIV, abril-junio, 1981, pp. 201223.

POLITICA INTERNACIONAL; ECONOMIA INTERNACIONAL; RELACIONES NORTE SUR; RELACIONES EXTERIORES.

02558 Wionczek, Miguel S. "El futuro de las relaciones chino-soviéticas y su probable impacto global", Estudios Intemacionales, N61, año XVI, enero-marzo, 1983, pp. 77-89.

CHINA; ASIA; URSS; POLITICA INTERNACIONAL; POLITICAMUNDIAL; EUROPA DEL ESTE; RELACIONES BILATERALES; RELACIONES EXTERIORES.

02611 Wionczek, Miguel S. "Las desventuras de la ALADI: 1980-1983", Estudios Internacionales, №68, año XVII, octubre-diciembre, 1984, pp. 441-458.

INTEGRACION ECONOMICA; INTEGRACION REGIONAL; AMERICA LATINA; ECONOMIA INTERNACIONAL; ALADI.

.02617. Wionczek, Miguel S. "La economía mundial en 1984 y sus perspectivas para el resto de los años ochenta", Estudios Internacionales, №69, año XVIII, enero-marzo, 1985, pp. 3-31.

ECONOMIA INTERNACIONAL; ESTADOS UNIDOS; AMERICA DEL NORTE; EUROPA; TERCER MUNDO; COMERCIO EXTERIOR. 


\section{Younger, Kenneth}

02314 Younger, Kenneth. "El papel de Gran Bretaña en la política internacional", Estudios Internacionales, №2, año I, julio, 1967, pp. 137-155. GRAN BRETAÑA; EUROPA; POLITICA INTERNACIONAL; POLITICA MUNDIAL.

\section{Zegers Santa Cruz, Fernando}

02469 Zegers Santa Cruz, Fernando. "El sistema antártico y la cuestión del aprovechamiento de los recursos en el área", Estudios Intemacionales, Ne47, año XII, julio-septiembre, 1979, pp. 293-321. ANTARTICA; RECURSOS NATURALES.

\section{Zorgbibe, Charles}

02579 Zorgbibe, Charles. "¿Qué seguridad para Africa?: tres imágenes del kaleidoscopio africano", Estudios Intemacionales, №63, año XVI, julio-septiembre, 1983, pp. 498-506. AFRICA; POLITICA INTERNACIONAL; SEGURIDAD. 


\title{
INDICE DE DESCRIPTORES
}

\author{
Estudios Internacionales \\ Nos. $1-99$
}

\begin{abstract}
Para localizar los títulos asociados a los descriptores que a continuación se señalan se ruega remitirse al Indice Secuencial, página 592.
\end{abstract}

\author{
ACTORES POLITICOS \\ 00236 \\ ACUERDO DE CARTAGENA \\ 01852 \\ ACUERDOS \\ 02287,02290 \\ AFGANISTAN \\ 02629 \\ AFRICA
}

$02216,02226,02237,02280,02287,02319,02455,02579,02623$

AGRESION - DERECHO INTERNACIONAL

02453

AGRICULTURA

02220,02394 
ALADI

$01852,02611,02668$

ALALC

01852

ALEMANIA

01130, 01133, 02196, 02217, 02299

ALEMANIA REP. FEDERAL

$02507,02526,02810$

ALIANZA PARA EL PROGRESO

02293, 02649, 02814

AMERICA

00604, 02178

AMERICA CENTRAL

02326

AMERICA CENTRAL Y CARIBE

$00220,00223,00236,00240,00243,00605,01301,01596,02176,02204$, $02221,02318,02323,02325,02454,02527,02578,02607,02613,02615$, 02635, 02666, 02699, 02709, 02726, 02756, 02811, 02915.

\section{AMERICA DEL NORTE}

00242, 00248, 00418, 00602, 01585, 01596, 02079, 02080, 02081, 02183, 02190, 02191, 02192, 02197, 02203, 02213, 02256, 02257, 02264, 02274, 02276, 02279, 02281, 02285, 02327, 02328, 02332, 02333, 02341, 02351, $02354,02369,02373,02380,02382,02391,02392,02393,02409,02410$, $02418,02422,02423,02457,02458,02466,02472,02478,02490,02518$, $02519,02520,02532,02535,02536,02537,02538,02548,02550,02551$, $02561,02584,02587,02594,02601,02607,02617,02619,02620,02624$, $02627,02637,02638,02639,02640,02641,02642,02644,02649,02650$, $02653,02655,02657,02669,02674,02679,02680,02684,02688,02708$, $02721,02727,02748,02752,02811,02814$.

\section{AMERICA DEL SUR}

$00221,00235,00247,00248,00249,01302,01303,01304,01585,01586$, $01593,01594,01.596,01645,01647,01648,01870,01871,01872,02079$, $02081,02082,02084,02191,02193,02205,02211,02214,02239,02260$, $02263,02265,00268,02269,02284,02286,02289,02293,02295,02301$, 02318, 02320, 02329, 02335, 02337, 02342, 02343, 02344, 02356, 02358, $02359,02361,02363,02368,02369,02370,02371,02373,02374,02378$, $02379,02389,02397,02398,02399,02400,02401,02402,02416,02417$, 
$02451,02457,02474,02487,02493,02500,02514,02521,02523,02524$, $02525,02526,02535,02536,02537,02538,02539,02541,02544,02545$, $02546,02547,02556,02557,02576,02577,02585,02586,02598,02606$, $02612,02622,02627,02628,02630,02633,02636,02644,02645,02655$, $02666,02672,02673,02677,02683,02685,02690,02695,02811,02840$, $02914,02916$.

\section{AMERICA LATINA}

00219, 00220, 00222, 00223, 00234, 00238, 00239, 00242, 00243, 00245, 00246, 00417, 00418, 00419, 00600, 00601, 00602, 01127, 01138, 01300, $01304,01305,01585,01586,01593,01595,01596,01647,01852,02080$, $02083,02084,02177,02180,02183,02189,02195,02198,02201,02203$, 02204, 02205, 02210, 02212, 02213, 02215, 02218, 02219, 02223, 02224, $02238,02241,02259,02261,02267,02271,02277,02281,02285,02290$, 02292, 02294, 02316, 02321, 02327, 02328, 02333, 02334, 02335, 02350, 02354, 02357, 02360, 02361, 02365, 02366, 02367, 02372, 02373, 02374, $02375,02376,02378,02381,02383,02385,02386,02387,02388,02389$, $02391,02393,02398,02399,02403,02406,02407,02408,02409,02411$, $02412,02418,02421,02428,02456,02457,02458,02459,02461,02462$, $02463,02464,02466,02467,02470,02472,02473,02476,02477,02478$, $02481,02482,02485,02486,02488,02489,02490,02491,02492,02494$, $02495,02496,02497,02499,02501,02502,02504,02509,02510,02511$, $02512,02515,02516,02518,02519,02520,02522,02523,00530,02531$, $02532,02535,02542,02544,02546,02548,02550,02551,02552,02553$, 02555, 02561, 02562, 02564, 02568, 02569, 02570, 02572, 02573, 02574, $02575,02580,02582,02583,02587,02588,02589,02591,02592,02593$, $02595,02596,02599,02600,02601,02602,02604,02605,02609,02610$, $02611,02613,02614,02616,02618,02619,02620,02623,02625,02626$, $02627,02631,02632,02637,02641,02647,02649,02650,02654,02656$, $02658,02662,02663,02664,02665,02666,02668,02669,02671,02675$, 02676, 02681, 02684, 02687, 02688, 02691, 02699, 02707, 02708, 02710, $02711,02712,02719,02720,02721,02722,02723,02724,02725,02728$, $02743,02744,02746,02750,02752,02755,02756,02809,02810,02813$, $02814,02913,02916,02917$.

\section{ANTARTICA}

$01129,01851,02469,02494,02513,02554,02673,02678$

\section{ANTILLAS NEERLANDESAS}

02756

\section{ARGENTINA}

$00248,01593,02263,02265,02295,02329,02356,02373,02378,02493$, 
$02524,02525,02535,02537,02544,02545,02586,02598,02606, .02622$, $02628,02672,02695$.

\section{ARMAMENTISMO}

$\therefore 02215,02298,02590,02646,02665,02666,02685$.

\section{ARMAS NUCLEARES}

02417,02646

\section{ASEAN}

$01126,01644,01645,01852,02082,02531,02689$

ASIA

$00219,00234,00418,01126,01645,01852,02080,02082,02175,02182$, $02194,02206,02207,02208,02216,02225,02242,02270,02296,02297$, $02300,02351,02382,02452,02558,02559,02623,02629,02680,02688$, 02691,02752 .

ASIA PACIFICO

00234, 02082

AUSTRALIA

02181, 02200, 02329, 02395

AUTORITARISMO

00221,02616

BANCOS

02747

BANCOS REGIONALES DE DESARROLLO

02426, 002553

BEAGLE

02606

BELLO, ANDRES

02744

\section{BIBLIOGRAFIA}

00604, 01133, 01140, 01595, 01644, 01873, 02710, 02809, 02911.

BID

02325,02707

\section{BIOGRAFIAS}

02344 
BOLIVIA

02268,02363

BRASIL

$00235,01303,01593,01645,02301,02320,02337,02361,02373,02374$, $02416,02417,02457,02487,02493,02521,02523,02524,02525,02526$, $02536,02538,02546,02547,02556,02557,02576,02577,02585,02627$, $02628,02630,02645,02677,02685,02695$.

\section{CAMBIO SOCIAL}

$02278,02516,02571$

CANADA

$02190,02279,02333$

\section{CAPITALISMO}

$02202,02261,02429,02562,02651,02751$

CASOS

02081

CEPAL

$02083,02321,02330,02361,02588,02589,02602$

\section{CHECOSLOVAQUIA}

02176

\section{CHILE}

$00221,01304,01594,01645,01647,01648,01870,01871,01872,02079$, $02081,02082,02084,02211,02239,02284,02289,02293,02335,02342$, 02344, 02358, 02359, 02368, 02369, 02370, 02371, 02400, 02401, 02474, $02500,02539,02541,02606,02673,02683,02811,02840,02916$.

\section{CHINA}

$01648,02182,02207,02208,02225,02382,02558,02559,02680$

\section{CIENCIA Y TECNOLOGIA}

02190, 02223, 02271, 02353, 02366, 02377, 02378, 02386, 02425, 02480, $02560,02658,02659,02660,02661,02662,02712$.

\section{CIENCIAS SOCLALES}

02387, 02749

\section{CLI}

01646

\section{CLASES SOCIALES}

00415 
CLUB DE ROMA 02383

COBRE

$02188,02289,02358,02624$.

COLOMBIA

00601, 01303, 02214, 02402, 02451, 02636, 02690.

COMERCIO EXTERIOR

00219, 00237, 00416, 02080, 02082, 02191, 02192, 02198, 02266, 02317, 02362, 02396, 02419, 02471, 02508, 02534, 02557, 02565, 02566, .02617, $02641,02642,02711$.

COMERCIO INTERNACIONAL

01127

COMUNICACIONES

02189

COMUNIDAD ECONOMICA. EUROPEA

00222, 00416, 01126, 02192, 02198, 02475, 02608; 02609, 02661, 02676, 02688 .

COMUNIDADES EUROPEAS

$00222,01305,02509,02745,02812$

CONCERTACION POLITICA

$00223,00242,01852,02614,02723,02724,02725,02745,02746$.

CONDICIONES ECONOMICAS

$01586,02084,02185,02268,02406,02421$.

CONDICIONES SOCLALES

01586,02268 .

CONFERENCIAS

$02241,02361$.

CONFLICTOS

$00245,02194,02206,02351,02515,02524,02535,02544,02545,02546$, $02547,02548,02550,02552,02606,02615,02629,02630,02635,02646$, $02672,02709,02814$.

CONGO

$02226,02287$. 
CONO SUR

00249

CONSTITUCION

02197

CONTROL DE ARMAMENTOS

02685

CONTROVERSLAS, SOLUCIONDE

02081

CONVENIOS

02240

COOPERACION

02285

COOPERACION ECONOMICA

00239, 00419, 01126, 01305, 01645, 02191, 02198, 02329, 02408, 02459, $02515,02531,02676,02754$.

COOPERACION INTERNACIONAL

01656, 02364, 02451, 02497, 02499, 02531, 02595, 02596, 02609, 02621, 02687,02812 .

COOPERACION POLITICA

02812

COOPERACION REGIONAL

$00220,00223,00242,00249,00418,01647,01852,02515,02524,02530$, $02609,02664,02665$.

COOPERACION TECNOLOGICA

$00419,02425$.

COREA, REPUBLICA DE

02691

CORPORACION ANDINA DE FOMENTO

02240

CRECIMIENTTO ECONOMICO

$01127,02083,02917$.

CRISIS

02193, 02199, 02202, 02280, 02370, 02427, 02517, 02540, 02562, 02563, $02564,02572,02581,02582,02588,02589,02623,02625,02633,02729$. 
CUBA

$02323,02527,02811,02915$.

CUENCA DEL PACIFICO

$00234,00239,01644,01645,01647,01872,02080,02082$.

CUENCA DEL PLATA

02515

CULTURA

$02182,02207,02208,02428,02541$.

CULTURA POLITICA

02189

\section{DELIMITACION MARITIMA}

01646

\section{DEMOCRACIA}

$00600,00606,01585,01586,02080,02084,02269,02599,02604,02632$, 02679,02695 .

\section{DEMOCRATIZACION}

00221, 00242, 00249, 00417, 01138, 01586, 01593, 01595, 02616, 02687, 02915 .

\section{DEPENDENCIA}

$00242,01852,02200,02202,02203,02204,02211,02215,02218,02261$, $02281,02316,02327,02328,02334,02353,02356,02386,02391,02427$, $02429,02456,02530,02607,02726,02753,02813,02814$.

\section{DEPENDENCIA ECONOMICA}

$02204,02316,02327,02328,02429,02527,02571,02593$.

\section{DERECHO COMUNITARIO}

02812

\section{DERECHO DEL MAR}

00244, 01646, 01851, 02272, 02324, 02468, 02512, 02543, 02603.

\section{DERECHO ESPACIAL}

02659

\section{DERECHO INTERNACIONAL}

$01301,01646,01656,01851,01873,02262,02358,02453,02468,02513$, $02659,02911,02912$. . 


\section{DERECHOS HUMANOS}

02081, 02575, 02600, 02679.

\section{DESARME}

$00247,02666$.

\section{DESARROLLO}

$00247,02223,02671$.

\section{DESARROLLO ECONOMICO}

00417, 01138, 01645, 01869, 02083, 02084, 02180, 02204, 02214, 02218, 02220, 02225, 02258, 02259, 02265, 02268, 02285, 02292, 02293, 02316, $02322,02331,02338,02361,02366,02367,02377,02379,02380,02385$, $02386,02404,02405,02406,02411,02420,02421,02426,02428,02451$, $02461,02467,02470,02479,02480,02483,02486,02507,02510,02539$, $02559,02602,02626,02718,02726,02743,02751,02753$.

\section{DESARROLLO SOCIAL}

$00417,01138,02259,02915$.

\section{DESARROLLO SUSTENTABLE} 02917

\section{DESARROLLO TECNOLOGICO} 02353

\section{DEUDA EXTERNA}

$00237,02080,02539,02568,02569,02570,02574,02580,02582,02583$, $02585,02586,02587,02588,02589,02604,02644,02647,02675,02711$, $02712,02746,02915$.

\section{DIALOGO NORTE SUR}

$02412,02414,02415,02462,02467,02750$.

\section{DIPLOMACIA}

$01656,02683$.

\section{DISCURSOS}

$01871,02084,02239,02276,02286,02325,02330,02332,02342,02359$, $02389,02402,02500,02538$.

\section{DISTENSION}

$02349,02382,02504,02517$.

\section{DOCUMENTOS}

$02081,02239,02240,02241,02263,02264,02275,2276,02285,02286$, $02287,02288,02289,02290,02325,02330,02332,02342,02359,02361$, 
$02371,02376,02383,02389,02394,02401,02402,02403,02509,02588$, $02589,02602,02712$.

\section{DROGAS}

$00602,00604,02080$.

\section{ECOLOGIA}

$02331,02338,02367,02481$.

\section{ECONOMIA}

02749

\section{ECONOMIA INTERNACIONAL}

$00416,01305,01645,01869,02183,02191,02192,02198,02199,02202$, 02203, 02238, 02258, 02261, 02262, 02317, 02318, 02319, 02321, 02327, $02328,02352,02354,02355,02362,02364,02377,02379,02383,02385$, $02390,02398,02399,02403,02404,02406,02413,02414,02415,02416$, $02419,02420,02421,02426,02429,02454,02455,02458,02459,02460$, $02464,02465,02466,02467,02470,02471,02476,02477,02483,02486$, $02487,02492,02501,02503,02505,02506,02507,02508,02509,02514$, $02516,02527,02528,02531,02532,02533,02534,02540,02553,02557$, $02562,02563,02564,02565,02566,02567,02568,02569,02570,02571$, $02572,02574,02580,02581,02582,02583,02584,02585 ;$; 02586, 02587, $02588,02589,02593,02596,02597,02601,02602,02604,02610,02611$, $.02612,02613,02617,02624,02625,02626,02627,02628,02638,02639$, $02640,02641,02642,02644,02645,02647,02648,02650,02651,02652$, $02656,02658,02663,02675,02676,02688,02691,02707,02711,02712$, $02719,02720,02743,02746,02747,02751,02752,02753,02754,02813$, $02915,02917$.

\section{EDUCACION}

02365,02541 .

EL SALVADOR

02709

\section{ELECCIONES}

\section{4}

\section{EMPRESAS TRANSNACIONALES}

$02188,02200,02203,02205,02261,02277,02279,02287,02317,02336$, $02358,02377,02470,02528,02597,02651,02747,02751$.

\section{ENERGIA}

$02317,02410,02596$. 
ENERGIA NUCLEAR

$02295,02417,02479,02685$.

ESPACIO EXTERIOR

02659

ESPACIOS MARITIMOS

02603

ESPAÑA

$02609,02634$.

ESQUIPULAS

$00240,00605$.

ESTADO

$00417,02218,02682,02917$.

\section{ESTADOS UNIDOS}

$00242,00248,00418,00602,01585,01596,02079,02080,02081,02183$, $02190,02191,02192,02197,02203,02213,02256,02257,02274,02276$, $02281,02285,02296,02327,02328,02341,02351,02354,02369,02380$, $02382,02391,02392,02393,02409,02410,02418,02422,02423,02457$, $02458,02466,02472,02478,02490,02518,02519,02520,02532,02535$, $02536,02537,02548,02550,02551,02561,02587,02594,02601,02607$, $02617,02619,02620,02624,02627,02637,02638,02639,02640,02641$, $02642,02644,02649,02650,02653,02655,02657,02669,02679,02680$, $02684,02688,02708,02721,02727,02748,02752,02811,02814$.

\section{ESTRATEGIA}

$02215,02274,02297,02298,02341,02351,02423,02518,02672,02684$, 02815 .

\section{ESTUDIO Y ENSEÑANZA.}

02912

\section{ETICA}

02560

\section{EUROPA}

$00243,00416,01305,02184,02192,02194,02217,02233,02275,02278$, $02299,02314,02315,02340,02424,02475,02491,02497,02507,02521$, $02526,02540,02555,02556,02595,02608,02609,02617,02625,02634$, $02635,02644,02661,02676,02680,02688,02745,02810,02812$. 
EUROPA DEL ESTE

$01300,02176,02185,02222,02256,02274,02382,02558,02629,02684$, 02748.

\section{EUROPA OCCIDENTAL}

$00222,00415,00418,00419,01126,01130,01133,01305,02595,02635$, 02752,02916 .

EXPORTACIONES

02082,02642 .

EYZAGUIRRE, JAIME

02344

FONDOS MARINOS

$00244,02468$.

FORO LATINOAMERICANO

$02376,02383,02403$.

FRANCIA

$02184,02194,02278,02315$.

FREI MONTÁLVA, EDUARDO

02401

FRONTERAS

01303,02671 .

FUERZAS ARMADAS

$00246,01304,02193,02207,02216,02222,02265,2267,02337,02343$, $02381,02424,02490,02518,02622,02664,02729$.

FUTUROLOGLA

02384,02686 .

GATT

$00237,02192,02534,02545,02712$.

GEOPOLITICA

01303

GOLPES DE ESTADO

02300, 02369, 02424, 02914.

GRAN BRETAÑA

02314, 02916. 
GRANDES POTENCIAS

$00245,02082,02280,02423,02517,02526,02657,02748,02752$.

GRUPO ANDINO

$02195,02273,02326,02397,02398,02399,02400,02514,02612$.

GRUPO CONTADORA

$00223,01852,02614,02615,02723$.

GRUPO DE LOS OCHO

$00223,00240,02687,02723,02724,02746$.

GRUPO DE RIO

01852

GUATEMALA

02709

GUERRA

02194, 02242, 02296, 02297, 02672.

GUERRA FRIA

$02237,02274,02504,02517$.

GUERRA MUNDIAL II

00248

GUERRILLA

00604

GUERRILLAS

$02363,02810$.

GUEVARA, ERNESTO CHE

02288

GUYANA

02205

HISTORIA

$02079,02080,02184,02260,02282,02291,02294,02481,02482,02511$, $02513,02607,02637,02748$.

HUNGRIA

02185

IGLESIA CATOLICA

$02320,02371,02674$. 
IMPERIALISMO

02456

INDEMNIZACION JUDICIAL

02081

INDICE

01134, 02909, 02910.

INDONESIA

02300

INDUSTRIALIZACION

$00219,01645,02420$.

INICIATIVA PARA LAS AMERICAS

02079

INSTITUTO DE ESTUDIOS INTERNACIONALES

$01871,01872,02284,02840$.

\section{INTEGRACION}

01593, 02282, 02294, 02394.

\section{INTEGRACION ECONOMICA}

00249, 01585, 01593, 02080, 02195, 02201, 02210, 02219, 02221, 02224, $02238,02263,02264,02266,02273,02277,02290,02294,02318,02326$, $02372,02374,02375,02379,02396,02397,02398,02399,02400,02491$, $02492,02514,02515,02522,02542,02608,02611,02612,02613,02668$, $02689,02725,02726,02745,02755,02917$.

\section{INTEGRACION FRONTERIZA}

00238

\section{INTEGRACION POLITICA}

$01585,02755$.

INTEGRACION REGIONAL

00223, 00236, 00238, 00249, 01645, 01647, 01852, 02080, 02195, 02201, $02210,02219,02221,02224,02238,02260,02273,02294,02318,02326$, $02350,02372,02374,02375,02379,02396,02397,02398,02399,02400$, $02473,02491,02492,02514,02515,02522,02542,02608,02611,02612$, $02614,02668,02671,02689,02723,02724,02725,02726,02744,02745$.

\section{INTERVENCION - DERECHO INTERNACIONAL}

02176, 02197, 02296, 02297, 02369, 02629, 02811, 02814. 
INVERSIONES EXTRANJERAS

00237, 02080, 02082, 02188, 02200, 02279, 02397.

ISLAS DEL PACIFICO

01644

ISLAS MALVINAS

$02535,02544,02545,02546,02547,02548,02550,02551,02614,02622$, 02672 .

ISRAEL

02345

ITALIA

02340

JAMAICA

02325

JAPON

$00234,00418,02080,02082,02452,02680,02688,02752$.

KENIA

02455

KISSINGER, HENRY

02392

LEGISLACION

02468

LIBRE COMERCIO

$02080,02266,02396$.

LIDERES

02811

MAR

02815

MARGINALIDAD

02259

MARXISMO

02182

MEDIO AMBIENTE

$01656,01851,02331,02338,02367,02481$. 
MEDIO ORIENTE 02345

MEDIOS DE COMUNICACION 02211, 02560

METODOLOGIA 01139, 02291, 02913.

MEXICO

$02264,02332,02373,02538,02584,02627,02674$.

MICRONESIA

02341

MILITARISMO

02267, 02729

MINISTERIO DE RELACIONES EXTERIORES 02683

MODERNIZACION 02343

MOVIMIENTOS SOCIALES 02633

NACIONALISMO 02282

NACIONALIZACION $02205,02358$.

NACIONES UNIDAS $02359,02500,02678$.

NEGOCLACIONES 00236, 02460, 02486, 02673.

NEUTRALIDAD

00248

NIC's 00219, 01645, 02082, 02691.

NICARAGUA 02810 


\section{ESTUDIOS INTERNACIONALES}

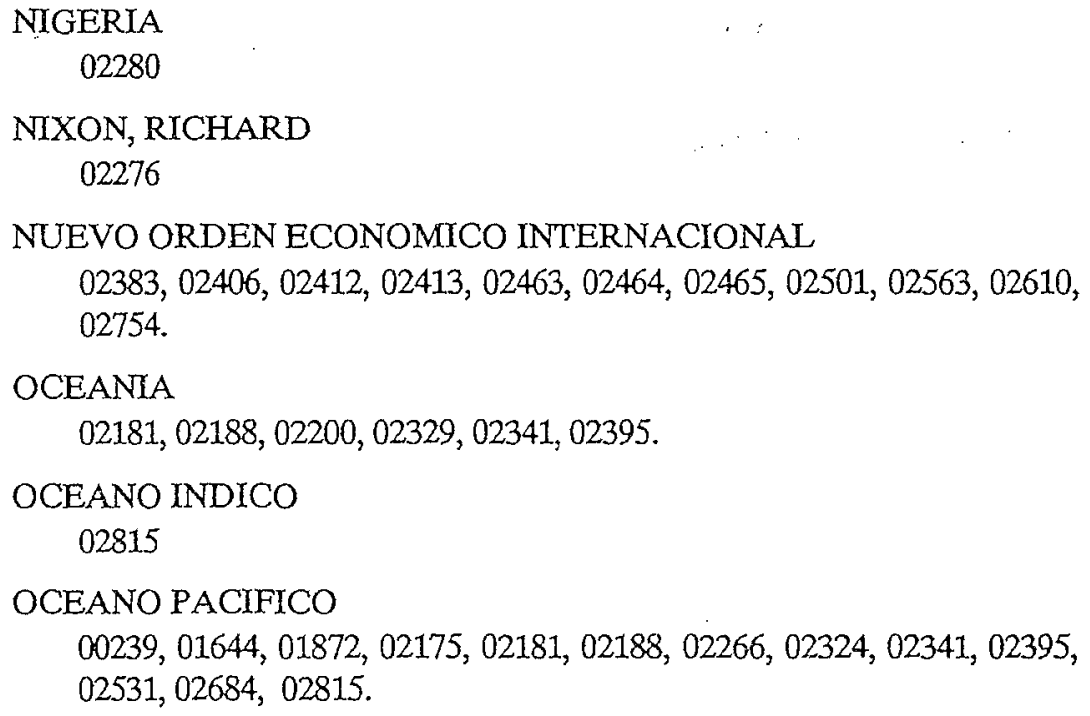


PACTO ANDINO

$02260,02263,02264,02273,02396,02397,02401,02402,02514,02612$, 02614.

PACTO DE VARSOVIA

02275

PAISES ARABES

$02719,02720$.

PAISES DESARROLLADOS

$02471,02663,02712$.

PAISES EN DESARROLLO

$02258,02326,02338,02404,02420,02471,02483,02581,02623$.

PAISES NO ALINEADOS

02187, 02283, 02357, 02680 .

PAPUA NUEVA GUINEA

02188

PARAGUAY

01302

PARLAMENTO EUROPEO

02475

PARTICIPACION POLITICA

02193

PARTIDOS POLITICOS

01304,02555 .

PAZ

$00247,00600,00601,01301,02590,02615,02636,02682$.

PERU

$00600,02193,02286,02335,02343,02633,02666,02729,02914$.

PESCA

$02210,02272$.

PETROLEO

$02317,02364,02410,02427,02596$.

PODER

$02621,02637,02638,02639$. 
PODER LEGISLATIVO

02197

POLITICA

00602

POLITICA ECONOMICA

$02084,02185,02533,02539,02570,02580,02584,02640,02647,02663$, 02675, 02687, 02712, 02915, 02916, 02917.

\section{POLITICA INTERNACIONAL}

00220, 00222, 00235, 00236, 00238, 00243,00601, 01135, 01302; 01303, 01305, 01593, 01594, 01596, 01648, 01869, 01870, 02079, 02083, 02177, 02194, 02196, 02197, 02203, 02206, 02208, 02213, 02217, 02224, 02256, 02257, 02261, 02270, 02274, 02281, 02298, 02299, 02301,02314, 02329, $02333,02339,02340,02345,02349,02372,02373,02374,02380,02382$, $02391,02392,02393,02398,02400,02407,02408,02409,02412,02414$, $02418,02419,02422,02423,02427,02452,02454,02455,02457,02462$, $02463,02464,02465,02472,02474,02478,02483,02484,02487,02489$, $02490,02493,02494,02497,02499,02501,02502,02503,02505,02506$, $02507,02509,02510,02511,02513,02518,02519,02520,02521,02522$, $02523,02524,02525,02526,02527,02530,02531,02535,02536,02537$, $02541,02544,02545,02546,02547,02548,02550,02551,02552,02556$, $02557,02558,02561,02573,02575,02576,02578,02579,02591,02592$, $02594,02595,02596,02598,02600,02601,02605,02606,02607,02618$, $02619,02620,02622,02623,02627,02628,02629,02630,02634,02635$, $02636,02637,02638,02639,02643,02646,02649,02650,02653,02654$, $02655,02656,02657,02661,02662,02664,02665,02666,02670,02677$, $02679,02681,02682,02683,02685,02687,02689,02690,02695,02699$, $02708,02710,02719,02720,02721,02722,02724,02725,02743,02745$, $02750,02751,02752,02756,02809,02811,02812,02813,02814,02815$, 02917.

\section{POLITICA MILITAR}

$02176,02274,02664$.

\section{POLITICA MUNDIAL - INTEGRACION REGIONAL} 02573

\section{POLITICA MUNDIAL}

$00245,00248,01135,01137,01869,02175,02176,02178,02187,02192$, $02219,02233,02237,02260,02261,02280,02282,02283,02288,02298$, $02299,02314,02315,02319,02321,02322,02331,02338,02339,02345$, $02349,02350,02353,02355,02356,02357,02360,02380,02382,02384$, . $02423,02479,02484,02500,02504,02516,02517,02518,02529,02540$, 
$02543,02544,02556,02558,02562,02563,02577,02590,02591,02621$, $02623,02630,02637,02639,02653,02656,02673,02680,02686,02727$, $02748,02752,02815$.

\section{POLITICA SOCIAL}

$02084,02580,02917$.

\section{POLITICA.Y GOBIERNO}

00221, 00601, 01302, 01304, 01596, 01870, 02184, 02189, 02193, 02201, $02216,02269,02300,02335,02337,02343,02363,02368,02369,02370$, $02371,02381,02410,02422,02424,02452,02482,02544,02555,02575$, $02598,02599,02600 ; 02616,02622,02631,02632,02633,02636,02643$, 02654, 02674, 02677, 02682, 02695, 02709, 02729, 02811, 02814, 02914, 02915 .

\section{POPULISMO}

02729

PORTUGAL

02424

\section{PRIVATIZACIONES}

02916

\section{PRODUCTOS BASICOS}

$02336,02362,02364,02427$.

\section{PROTECCION AMBIENTAL}

01129, $01851,02080$.

\section{PROTECCIONISMO}

02624

PUERTO RICO

02607

RECURSOS ENERGETICOS

02596

\section{RECURSOS MARINOS}

02210, 02272, 02468, 02512.

\section{RECURSOS MINERALES}

C0244, 02188, 02468, 02554.

\section{RECURSOS NATURALES}

01129, 02188, 02205, 02210, 02272, 02336, 02469. 
REFORMA AGRARIA

$02212,02286$.

\section{REFORMAS}

01586, 01869, 02185, 02667, 02691, 02915, 02917.

\section{RELACIONES BILATERALES}

00220, 00222, 00248, 01648, 02079, 02080, 02525, 02558, 02606, 02628, 02811.

\section{RELACIONES ECONOMICAS}

$02192,02327,02328$.

\section{RELACIONES ECONOMICAS INTERNACIONALES}

00234, 01126, 01127, 02079, 02082, 02183, 02191, 02192, 02198, 02203, $02328,02354,02390,02415,02416,02458,02459,02460,02466,02503$, $02508,02528,02532,02533,02565,02567,02593,02628,02676,02720$, 02754 .

\section{RELACIONES EXTERIORES}

$00220,00221,00235,00236,00238,00243,00418,01303,01305,01585$, 01594, 01596, 01648, 01869, 01870, 02079, 02080, 02082, 02083, 02194, $02208,02270,02301,02319,02333,02340,02354,02359,02372,02374$, $02383,02391,02393,02400,02407,02408,02409,02412,02414,02418$, $02419,02422,02427,02452,02455,02457,02462,02467,02472,02474$, $02483,02487,02490,02493,02497,02501,02502,02503,02505,02505$, $02511,02518,02519,02520,02521,02522,02523,02524,02526,02527$, $02536,02537,02540,02547,02551,02556,02557,02558,02561,02573$, $02577,02591,02592,02594,02595,02596,02598,02609,02619,02620$, $02627,02629,02644,02646,02650,02652,02655,02677,02690,02699$, $02708,02719,02720,02721,02722,02756,02809,02813$.

\section{RELACIONES INTERNACIONALES}

00606, 01130, 01135, 01137, 01647, 01873, 02186, 02485, 02541, 02670, $02681,02690,02812$.

\section{RELACIONES INTERNACIONALES - ESTUDIO Y ENSEÑANZA} $01140,02186,02284,02430,02485,02488,02495,02496,02813,02840$, $02912,02913$.

\section{RELACIONES INTERNACIONALES - TEORIA}

00241, 01128, 01135, 01136, 01137, 01139, 01140, 02913.

\section{RELACIONES NORTE SUR}

$00245,01869,02390,02412,02414,02415,02419,02458,02460,02462$, 
$02463,02471,02501,02503,02505,02506,02508,02509,02529,02538$, $02565,02652,02718,02719,02750$.

RESEÑA DE LIBROS

$01131,01132$.

REUNIFICACION

$01130,01133$.

REUNION

$02588,02589$.

REUNIONES CUMBRES

$00240,02687$.

REVOLUCIONES

02193, 02207, 02323, 02335.

\section{SEGURIDAD}

01300, 01301, 02213, 02233, 02274, 02297, 02298, 02341, 02423, 02489, $02518,02552,02579,02618,02634,02644,02664,02666,02669,02672$, $02684,02815$.

SEGURIDAD ALIMENTARIA.

$02179,02394$.

SEGURIDAD INTERNACIONAL

01656, 02382, 02484, 02489.

SEGURIDAD NACIONAL

02265

SEGURIDAD REGIONAL

$00246,02552,02605,02655$.

SELA

$01852,02473$.

SISTEMA ELECTORAL 01304

SISTEMA INTERAMERICANO 02213, 02489, 02535, 02546, 02548, 02552, 02667, 02669.

SISTEMA MONETARIO INTERNACIONAL $00237,02199,02352$.

SISTEMA POLITICO

02267 
SOBERANIA 02604

SOCIALDEMOCRACIA

02728

SOCIALISMO

$02176,02182,02185,02559$.

SOCIEDAD

00415, 02259, 02278, 02388, 02461, 02516.

SOCIOLOGLA

02387

TECNOLOGIA $02660,02661$.

TEORIA ECONOMICA $02083,02749,02753$.

TERCER MUNDO

$00245,00418,01869,02187,02226,02349,02357,02362,02380,02408$, $02411,02412,02425,02476,02507,02526,02581,02617,02652,02653$, $02656,02718,02754$.

TERRORISMO

$00600,00604,00605,00606,02810$.

TOMA DE DECISIONES

00236

TRANSFERENCIA DE TECNOLOGIA

02386

TRANSICION DEMOCRATICA

$00221,00249,01302,01304,01586,01593,01595,01596,02084,02643$.

TRATADO ANTARTICO

01851, 02513 .

TRATADO DE TLATELOLCO

$02489,02605,02665$.

TRATADOS

$01300,02191$.

UNCTAD

$02180,02330,02332$. 


\section{UNIVERSIDAD DE CHILE}

$01871,01872,02284$.

UNIVERSIDADES

02271

URSS

02222, 02256, 02274, 02382, 02558, 02629, 02684, 02748.

URUGUAY

01593

VENEZUELA

01303, 02191, 02269, 02318, 02389.

VIETNAM

02194, 02206, 02242, 02296, 02297, 02351.

\section{VIOLENCIA}

$00601,00604,00605,02363,02810$.

ZAMBIA

02289

ZONA ECONOMICA EXCLUSIVA

01646

ZONAS DESNUCLEARIZADAS

$02605,02665$. 


\title{
INDICE SECUENCIAL
}

\author{
Estudios Internacionales \\ Nos. $1-99$
}

00219 Moneta, Carlos J. "Los países asiáticos de ruciente industrialización en la década del 90. Elementos para un debate latinoamericano", Estudios Internacionales, №87, año XXII, julio-septiembre 1989, pp. 279-297.

ASIA; INDUSTRIALIZACION; AMERICA LATINA; COMERCIO EXTERIOR; NIC'S.

00220 Heine, Jorge. "Latinos y antillanos: las relaciones entre América Latina y el Caribe en los noventa", Estudios Internacionales, N887, año XXII, julio-septiembre 1989, pp. 298-307.

AMERICA LATINA; AMERICA CENTRAL Y CARIBE; COOPERACION REGIONAL; RELACIONES BILATERALES; RELACIONES EXTERIORES; POLITICA INTERNACIONAL.

00221 Portales, Carlos. "Los factores externos y el régimen autoritario. Evolución e impacto de las Relaciones Internacionales de Chile en el proceso de transición a la democracia", Estudios Internacionales, Ne87, año XXII, julio-septiembre 1989, pp. 308-341.

CHILE; AMERICA DEL SUR; RELACIONES EXTERIORES; AUTORITARISMO; DEMOCRATIZACION; TRANSICION DEMOCRATICA; POLITICA Y GOBIERNO.

00222 Klaveren, Alberto van. "Las relaciones entre Europa Occidental y América Latina: una profundización esquiva", Estudios Internacionales, Ne87, año XXII, julio-septiembre 1989, pp. 342-364.

AMERICA LATINA; EUROPA OCCIDENTAL; COMUNIDADES EUROPEAS; RELA CIONES BILATERALES; COMUNIDAD ECONOMICA EUROPEA; POLITICA INTERNACIONAL. 
00223 Frohmann, Alicia. "De Contadora al Grupo de los Ocho: el reaprendizaje de la concertación política regional", Estudios Intemacionales, №87, año XXII, julio-septiembre 1989, pp. 365-427.

GRUPO CONTADORA; GRUPO DE LOS OCMO; INTEGRACION REGIONAL; COOPERACION REGIONAL; AMERICA LATINA; AMERICA CENTRAL Y CARIBE; CONCERTACION POLITICA.

00234 Ferrero Costa, Eduardo. "Las relaciones de América Latina con el Japón y otros países asiáticós de la Cuenca del Pacífico", Estudios Intenaacionales, Ne88, año XXI, octubre-diciembre 1989, pp. 439462.

AMERICA LATINA; ASIA; JAPON; CUENCA DEL PACIFICO; RELACIONES ECONOMICAS INTERNACIONALES; ASIA PACIFICO.

00235 Hirst, Mónica; Segre, Magdalena. "La política exterior de Brasil en 1988: los avances posibles", Estudios Intemacionales, No88, año XXII, octubre-diciembre 1989, pp. 463-488.

BRASIL; AMERICA DEL SUR; RELACIONES EXTERIORES; POLITICA INTERNACIONAL.

00236 Eguizábal, Cristina; Rojas Aravena, Francisco. "Política exterior, negociación y procesos de decisión en Centroamérica: elementos para una aproximación", Estudios Intemacionales, №88, año XXII, octubre-diciembre 1989, pp. 489-513.

AMERICA CENTRAL Y CARIBE; RELACIONES EXTERIORES; ACTORES POLITICOS; INTEGRACION REGIONAL; POLITICA INTERNACIONAL; NEGOCIACIONES; TOMA DE DECISIONES.

00237. Ebenroth, Carsten Thomas. "Internacionalización de la economía. Instituciones concurrentes, manejo de deuda externa e inversiones extranjeras", Estudios Intemacionales, №88, año XXI, octubre-diciembre 1989, pp. 514-558.

COMERCIO EXTERIOR; GATT; SISTEMA MONETARIO INTERNACIONAL; IN. VERSIONES EXTRANJERAS; DEUDA EXTERNA.

00238 Bernal Meza, Raúl. "El rol de las regiones en la política exterior: su potencial de articulación con los países limitrofes", Estudios Intemacionales, №88, año XXII, octubre-diciembre 1989, pp. 559-587.

AMERICA LATINA; INTEGRACION FRONTERIZA; INTEGRACION REGIONAL; RELACIONES EXTERIORES; POLITICA INTERNACIONAL.

00239 Orrego Vicuña, Francisco. "La cooperación en el Pacífico: una perspectiva desde América Latina", Estudios Intemacionales, N86, año XXII, abril-junio 1989, pp. 131-152.

COOPERACION ECONOMICA; CUENCA DEL PACIFICO; AMERICA LATINA; OCEANO PACIFICO.

00240 Rojas Aravena, Francisco. "El proceso de Esquipulas: el desarrollo 
conceptual y los mecanismos operativos", Estudios Internacionales, No86, año XXIT, abril-junio 1989, pp. 224-247.

ESQUIPULAS; AMERICA CENTRAL Y CARIBE; REUNIONES CUMBRES; GRUPO DELOS OCHO.

00241 Arenal, Celestino del. "La teoría de las relaciones internacionales hoy: debates y paradigmas", Estudios Internacionales, №86, año XXI, abril-junio 1989, pp. 153-182.

RELACIONES INTERNACIONALES - TEORIA.

00242 Karl, Terry Lynn. "Hegemonías y empresarios políticos: dependencia, democratización y cooperación en las Américas", Estudios Internacionales, №86, año XXII, abril-junio 1989, pp. 183-223.

COOPERACION REGIONAL; DEMOCRATIZACION; AMERICA LATINA; AMERICA DEL NORTE; CONCERTACION POLITICA; ESTADOS UNIDOS; DEPENDENCIA.

00243 Serbin, Andrés. "América Latina y la 'Conexión Europea' del Caribe no-hispánico", Estudios Intemacionales, Ne86, año XXI, abril-junio 1989, pp. 248-276.

AMERICA LATINA; AMERICA CENTRAL Y CARIBE; EUROPA; RELACIONES EXTERIORES; POLITICA INTERNACIONAL.

00244 Orrego Vicuña, Francisco. "El régimen de los minerales de los fondos marinos: términos y condiciones de una renegociación", Estudios Intemacionales, №85, año XXII, enero-marzo 1989, pp. 42-52. FONDOS MARINOS; DERECHO DEL MAR; RECURSOS MINERALES.

00245 Thiago Cintra, José. "Conflictos regionales: tendencias en un período de transición", Estudios Intemacionales, N285, año XXII, enero-marzo 1989, pp. 21-41.

CONFLICTOS; GRANDES POTENCIAS; TERCER MUUNDO; RELACIONES NORTE SUR; AMERICA LATINA; POLITICA MUNDIAL.

00246 Portales, Carlos. "Seguridad compartida en América Latina: desafío del siglo XXI", Estudios Intemacionales, N285, año XXII, enero-marzo 1989, pp. 10-20.

SEGURIDAD REGIONAL; AMERICA LATINA; FUERZAS ARMADAS.

00247 Wagner Tizón, Alan. "Paz, desarme y desarrollo en América del Sur", Estudios Intemacionales, NNe85, año XXI, enero-marzo 1989, pp. 3-9.

AMERICA DEL SUR; PAZ; DESARME; DESARROLLO.

00248 Diéguez M., María Isabel. "La neutralidad de Argentina durante la Segunda Guerra Mundial", Estudios Internacionales, Ne85, año XXII, enero-marzo 1989, pp. 53-77.

ARGENTINA; AMERICA DEL SUR; GUERRA MUNDIAL $\|_{j}$ ESTADOS UNIDOS; 
AMERICA DEL NORTE; RELACIONES BILATERALES; NEUTRALIDAD; POLITICA MUNDIAL.

$\because \because \cdots$

00249 Schmitter, Philippe C. "Idealismo, cambio de régimen y cooperación regional: lecciones del Cono Sur de América Latina", Estudios Internacionales, N285, año XXII, enero-marzo 1989, pp. 78-130.

AMERICA DEL SUR; CONO SUR; COOPERACION REGIONAL; DEMOCRATIZACION; INTEGRACION REGIONAL; INTEGRACION ECONOMICA; TRANSICION DEMOCRATICA.

00415 Giner, Salvador; Moreno, Luis. "La sociedad civil en Europa Occidental", Estudios Internacionales, №89, año XXIII, enero-marzo 1990 , pp. 3-20.

EUROPA OCCIDENTAL; CLASES SOCIALES; SOCIEDAD.

00416 Lipietz, Alain. "Hacia una nueva inserción de Europa en la economía mundial", Estudios Intemacionales, Ne89, año XXIII, enero-marzo 1990 , pp. $21-44$.

EUROPA; ECONOMIA INTERNACIONAL; COMERCIO EXTERIOR; COMUNIDAD ECONOMICA EUROPEA.

00417 Guimaraes, Roberto P. "El Leviatán acorralado: continuidad y cambio en el papel del Estado en América Latina", Estudios Intemacionales, Ne89, año XXIII, enero-marzo 1990, pp. 45-81.

AMERICA LATINA; ESTADO; DESARROLLO ECONOMICO; DEMOCRATIZACION; DESARROLLO SOCIAL.

00418 Klaveren, Alberto van. "Las relaciones internacionales de América Latina en la década de 1980: cambio y continuidad", Estudios Internacionales, Ne89, año XXIII, enero-marzo 1990, pp. 82-118.

AMERICA LATINA; RELACIONES EXTERIORES; ESTADOS UNIDOS; EUROPA OCCIDENTAL; ASIA; JAPON; AMERICA DEL NORTE; TERCER MUNDO; COOPERACION REGIONAL.

00419 Jaworski C., Helán. "Las políticas de cooperación de Europa Occidental hacia América Latina y sus posibilidades futuras", Estudios Intemacionales, Ne89, año XXII, enero-marzo 1990, pp. 119-140.

AMERICA LATINA; EUROPA OCCIDENTAL; COOPERACION ECONOMICA; COOPERACION TECNOLOGICA.

00600 García-Sayán, Diego. "Terrorismo y pacificación en el Perú", Estudios Internacionales, Ne90, año XXIII, abril-junio 1990, pp. 221-239. TERRORISMO; AMERICA LATINA; PERU; DEMOGRACIA; PAZ.

00601 Tokatlian, Juan Gabriel; Pardo, Rodrigo. "Violencia política, paz interna y política internacional" Estudios Intemacionales, $\mathrm{N}^{\mathrm{N}} \mathrm{g0}$, año XXIII, abril-junio 1990, pp. 187-220.

VIOLENCIA; COLOMBIA; AMERICA LATINA; POLITIGA Y GOBIERNO; PAZ; POLITICA INTERNACIONAL: 
00602 Bustamante, Fernando. "La política de Estados Unidos contra el narcotráfico y su impacto en América Latina", Estudios Internacionales, №90, año XXIII, abril-junio 1990, pp. 240-271.

ESTADOS UNIDOS; AMERICA DEL NORTE; AMERICA LATINA; DROGAS; POLITICA.

00604 Instituto de Estudios Internacionales-Biblioteca. "Bibliografía: Violencia política, terrorismo, guerrilla y narcotráfico en América", Estudios Intemacionales, №90, año XII, abril-junio 1990, pp. 272276.

BIBLIOGRAFIA; TERRORISMO; GUERRILLA; VIOLENCIA; DROGAS; AMERICA,

00605 Rojas Aravena, Francisco. "Violencia política y orden internacional: el terrorismo en Centroamérica", Estıdios Intemacionates, №90, año XXIII, abril-junio 1990, pp. 166-186.

VIOLENCIA; TERRORISMO; AMERICA CENTRAL Y CARIBE; ORDEN MUNDIAL; ESQUIPULAS.

00606 Varas, Augusto. "Jaque a la democracia: terrorismo y anti-terrorismo en las relaciones sociales e internacionales contemporáneas", Estudios Intemacionales, №90, año XXIII, abril-junio 1990, pp. 154-165. TERRORISMO; RELACIONES INTERNACIONALES; DEMOCRACIA.

01126 Mols, Manfred. "Comunidad Europea-Asean: ¿un modelo de cooperación interregional?", Estudios Intenacioilales, N92, año XXIII, octubre-diciembre 1990, pp. 424-443.

ASEAN; ASIA; COMUNIDAD ECONOMICA EUROPEA; EUROPA OCCIDENTAL; COOPERACION ECONOMICA; RELACIONES ECONOMICAS INTERNACIONALES.

01127 García Menéndez, José Ramón. "Estilos de crecimiento económico periférico e inserción de América Latina en el mercado mundial", Estudios Internacionales, №92, año XXIII, octubre-diciembre 1990, pp. 444-463.

AMERICA LATINA; CRECIMIENTO ECONOMICO; COMERCIO INTERNACIONAL; RELACIONES ECONOMICAS INTERNACIONALES.

01128 Moneta, Carlos J. "La teoría de las relaciones internacionales: el realismo y sus límites", Estudios Intemacionales, N992, año XXIII, octubre-diciembre 1990, pp. 464-498.

RELACIONES INTERNACIONALES-TEORIA.

01129 Pinochet de la Barra, Oscar. "Antártica, un continente para el tercer milenio", Estudios Intemacionales, N292, año XXIII, octubre-diciembre 1990, pp. 499-511.

ANTARTICA; RECURSOS NATURALES; PROTECCION AMBIENTAL.

01130 Hofmeister, Wilhelm. "La resolución de la cuestión alemana: su 
dimensión nacional e internacional", Estudios Internacionales, Ne92, año XXIII, octubre-diciembre 1990, pp. 512-531.

EUROPA OCCIDENTAL; ALEMANIA; REUNIFICACION; RELACIONES INTERNACIONALES.

01131 Fermandois Huerta, Joaquín. "Expansion of third world Navies", de: Michael A. Morris (Reseña), Estudios Internacionales, No92, año XXIII, octubre-diciembre 1990,pp. 532-537.

RESEÑA DE LIBROS.

01132 Tomassini, Luciano. "International Relations Theory: realism, pluralism, globalism", de: Paul R. Viotti y Mark V. Kauppi (Reseña). Estudios Internacionales, N292, año XXIII, octubre-diciembre 1990, pp. 538-539.

RESEÑA DE LIBROS.

01133 Instituto de Estudios Internacionales - Biblioteca. "Bibliografía: Alemania 1988-1990", Estudios Internacionales, №92, año XXIII, octubre-diciembre 1990, pp. 540-543.

BIBLIOGRAFIA; ALEMANIA; REUNIFICACION; EUROPA:OCCIDENTAL.

01134 Instituto de Estudios Internacionales - Biblioteca. "Indice Estudios Internacionales, año XXI, Ns. 85-88, 1989", Estudios Internacionales, Ne89, año XXIII, enero-marzo 1990, pp. 141-151. INDICE.

01135 Tomassini, Luciano. "La política internacional después del muro", Estudios Internacionales, No91, año XXIII, julio-septiembre 1990, pp. 281-338.

RELACIONES INTERNACIONALES-TEORIA; POLITICA INTERNACIONAL; POLITICA MUNDIAL; RELACIONES INTERNACIONALES; ORDEN MUNDIAL.

01136 Tokatlian, Juan Gabriel; Pardo, Rodrigo. "La teoría de la interdependencia: iun paradigma alternativo al realismo?", Estudios Internacionales, N.91, año XXIII, julio-septiembre 1990, pp. 339-382. RELACIONES INTERNACIONALES-TEORIA.

01137 Pérez Llana, Carlos. "Los Noventa: una nueva agenda internacional para una nueva década", Estudios Internacionales, Ne91, año XXIII, julio-septiembre 1990, pp. 383-398.

ORDEN MUNDIAL; RELACIONES INTERNACIONALES; POUTICA MUNDIAL; RELACIONES INTERNACIONALES-TEORIA.

01138 Sunkel, Osvaldo. "Perspectivas democráticas y crisis de desarrollo", Estudios Internacionales, Ne91, año XXIII, julio-septiembre 1990, pp. 399-407.

AMERICA LATINA; DEMOCRATIZACION; DESARROLLO SOCIAL; DESARROLLO ECONOMICO. 
01139 Schmied, Julie. "El debate metodológico entre 'clásicos' y 'científicos' en las relaciones internacionales", Estudios Intemacionales, No91, año XXIII, julio-septiembre 1990, pp. 408-417.

RELACIONES INTERNACIONALES-TEORIA; METODOLOGIA.

01140 Instituto de Estudios Internacionales-Biblioteca. "Bibliografía: Teoría y estudio de las relaciones internacionales", Estudios Intemacionales, Nº1, año XXIIr, julio-septiembre 1990, pp. 418-421.

BIBLIOGRAFIA; RELACIONES INTERNACIONALES - ESTUDIO Y ENSEÑANZA; RELACIONES INTERNACIONALES-TEORIA.

01300 Mares, David R. "Escenarios de seguridad en Europa Oriental y América Latina", Estudios Internacionales, No93, año 24, enero-marzo 1991, pp. 19-41.

AMERICA LATINA; EUROPA DEL ESTE; SEGURIDAD; TRATADOS.

01301 Orrego Vicuña, Francisco. "Nuevas modalidades para el restablecimiento de la paz y seguridad en el derecho internacional: el Grupo de Observadores de las Naciones Unidas en Centroamérica", Estudios Intemacionales, N93, año XXIV, enero-marzo 1991, pp. 3-18. AMERICA CENTRAL Y CARIBE; PAZ; ONUCA; SEGURIDAD; DERECHO INTERNACIONAL.

01302 Fernández Estigarribia, José Félix. "Perspectivas de cambio de la política exterior paraguaya", Estudios Intemacionales, No93, año 24, enero-marzo 1991, pp. 42-52.

PARAGUAY; AMERICA DEL SUR; POLITICA INTERNACIONAL; TRANSICION DEMOCRATICA; POLITICA Y GOBIERNO.

01303 Tokatlian, Juan Gabriel; Barrera, Cristina. "Geografía, desarrolio regional y política exterior: el caso de la frontera tripartita colombovenezolana-brasileña en la Intendencia del Guainia: una perspectiva desde Colombia", Estudios Internacionales, NN93, año XXIV, eneromarzo 1991, pp. 53-80.

COLOMBIA; AMERICA DEL SUR; POLITICA INTERNACIONAL; GEOPOLITICA; FRONTERAS; RELACIONES EXTERIORES; BRASIL; VENEZUELA.

01304 Gutiérrez Bermedo, Hernán. "Análisis comparativo del sistema de partidos y las elecciones generales en Chile 1989", Estudios Internacionales, No93, año XXIV, enero-marzo 1991, pp. 81-105.

CHILE; AMERICA DEL SUR; TRANSICION DEMOCRATICA; PARTIDOS POLITICOS; ELECCIONES; SISTEMA ELECTORAL; AMERICA LATINA; FUERZAS ARMADAS; POLITICA Y GOBIERNO.

01305 Heine, Jorge. "¿Cooperación o divergencia? Hacia una nueva agenda en las relaciones europeo-latinoamericanas", Estudios Internacionales, Ne93, año XXIV, enero-marzo 1991, pp. 106-158.

AMERICA LATINA; EUROPA; EUROPA OCCIDENTAL; RELACIONES EXTERIO- 
RES; COMUNIDADES EUROPEAS; COOPERACION ECONOMICA; ECONOMIA INTERNACIONAL; POLITICA INTERNACIONAL.

01585 Caputo, Dante M.; Sábato, Jorge F. "Perspectivas de la integración político-económica continental: la integración de las democracias pobres: oportunidades y peligros", Estudios Internacionales, №94, año XXIV, abril-junio 1991, pp. 194-208.

AMERICA LATINA; ESTADOS UNIDOS; AMERICA DEL NORTE; AMERICA DEL SUR; INTEGRACION POLITICA; INTEGRACION ECONOMICA; RELACIONES EXTERIORES; ESTADOS UNIDOS; AMERICA DEL NORTE; DEMOCRACIA.

01586 Lechner, Norbert. "Condiciones socio-culturales de la transición democrática: a la búsqueda de la comunidad perdida", Estudios Intemacionales, Ne94, año XXIV, abril-junio 1991, pp. 209-228.

TRANSICION DEMOCRATICA; DEMOCRACIA; DEMOCRATIZACION; AMERICA LATINA; AMERICA DEL SUR; REFORMAS; CONDICIONES SOCIALES; CONDICIONES ECONOMICAS.

01593 Nohlen, Dieter; Fernández B., Mario. "Democratización y política exterior: análisis comparado en torno a tres casos: Argentina, Brasil y Uruguay", Estudios Intemacionales, Ne94, año XXIV, abril-junio 1991,pp. 229-259.

ARGENTINA; BRASIL; URUGUAY; AMERICA DEL SUR; POLITICA INTERNACIONAL; DEMOCRATIZACION; TRANSICION DEMOCRATICA; AMERICA LATINA; INTEGRACION; INTEGRACION ECONOMICA.

01594 Wilhelmy, Manfred. "Los objetivos en la política exterior latinoamericana", Estudios Internacionales, No94, año XXIV, abril-junio 1991, pp. 176-193.

CHILE; AMERICA DEL SLR; POLITICA INTERNACIONAL; RELACIONES EXTERIORES.

01595 Instituto de Estudios Internacionales - Biblioteca. "Bibliografía: Transición a la democracia en América Latina", Estudios Intemacionales, №94, año XXIV, abril-junio 1991, pp. 291-295.

BIBLIOGRAFIR; AMERICA LATINA; TRANSICION DEMOCRATICA.

01596 Busso; Anabella. "Estados Unidos y la democratización latinoamericana: los condicionantes externos", Estudios Internacionales, $N^{294}$, año XXIV, abril-junio 1991, pp. 260-289.

ESTADOS UNIDOS; AMERICA DEL NORTE; AMERICA LATINA; DEMOCRATIZACION; AMERICA DEL SUR; RELACIONES EXTERIORES; TRANSICION DEMOCRATICA; POLITICA Y GOBIERNO; POLITICA INTERNACIONAL; AMERICA CENTRAL Y CARIBE.

01644 Instituto de Estudios Internacionales - Biblioteca. "Bibliografía: Cuenca del Pacífico", Estudios Internacionales, N995, año XXIV, julio-septiembre 1991, pp. 419-424. 
BIBLIOGRAFIA; CUENCA DEL'PACIFICO; ISLAS DEL PACIFICO; OCEANO PACIFICO; ASEAN.

01645 Porto de Oliveira, Amaury. "Chile y Brasil: intereses conjuntos en el Pacífico", Estudios Internacionales, Ne95, año XXIV, julio-septiembre 1991, pp. 408-418.

CHILE; BRASIL; AMERICA DEL SUR; CUENCA DEL PACIFICO; ASIA; NIC's; ASEAN; INTEGRACION REGIONAL; DESARROLLO ECONOMICO; COOPERACION ECONOMICA; INDUSTRIALIZACION; ECONOMIA INTERNACIONAL.

01646 Orrego Vicuña, Francisco. "El papel de la Corte Internacional de Justicia y otros tribunales en el desarrollo del derecho de la delimitación marítima", Estudios Intemacionales, Ne95, año XXIV, julioseptiembre 1991, pp. 384-407.

CIJ; DELIMITACION MARITIMA; DERECHO DEL MAR; DERECHO INTERNACIONAL; ZONA ECONOMICA EXCLUSIVA.

01647 Moreno Laval, Celso. "América Latina y la Cuenca del Pacífico: una visión chilena", Estudios Intemacionales, No95, año XXIV, julio-septiembre 1991, pp. 368-383.

AMERICA LATINA; CHILE; AMERICA DEL SUR; CUENCA DEL PACIFICO; RELACIONES INTERNACIONALES; INTEGRACION REGIONAL; COOPERACION REGIONAL.

01648 Matta, Javier Eduardo. "Chile y la República Popular China: 19701990", Estudios Intemacionales, Ne95, año XXIV, julio-septiembre 1991, pp. 347-367.

CHILE; AMERICA DEL SUR; CHINA; RELACIONES BILATERALES; POLITICA INTERNACIONAL; RELACIONES EXTERIORES.

01656 González, Raimundo. "Algunas reflexiones sobre una diplomacia multilateral contemporánea", Estudios Intemacionales, N95, año XXIV, julio-septiembre 1991, pp. 303-346.

DIPLOMACIA; COOPERACION INTERNACIONAL; DERECHO INTERNACIONAL; SEGURIDAD INTERNACIONAL; MEDIO AMBIENTE.

01851 Orrego Vicuña, Francisco. "El proceso de cambios en el derecho internacional de los espacios comunes", Estudios Internacionales, Ne96, año XXIV, octubre-diciembre 1991, pp. 518-537.

DERECHO INTERNACIONAL; DERECHO DEL MAR; ANTARTICA; MEDIO AMBIENTE; PROTECCION AMBIENTAL; TRATADO ANTARTICO.

01852 Gutiérrez Bermedo, Hernán; Wilhelmy, Manfred. "Concepciones latinoamericanas y asiáticas sobre cooperación regional", Estudios Intemacionales, No96, año XXIV, octubre-diciembre 1991, pp. 472517.

AMERICA LATINA; ASIA; COOPERACION REGIONAL; INTEGRACION REGIONAL; DEPENDENCIA; ALALC; ALADI; ACUERDO DE CARTAGENA; SELA; CONCERTACION POLITICA; GRUPO DE RIO; GRUPO CONTADORA; ASEAN. 
01869 Heine, Jorge. "¿Cayó también el Tercer Mundo? El Sur ante el nuevo orden global", Estudios Intemacionales, №96; año XXIV, octubrediciembre 1991, pp. 456-471.

TERCER MUNDO; POLITICA MUNDIAL; REFORMÁS; RELACIONES NORTE SUR; POLITICA INTERNACIONAL; DESARROLLO ECONOMICO; RELACIONES EXTERIORES; ECONOMIA INTERNACIONAL.

01870 Fermandois Huerta, Joaquín. "De una inserción a otra: política exterior de Chile, 1966-1991", Estudios Intemacionales, №6, año XXIV, octubre-diciembre 1991, pp. 433-455.

CHILE; AMERICA DEL SUR; POLITICA INTERNACIONAL; RELACIONES EXTERIORES; POLITICA Y GOBIERNO.

01871 Infante Caffi, María Teresa. "Vigésimo quinto aniversario del Instituto de Estudios Internacionales de la Universidad de Chile", Estudios Intemacionales, №96; año XXIV, octubre-diciembre 1991, pp. 429:432.

INSTITUTO DE ESTUDIOS INTERNACIONALES; UNIVERSIDAD DE CHILE; CHILE; AMERICA DEL SUR; DISCURSOS.

01.872 Cousiño Cousiño, José Antonio: "El Instituto de Estudios Internacionales: 25 años de vinculación con la Cuenca del Pacífico", Estudios Internacionales, N96, año XXIV, octubre-diciembre 1991, pp. 538563.

CHILE; AMERICA DEL SUR; INSTITUTO DE ESTUDIOS INTERNACIONALES; UNIVERSIDAD DE CHILE; CUENCA DEL PACIFICO; OCEANO PACIFICO.

01873 Orrego Vicuña, Francisco. "Bibliografía crítica de la década 19811990: relaciones internacionales y derecho internacional", Estudios Internacionales, N²96, año XXIV, octubre-diciembre 1991, pp. 564 569.

RELACIONES INTERNACIONALES; DERECHO INTERNACIONAL; BIBLIOGRAFIA.

02079 Morandé Lavín, José. "Chile y los Estados Unidos: distanciamiento y aproximaciones", Estudios Internacionales, No97, año XXV, enero$\therefore$ marzo 1992, pp. 3-22.

CHILE; AMERICA DEL SUR; ESTADOS UNIDOS; AMERICA DEL NORTE; RELACION̦ESS BILATERALES; RELACIONES EXTERIORES; RELACIONES ECONOMICAS INTERNACIONALES; HISTORIA; POLITICA INTERNACIONAL; INICIATIVA PARA LAS AMERICAS.

02080 Orrego Vicuña, Francisco. "Las relaciones entre los países de América Latina y los Estados Unidos: límites regionales y entendimientos globales", Estudios Internacionales, $\mathrm{N}^{897}$, año XXV, enero-marzo 1992, pp. 23-40.

AMERICA LATINA; ESTADOS UNIDOS; AMERICA; DEL NORTE; RELACIONES BILATERALES; RELACIONES EXTERIORES; HISTORIA; LIBRE COMERCIO; IN- 
TEGRACION REGIONAL; INTEGRACION ECONOMICA; COMERCIO EXTERIOR; DEUDA EXTERNA; INVERSIONES EXTRANJERAS; CUENCA DELPACIFICO; ASIA; JAPON; DEMOCRACIA; DROGAS; PROTECCION AMBIENTAL.

02081 Aguilar Mandsley, Andrés; Orrego Vicuña, Francisco; Sanguinetti, Julio María; Wilkey, Malcolm; Freeland, John. "Decisión de la Comisión para la Solución de Controversias entre Chile y Estados Unidos sobre el Caso Letelier Moffit, 11 de enero de 1992", Estudios Internacionales, Ne97, año XXV, enero-marzo 1992, pp. 136-153.

ESTADOS UNIDOS; AMERICA DEL NORTE; CHILE; AMERICA DEL SUR; CONTROVERSIAS, SOLUCION DE; INDEMNIZACION JUDICIAL; CASOS; DOCUMENTOS; DERECHOS HUMANOS.

02082 Armanet Armanet, Pilar. "Política de Chile en la Cuenca del Pacífico: perspectivas para la década del noventa", Estudios Internacionales, N97, año XXV, enero-marzo 1992, pp. 41-72.

CHILE; AMERICA DEL SUR; CUENCA DEL PACIFICO; RELACIONES EXTERIORES; RELACIONES ECONOMICAS INTERNACIONALES; NIC'S; ASEAN; ASIA; JAPON; ASIA PACIFICO; COMERCIO EXTERIOR; EXPORTACIONES; INVERSIONES EXTRANJERAS; GRANDES POTENCIAS; ORGANIZACIONES REGIONALES.

02083 Tomassini, Luciano. "Desarrollo económico e inserción externa en América Latina: un proyecto elusivo", Estudios Intemacionales, No97, año XXV, enero-marzo 1992, pp. 73-116.

AMERICA LATINA; DESARROLLO ECONOMICO; POLITICA INTERNACIONAL; RELACIONES EXTERIORES; CRECIMIENTO ECONOMICO; TEORIA ECONOMF CA; CEPAL.

02084 Sunkel, Osvaldo. "La consolidación de la democracia y del desarrollo en Chile: desafíos y tareas", Estudios Intemacionales, N@97, año XXV, enero-marzo 1992, pp. 117-135.

CHILE; AMERICA DEL SLR; DEMOCRACIA; AMERICA LATINA; TRANSICION DEMOCRATICA; CONDICIONES ECONOMICAS; DESARROLLO ECONOMICO; POLITICA ECONOMICA; DISCURSOS; POLITICA SOCIAL.

02175 Aberastury, Marcelo. "Asia Oriental y Meridional y el Pacífico: Inicios de 1972", Estudios Intemacionales, No17, año V, enero-marzo 1972, pp. 3-24.

ASIA; POLITICA MUNDIAL; OCEANO PACIFICO.

02176 Acosta, Mercedes; Vilas, Carlos María. "Santo Domingo y Checoslovaquia en la Política de Bloques", Estudios Internacionales, No8, año II, enero-marzo 1969, pp. 565-576.

EUROPA DEL ESTE; POLITICA MUNDIAL; SOCIALISMO; AMERICA CENTRAL Y CARIBE; CHECOSLOVAQUIA; POLITICA MILITAR; INTERVENCION-DERECHO INTERNACIONAL.

02177 Almeyda, Clodomiro. "La OLAS y la crisis política en América Lati- 
na", Estudios Internacionales, Nº3-4, año I, octubre-marzo 1967-1968, pp. $427-442$.

AMERICA LATINA; POLITICA INTERNACIONAL; OLAS.

02178 Araujo Castro, José Augusto de. "El continente americano dentró de la proḅlemática mundial", Estudios Intemacionales, No20, año V, octubre-diciembre 1972, pp. 3-39.

POLITICA MUNDIAL; AMERICA.

02179 Aziz, Sartaj. "Los verdaderos problemas de la crisis de alimentos", Estidios Internacionales, №30, año VIII, abril-junio 1975, pp. 119130.

SEGURIDAD ALIMENTARIA.

02180 Baltra, Alberto. "América Latina y la Segunda UNCTAD", Estudios Internacionales, №8, año II, enero-marzo 1969, pp. 449-460. AMERICA.LATINA; UNCTAD; DESARROLLO ECONOMICO.

02181 Ball, W. MacMahon. "Australia en el Pacífico", Estudios Internacionales, N220, año V, octubre-diciembre 1972, pp. 40-52.

AUSTRALIA; OCEANIA; OCEANO PACIFICO.

02182 Bambirra, Vania. "La revolución cultural y el marxismo", Estudios Internacionales, №7, año II, octubre-diciembre 1968, pp. 406-416. MARXISMO; SOCIALISMO; ASIA; CHINA; CULTURA.

02183 Bergsten C., Fred. "Relaciones económicas entre Estados Unidos y Latinoamérica: la estructura internacional y algunos enfoques posibles", Estudios Internacionales, №31, año VIII, julio-septiembre 1975, pp. 19-41.

ESTADOS UNIDOS; AMERICA LATINA; ECONOMIA INTERNACIONAL; RELACIONES ECONOMICAS INTERNACIONALES; AMERICA DEL NORTE.

02184 Bernstein, Enrique. "Situación política en víspera de mayo de 1968", Estudios Intemacionales, №19, año V, julio-septiembre 1972, pp. 103-166.

EUROPA; FRANCIA; HISTORIA; POLITICA Y GOBIERNO.

02185 Bognar, Jozsef. "Reforma económica en Hungría", Estudios Internacionales, NQ10, año III, julio-septiembre 1969, pp. 107-123. SOCIALISMO; EUROPADEL ESTE; HUNGRIA; POLITICA ECONOMICA; REFORMAS; CONDICIONES ECONOMICAS.

02186 Bull, Hedley. "Las relaciones internacionales como ocupación académica", Estudios Internacionales, N²8, año VI, octubre-diciembre 1974, pp. 76-93.

RELACIONES INTERNACIONALES; RELACIONES INTERNACIONALES - ESTUDIO Y ENSEÑANZZA. 
02187 Burton, J. W. "No-alineación y política mundial contemporánea", Estudios Intemacionates, №9, año III, abril-junio 1969, pp. 32-47. TERCER MUNDO; POLITICA MUNDIAL; PAISES NO ALINEADOS.

02188 Byth; James. "Niugini: una nueva nación cuprífera én el Pacífico se acerca a su independencia", Estudios Internacionales, №22, año VI, abril-junio 1973, pp. 82-105.

COBRE; RECURSOS NATURALES; OCEANO PACIFICO; EMPRESAS TRANSNACIONALES; RECURSOS MINEFALES; OCEANIA; PAPUA NUEVA GUINEA; INVERSIONES EXTRANJERAS.

02189 Ciria, Alberto. "La comunicación política en América Latina: algunos de sus problemas", Estudios Intemacionales, No8, año II, eneromarzo 1969, pp. 530-542.

AMERICA LATINA; POLITICA Y GOBIERNO; CULTURA POLITICA; COMUNICACIONES.

02190 Clarkson,Stephen. "La intelligentsia satélite: los intelectuales canadienses frente a los Estados Unidos", Estudios Intemacionales, №18, año V, abril-junio 1972, pp. 41-67.

CANADA; ESTADOS UNIDOS; AMERICA DEL NORTE; CIENCIAY TECNOLOGIA.

02191 Claverie Rodríguez, Heliodoro; Echeverría, Pedro Luis; Villalba Vera, Jovito. "El tratado modificado de reciprocidad comercial entre Venezuela y los Estados Unidos", Estudios Internacionales, №19, año V, julio-septiembre 1972, pp. 91-102.

VENEZUELA; ESTADOS UNIDOS; ECONOMIA INTERNACIONAL; COMERCIO EXTERIOR; TRATADOS; COOPERACION ECONOMICA; RELACIONES ECONOMICAS INTERNACIONALES; AMERICA DEL SUR; AMERICA DEL NORTE.

02192 Constantinesco, Leontin. "Las relaciones Estados Unidos-Comunidad Económica Europea en la perspectiva de la Rueda Nixon", Estudios Internacionales, N221, año VI, enero-marzo 1973, pp. 44-54. ESTADOSUNIDOS; COMUNIDAD ECONOMICA EUROPEA; RELACIONES ECO NOMICAS; COMERCIO EXTERIOR; POLITICA MUNDIAL; ECONOMIA INTERNACIONAL; GATT; AMERICA DEL NORTE; RELACIONES ECONOMICAS INTERNACIONALES; EUROPA.

02193 Delgado, Carlos. "Sobre algunos problemas de la participación en la Revolución Peruana", Estudios Intemacionales, N²1, año VI, eneromarzo 1973, pp. 24-43.

PERU; FUERZAS ARMADAS; AMERICA DEL SUR; REVOLUCIONES; POLITICA Y GOBIERNO; CRISIS; PARTICIPACION POLITICA.

02194 Devillers, Philippe. "Francia y la Segunda Guerra del Vietnam", Estudios Internacionales, №6, año II, julio-septiembre 1968, pp. 214-241.

FRANCIA; VIETNAM; CONFLICTOS; EUROPA; POLITICA INTERNACIONAL; ASIA; GUERRA; RELACIONES EXTERIORES. 
02195 Díaz Alejandro, Carlos. "El Grupo Andino en el proceso de integración latinoamericana", Estudios Intemacionales, №6, año II, julioseptiembre 1968, pp. 242-257.

GRUPO ANDINO; INTEGRACION ECONOMICA; AMERICA LATINA; INTEGRACION REGIONAL,

02196 End, Heinrich. "La política exterior del gobierno Kiesinger-Brandt", Estıdios Intemacionales, №7, año II, octubre-diciembre 1968, pp. 358:367.

POLITICA INTERNACIONAL; ALEMANIA.

02197 Faúndez, Julio: "El Presidente de Estados Unidos y ia facultad para hacer la guerra", Estudios Internacionales, №15, año IV, octubre-diciembre 1970, pp. 60-83.

ESTADOS UNIDOS; POLITICA INTERNACIONAL; CONSTITUCION; AMERICA DEL NORTE; PODERLEGISLATIVO; INTERVENCION - DERECHOINTERNACIONAL.

02198 Ferrer, Aldo. "Relaciones económicas entre la Comunidad Económica Europea y América Latina", Estudios Intemacionales, №24, año VI, octubre-diciembre 1973, pp. 3-42.

ECONOMIA INTERNACIONAL; COMUNIDAD ECONOMICA EUROPEA; AMERICA LATINA; COMERCIO EXTERIOR; COOPERACION ECONOMICA; RELACIONES ECONOMICAS INTERNACIONALES.

02199 Ferrer, Aldo. "La crisis del Sistema Monetario Internacional: un enfoque estructuralista", Estudios Internacionales, №30, año VII, abril-junio 1975, pp. 48-99.

ECONOMIA INTERNACIONAL; SISTEMA MONETARIO INTERNACIONAL; CRISIS.

02200 Fogarty, John. "Australia y el problema de las inversiones extranjeras", Estudios Internacionales, N222, año VI, abril-junio 1973, pp. 106-118.

AUSTRALIA; INVERSIONES EXTRANJERAS; DEPENDENCIA; OCEANIA; EMPRESAS TRANSNACIONALES.

02201. Frondizi, Arturo. "El problema nacional de América Latina y ciertos "esquemas de integración regional", Estudios Internacionales, Ne3-4, año İ, octubre-marzo 1967-1968, pp. 285-303.

AMERICA LATINA; INTEGRACION ECONOMICA; INTEGRACION REGIONAL; POLITICA Y GOBIERNO.

02202 Furtado, Celso. "Una interpretación estructuralista de la 'crisis' actual del capitalismo", Estudios Intemacionàles, №30, año VIII, abriljunio 1975, pp. 3-47.

ECONOMIA INTERNACIONAL; CAPITALISMO; DEPENDENCIA; CRISIS.

02203 Furtado, Celso. "La concentración del poder económico en los Esta- 
dos Unidos y sus proyecciones en América Latina", Estudios Internacionales, №3-4, año I, octubre-marzo 1967-1968, pp. 323-336.

ECONOMIA INTERNACIONAL; ESTADOS UNIDOS; AMERICA LATINA; DEPENDENCIA; EMPRESAS TRANSNACIONALES; AMERICA DEL NORTE; RELACIONES ECONOMICAS INTERNACIONALES; POLITICA INTERNACIONAL.

02204 Girvan, Norman. "Teorías de dependencia económica en el Caribe y Latinoamerica: un estudio comparativo", Estudios Internacionales, N²3, año VI, julio-septiembre 1973, pp. 23-60.

AMERICA LATINA; DEPENDENCIA; DESARROLLO ECONOMICO; AMERICA CENTRAL Y CARIBE; DEPENDENCIA ECONOMICA.

02205 Girvan, Norman. "El conflicto de Guyana-Alcan y la nacionalizacióni de Demba", Estudios Internacionales, №19, año V, julio-septiembre 1972, pp. 71-90.

AMERICA LATINA: GUYANA; NACIONALIZACION; RECURSOS NATURALES; EMPRESAS TRANSNACIONALES; AMERICA DEL SUR.

02206 Gittings, John. "Uitimos libros sobre Vietnam", Estudios Intemacionales, №2, año I, julio 1967, pp. 212-226.

VIETNAM; CONFLICTOS; POLITICA INTERNACIONAL; ASIA.

02207 Gittings, John. "El Ejército Popular de Liberación y la Revolución Cultural", Estudios Intemacionales, Ne5, año II, abril-junio 1968, pp. 3-37.

CHINA; ASIA; FUERZAS ARMADAS; CULTURA; REVOLUCIONES.

02208 Gittings, John. "iTiene China una política exterior?", Estudios Internacionales, $\mathrm{N}^{2} 1$, año $\mathrm{l}$, abril 1967, pp. 76-94.

POUTICA INTERNACIONAL; CHINA; ASIA; CULTURA; RELACIONES EXTERIORES.

02210 Luna, Julio. "El desarrollo pesquero y la integración regional", Estudios Internacionales, №14, año IV, julio-septiembre 1970, pp. 133149 .

INTEGRACION REGIONAL; INTEGRACION ECONOMICA; PESCA; AMERICA LATINA; RECURSOS NATURALES; RECURSOS MARINOS.

02211 Mattelart, Marcel. "La dependencia de los medios de comunicación de masas en Chile", Estudios Intemacionales, №13, año IV, abril-junio 1970, pp. 124-154.

DEPENDENCIA; CHILE; AMERICA DEL SUR; MEDIOS DE COMUNICACION.

02212 García, Antonio. "Proceso y frustración de las reformas agrarias en América Latina", Estudios Internacionales, №3-4, año I, octubremarzo 1967-1968, pp. 353-410.

AMERICA LATINA; REFORMA AGRARIA.

02213 Faúndez, Julio. "El sistema interamericano de seguridad en la polí- 
tica exterior de Estados Unidos", Estudios Internacionales, №11, año III, octubre-diciembre 1969, pp. 372-392.

SISTEMA INTERAMERICANO; SEGURIDAD; ESTADOS UNIDOS; AMERICA LATINA; POLITICA INTERNACIONAL; AMERICA DEL NORTE.

02214 Croner, Claes. "Estudios sobre el subdesarrollo colombiano: comentario crítico", Estudios Intemacionales, №14, año IV, julio-septiembre 1970, pp. 117-132.

DESARROLLO ECONOMICO; COLOMBIA; AMERICA DEL SUR.

02215 Joxe, Alain; Cadena, Cecilia. "El armamentismo de los países dependientes: el caso latinoamericano", Estudios Internacionales, №14, año IV, julio-septiembre 1970, pp. 3-81.

ARMAMENTISMO; DEPENDENCIA; AMERICA LATINA; ESTRATEGIA.

02216 Mirski, Gueorgui. "El papel político del ejército de los países en Asia y Africa", Estudios Intemacionales, N213; año IV, abril-junio 1970, pp. 3-20.

FUERZAS ARMADAS; ASIA; AFRICA; POLITICA Y GOBIERNO.

02217 Kaiser, Karl. "Una nueva política oriental en Alemania", Estudios Internacionales, №8, año II, enero-marzo 1969, pp. 543-564. ALEMANIA; EUROPA; POLITICA INTERNACIONAL.

02218 Kaplan, Marcos. "Estado, dependencia externa y desarrollo en América Latina", Estudios Intemacionales, N6, año II, julio-septiembre 1968, pp. 179-213.

ESTADO; DEPENDENCIA; DESARROLLO ECONOMICO; AMERICA LATINA.

02219 Godoy, Horacio H. "La integración de América Latina y el proceso del poder mundial", Estudios Internacionales, N27, año II, octubrediciembre 1968, pp. 368-386.

INTEGRACION REGIONAL; INTEGRACION ECONOMICA; AMERICA LATINA; POLITICA MUNDIAL.

02220 Feder, Ernest. "Desarrollo agrícola y crecimiento económico", Estudios Intemacionales, №7, año II, octubre-diciembre 1968, pp. 417422.

AGRICULTURA; DESARROLLO ECÖNOMICO.

02221 Barraclough, Solon Z. "Integración en América Central", Estudios Internacionales, N5, año II, abril-junio 1968, pp. 151-157.

AMERICA CENTRAL Y CARIBE; INTEGRACION REGIONAL; INTEGRACION ECONOMICA.

02222 Kolkowicz, Roman. "Una herejía santificada: Idea y realidad del Ejército Rojo", Estudios Internacionales, N5, año II, abril-junio 1968, pp. 64-84.

FUERZAS ARMADAS; UASS; EUROPA DEL ESTE: 
02223 Herrera, Amilcar O. "La ciencia en el desarrollo de América Latina", Estudios Intemacionales, N25, año II, abril-junio 1968, pp. 38-63. AMERICA LATINA; CIENCIA Y TECNOLOGIA; DESARROLLO.

02224 Herrera Lane, Felipe. "La tarea inconclusa: América Latina integrada", Estudios Internacionales, N²1, año VI, enero-marzo 1973, pp. 3-23.

INTEGRACION ECONOMICA; INTEGRACION REGIONAL; AMERICA LATINA; POLITICA INTERNACIONAL.

02225 Gurley, John G. "El desarrollo económico de China comunista", Estudios Internacionales, №3-4, año I, octubre-marzo 1967-1968, pp. $304-322$.

DESARROLLO ECONOMICO; CHINA; ASIA.

02226 Gott, Richard. "El Congo a partir de Mobutu", Estudios Internacionales, №3-4; año I, octubre-marzo 1967-1968, pp. 443-489. CONGO; AFRICA; TERCER MUNDO.

02233 Joxe, Alain. "Hacia una nueva concepción de la seguridad europea", Estudios Internacionales, N², año I, julio 1967, pp. 156-188. SEGURIDAD; EUROPA; POLITICA MUNDIAL.

02237 Gott, Richard. "El sur de Africa y el fin de la guerra fría", Estudios Internacionales, No1, año I, abril 1967, pp. 95-109.

AFRICA; GUERRA FRIA; POLITICA MUNDIAL.

02238 Herrera Lane, Felipe. "Viabilidad de una comunidad latinoamericana", Estudios Internacionales, No1, año I, abril 1967, pp. 21-42.

INTEGRACION REGIONAL; INTEGRACION ECONOMICA; AMERICA LATINA; ECONOMIA INTERNACIONAL.

02239 Discurso pronunciado por el Ministro de Relaciones Exteriores de Chile Clodomiro Almeyda M., en el III Período Ordinario de Sesiones de la Asamblea General de la Organización de Estados Americanos. Estudios Intemacionales, N221, año VI, enero-marzo 1973, pp. 84-96.

DOCUMENTOS; DISCURSOS; OEA; CHILE; AMERICA DEL SUR.

02240 Convenio Constitutivo de la Corporación Andina de Fomento. Estudios Internacionales, №6, año Ir, julio-septiembre 1968, pp. 295-312. CORPORACION ANDINA DE FOMENTO; CONVENIOS; DOCUMENTOS.

02241 Parte final de la Declaración General de la Primera Conferencia de la Organización Latinoamericana de Solidaridad, La Habana, agosto 1967. Estudios Internacionales, №3-4, año I, octubre-marzo 19671968, pp. 440-442.

DOCUMENTOS; CONFERENCIAS; AMERICA LATINA; OLAS. 
02242 Gittings, John. "La nueva guerra de Indochina", Estudios Internacionales, №14, año IV, julio-septiembre 1970, pp. 104-116. VIETNAM;ASIA;:GUERRA.

02256 Godoy; Horacio H. "Los acuerdos entre los Estados Unidos y la Unión de las Repúblicas Socialistas Soviéticas", Estudios Internacionales, N228, año VII, octubre-diciembre 1974, pp. 3-48.

ESTADOS UNIDOS; POLITICA INTERNACIONAL; AMERICA DEL NÖRTE; EUROPA DEL ESTE; URSS.

02257 Hoffmann, Stanley. "El estilo norteamericano: su pasado, sus principios", Estudios Intemacionales, №9, año III, abril-junio 1969, pp. 48-62.

ESTADOS UNIDOS; POLITICA INTERNACIONAL; AMERICA DEL NORTE.

02258 Kadar, Bela "Los países pequeños en la economía mundial", Estudios Internacionales, №16, año IV, enero-marzo 1971, pp. 158-188. ECONOMIA INTERNACIONAL; DESARROLLO ECONOMICO; PAISES EN DESARROLLO. $\because \cdots$

02259 Ribeiro, Darcy. "El desafío de la marginalidad", Estudios Intemacionales, N¹6, año IV, enero-marzo 1971, pp. 93-125.

DESARROLLO ECONOMICO; SOCIEDAD; AMERICA LATINA; DESARROLLO SOCIAL; MARGINALIDAD.

02260 Véliz, Claudio. "Cambio y continuidad: El Pacto Andino en la historia contemporánea", Estudios Internacionales, №16, año IV, eneromarzo 1971, pp. 62-92.

PACTO ANDINO; AMERICA DEL SUR; INTEGRACION REGIONAL; POLITICA MUNDIAL; HISTORIA.

02261 Sunkel, Osvaldo. "Capitalismo transnacional y desintegración nacional en América Latina", Estudios Intemacionales, No16, año IV, enero-marzo 1971, pp. 3-61:

CAPITALISMO; ECONOMIA INTERNACIONAL; POLITICAINTERNACIONAL; POLTICA MUNDIAL; AMERICA LATINA; DEPENDENCIA; EMPRESAS.TRANSNACIONALES.

02262 Murphy, Cornelius F. "Coacción económica y tratados desiguales", Estudios Internacionales, №14, año IV, julio-septiembre 1970, pp. 82-103.

DERECHO INTERNACIONAL; ECONOMIA INTERNACIONAL.

02263 Declaración conjunta constitutiva de la Comisión Andino-Argentina, establecida durante el X periodo ordinario de sesiones de la Comisión del Acuerdo de Cartagena, el 17 de noviembre de 1972. 
Estudios Internacionales, №20, año V, octubre-diciembre 1972, pp. 75-77.

INTEGRACION ECONOMICA; DOCUMENTOS; ARGENTINA; PACTO ANDINO; AMERICA DEL SUR.

02264 Comisión Mixta-Andino-Mexicana establecida durante el X período de sesiones ordinarias de la Comisión del Acuerdo de Cartagena, 17 de noviembre de 1972. Estudios Internacionales, Ne20, año V, octubre-diciembre 1972, pp. 78-84.

DOCUMENTOS; INTEGRACION ECONOMICA; MEXICO; PACTO ANDINO; AMERICA DEL NORTE.

02265 Snow, Peter G. "Desarrollo económico y seguridad nacional en el régimen militar argentino", Estudios Internacionales, N²0, año V, octubre-diciembre 1972, pp. 67-74.

DESARROLLO ECONOMICO; FUERZAS ARMADAS; SEGURIDAD NACIONAL; ARGENTINA; AMERICA DEL SUR.

02266 Kojima, Kiyoshi. "Un área de libre comercio del Pacífico", Estudios Intemacionales, №20, año V, octubre-diciembre 1972; pp. 53-66.

COMERCIO EXTERIOR; OCEANO PACIFICO; INTEGRACION ECONOMICA; LIBRE COMERCIO.

02267 Sepúlveda, Alberto. "El militarismo desarrollista en América Latina", Estudios Intemacionales, N¹5, año IV, octubre-diciembre 1970 , pp. 97-124.

AMERICA LATINA; FUERZAS ARMADAS; SISTEMA POLITICO; MILITARISMO.

02268 Kalecki, Michal; Kula, Marcin. "Notas sobre los aspectos sociales y económicos de los 'regímenes intermedios': el caso de Bolivia", Estudios Intemacionales, №15, año IV, octubre-diciembre 1970, pp. 84-96.

BOLIVIA; AMERICA DEL SUR; DESARROLLO ECONOMICO; CONDICIONES SOCIALES; CONDICIONES ECONOMICAS.

02269 Petras, James. "Venezuela: una década de democracia capitalista", Estudios Intemacionales, №15, año IV, octubre-diciembre 1970, pp. 42-59.

VENEZUELA; AMERICA DEL SUR; POLITICA Y GOBIERNO; DEMOCRACIA.

02270 Sathyamurthy, T. V. "Las relaciones internacionales asiáticas: perspectivas contemporáneas", Estudios Internacionales, N¹5, año IV, octubre-diciembre 1970, pp. 3-41.

ASIA; POLITICA INTERNACIONAL; RELACIONES EXTERIORES.

02271 Sunkel, Osvaldo. "La Universidad Latinoamericana ante el avance científico y técnico; algunas reflexiones", Estudios Internacionales, №13, año IV, abril-junio 1970, pp. 60-89.

AMERICA LATINA; CIENCIA Y TECNOLOGIA; UNIVERSIDADES. 
02272 Oldfelt, Carin. "Estudio comparativo sobre zonas pesqueras en el mundo", Estudios Internacionales, N¹3, año IV, abril-junio 1970, pp. 21-37.

PESCA; RECURSOS NATURALES; DERECHO DEL MAR; RECURSOS MARINOS.

02273 Orrego Vicuña, Francisco. "Dilemas en el Grupo Andino", Estudios Internacionales, №11, año III, octubre-diciembre 1969, pp. 352-371. PACTO ANDINO; INTEGRACION ECONOMICA; INTEGRACION REGIONAL; GRUPO ANDINO.

02274 Sweedler, Alan. "La política de seguridad de Estados Unidos en la post Guerra Fría", Estudios Intemacionales №99, año XXV, julioseptiembre 1992, pp. 405-426.

ESTADOS UNIDOS; AMERICA DEL NORTE; SEGURIDAD; POLITICA MILITAR; GUERRA FRIA; URSS; EUROPA DEL ESTE; POLITICAINTERNACIONAL; ESTRATEGIA.

02275 Mensaje de los Estados signatarios del Tratado de Varsovia a los países europeos. Estudios Intemacionales, №10, año III, julio-septiembre 1969, pp. 231-235.

DOCUMENTOS; EUROPA; PACTO DE VARSOVIA.

02276 Discurso del Presidente Nixon en la sesión conmemorativa del Tratado de la Organización del Atlántico Norte", Estudios Internacionales, No10, año III, julio-septiembre 1969, pp. 236-242.

DOCUMENTOS; DISCURSOS; OTAN; NIXON, RICHARD; ESTADOS UNIDOS; AMERICA DEL NORTE.

02277 Kaplan, Marcos. "Corporaciones públicas multinacionales para el desarrollo y la integración", Estudios Intemacionales, №10, año III, julio-septiembre 1969, pp. 186-230.

AMERICA LATINA; INTEGRACION ECONOMICA; EMPRESAS TRANSNACIONALES.

02278 Martins, Luciano. "Mayo de 1968: una revolución nueva e intransitiva", Estudios Intemacionales, №10, año III, julio-septiembre 1969, pp. 158-185.

EUROPA; SOCIEDAD; CAMBIO SOCIAL; FRANCIA.

02279 Watkins, Melville H. "Canadá: industria y propiedad extranjera", Estudios Intemacionales, №10, año III, julio-septiembre 1969, pp. 144-157.

CANADA; AMERICA DEL NORTE; EMPRESAS TRANSNACIONALES; INVERSIONES EXTRANJERAS.

02280 Ortíz, Eduardo. "Las grandes potencias y la crisis de Nigeria", Estudios Internacionales, Ne9, año III, abril-junio 1969, pp. 63-76. POLITICA MUNDIAL; AFRICA; NIGERIA; GRANDES POTENCIAS; CRISIS. 
02281 Sunkel, Osvaldo. "Ësperando a Godot: América Latina ante la nueva administración republicana de los Estados Unidos", Estudios Internacionales, $\mathrm{N}^{29}$, año $\mathrm{II}$, abril-junio 1969, pp. 23-31.

AMERICA LATINA; POLITICA INTERNACIONAL; ESTADOS UNIDOS; DEPENDENCIA; AMERICA DEL NORTE.

02282 Véliz, Claudio. "Centralismo, nacionalismo e integración", Estudios Internacionales, N9, año II, abril-junio 1969, pp. 3-22. INTEGRACION; NACIONALISMO; POLITICA MUNDIAL; HISTORIA.

02283 Tadíc, Bojana. "No-alineación, un vistazo histórico y conceptual", Estudios Internacionales, №10, año III, julio-septiembre 1969, pp. 124-143.

POLITICA MUNDIAL; PAISES NO ALINEADOS.

02284 Véliz, Claudio. "El Instituto de Estudios Internacionales", Estudios Intemacionales, №1, año I, abril 1967, pp. 3-7.

INSTITUTO DE ESTUDIOS INTERNACIONALES; RELACIONES INTERNACIONALES - ESTUDIO Y ENSENNANZA; CHILE; AMERICA DEL SUR; UNIVERSIDAD DE CHILE.

02285 Consenso Latinoamericano de Viña del Mar. Estudios Intennacionales, No11, año III, octubre-diciembre 1969, pp. 403-418.

AMERICA LATINA; COOPERACION; ESTADOS UNIDOS; DOCUMENTOS; AMERICA DEL NORTE; DESARROLLLO ECONOMICO.

02286 Mensaje a la Nación del Presidente de la República del Perú, General Juan Velasco Alvarado sobre la Reforma Agraria; Lima, 24 de junio de 1969. Estudios Internacionales, Ne11, año III, octubre-diciembre 1969, pp. 393-402.

PERU; AMERICA DEL SUR; REFORMA AGRARIA; DOCUMENTOS; DISCURSOS.

02287 El acuerdo entre GECOMIN y la Societé Générale des Minerais, Kinshasa, 15 de febrero de 1967. Estudios Intemacionales, N³-4, año I, octubre-marzo 1967-1968, pp. 485-487.

DOCUMENTOS; ACUERDOS; CONGO; AFRICA; EMPRESAS TRANSNACIONALES.

02288 Carta enviada por Ernesto 'Che' Guevara al Secretario Ejecutivo de la Organización de Solidaridad de los Pueblos de Africa, Asia y América Latina (OSPAAAL); La Habana, abril de 1967. Estudios Internacionales, N22, año I, julio 1967, pp. 272-282. DOCUMENTOS; POLITICA MUNDIAL; GUEVARA, ERNESTO CHE.

02289 Texto de la Declaración Conjunta emitida por los Presidentes de Chile, Don Eduardo Frei, y de Zambia, señor Kenneth Kaunda; Santiago, 30 de noviembre de 1966. Estudios Internacionales, №1, año I, abril 1967, pp. 115-118.

DOCUMENTOS; ZAMBIA; CHILE; AMERICA DEL SUR; COBRE. 
02290 Acta de los Acuerdos de la Reunión de Presidentes (Punt́a del Este, Uruguay, 14 de abril de 1967. Estudios Intemacionales, №2, año I, julio 1967, pp. 252-271.

DOCUMENTOS; ACUERDOS; INTEGRACION ECONOMICA; AMERICA LATINA.

02291 Toynbee, Arnold. "El estudio de la historia contemporánea", Estudios Intemacionales, No1, año I, abril 1967, pp. 8-20.

HISTORIA; METOOOOLOGIA.

02292 Sunkel, Osvaldo. "La tarea política y teórica del planificador en América Latina", Estudios Internacionates, No8, año II, enero-marzo 1969, pp. 519-529. DESARROLLO ECONOMICO; AMERICA LATINA.

02293 O'Brien, Philip. "La Alianza para el Progreso y los préstamos por programa a Chile", Estıdios Intemacionales, N28, año II, enero-marzó 1969, pp. 461-489.

CHILE; AMERICA DEL SUR; ALIANZA PARA EL PROGRESO; DESARROLLO ECONOMICO.

02294 Silva Castro, Raúl. "Juan Egaña, precursor de la integración latinoamericana", Estudios Intemacionales, No7, año II, octubre-diciembre 1968, pp. 387-405.

INTEGRACION REGIONAL; 'INTEGRACION ECONOMICA; AMERICA LATINA; HISTORIA; INTEGRACION.

02295 Sábato, Jorge A. "Energía atómica en Argentina", Estudios Intemacionales, N27, año II, octubre-diciembre 1968, pp. 332-357. ARGENTINA; AMERICA DEL SUR; ENERGIA NUCLEAR.

02296 Thomson, James C. "Vietnam: un caso clásico", Estudios Inteniacionales, N27, año II, octubre-diciembre 1968, pp. 317-331.

VIETNAM; ASIA; ESTADOS UNIDOS; GUERRA; INTERVENCION - DERECHO INTERNACIONAL.

02297 Joxe, Alain. "Doctrina estratégica y guerras de intervención", Estudios Internacionales, N6, año II, julio-septiembre 1968, pp. 276-286. SEGURIDAD; ESTRATEGIA; VIETNAM; INTERVENCION - DERECHO INTERNACIONAL; GUERRA; ASIA.

02298 Joxe, Alain. "Cohetes anticohetes: Regreso a las estrategias defensivas", Estudios Internacionales, №5, año II, abril-junio 1968, pp. 115137.

SEGURIDAD; ESTRATEGIA; POLITICA MÚNDIAL; POLITICA INTERNACIONAL; ARMAMENTISMO.

02299 Lowenthal, Richard. "Alemania y el fin del sistema bipolar en la 
política internacional", Estudios Internacionales, N23-4, año I, octubre-marzo 1967-1968, pp. 411-426.

ALEMANIA; EUROPA; POLITICA. MUNDIAL; POLITICA INTERNACIONAL.

02300. Wertheim, W. F. "Indonesia antes y después del Golpe de Untung", Estudios. Intemacionales, №3-4, año I, octubre-marzo 1967-1968, pp. 337-352.

INDONESIA; ASIA; POLITICA Y GOBIERNO; GOLPES DE ESTADO.

02301 Wallis, Víctor. "La experiencia del Brasil con una política exterior independiente", Estudios Internacionales, №2, año I, julio 1967; pp. 189-211.

BRASIL; AMERICA DEL SUR; POLITICA INTERNACIONAL; RELACINES EXTERIORES.

02314 Younger, Kenneth. "El papel de Gran Bretaña en la política internacional", Estudios Internacionales, N2, año I, julio 1967, pp. 137-155. GRAN BRETAÑA; EUROPA; POLITICA INTERNACIONAL; POLITICA MUNDIAL.

02315 Vernant, Jacques. "El mundo, Europa y Francia", Estudios Intemacionales, N22, año I, julio 1967, pp. 123-136.

POLITICA MUNDIAL; EUROPA; FRANCIA.

02316 Sunkel, Osvaldo. "Política nacional de desarrollo y dependencia externa", Estidios Intemacionales, №1, año I, abril 1967, pp. 43-75. DEPENDENCIA; DESARROLLO ECONOMICO; AMERICA LATINA; DEPENDENCIA. ECONOMICA.

02317 Orrego Vicuña, Francisco. "De la crisis de la energía al concepto del patrimonio económico de la humanidad: criterios para reestructurar el sistema económico internacional", Estudios Internacionales, №32, año VIII, octubre-diciembre 1975, pp. 3-32.

ECONOMIA INTERNACIONAL; ENERGIA; PETROLEO; EMPRESAS TRANSNACIONALES; COMERCIO EXTERIOR.

02318 Hurtado, Héctor; Pazos, Javier; Mayobre, Eduardo. "El Caribe y Venezuela: integración de la integración", Estudios Internacionales, N²7, año VII, julio-septiembre 1974, pp. 3-30.

AMERIC̈A CENTRAL Y CARIBE; VENEZUELA; INTEGPACION REGIONAL; INTEGRÁCION ECONOMICA; ECONOMIA INTERNACIONAL; AMERICA DEL SUR.

02319 Moneta, Carlos J. "Africa y los grandes actores externos", Estudios Internacionales, N227, año VII, julio-septiembre 1974, pp. 31-75.

AFRICA; POLITICA MUNDIAL; ECONOMIA INTERNACIONAL; RELACIONES EXTEPIOPES.

02320 Ireland, Rowan. "La Iglesia Católica del Brasil: límites del aggiorna- 
mento", Estudios Intemacionales, №27, año VII, julio-septiembre 1974, pp. 76-90.

IGLESIA CATOLICA; BRASIL; AMERICA DEL SUR.

02321 "América Latina en un contexto de grandes mutaciones internacionales". Anticipo del capítulo I del Estudio Económico de América Latina, 1973, de CEPAL. Estudios Internacionales, No27, año VII, julio-septiembre 1974, pp. 91-126.

CEPAL; AMERICA LATINA; ECONOMIA INTERNACIONAL; POLITICA MUNDIAL.

02322 Hirschman, Albert O. "Liderazgo, percepción del cambio y subdesarrollo", Estudios Intemacionales, N6, año II, julio-septiembre 1968, pp. 258-270.

DESARROLLO ECONOMICO; POLITICA MUNDIAL.

02323 Thomas, Hugh. "Cuba: la revolución y sus raíces históricas", Estudios Intemacionales, №16, año IV, enero-marzo 1971, pp. 126-157. CUBA; AMERICA CENTRAL Y CARIBE; REVOLUCIONES.

02324 Teitelboin, Sergio. "Los países del Pacífico Sur y el mar territorial", Estudios Intemacionales, Ne13, año IV, abril-junio 1970, pp. 38-59. OCEANO PACIFICO; DERECHO DEL MAR.

02325 Discurso del Primer Ministro de Jamaica, señor Michael Manley, en la XIV Reunión de la Asamblea de Gobernadores del Banco Interamericano de Desarrollo. Estudios Internacionales, N²2, año VI, abril-junio 1973, pp. 119-124.

DOCUMENTOS; DISCURSOS; BID; JAMAICA; AMERICA CENTRAL Y CARIBE.

02326 Peña, Félix. "El Grupo Andino: un nuevo enfoque de la participación internacional de los países en desarrollo", Estudios Intemacionales, N²2, año VI, abril-junio 1973, pp. 44-81.

GRUPO ANDINO; INTEGRACION REGIONAL; INTEGRACION ECONOMICA; AMERICA CENTRAL; PAISES EN DESARROLLO.

02327 Sunkel, Osvaldo. "Relaciones económicas entre América Latina y Estados Unidos: comentarios al trabajo de Anibal Pinto", Estudios Internacionales, №22, año VI, abril-junio 1973, pp. 32-43.

AMERICA LATINA; ESTADOS UNIDOS; DEPENDENCIA; RELACIONES ECONOMICAS; ECONOMIA INTERNACIONAL; AMERICA DEL NORTE; DEPENDENCIA ECONOMICA.

02328 Pinto, Aníbal. "Relaciones económicas entre América Latina y Estados Unidos: implicaciones y perspectivas políticas", Estudios Internacionales, N222, año VI, abril-junio 1973, pp. 3-31.

ECONOMIA INTERNACIONAL; RELACIONES ECONOMICAS; ESTADOS UNIDOS; AMERICA LATINA; DEPENDENCIA; RELACIONES ECONOMICAS INTERNACIONALES; AMERICA DEL NORTE; DEPENDENCIA ECONOMICA. 
02329 Moneta, Carlos J. "Argentina y Australia: esquemas para la cooperación", Estudios Internacionales, N²1, año VI, enero-marzo 1973, pp. 55-83.

ARGENTINA; AMERICA DEL SUR; AUSTRALIA; COOPERACION ECONOMICA; POLITICA.INTERNACIONAL; OCEANIA.

02330 Exposición del Señor Enrique V. Iglesias, Secretario Ejecutivo de la Comisión Económica para América Latina en el Tercer Periodo de Sesiones de la Conferencia de las Naciones Unidas sobre Comercio y Desarrollo, Santiago, 25 de abril de 1972. Estudios Internacionales, №18, año V, abril-junio 1972, pp. 128-141.

DOCUMENTOS; DISCURSOS; UNCTAD; CEPAL.

02331. Tomassini, Luciano. "Implicaciones internacionales del deterioro ambiental", Estudios Internacionales, №18, año V, abril-junio 1972, pp. 88-118.

MEDIO AMBIENTE; POLITICA MUNDIAL; DESARROLLO ECONOMICO; ECOLOGIA.

02332 Discurso pronunciado por el Presidente Constitucional de la República Mexicana, Lic. Luis Echeverría Alvarez, en la reunión plenaria del Tercer Período de Sesiones de la Conferencia de las Naciones Unidas sobre Comercio y Desarrollo, Santiago de Chile, 19 de abril de 1972. Estudios Internacionales, №18, año V, abril-junio 1972, pp. 119-127.

DOCUMENTOS; DISCURSOS; UNCTAD; MEXICO; AMERICA DEL NORTE.

02333 Ogelsby, J. C. M. "Relaciones canadiense-latinoamericanas, pasadas, presentes y futuras", Estudios Intemacionales, NN18, año V, abril-junio 1972, pp. 68-87.

CANADA; AMERICA LATINA; POLITICA INTERNACIONAL; RELACIONES EXTERIORES; AMERICA DEL NORTE,

02334 Niekerk, Arnold van. "La pendiente de la dependencia: Una visión desde afuera", Estudios Intemacionales, NNe18, año V, abril-junio 1972, pp. 29-40.

DEPENDENCIA; AMERICA LATINA.

02335 Ribeiro, Darcy. "Nuevos caminos de la Revolución Latinoamericana", Estudios Internacionales, No18, año V, abril-junio 1972, pp. 3-28. AMERICA LATINA; REVOLUCIONES; PERU; CHILE; AMERICA DEL SUR; POLITICA Y GOBIERNO.

02336 Moran, Theodore H. "Nuevo trato a las materias primas", Estudios Internacionales, $\mathrm{N}^{\circledR} 19$, año V, julio-septiembre 1972, pp. 56-70. RECURSOS NATURALES; EMPRESAS TRANSNACIONALES; PRODUCTOS BASicos. 
02337 Schmitter, Philippe C. "La portugalización de Brasil", Estudios Internacionaies, $N$ N19, año $V$, julio-septiembre 1972, pp. 3-55.

BPASIL; AMERICA DEL SUR; POLITICA Y GOBIERNO; FUERZAS AFIMADAS.

02338 Jaguaribe, Helio. "El equilibrio ecológico mundial y los países subdesarrollados", Estudios Internacionales, №17, año V, enero-marzo 1972, pp. 92-123.

MEDIO AMBIENTE; DESARROLLO ECONOMICO; POLITICA MUNDIAL; PAISES EN DESARROLLO; ECOLOGIA.

02339 Holbraad, Carsten. "El papel de las potencias medias en la política internacional", Estudios Internacionales, №17, año V, enero-marzo 1972, pp. 53-75.

POLITICA INTERNACIONAL; POLITICA MUNDIAL.

02340 Merlini, Cesare. "La posición internacional de Italia. Oportunidades y tentaciones", Estudios Intemacionales, №17, año V, enero-marzo 1972, pp. 76-91.

ITALIA; EUROPA; POLITICA INTERNACIONAL; RELACIONES EXTERIORES.

02341 Mihaly, Eugene B. "La estrategia de los Estados Unidos en el Pacífico Occidental y el dilema de Micronesia", Estudios Internacionales, NN17, año V, enero-marzo 1972, pp. 25-39.

ESTADOS UNIDOS; OCEANO PACIFICO; OCEANIA; SEGURIDAD; ESTRATEGIA; AMERICA DEL NORTE; MICRONESIA.

02342 Discurso pronunciado por el Ministro de Relaciones Exteriores de Chile, señor Clodomiro Almeyda ante la Asamblea General de los Estados Americanos, reunida en San José de Costa Rica, el 15 de abril de 1971. Estudios Intemacionales, №16, año IV, enero-marzo 1971, pp. 189-198.

DOCUMENTOS; DISCURSOS; OEA; CHILE; AMERICA DEL SUR.

02343 Petras, James; Rimensnyder, Nelson. "Los militares y la modernización del Perú", Estudios Internacionales, №13, año IV, abril-junio 1970, pp. 90-123.

FUERZAS ARMADAS; MODERNIZACION; PERU; AMERICA DEL SUR; POLITICA $Y$ GOBIERNO.

02344 Ortíz, Eduardo. "Jaime Eyzaguirre", Estudios Internacionales, N27, año II, octubre-diciembre 1968, pp. 315-316.

EYZAGUIRRE, JAIME; CHILE; AMERICA DEL SUR; BIOGRAFIAS.

02345 Naudon, Carlos. "Cinco libros sobre Israel", Estudios Internacionales, N6, año II, julio-septiembre 1968, pp. 271-275.

ISRAEL; POLITICA MUNDIAL; POLITICA INTERNACIONAL; MEDIO ORIENTE.

02349 Muñoz, Heraldo; Sánchez, Walter. "La détente y el sistema interna- 
cional", Estudios Intemacionales, Ne32, año VII, octubre-diciembre 1975, pp. 103-122.

POLITICA INTERNACIONAL; POLITICA MUNDIAL; TERCER MUNDO; DISTENSION.

02350 Lafer, Celso' "Una redefinición del orden mundial y la Alianza Latinoamericana. Perspectivas y posibilidades", Estudios Internacionales, №31, año VIII, julio-septiembre 1975, pp. 42-58.

POLITICA MUNDIAL; AMERICA LATINA; INTEGRACION REGIONAL; ORDEN MUNDIAL.

02351 Jaguaribe, Helio. "El Vietnam y los Estados Unidos", Estudios Internacionales, No31, año VIII, julio-septiembre 1975, pp. 3-18.

VIETNAM; ASIA; ESTADOS UNIDOS; CONFLICTOS; ESTRATEGIA; AMERICA DEL NORTE.

02352 Palma, Pedro A. "Análisis del Sistema Monetario Internacional", Esitudios Intenacionales, N³2, año VIII, octubre-diciembre 1975, pp. 51-102.

ECONOMIA INTERNACIONAL; SISTEMA MONETARIO INTERNACIONAL.

02353 Halty Carrere, Máximo. "¿Hacia un nuevo orden tecnológico?, Estudios Intemacionales, Ne32, año VIII, octubre-diciembre 1975, pp. 33-50.

DESARROLLO TECNOLOGICO; DEPENDENCIA; POLITICA MUNDIAL; CIENCIA Y TECNOLOGIA.

02354 Hansen, Roger. "Relaciones económicas entre los Estados Unidos y América Latina. ¿Bilaterales, regionales o globales?" Estudios Internacionales, №31, año VIII, julio-septiembre 1975, pp. 59-99.

ECONOMIAINTERNACIONAL; ESTADOS UNIDOS; AMERICA LATINA; AMERICA DEL NORTE; RELACIONES ECONOMICAS INTERNACIONALES; RELACIONES EXTERIORES.

02355 Hodara, Joseph. "La coyuntura internacional: cuatro versiones", Estudios Intemacionales, №31, año VIII, julio-septiembre 1975, pp. 100-113.

ECONOMIA INTERNACIONAL; POLITICA MUNDIAL.

02356 Imaz, José Luis, de. "¿Adiós a la teoría de la dependencia? Una perspectiva desde la Argentina" Estudios Internacionales, N228, año VII, octubre-diciembre 1974, pp. 49-75.

DEPENDENCIA; ARGENTINA; AMERICA DEL SUR; POLITICA MUNDIAL.

02357 Pérez Llana, Carlos. "América Latina y los países no alineados", Estudios Internacionales, №24, año VI, octubre-diciembre 1973, pp. 43-65.

america latina; PAISES NO ALINEAdOS; POLITICA MUNDIAL; TERCER MUNDO. 
02358 Orrego Vicuña, Francisco. "Algunos problemas de derecho internacional planteados por la nacionalización de la industria del cobre en Chile", Estudios Internacionales, №24, año VI, octubre-diciembre 1973, pp. 66-88.

DEP.ECHO INTERNACIONAL; NACIONALIZACION; COBRE; CHILE; AMERICA DEL SUR; EMPRESAS TRANSNACIONALES.

02359 Discurso pronunciado por el Ministro de Relaciones Exteriores de Chile, Almirante Ismael Huerta, ante la Asamblea de las Naciones Unidas, en Nueva York, el día 9 de octubre de 1973. Estudios Internacionales, N224, año VI, octubre-diciembre 1973, pp. 89-106. DOCUMENTOS; DISCURSOS; CHILE; AMERICA DEL SUR; NACIONES UNIDAS; RELACIONES EXTERIORES.

02360 Silva Michelena, José A. "Tendencias recientes en la política mundial", Esiudios Intemacionales, N²3, año VI, julio-septiembre 1973, pp. 3-22.

POLITICA MUNDIAL; AMERICA LATINA.

02361 Exposición pronunciada por el Embajador del Brasil Miguel A. Ozorio de Almeida en el Vigesimoquinto Período de Sesiones de la Cepal (Quito, marzo 27 de 1973). Estudios Intemacionales, №23, año VI, julio-septiembre 1973, pp. 105-121.

DOCUMENTOS; CEPAL; CONFERENCIAS; AMERICA LATINA; DESARROLLO ECONOMICO; BRASIL; AMERICA DEL SUR.

02362 Villagrán Kramer, Francisco. "Mecanismos de regularización internacional de productos básicos", Estudios Internacionales, №23, año VI, julio-septiembre 1973, pp. 61-92.

PRODUCTOS BASICOS; COMERCIO EXTERIOR; TERCER MUNDO; ECONOMIA INTERNACIONAL.

02363 Gott, Richard. "La experiencia guerrillera en Bolivia", Estudios Internacionales, N25, año II abril-junio 1968, pp. 85-114.

BOLIVIA; AMERICA DEL SUR; GUERRILLAS; VIOLENCIA; POLITICA Y GOBIERNO.

02364 Grant, James P. "Las naciones de la OPEP: ¿Asociados o competidores?", Estudios Intemacionales, No30, año VIII, abril-junio 1975, pp. 100-118.

ECONOMIA INTEPNACIONAL; OPEP; PETROLEO; PRODUCTOS BASICOS; COOPERACION INTERNACIONAL.

02365 Herrera Lane, Felipe. "América Latina y el desafío internacional para la educación", Estudios Intemacionales, N225, año VII, eneromarzo 1974, pp. 3-15.

EDUCACION; AMERICA LATINA.

02366 Sagasti, Francisco R,; Guerrero, Mauricio. "Situación de la ciencia y 
tecnología en América Latina", Estudios Internacionales, №25, año VII, enero-marzo 1974, pp. 16-56.

CIENCIA Y TECNOLOGIA; AMERICA LATINA; DESARROLLO ECONOMICO.

02367 Sachs, Ignacy. "Ecodesarrollo: un aporte a la definición de estilos de desarrollo para América Latina", Estudios Internacionales, №25, año VII, enero-marzo 1974, pp. 57-77.

MEDIO AMBIENTE; DESARROLLO ECONOMICO; AMERICA LATINA; ECOLOGIA.

02368 Jaguaribe, Helio. "Los acontecimientos chilenos", Estudios Internacionales, N226, año VII, abril-junio 1974, pp. 3-19. CHILE; AMERICA DEL SUR; POLITICA Y GOBIERNO.

02369 Sigmund, Paul E. "El bloqueo invisible y la caída de Allende", Estutdios Internacionales, №26, año VII, abril-junio 1974, pp. 20-38.

CHILE; AMERICA DEL SUR; POLITICA Y GOBIERNO; ESTADOS UNIDOS; AMERICA DEL NORTE; GOLPES DE ESTADO; INTERVENCION - DERECHO INTERNACIONAL.

02370 Palma Vicuña, Ignacio. "Aportes para un análisis de la crisis chilena", Estudios Intemacionales, №26, año VII, abril-junio 1974, pp. 39-67. CHILE; AMERICA DEL SUR; POLITICA Y GOBIERNO; CRISIS.

02371 Declaración del Episcopado chileno sobre la reconciliación en Chile, Santiago, 24 de abril de 1974. Estudios Intemacionales, №26, año VII, abril-junio 1974, pp. 68-73.

DOCUMENTOS; CHILE; AMERICA DEL SUR; IGLESIA CATOLICA; POLITICOAY Y GOBIERNO.

02372 Tomassini, Luciano. "Tendencias favorables o adversas a la formación de un sistema regional latinoamericano", Estudios Intemaciontales, N229, año VIII, enero-marzo 1975, pp. 3-46.

AMERICA LATINA; INTEGRACION REGIONAL; INTEGRACION ECONOMICA; POLITICA INTERNACIONAL; RELACIONES EXTERIORES.

02373 Pérez Llana, Carlos. "¿Potencias intermedias o países mayores?" La política exterior de Argentina, Brasil y México", Estudios Internacionales, N229, año VIII, enero-marzo 1975, pp. 47-105.

POLITICA INTERNACIONAL; ARGENTINA; BRASIL; MEXICO; AMERICA LATINA; AMERICA DEL NORTE; AMERICA DEL SUR.

02374 Jaguaribe, Helio. "El Brasil y la América Latina", Estudios Internacionales, Ne29, año VIII, enero-marzo 1975, pp. 106-136.

BRASIL; AMERICA LATINA; POLITICA INTERNACIONAL; INTEGRACION REGIONAL; INTEGRACION ECONOMICA; AMERICA DEL SUR; RELACIONES EXTERIORES.

02375 Peña, Félix "Tendencias y perspectivas de la integración económica 
en América Latina", Estudios Internacionales, №29, año VIII, eneromarzo 1975, pp. 137-152.

INTEGRACION ECONOMICA; INTEGRACION REGIONAL; AMERICA LATINA.

02376 Acto constitutivo del Foro Latinoamericano. Estudios Internacionales, №29, año VIII, enero-marzo 1975, pp. 153-155.

DOCUMENTOS; FORO LATINOAMERICANO; AMERICA LATINA.

02377 Dam, André, van. "El triunfo del caballo", Estudios Internacionales, Ne34, año IX, abril-junio 1976, pp. 3-9.

ECONOMIA INTERNACIONAL; DESARROLLO ECONOMICO; CIENCIA Y TECNOLOGIA; EMPRESAS TRANSNACIONALES.

02378 Diamand, Marcelo. "Las posibilidades de una técnica nacional en Latinoamerica: El caso argentino", Estudios Internacionales, №34, año IX, abril-junio 1976, pp. 10-41.

CIENCIA Y TECNOLOGIA; AMERICA LATINA; ARGENTINA; AMERICA DEL SUR.

02379 Tironi B., Ernesto. "Las estrategias nacionales de desarrollo y la integración de los países andinos", Estudios Internacionales, №34, año IX, abril-junio 1976, pp. 58-102.

DESARROLLO ECONOMICO; INTEGRACION REGIONAL; INTEGRACION ECONOMICA; ECONOMIA INTERNACIONAL; AMERICA DEL SUR.

02380 Fagen, Richard. "La política exterior de los Estados Unidos y el desarrollo del Tercer Mundo", Estudios Internacionales, N235, año IX, julio-septiembre 1976, pp. 3-37.

POLITICA INTERNACIONAL; ESTADOS UNIDOS; TERCER MUNDO; DESARROLLO ECONOMICO; POLITICA MUNDIAL; AMERIGA DEL NORTE.

02381 Lowenthal, Abraham F. "Ejércitos y política en América Latina", Estudios Internacionales, №35, año IX, julio-septiembre 1976, pp. 38-64.

FUERZAS ARMADAS; AMERICA LATINA; POLITICA Y GOBIERNO.

02382 Sánchez, Walter. "El triángulo Washington-Moscú-Pekin y el proceso de distensión Internacional", Estudios Internacionales, N³5, año IX, julio-septiembre 1976, pp. 65-117.

POLITICA MUNOIAL; ESTADOS UNIDOS; CHINA; POLITICA INTERNACIONAL; AMERICA DEL NORTE; ASIA; URSS; EUROPA DEL ESTE; DISTENSION; SEGURIDAD INTERNACIONAL.

02383 Diálogo entre dos Continentes: Club de Roma y Foro Latinoamericano, Roma 1976. Estudios Internacionales, Ne35, año IX, julio-septiembre 1976, pp. 118-122.

DOCUMENTOS; NUEVO ORDEN ECONOMICO INTERNACIONAL; ECONOMIA INTERNACIONAL; FORO LATINOAMERICANO; CLUB DE ROMA; RELACIONES EXTERIORES; AMERICÁ LATINA.

02384 Jaguaribe, Helio. "El estudio del futuro y de la supervivencia del 
hombre", Estudios Internacionales, №36, año IX, septiembre-diciembre 1976, pp. 3-10.

POLITICA MUNDIAL; FUTUROLOGIA.

02385 Furtado, Celso. "El conocimiento económico de América Latina", Estudios Internacionales, №36, año IX, septiembre-diciembre 1976, pp. 11-23.

DESARROLLO ECONOMICO; AMERICA LATINA; ECONOMIA INTERNACIONAL.

02386 Sábato, Jorge A. "El cambio tecnológico necesario y posible", Estudios Intemacionales, №36, año IX, septiembre-diciembre 1976, pp. 24-41.

CIENCIAY TECNOLOGIA; DESARROLLO ECONOMICO; DEPENDENCIA; AMERICA LATINA; TRANSFERENCIA DE TECNOLOGIA.

02387 Niekerk, Arnold van. "La sociología latinoamericana: un testimonio epistemológico", Estudios Internacionales, N³6, año IX, septiembrediciembre 1976, pp. 42-73.

AMERICA LATINA; SOCIOLOGIA; CIENCIAS SOCIALES.

02388 Uslar Pietri, Arturo. "Lo específico del hombre latinoamericano", Estudios Intemacionales, №36, año IX, septiembre-diciembre 1976, pp. 74-89.

SOCIEDAD; AMERICA LATINA.

02389 Discurso del Presidente Carlos Andrés Pérez pronunciado el 3 de mayo de 1976, con ocasión de la inaguración del Seminario América Latina, conciencia y nación, organizado en Caracas por el Instituto de Altos Estudios de América Latina de la Universidad Simón Bolívar. Estudios Intemacionales, №36, año IX, septiembre-diciembre 1976, pp. 90-96.

DISCURSOS; AMERICA LATINA; DOCUMENTOS; VENEZUELA; AMERICA DEL SUR.

02390 Díaz Alejandro, Carlos. "Relaciones Norte - Sur: el componente económico", Estudios Intentacionales, №37, año X, enero-marzo 1977, pp. 3-44.

ECONOMIA INTERNACIONAL; RELACIONES NORTE SUR; RELACIONES ECONOMICAS INTERNACIONALES.

02391 Lowenthal, Abraham F. "El fin de la presunción hegemónica", Estudios Internacionales, N237, año X, enero-marzo 1977, pp. 45-67. ESTADOS UNIDOS; AMERICA. LATINA; POLITICA INTERNACIONAL; AMERICA DEL NORTE; RELACIONES EXTERIORES; DEPENDENCIA.

02392 Pérez Llana, Carlos. "El legado de Henry Kissinger: algunas implicancias de su gestión", Estudios Intemacionales, N³7, año X, eneromarzo 1977, pp. 68-91. 
POLITICA INTERNACIONAL; ESTADOS UNIDOS; AMERICA DEL NORTE; KISSINGER, HENRY.

02393 Aftalión, Marcelo E. "La política exterior norteamericana y América Latina", Estudios Intemacionales, Ne37, año X, enero-marzo 1977, pp. 92-104.

POLITICA INTERNACIONAL; ESTADOS UNIDOS; AMERICA LATINA; AMERICA DEL NORTE; RELACIONES EXTERIORES.

02394 Diálogo sobre integración y desarrollo. Estudios Intemacionales, Ne37, año X, enero-marzo 1977, pp. 105-109.

DOCUMENTOS; SEGURIDAD ALIMENTARIA; AGRICULTURA; INTEGRACION.

02395 Grant, Bruce. "Australia y el Pacífico", Estudios Intemacionales, No17, año V, enero-marzo 1972, pp: 40-52.

AUSTRALIA; OCEANIA; OCEANO PACIFICO.

02396 Ffrench-Davis, Ricardo. "Pacto Andino y libre comercio", Estudios Intemacionales, $N^{0} 38$, año $X$, abril-junio 1977, pp. 3-11.

INTEGRACION ECONOMICA; INTEGRACION REGIONAL; PACTO ANDINO; COMERCIO EXTERIOR; LIBRE COMERCIO.

02397 Tironi B., Ernesto. "La Decisión 24 sobre capitales extranjeros en el Grupo Andino", Estudios Inlemacionales, N³8, año X, abril-junio 1977, pp. 12-26.

INVERSIONES EXTRANJERAS; GRUPO ANDINO; INTEGRACIONECONOMICA; INTEGRACION REGIONAL; AMERICA DEL SUR; PACTO ANDINO.

02398. Valdés Subercaseaux, Gabriel. "Situación del Grupo Andino en el contexto latinoamericano e internacional", Estudios Intemacionales, Ne38, año $X$, abril-junio 1977, pp. 27-46.

GRUPO ANDINO; AMERICA LATINA; POLITICA INTERNACIONAL; INTEGRACION ECONOMICA; INTEGRACION REGIONAL; AMERICA DEL SUR; ECONOMIA INTERNACIONAL.

02399 Salgado, Germánico. "Integración, conciliación de políticas y diferencias de estructura económica", Estudios Intemacionales, N³8, año $X$, abril-junio 1977, pp. 47-66.

INTEGRACION REGIONAL; INTEGRACION ECONOMICA; ECONOMIA INTERNACIONAL; GRUPO ANDINO; AMERICA DEL SUR; AMERICA LATINA.

02400 Wilhelmy, Manfred. "La política exterior chilena y el Grupo Andino", Estudios Intemacionales, N³8, año $X$, abril-junio 1977, pp. 67-87. POLITICA INTERNACIONAL; CHILE; AMERICA DEL SUR; GRUPO ANDINO; INTEGRACION REGIONAL; INTEGRACION ECONOMICA; RELACIONES EXTERIORES.

02401 Sobre el Pacto Andino. Carta dirigida por el ex Presidente de Chile, señor Eduardo Frei, al director de El Mercurio de Santiago, el 28 de 
agosto de 1976. Estudios Internacionales, №38, año X, abril-junio 1977, pp. 88-93.

DOCUMENTOS; PACTO ANDINO; CHILE; AMERICA DEL SUR; FREI MONTALVA, EDUARDO.

02402 Reformas al Pacto Ándino: Discurso pronunciado por el Presidente de Colombia, señor Alfonso López Michelsen, en Medellín, el 18 de septiembre de 1976. Estudios Internacionales, N³8, año X, abril-junio 1977, pp. 94-106.

DOCUMENTOS; DISCURSOS; PACTO ANDINO; COLOMBIA; AMERICA DEL SUR.

02403 Cuarta Reunión del Foro Latinoamericano, México, D. F, 7 al 9 de mayo de 1977. Estudios Intemacionales, №38, año X, abril-junio 1977, pp. 107-128.

DOCUMENTOS; AMERICA LATINA; FORO LATINOAMERICANO; ECONOMIA INTERNACIONAL.

02404 Diamand, Marcelo. "Hacia el cambio del paradigma económico a través de la experiencia de los países en desarrollo", Estudios Internacionales, №39, año X, julio-septiembre 1977, pp. 3-56.

ECONOMIAINTERNACIONAL; DESARROLLO ECONOMICO; PAISES EN DESARROLLO.

02405 Flores de la Peña, Horacio. "Un nuevo modelo de desarrollo", Estudios Intentacionales, Ne39, año X, julio-septiembre 1977, pp. 57-80. DESARROLLO ECONOMICO.

02406 Iglesias, Enrique V. "Situación y perspectivas de América Latina", Estudios Internacionales, №39, año X, julio-septiembre 1977, pp. 81-123.

AMERICA LATINA; DESARROLLO ECONOMICO; ECONOMIA INTERNACIONAL; NUEVO ORDEN ECONOMICO INTERNACIONAL; CONDICIONES ECONOMICAS.

02407 Véliz, Claudio. "Errores y omisiones: Notas sobre la política exterior de los países de América Latina durante los últimos diez años", Estudios Internacionales, №40, año X, octubre-diciembre 1977, pp. 5-12.

POLITICA INTERNACIONAL; AMERICA LATINA; RELACIONES EXTERIORES.

02408 Herrera Lane, Felipe. "América Latina y el Tercer Mundo", Estudios Internacionales, N40, año X, octubre-diciembre 1977, pp. 13-32.

AMERICA LATINA; TERCER MUNDO; POLITICA INTERNACIONAL; COOPERACION ECONOMICA; RELACIONES EXTERIORES.

02409 Jaguaribe, Helio. "El Informe Linowitz y las relaciones Estados Unidos-América", Estudios Intemacionales, ํ40, año X, octubre-diciembre 1977, pp. 47-59. 
ESTADOS UNIDOS; AMERICA'LATINA; RELACIONES EXTERIORES; POLITICA INTERNACIONAL; AMERICA DEL NORTE.

02410 Lagos, Gustavo. "El Plan Carter y 'La Guerra de la Energía", Estudios Internacionales, N40, año X, octubre-diciembre 1977, pp.60-88. ESTADOS UNIDOS; POLITICA Y GOBIERNO; ENERGIA; AMERICA DEL NORTE; PETROLEO.

02411 Orrego Vicuña, Francisco. "Las alternativàs de América Latina como clase media de las naciones", Estudios Intënacionales, N40, año X, octubre-diciembre 1977, pp. 89-110.

AMERICA LATINA; DESARROLLO ECONOMICO; TERCER MUNDO.

02412 Tomassini, Luciano. "Falencias y falacias: notas sobre el estudio de las relaciones Norte-Sur", Estudios Intemacionales, N40, año X, octubre-diciembre 1977, pp. 111-130.

NUEVO ORDEN ECONOMICO INTERNACIONAL; AMERICA LATINA; POLITICA INTERNACIONAL; TERCER MUNDO; DIALOGO NORTE SUR; RELACIONES NORTE SUR; RELACIONES EXTERIORES; POLITICA INTERNACIONAL.

02413 Ward, Bárbara. "Perspectivas históricas del Nuevo Orden Económico Internacional", Estudios Intemacionales, No41, año XI, eneromarzo 1978, pp. 5-15.

NUEVO ORDEN ECONOMICO INTERNACIONAL; ECONOMIA INTERNACIONAL.

02414 Haq, Mahbub ul. "El Diălogo Norte-Sur: la segunda fase", Estudios Internacionales, №41, año XI, enero-marzo 1978, pp. 16-26.

DIALOGO NORTE SUR; ECONOMIA INTERNACIONAL; RELACIONES NORTE SUR; RELACIONES EXTERIORES; POLITICAA INTERNACIONAL.

02415 Tomassini, Luciano. "Intereses mutuos: las verdaderas bases del Diálogo Norte-Sur", Estudios Internacionales, №41, año XI, eneromarzo 1978, pp. 27-50.

DIALOGO NORTE SUR; ECONOMIA INTERNACIONAL; RELACIONES NORTE SUR; RELACIONES ECONOMICAS INTERNACIONALES.

02416 Sampaio Malan, Pedro. "Las relaciones económicas internacionales del Brasil: notas para una agenda de investigación", Estudios Intemacionales, Ne41, año XI, enero-marzo 1978, pp. 51-72.

ECONOMIA INTERNAGIONAL; BRASIL; AMERICA DEL SUR; RELACIONES ECONOMICAS INTERNACIONALES.

02417 Sábato, Jorge A. "El plan nuclear brasileño y la bomba atómica", Estudios Internacionales, N41, año XI, enero-marzo 1978, pp. 73-82. ENERGIA NUCLEAR; BRASIL; AMERICA DEL SUR; ARMAS NUCLEARES.

02418 Vargas Hidalgo, Rafael. "Estados Unidos y América Latina bajo la "presidencia de Carter", Estudios Intemacionales, No41, año XI, enero-marzo 1978, pp. 83-119. 
ESTADOS UNIDOS; AMERICA LATINA; POLITICA INTERNACIONAL; AMERICA DEL NORTE; RELACIONES EXTERIORES.

02419 Sewell, John. "¿Pueden prosperar los países ricos sin que progresen los países pobres?", Estudios Internacionales, N42, año XI, abril-junio 1978 , pp. 39-65.

ECONOMIA INTERNACIONAL; COMERCIO EXTERIOR; RELACIONES NORTE SUR; POLITICA INTERNACIONAL; RELACIONES EXTERIORES.

02420 Perry, Guillermo. "Mercados mundiales de manufacturas, industrialización y política comercial de los países en desarrollo", Estudios Intemacionales, №42, año XI, abril-junio 1978, pp. 66-94.

DESARROLLO ECONOMICO; ECONOMIA INTERNACIONAL; INDUSTRIALIZACION; PAISES EN DESARROLLO.

02421 Iglesias, Enrique V. "¿Va América Latina hacia la bancarrota?", Estudios Intemacionales, Ne42, año XI, abril-junio 1978, pp. 95-110. DESARROLLO ECONOMICO; AMERICA LATINA; ECONOMIA INTERNACIONAL; CONDICIONES ECONOMICAS.

02422 Wilhelmy, Manfred. "La política exterior de Estados Unidos: dinámica interna y nuevos problemas", Estudios Internacionales, Ne42, año XI, abril-junio 1978, pp. 111-134.

POLITICA INTERNACIONAL; ESTADOS UNIDOS; POLITICA Y GOBIERNO; AMERICA DEL NORTE; RELACIONES EXTERIORES.

02423 Joxe, Alain. "¿Fin de la preponderancia estratégica norteamericana?", Estudios Internacionales, Ne11, año III, octubre-diciembre 1969, pp. 273-320.

SEGURIDAD; ESTRATEGIA; ESTADOS UNIDOS; POLITICA MUNDIAL; POLITICA INTERNACIONAL; AMERICA DELL NORTE; GRANDES POTENCIAS.

02424 Grayson, George W. "Portugaly el movimiento de las Fuerzas Armadas", Estudios Intemacionales, Ne33, año IX, enero-marzo 1976, pp. 3-46.

PORTUGAL; EUROPA; FUERZAS ARMADAS; POLITICAY GOBIERNO; GOLPES DE ESTADO.

02425 Sagasti, Francisco R. "Autodependencia tecnológica y cooperación en los países del Tercer Mundo", Estudios Intemacionales, N³3, año IX, enero-marzo 1976, pp. 47-61.

CIENCIA Y TECNOLOGIA; TERCER MUNDO; COOPERACION TECNOLOGICA.

02426 Langlois, Juan Carlos. "Una nueva dimensión para los Bancos de Desarrollo", Estudios Internacionales, N³3, año IX, enero-marzo 1976, pp. 62-70.

ECONOMIA INTERNACIONAL; DESARROLLO ECONOMICO; BANCOS REGIONALES DE DESARROLLO.

02427 Muñoz, Heraldo. "Dependencia estratégica y no-estratégica: mate- 
rias primas y relaciones internacionales en la perspectiva de la crisis i petrolera", Estudios Internacionates, N233, año IX, enero-marzo 1976, pp. 71-108.

DEPENDENCIA; POLITICA INTERNACIONAL; PETROLEO; CRISIS; PRODUC-، TOS BASICOS; RELACIONES EXTERIORES.

02428 Herrera Lane, Felipe. "El desarrollo y las políticas culturales en" América Latina", Estudios Internacionales, №43, año XI, julio-septiembre 1978, pp. 26-46.

DESARROLLO ECONOMICO; AMERICA LATINA; CULTURA.

02429 Prebisch, Raúl. "Notas sobre el desarrollo del capitalismo periférico", Estudios Internacionales, №43, año XI, julio-septiembre 1978, pp. 3-25.

ECONOMIA INTERNACIONAL; CAPITALISMO; DEPENDENCIA; DEPENDENCIA ECONOMICA.

02430 Lafer, Celso. "El estudio de Ias relaciones internacionales: necesidades y perspectivas", Estudios Internacionales, №43, año XI, julio-septiembre 1978, pp. 47-56.

RELACIONES INTERNACIONALES - ESTUDIO Y ENSEÑANZA.

02451 Cepeda Ulloa, Fernando. "La influencia de las agencias internacionales en el proceso de desarrollo de Colombia 1950-1974", Estudios Internacionales, №43, año XI, julio-septiembre 1978, pp. 57-75. DESARROLLO ECONOMICO; COLOMBIA; AMERICA DEL SUR; COOPERACION INTERNACIONAL; ORGANIZACIONES INTERNACIONALES.

02452 Andrade Lleras, Gustavo. "Hacia adónde va el Japón", Estudios Intemacionales, N243, año XI, julio-septiembre 1978, pp. 76-89. JAPON; ASIA; POLITICA INTERNACIONAL; POLITICA Y GOBIERNO; RELACIONES EXTERIORES.

02453 Díaz Albónico, Rodrigo. "Los elementos objetivos y subjetivos en la definición internacional de la agresión", Estudios Internacionales, $N^{2} 43$, año XI, julio-septiembre 1978, pp. 90-107. DERECHO INTERNACIONAL; AGRESION - DERECHO INTERNACIONAL.

02454 Villamil, José J. "El futuro del Caribe: su marco institucional", Estudios Internacionales, №44, año XI, octubre-diciembre 1978, pp. 28 44.

AMERICA CENTRAL Y CARIBE; POLITICA INTERNACIONAL; ECONOMIA INTERNACIONAL.

02455 Godfrey, Martin; Langdon, Steven. "iSocios en el desarrollo? La tesis de la transnacionalización en el contexto keniano", Estudios Intemacionales, Ne44, año XI, octubre-diciembre 1978, pp. 45.70.

KENIA; AFRICA; ECONOMIA INTERNACIONAL; POLITICA INTERNACIONAL; RELACIONES EXTERIORES. 
02456 Muñoz, Heraldo. "Cambio y continuidad en el debate sobre la dependencia y el imperialismo", Estudios Internacionales, No44, año XI, octubre-diciembre 1978, pp. 88-138.

DEPENDENCIA; IMPERIALISMO; AMERICA LATINA.

02457 Azevedo da Silveira, Antonio. "Las relaciones entre América Latina y los Estados Unidos", Estudios Intemacionales, N45, año XII, enero-marzo 1979, pp. 3-13.

AMERICA LATINA; ESTADOS UNIDOS; AMERICA DEL NORTE; POLITICAINTERNACIONAL; RELACIONES EXTERIORES; BRASIL; AMERICA DEL SUR.

02458 Iglesias, Enrique V. "Perspectivas económicas de América Latina y sus implicaciones para los Estados Unidos", Estudios Internacionales, №45, año XII, enero-marzo 1979, pp. 14-26.

ECONOMIAINTERNACIONAL; AMERICA LATINA; ESTADOS UNIDOS; AMERICA DEL NORTE; RELACIONES NORTE SUR; RELACIONES ECONOMICAS INTER NACIONALES.

02459 Ortíz Mena, Antonio. "Las relaciones económicas entre América Latina y la OECD: nuevas perspectivas", Estudios Internacionales, N45, año XII, enero-marzo 1979, pp. 27-35.

ECONOMIA INTERNACIONAL; AMERICA LATINA; OECD; COOPERACION ECONOMICA; RELACIONES ECONOMICAS INTERNACIONALES.

02460 Rostow, W. W. "Cómo romper la impasse en las negociaciones económicas multilaterales Norte-Sur", Estudios Intemacionales, $N^{2} 45$, año XII, enero-marzo 1979, pp. 36-55.

ECONOMIA INTERNACIONAL; RELACIONES NORTE SUR; NEGOCIACIONES; RELACIONES ECONOMICAS INTERNACIONALES.

02461 Valdés Subercaseaux, Gabriel. "Reflexiones sobre el futuro de América Latina", Estudios Internacionales, №45, año XII, enero-marzo 1979, pp. 56-67.

AMERICA LATINA; SOCIEDAD; DESARROLLO ECONOMICO.

02462 Pérez Llana, Carlos. "Perspectivas de América Latina en el diálogo Norte-Sur", Estudios Internacionales, N46, año XII, abril-junio 1979, pp. 131-143.

AMERICA LATINA; DIALOGO NORTE SUR; RELACIONES NORTE SUR; POLTTCA INTERNACIONAL; RELACIONES EXTERIORES.

02463 Russell, Roberto; Carballal, Teresa. "América Latina ¿Hacia qué nuevo orden internacional?", Estudios Internacionales, №46, año XII, abril-junio 1979, pp. 144-176.

AMERICA LATINA; POLITICA INTERNACIONAL; RELACIONES NORTE SUR; NUEVO ORDEN ECONOMICO INTERNACIONAL.

02464 Casanova, Manuel. "La participación de América Latina en el siste- 
ma económico internacional de la postguerra", Estudios Internacionales, $\mathrm{N}^{\vee} 46$, año XII, abril-junio 1979, pp. 177-203.

AMERICA LATINA; ECONOMIA INTERNACIONAL; NUEVO ORDEN ECONOMICO INTERNACIONAL; POLITICA INTERNACIONAL.

02465 Tomassini, Luciano. "El nuevo orden económico internacional: varios enfoques", Estudios Intemacionales, №46, año XII, abril-junio 1979, pp. 204-219.

NUEVO.ORDEN ECONOMICO INTERNACIONAL; POLITICA INTERNACIONAL; ECONOMIA INTERNACIONAL.

02466 Bergsten C., Fred. "Relaciones económicas entre los Estados Unidos y América Latina", Estudios Internacionales, Ne47, año XII, julio-septiembre 1979, pp. 247-257.

ECONOMIA INTERNAGIONAL; ESTADOS UNIDOS; AMERICA DEL NORTE; AMERICA LATINA; RELACIONES ECONOMICAS INTERNACIONALES.

02467 González, Norberto. "Prioridades de América Latina en el Diálogo Norte-Sur", Estudios Intemacionales, Ne47, año XII, julio-septiembre 1979, pp. 258-274.

AMERICA LATINA; DIALOGO NORTE SUR; DESARROLLO ECONOMICO; ECONOMIA INTERNACIONAL; RELACIONES EXTERIORES.

02468 Orrego Vicuña, Francisco. "La legislación unilateral para la explotación de los fondos marinos: su incompatibilidad con el derecho internacional", Estudios Intemacionales, N47, año XII, julio-septiembre 1979, pp. 275-292.

DERECHO INTERNACIONAL; DERECHO DEL MAR; RECURSOS MINERALES; FONDOS MARINOS; RECURSOS MARINOS; LEGISLACION.

02469 Zegers Santa Cruz, Fernando. "El sistema antártico y la cuestión del aprovechamiento de los recursos en el área", Estudios Internacionales, No47, año XII, julio-septiembre 1979, pp. 293-321. ANTARTICA; RECURSOS NATURALES.

02470 Kñakal, Jan. "Las empresas transnacionales en el desarrollo contemporáneo de América Latina", Estudios Intemacionales, NQ47, año XII, julio-septiembre 1979, pp. 322-350.

DESARROLLO ECONOMICO; AMERICALATINA; ECONOMIAINTERNACIONAL; EMPRESAS TRANSNACIONALES.

02471 Grunwald, Joseph. "El comercio intraindustrial Norte-Sur: compartir la producción industrial entre los países en desarrollo y desarrollados", Estudios Internacionales, N48, año XII, octubre-diciembre 1979, pp. 372-389.

RELACIONES NORTE SUR; ECONOMIA INTERNACIONAL; COMERCIO EXTERIOR; PAISES DESARROLLADOS; PAISES EN DESARROLLO.

02472 Lagos, Gustavo; Klaveren, Alberto van. "Las relaciones interameri- 
canas en una perspectiva global", Estudios Internacionales, N48, año XII, octubre-diciembre 1979, pp. 390-418.

POLITICA INTERNACIONAL; ESTADOS UNDDOS; AMERICA DEL NORTE; AMERICA LĀTINA: RELACIONES EXTERIORES.

02473 Chaparro, Patricio. "El Sistema Económico Latinoamericano (SELA), como instancia de mediación, representación y acción política, ¿destinado al fracaso?", Estudios Internacionales, No48, año XII, octubre-dicienibre 1979, pp. 419-439.

AMERICA LATINA; SELA; INTEGRACION REGIONAL.

02474 Wilhelmy, Manfred. "Hacia un análisis de la política exterior chilena contemporánea", Estudios Intemacionales, N248, año XII, octubrediciembre 1979, pp. 440-471.

POLITICA INTERNACIONAL; CHILE; AMERICA DEL SUR; RELACIONES EXTERIORES.

02475 Barros Charlín, Raymundo. "La elección del Parlamento Europeo por sufragio universal directo", Estudios Internacionales, Ne48, año XII, octubre-diciembre 1979, pp. 472-494. COMUNIDAD ECONOMICA EUROPEA; EUROPA; PARLAMENTO EUROPEO.

02476 Ferrer, Aldo. "La economía internacional desde una perspectiva latinoamericana", Estudios Intemacionales, №49, año XIII, eneromarzo 1980, pp. 3-37.

ECONOMIA INTERNACIONAL; AMERICA LATINA; TERCER MUNDO.

02477 Berrocal Soto, Fernando. "América Latina en la década de los 80 ", Estudios Intemacionates, №49, año XIII, enero-marzo 1980, pp. 38-53.

AMERICA LATINA; ECONONIA INTERNACIONAL.

02478 Lowenthal, Abraham F.; Fishlow, Albert. "Los nuevos intereses de los Estados Unidos en el hemisferio occidental", Estudios Intemacio nales, №49, año XIII, enero-marzo 1980, pp. 54-69.

ESTADOS UNIDOS; AMERICA DEL NORTE; AMERICA LATINA; POLITICAINTERR NACIONAL.

02479 Sábato, Jorge A.; Ramesh, Jairman. "Programas de energía nuclear en el mundo en desarrollo: su fundamento e impacto", Estudios Internacionales, Ne49, año XII, enero-marzo 1980, pp. 70-85. ENERGIA NUCLEAR; DESARROLLO ECONOMICO; POLITICA MUNDIAL.

02480 Sagasti, Francisco R. "Políticas de ciencia y tecnología para el desarrollo", Estudios Intemacionales, Ne49, año XIII, enero-marzo 1980, pp. 86-111.

CIENCIA Y TECNOLOGIA; DESARROLLO ECONOMICO.

02481 Gligo, Nicolo; Morello, Jorge. "Notas sobre la historia ecológica de 
América Latina", Estudios Intemacionales, №49, año XIII, eneromarzo 1980, pp. 112-148.

MEDIO AMBIENTE; HISTORIA; AMERICA LATINA; ECOLOGIA.

02482 Véliz, Claudio. "La tradición centralista en América Latina", Estudios Internacionales, N250, año XIII, abril-junio 1980, pp. 151-162. AMERICA LATINA; HISTORIA; POLITICA Y GOBIERNO.

02483 Sunkel, Osvaldo; Tomassini, Luciano. "La crisis del sistema transnacional y el cambio en las relaciones internacionales de los países en desarrollo", Estudios Internacionales, №50, año XIII, abril-junio 1980, p.p. 163-207.

ECONOMIAINTERNACIONAL; DESARROLLO ECONOMICO; RELACIONES EXTERIORES; POLITICA INTERNACIONAL; PAISES EN DESARROLLO.

02484 Ullman, Richard. "Seguridad internacional en los ochenta", Estudios Internacionales, No50, año XIII, abril-junio 1980, pp. 208-235.

POLITICA INTERNACIONAL; POLITICA MUNDIAL; SEGURIDAD INTERNACIONAL.

02485 Lagos, Gustavo. "Tendencias y perspectivas del estudio de las relaciones internacionales: tareas para América Latina", Estudios Internacionales, N250, año XIII, abril-junio 1980, pp. 236-251.

AMERICA LATINA; RELACIONES INTERNACIONALES; RELACIONES INTERNACIONALES - ESTUDIO Y ENSEÑANZA.

02486 Lagos, Ricardo. "América Latina: algunos hechos económicos recientes y su poder de negociación", Estudios Internacionales, №51, año XIII, julio-septiembre 1980, pp. 291-308.

AMERICA LATINA; ECONOMIAINTERNACIONAL; DESARROLLOECONOMICO; NEGOCIACIONES.

02487 Lafer, Celso. "La política exterior brasileña: Balance y perspectivas", Estudios Internacionales, No51, año XIII, julio-septiembre 1980, pp. 309-327:

POITICA INTERNACIONAL; BRASIL; AMERICA DEL SUR; ECONOMIA INTERNACIONAL; RELACIONES EXTERIORES.

02488 Muñoz, Heraldo. "Los estudios internacionales en América Latina: problemas fundamentales", Estudios Internacionales, №51, año XIII, julio-septiembre 1980, pp. 328-344.

AMERICA LATINA; RELACIONES INTERNACIONALES - ESTUDIO Y ENSEÑANZA.

02489 Díaz Albónico, Rodrigo. "El sistema de seguridad interamericana y sus nuevos desarrollos a través del Tratado de Tlatelolco", Estudios Internacionales, N251, año XIII, julio-septiembre 1980, pp. 345-381. SEGURIDAD; SISTEMA INTERAMERICANO; TRATADO DE TLATELOLCO; AMERICA LATINA; POLITICA INTERNACIONAL; SEGURIDAD INTERNACIONAL. 
02490 Marcella, Gabriel. "Las relaciones militares entre los Estados Unidos y América Latina. Crisis e interrogantes futuras", Estudios Intemacionales, №51, año XIII, julio-septiembre 1980, pp. 382-400.

FUERZAS ARMADAS; ESTADOS UNIDOS; AMERICA LATINA; POLITICA INTERNACIONAL; AMERICA DEL NORTE; RELACIONES EXTERIORES.

02491 Mols, Manfred. "Observaciones europeas sobre la integración latinoamericana", Estudios Intemacionales, №51, año XIII, julio-septiembre 1980, pp. 401-412.

EUROPA; AMERICA LATINA; INTEGRACION REGIONAL; INTEGRACION ECONOMICA.

02492 Almeida, Rómulo. "Reflexiones sobre la integración latinoamericana", Estudios Intemacionales, N52, año XIII, octubre-diciembre 1980, pp. 417-459.

INTEGRACION REGIONAL; INTEGRACION ECONOMICA; AMERICA LATINA; ECONOMIA INTERNACIONAL.

02493 Tulchin, Joseph S. "Una perspectiva histórica de la política argentina frente al Brasil", Estudios Internacionales, N252, año XIII, octubrediciembre 1980, pp. 460-480.

POLITICA INTERNACIONAL; ARGENTINA; BRASIL; AMERICA DEL SUR; RELACIONES EXTERIORES.

02494 Moneta, Carlos J. "América Latina y el sistema internacional en la década del ochenta: ¿Hacia un nuevo orden antártico?", Estudios Intemacionales, No52, año XIII, octubre-diciembre 1980, pp. 481526.

AMERICA LATINA; POLITICA INTERNACIONALi ANTARTICA.

02495 Green, Rosario. "La importancia del estudio de las relaciones internacionales de los países latinoamericanos", Estudios Intemacionales, №52, año XIII, octubre-diciembre 1980, pp. 527-544.

AMERICA LATINA: RELACIONES INTERNACIONALES - ESTUDIO Y ENSEÑANZA.

02496 Tomassini, Luciano. "Los estudios internacionales en América Latina: algunas contribuciones", Estudios Internacionales, №52, año XIII, octubre-diciembre 1980, pp. 545-552.

AMERICA LATINA; RELACIONES INTERNACIONALES -- ESTUDIO Y ENSEÑANZA.

02497 Orrego Vicuña, Francisco. "Europa y América Latina: ¿Hacia un rol internacional complementario?", Estudios Intemacionales, №53, año XIV, enero-marzo 1981, pp. 3-16.

EUROPA; AMERICA LATINA; POLITICA INTERNACIONAL; RELACIONES EXTERIORES; COOPERACION INTERNACIONAL.

02499 Sábato, Jorge A.; Caputo, Dante M.; Sábato, Jorge F. "Cooperación 
para el desarrollo: algunas reflexiones y propuestas", Estudios Inter-

$\therefore \quad$ nacionales, N553, año XIV, enero-marzo 1981, pp. 17-47.

AMERICA LATINA; POLITICA INTERNACIONAL; COOPERACION INTERNACIONAL.

02500 Salgado, Germánico. "Discurso pronunciado con motivo de la celebración del día de las Naciones Unidas, en Santiago el día 24 de octubre de 1980", Estudios Intemacionales, N253, año XIV, eneromarzo 1981, pp. 48-54.

NACIONES UNIDAS; POLITICA MUNDIAL; DISCURSOS; CHILE; AMERICA DEL SUR.

02501 Russell, Roberto; Carballal, Teresa. "El Nuevo Orden Económico Internacional: tendencias observables en el Norte y en los países mayores de América Latina", Estudios Intemacionales, №53, año XIV, enero-marzo 1981, pp. 55-88.

NUEVO ORDEN ECONOMICO INTERNACIONAL; RELACIONES NORTE SUR; AMERICA LATINA; ECONOMIA INTERNACIONAL; POLITICA INTERNACIONAL; RELACIONES EXTERIORES.

02502 Drekonia Kornat, Gerhald. "Aproximaciones a la política exterior latinoamericana", Estudios Intemacionales, №53, año XIV, eneromarzo 1981, pp. 89-104.

AMERICA LATINA; POLITICA INTERNACIONAL; RELACIONES EXTERIORES.

02503 Alcalde Cardoza, Javier. "Las relaciones económicas internacionales en la década del 80", Estudios Internacionales, No53, año XIV, enero-marzo 1981, pp. 105-135.

ECONOMIA INTERNACIONAL; POLTTICA INTERNACIONAL; RELACIONES NORTE SUR; RELACIONES EXTERIORES; RELACIONES ECONOMICAS INTERNACIONALES.

02504 Pinto, Aníbal. "Guerra Fría y distensión en América Latina: a la luz de los ensayos de don José Medina Echavarría", Estudios Intemacionales, No54, año XIV, abril-junio 1981, pp. 145-165.

POLITICA MUNDIAL; AMERICA LATINA; GUERRA FRIA; DISTENSION.

02505 Abdenur, Roberto; Sardenberg, Ronaldo. "Notas sobre las relaciones Norte-Sur y el Informe Brandt", Estudios Internacionales, №54, año XIV, abril-junio 1981, pp. 166-200.

RELACIONES NORTE SUR; ECONOMIA INTERNACIONAL; POLITICA INTERNACIONAL; RELACIONES EXTERIORES.

02506 Wionczek, Miguel S. "¿Qué puede hacerse con el Informe Brandt?", Estudios Internacionales, N954, año XIV, abril-junio 1981, pp. 201223.

POLITICA INTERNACIONAL; ECONOMIA INTERNACIONAL; RELACIONES NORTE SUR; RELACIONES EXTERIORES. 
02507 Nitsch, Manfred. "Los intereses de los países ricos y el desarrollo del Tercer Mundo: La República Federal de Alemania", Estudios Internacionales, №54, año XIV, abril-junio 1981, pp. 224-253.

TERCER MUNDO; DESARROLLO ECONOMICO; EUROPA; ECONOMIA INTERNACIONAL; POLITICA INTERNACIONAL; ALEMANIA REP. FEDERAL.

02508 Perry, Guillermo. "El Informe Brandt y el comercio de productos industrializados", Estudios Intemacionales, NN54, año XIV, abril-junio 1981, pp. 254-265.

COMERCIO EXTERIOR; ECONOMIA INTERNACIONAL; RELACIONES NORTE SUR; RELACIONES ECONOMICAS INTERNACIONALES.

02509 Los Documentos de Villa de Leyva. Estudios Intemacionales, Ne54, año XIV, abril-junio 1981, pp. 266-287.

DOCUMENTOS; AMERICA LATINA; RELACIONES NORTE SUR; POLITICA INTERNACIONAL; ECONOMIA INTERNACIONAL.

02510 Iglesias, Enrique V. "Perspectivas del desarrollo de América Latina", Estudios Internacionales, N955, año XIV, julio-septiembre 1981, pp. 311-321.

DESARROLLO ECONOMICO; AMERICA LATINA; POLITICA INTERNACIONAL.

02511 Sánchez, Walter. "Las relaciones internacionales de América Latina: marginalidad y autonomía", Estudios Internacionales, N255, año XIV, julio-septiembre 1981, pp. 322-356.

POLITICA INTERNACIONAL; AMERICA LATINA; HISTORIA; RELACIONES EXTERIORES.

02512 Lafourcade, Hernán. "Perspectivas del desarrollo de los recursos marinos en América Latina", Estudios Intemacionales, №55, año XIV, julio-septiembre 1981, pp. 357-379.

AMERICA LATINA; DERECHO DEL MAR; RECURSOS MARINOS.

02513 Pinochet de la Barra, Oscar. "Evolución política jurídica del problema antártico", Estudios Intemacionales, N255, año XIV, julio-septiembre 1981, pp. 380-393.

ANTARTICA; HISTORIA; POLITICA INTERNACIONAL; TRATADO ANTARTICO; DERECHO INTERNACIONAL.

02514 María, Luis G. de. "Balance político y económico de la integración andina durante 1980", Estudios Internacionales, N255, año XIV, julio-septiembre 1981, pp. 394-411.

INTEGRACION REGIONAL; INTEGRACION ECONOMICA; PACTO ANDINO; GRUPO ANDINO; ECONOMIA INTERNACIONAL; AMERICA DEL SUR.

02515 Nohlen, Dieter; Fernández B., Mario. "Cooperación y conflicto en la Cuenca del Plata", Estudios Intemacionales, №55, año XIV, julioseptiembre 1981, pp. 412-443.

INTEGRACION REGIONAL; INTEGRACION ECONOMICA; AMERICA LATINA; 
CUENCA DEL PLATA; COOPERACION REGIONAL; COOPERACION ECONOMICA; CONFLICTOS.

02516 Urquidi, Víctor L.; Sánchez, Vicente; Terrazas, Eduardo. "Perspectivasy alternativas de América Latina ante los problemas mundiales", Estudios Internacionales, №56, año XIV, octubre-diciembre 1981, pp. 447-473.

AMERICA LATINA; POLITICA MUNDIAL; SOCIEDAD; ECONOMIA INTERNACIONAL; CAMBIO SOCIAL.

02517 Lagos, Gustavo. "Entre la détente y la Guerra Fría: La crisis del destino manifiesto de las superpotencias", Estudios Internacionales, №56, año XIV, octubre-diciembre 1981, pp. 474-499.

POLITICA MUNDIAL; GUERRA FRIA; DISTENSION; GRANDES POTENCIAS; CRISIS.

02518 Varas, Augusto. "La reinserción de América Latina en el marco estratégico mundial", Estudios Internacionales, No56, año XIV, octubre-diciembre 1981, pp. 500-516.

AMERICA LATINA; SEGURIDAD; ESTRATEGIA; POLITICA MUNDIAL; FUERZAS ARMADAS; ESTADOS UNIDOS; AMERIGA DEL NORTE; RELACIONES EXTERIORES; POLITICA INTERNACIONAL.

02519 Roett, Riordan. "¿Tienen los Estados Unidos algún futuro en América Latina?", Estudios Internacionales, №56, año XIV, octubre-diciembre 1981, pp. 517-529.

ESTADOS UNIDOS; AMERICA DEL NORTE; AMERICA LATINA; POLITICAINTERNACIONAL; RELACIONES EXTERIORES.

02520 Soares de Lima, M. Regina; Hirst, Mónica. "Estados Unidos y América Latina: cerrando una Época en descomposición", Estudios Internacionales, №56, año XIV, octubre-diciembre 1981, pp. 530-552. ESTADOS UNIDOS; AMERICA DEL NORTE; AMERICA LATINA; POLITICA INTERNACIONAL; RELACIONES EXTERIORES.

02521 Pérez Llana, Carlos. "Brasil y Europa: el problema de las percepciones", Estudios Intemacionales, №56, año XIV, octubre-diciembre 1981, pp. 553-567.

BRASIL; AMERICA DEL SUR; EUROPA; POLITICA INTERNACIONAL; RELACIONES EXTERIORES.

02522 Orrego Vicuña, Francisco. "Hacia nuevas formas de integración económica en América Latina: lecciones de una experiencia", Estudios Intemacionales, №56, año XIV, octubre-diciembre 1981, pp. 568-577.

INTEGRACION ECONOMICA; INTEGRACION REGIONAL; AMERICA LATINA; POLITICA INTERNACIONAL; RELACIONES EXTERIORES. 
02523 Saraiva Guerreiro, Ramiro. "La política latinoamericana del Brasil", Estudios Intemacionales, №57, año XV, enero-marzo 1982, pp. 3-9. URASIL; AMERICA DEL SUR; POLITICA INTERNACIONAL; AMERICA LATINA; RELACIONES EXTERIORES.

02524 Jaguaribe, Helio. "Brasil-Argentina: Breve análisis de las relaciones de conflicto y cooperación", Estudios Intemacionales, №57, año XV, enero-marzo 1982, pp. 9-27.

BRASIL; ARGENTINA; POLITICA INTERNACIONAL; AMERICA DEL SUR; RELACIONES EXTERIORES; COOPERACION REGIONAL; CONFLICTOS.

02525 Peña, Félix. "Perspectivas de las relaciones entre la Argentina y el Brasil: algunos apuntes", Estudios Internacionales, №57, año XV, enero-marzo 1982, pp. 28-38.

ARGENTINA; BRASIL; AMERICA DEL SUR; POLITICA INTERNACIONAL; RELACIONES BILATERALES.

02526 Grabendorff, Wolf. "Brasily la República Federal de Alemania: ¿Un modelo para las relaciones entre el Primer y Tercer Mundo?", Estudios Intemacionales, №57, año XV, enero-marzo 1982, pp. 39-59. BRASIL; AMERICA DEL SUR; EUROPA; POLITICA INTERNACIONAL; GRANDES POTENCIAS; TERCER MUNDO; ALEMANIA REP. FEDERAL; RELACIONES EXTERIORES.

02527 Mesa-Lago, Carmelo. "La dependencia económica externa de Cuba y su repercusión sobre su política exterior", Estudios Internacionales, Ne57, año XV, enero-marzo 1982, pp. 60-87.

CUBA; AMERICA CENTRAL Y CARIBE; POLITICAINTERNACIONAL; ECONOMIA INTERNACIONAL; DEPENDENCIA ECONOMICA; RELACIONES EXTERIORES.

02528 Berríos, Rubén. "La empresa transideológica y las relaciones económicas Este-Oeste-Sur", Estudios Internacionales, N257, año XV, enero-marzo 1982, pp. 88-103.

ECONOMIAINTERNACIONAL; EMPRESASTRANSNACIONALES; RELACIONES ECONOMICAS INTERNACIONALES.

02529 Lafer, Celso. "Reflexiones sobre el tema del nuevo orden mundial en un orden internacional en transformación", Estudios Internacionales, Ne58, año XV, abril-junio 1982, pp. 127-165.

POLITICA MUNDIAL; RELACIONES NORTE SUR; ORDEN MUNDIAL.

02530 Tomassini, Luciano. "Interdepenđencia y desarrollo nacional", Estudios Intemacionales, №58, año XV, abril-junio 1982, pp. 166-189.

AMERICA LATINA; POLITICA INTERNACIONAL; DEPENOENCIA; COOPERACION REGIONAL.

02531 Orrego Vicuña, Francisco. "Perspectivas de la cooperación entre América Latina y los países de ASEAN", Estudios Internacionales, N258, año XV, abril-junio 1982, pp. 190-204. 
POLITICA INTERNACIONAL; AMERICA LATINA; ASEAN; OCEANO PACIFICO; ECONOMIAINTERNACIONAL; COOPERACION ECONOMICA; COOPERACION INTERNACIONAL.

02532 Bitar, Sergio. "América Latina y Estados Unidos: Relaciones económicas en los años setenta", Estudios Intemacionales, Ne58, año XV, abril-junio 1982, pp. $205-224$.

AMERICA LATINA; ESTADOS UNIDOS; AMERICA DEL NORTE; ECONOMIA INTERNACIONAL; RELACIONES ECONOMICAS INTERNACIONALES.

02533 Días David, Mauricio. "La transnacionalización económica versus la autonomía de las políticas nacionales", Estudios Internacionales, Ne59, año XV, julio-septiembre 1982, pp. 247-259.

ECONOMIA INTERNACIONAL; POLITICA ECONOMICA; RELACIONES ECONOMICAS INTERNACIONALES.

02534 Dunkel, Arthur. "El comercio internacional y la función del GATT", Estudios Intemacionales, №59, año XV, julio-septiembre 1982, pp. 295-303.

ECONOMIA INTERNACIONAL; COMERCIO EXTERIOR; GATT.

02535 Muñoz, Heraldo. "Efectos y lecciones del conflicto de las Malvinas", Estudios Intemacionales, N60, año XV, octubre-diciembre 1982, pp. 499-512.

ISLAS MALVINAS; SISTEMA INTERAMERICANO; AMERICA LATINA; ARGENT!NA; AMERICA DEL SUR; ESTADOS UNIDOS; AMERICA DEL NORTE; CONFLICTOS; POLITICA INTERNACIONAL.

02536 Jaguaribe, Helio. "El futuro de las relaciones entre el Brasil y los Estados Unidos", Estudios Intemacionales, No58, año XV, abril-junio 1982, pp. 225-231.

BRASIL; AMERICA DEL SUR; ESTADOS UNIDOS; AMERICA DEL NORTE; POLITICA INTERNACIONAL; RELACIONES EXTERIORES.

02537 Grabendorff, Wolf. "¿De país aislado a aliado preferido? Las relaciones entre Argentina y los Estados Unidos: 1976-1981", Estudios Intemacionales, Ne58, año XV, abril-junio 1982, pp. 232-239.

ARGENTINA; AMERICA DEL SUR; ESTADOS UNIDOS; AMERICA DEL NORTE; POLITICA INTERNACIONAL; RELACIONES EXTERIORES.

02538 Saraiva Guerreiro, Ramiro. "El mensaje del Brasil en la Conferencia de Cancún", Estudios Internacionales, Ne59, año XV, julio-septiembre 1982, pp. 243-246.

BRASIL; AMERICA DEL SUR; DISCURSOS; RELACIONES NORTE SUR; MEXICO; AMERICA DEL NORTE.

02539 Edwards, Sebastián. "Deuda externa, ahorro doméstico y crecimiento económico en Chile. Una perspectiva de largo plazo: 1982-1990", 
Estudios Intemacionales, №59, año XV, julio-septiembre 1982, pp. 260-275.

CHILE; AMERICA DEL SUR; DESARROLLO ECONOMICO; DEUDA EXTERNA; POLITICA ECONOMICA.

02540 Alcalde Cardoza, Javier. "La crisis de las relaciones atlánticas y la formación de un centro europeo (1968-1975); un ensayo interpretativo", Estudios Internacionales, №59, año XV, julio-septiembre 1982, pp. 276-294.

POLITICA MUNDIAL; EUROPA; ECONOMIA INTERNACIONAL; RELACIONES EXTERIORES; CRISIS.

02541 Martínez Sotomayor, Carlos. "Presencia de la educación y la cultura en las relaciones internacionales de Chile", Estudios Internacionales, Ne59, año XV, julio-septiembre 1982, pp. 304-323.

CHILE; AMERICA DEL SUR; CULTURA; EDUCACION; POLITICA INTERNACIONAL: RELACIONES INTERNACIONALES.

02542 Barros Charlín, Raymundo. "En torno a una obra sobre integración latinoamericana", Estudios Intemacionales, №59, año XV, julio-septiembre 1982, pp. 324-336.

AMERICA LATINA; INTEGRACION REGIONAL; INTEGRACION ECONOMICA.

02543 Paolillo, Felipe. "El impacto del nuevo derecho del mar en la evolución de la organización internacional", Estudios Intemacionales, N59, año XV, julio-septiembre 1982, pp. 337-357.

DERECHO DEL MAR; POLITICA MUNDIAL.

02544 Moneta, Carlos J. "El conflicto de las Islas Malvinas: su papel en la política exterior argentina en el contexto mundial", Estudios Internacionales, №60, año XV, octubre-diciembre 1982, pp. 361-409.

ISLAS MALVINAS; ARGENTINA; AMERICA DEL SUR; POLITICA INTERNACIONAL; POLITICA MUNDIAL; POLITICA Y GOBIERNO; AMERICA LATINA; CONFLICTOS.

02545 Pérez Llana, Carlos. "La política exterior de la Argentina post-Malvinas", Estudios Internacionales, $\mathrm{N}^{2} 60$, año XV, octubre-diciembre 1982, pp. 410-442.

ARGENTINA; ISLAS MALVINAS; AMERICA DEL SUR; POLITICA INTERNACIONAL; CONFLICTOS.

02546 Jaguaribe, Helio. "Reflexiones sobre el Atlántico Sur: América Latina y el Brasil ante la desarticulación del sistema interamericano", Estudios Internacionales, $\mathrm{N}^{\circ} 60$, año XV, octubre-diciembre 1982, pp. 443-461.

BRASIL; AMERICA DEL SUR; AMERICA LATINA; SISTEMA INTERAMERICANO; CONFLICTOS; ISLAS MALVINAS; POLITICA INTERNACIONAL.

02547 Lafer, Celso. "La política externa brasileña y la crisis en el Atlántico 
Sur: una evaluación", Estudios Internacionales, No60, año XV, octubre-diciembre 1982, pp. 462-472.

BRASIL; AMERICA DEL SUR; ISLAS MALVINAS; CONFLICTOS; POLITICAINTERNACIONAL; RELACIONES EXTERIORES.

02548 Orrego Vicuña, Francisco. "La crisis del Atlántico Sur y su influencia en el sistema regional", Estudios Internacionales, $N^{2} 60$, año XV, octubre-diciembre 1982, pp. 473-498.

ISLAS MALVINAS; SISTEMA INTERAMERICANO; CONFLICTOS; AMERICA LATINA; ESTADOS UNIDOS; ANERICA DEL NORTE; POLITICA INTERNACIONAL.

02550 Sábato, Jorge A. "¿Cómo entenderse con Estados Unidos?", Estıdios Internacionales, №60, año XV, octubre-diciembre 1982, pp. 513-518. ESTADOS UNIDOS; AMERICA DEL NORTE; ISLAS MALVINAS; CONFLICTOS; AMMERICA LATINA; POLITICA INTERNACIONAL.

02551 Orrego Vicuña, Francisco. "El elusivo entendimiento entre América Latina y los Estados Unidos", Estudios Intemacionales, №60, año XV, octubre-diciembre 1982, pp. 519-532.

AMERICA LATINA; ESTADOS UNIDOS; AMERICA DEL NORTE; POLITICA INTERNACIONAL; ISLAS MALVINAS; RELACIONES EXTERIORES.

02552 Tomassini, Luciano. "Hacia un sistema latinoamericano de seguridad regional", Estudios Intemacionales, No60, año XV, octubre-diciembre 1982, pp. 533-541.

AMERICA LATINA; SEGURIDAD; SISTEMA INTERAMERICANO; CONFLICTOS; POLITICA INTERNACIONAL; SEGURIDAD REGIONAL.

02553 Herrera Lane, Felipe. "La Banca de Fomento Latinoamericana y la empresa privada: una perspectiva internacional", Estudios Intemacionales, No61, año XVI, enero-marzo 1983, pp. 3-13.

ECONOMIA INTERNACIONAL; AMERICA LATINA; BANCOS REGIONALES DE DESARROLLO.

02554 Orrego Vicuña, Francisco. "La definición de un régimen para los recursos minerales antárticos: opciones básicas", Estudios Internacionales, N261, año XVI, enero-marzo 1983, pp. 14-30.

ANTARTICA; RECURSOS MINERALES.

02555 Cardoso, Fernando H. "América Latina y la influencia de los modelos políticos europeos en los años 80", Estudios Intemacionales, N61, año XVI, enero-marzo 1983, pp. 31-46.

AMERICA LATINA; EUROPA; POLITICA Y GOBIERNO; PARTIDOS POLITICOS.

02556 Mota Sardenberg, Ronaldo. "Brasil-Europa y là reestructuración del poder internacional", Estudios Internacionales, N61, año XVI, enero-marzo 1983, pp. 47-57.

BRASIL; AMERICA DEL SUR; EUROPA; POLITICA INTERNACIONAL; POUTICA MUNDIAL; RELACIONES EXTERIORES. 
02557 Fendt, Roberto. "Comercio exterior y políticas exteriores en Brasil: problemas y prioridades", Estudios Internacionales, No61, año XVI, enero-marzo 1983, pp. 58-76.

BRASIL; AMERICA DEL SUR; COMERCIO EXTERIOR; POLITICA INTERNACIONAL; ECONOMIA INTERNACIONAL; RELACIONES EXTERIORES.

02558 Wionczek, Miguel S. "El futuro de las relaciones chino-soviéticas y su probable impacto global", Estudios Internacionales, №61, año XVI, enero-marzo 1983, pp. 77-89.

CHINA; ASIA; URSS; POLITICA INTERNACIONAL; POLITICA MUNDIAL; EUROPA DEL ESTE; RELACIONES BILATERALES; RELACIONES EXTERIORES.

02559 Ness, Peter van; Raichur, Satish. "Dilemas del desarrollo en China: 1949-1980", Estudios Intemacionales, N61, año XVI, enero-marzo 1983, pp. 90-116.

CHINA; ASIA; DESARROLLO ECONOMICO; SOCIALISMO.

02560 Cousiño Cousiño, José Antonio. "Tecnología y ética en el Nuevo Orden Informativo", Estudios Intemacionales, N²61, año XVI, enero-marzo 1983, pp. 117-133.

CIENCIA Y TECNOLOGIA; MEDIOS DE COMUNICACION; ETICA.

02561 Insulza, José Miguel. "La política de la administración Reagan hacia América Latina: un primer balance", Estudios Internacionales, №61, año XVI, enero-marzo 1983, pp. 134-165.

ESTADOS UNIDOS; AMERICA DEL NORTE; AMERICA LATINA; POLITICAINTEPR NACIONAL; RELACIONES EXTERIORES.

02562 Prebisch, Raúl. "La crisis del capitalismo y la periferia", Estudios Intemacionales, N262, año XVI, abril-junio 1983, pp. 169-179.

CAPITALISMO; AMERICA LATINA; ECONOMIA INTERNACIONAL; CRISIS; POLLTICA MUNDIAL.

02563 Galtung, Johan. "Análisis del carácter de la crisis internacional actual", Estudios Intemacionales, N262, año XVI, abril-junio 1983, pp. 180-210.

POLITICAMUNDIAL; NUEVO ORDEN ECONOMICO INTERNACIONAL; ECONOMIA INTERNACIONAL; CRISIS.

02564 Iglesias, Enrique V. "La crisis económica internacional y las perspectivas de América Latina", Estudios Internacionales, N²62, año XVI, abril-junio 1983, pp. 211-231.

ECONOMIA INTERNACIONAL; AMERICA LATIIFA; CRISIS.

02565 Hager, Wolfgang. "El comercio Norte-Sur y la autonomía socioeconómica: una fórmula de paz", Estudios Internacionales, №62, año XVI, abril-junio 1983, pp. 232-246.

RELACIONES NORTE SUR; COMERCIO EXTERIOR; ECONOMIA INTERNACIONAL; RELACIONES ECONOMICAS INTERNACIONALES. 
02566 Figueredo, Reynaldo. "Hacia una nueva apreciación del sistema de comercio internacional", Estudios Intemacionales, №62, año XVI, abril-junio 1983, pp. 247-254.

ECONOMIA INTERNACIONAL; COMERCIO EXTERIOR.

02567 Spraos, John. "El deterioro de la relación de intercambio: algunas perspectivas", Estudios Intemacionales, №62, año XVI, abril-junio 1983, pp. 255-280.

ECONOMIA INTERNACIONAL; RELACIONES ECONOMICAS INTERNACIONALES.

02568 Ffrench-Davis, Ricardo. "Deuda externa y balanza de pagos de América Latina: tendencias recientes y perspectivas", Estudios Internacionales, №62, año XVI, abril-junio 1983, pp. 281-304. ECONOMIA INTERNACIONAL; AMERICA LATINA; DEUDA EXTERNA.

02569 Massad, Carlos. "América Latina: aspectos principales del financiamiento externo", Estudios Intemacionales, No62, año XVI, abril-junio 1983, pp. 305-314.

AMERICA LATINA; ECONOMIA INTERNACIONAL; DEUDA EXTERNA.

02570 Ferrer, Aldo. "La deuda externa y las políticas nacionales", Estudios Intemacionales, №62, año XVI, abril-junio 1983, pp. 315-329.

ECONOMIA INTERNACIONAL; DEUDA EXTERNA; AMERICA LATINA; POLITICA ECONOMICA.

02571 Urquidi, Víctor L. "La interdependencia económica global y el cambio social", Estudios Intenacionales, N62, año XVI, abril-junio 1983, pp. 330-335.

ECONOMIAINTERNACIONAL; DEPENDENCIA ECONOMICA; CAMBIO SOCIAL.

02572 Betancourt, Belisario. "La capacidad de respuesta de América Latina ante la crisis", Estudios Internacionales, N263, año XVI, julio-septiembre 1983, pp. 339-349.

ECONOMIA INTERNACIONAL; AMERICA LATINA; CRISIS.

02573 Tomassini, Luciano. "Las relaciones internacionales de América Latina en.los escenarios posibles en el largo plazo", Estudios Intemacionales, $\mathrm{N}^{2} 63$, año XVI, julio-septiembre 1983, pp. 350-378. .

AMERICA LATINA; POLITICA INTERNACIONAL; POLITICA MUNDIAL; INTEGRACION REGIONAL; RELACIONES EXTERIORES.

02574 Lafourcade, Hernán. "Hacia la reorganización del mecanismo de reciclaje financiero internacional", Estudios Intemacionales, No63, año XVI, julio-septiembre 1983, pp. 379-390.

ECONOMIA INTERNACIONAL; DEUDA EXTERNA; AMERICA LATINA.:

02575 Orrego Vicuña, Francisco. "Políticas internas e influencias externas 
en el debate sobre derechos humanos en América Latina", Estudios Internacionales, Ne63, año XVI, julio-septiembre 1983, pp. 391-405. AMERICA LATINA; DERECHOS HUMANOS; POLITICA INTERNACIONAL; POLITICA Y GOBIERNO.

02576 Cançado Trindade, Antonio Augusto. "Posiciones internacionales del Brasil al nivel unilateral", Estudios Intemacionales, №63, año XVI, julio-septiembre 1983, pp. 406-458.

BRASIL; AMERICA DEL SUR; POLITICA INTERNACIONAL.

02577 Aleixo, José Carlos Brandi. "Líneas generales de la política externa del Brasil", Estudios Intemacionales, N63, año XVI, julio-septiembre 1983, pp. 459-482.

BRASIL; AMERICA DEL SUR; POLTICA MUNDIAL; RELACIONES EXTERIORES.

02578 Grabendorff, Wolf. "América Central como región de crisis internacional", Estudios Intemacionales, N63, año XVI, julio-septiembre 1983, pp. 483-497.

AMERICA CENTRAL Y CARIBE; POLITICA INTERNACIONAL.

02579 Zorgbibe, Charles. "¿Qué seguridad para Africa?: tres imágenes del kaleidoscopio africano", Estudios Intemacionales, N63, año XVI, julio-septiembre 1983, pp. 498-506.

AFRICA; POLITICA INTERNACIONAL; SEGURIDAD.

02580 Prebisch, Raúl. "Hacia la recuperación económica y la equidad social", Estudios Intemacionales, №64, año XVI, octubre-diciembre 1983, pp. 510-522.

ECONOMIA. INTERNACIONAL; AMERICA LATINA; DEUDA EXTERNA; POLITICA SOCIAL; POLITICA ECONOMICA.

02581 Urquidi, Víctor L. "La actual depresión internacional y los países en vías de desarrollo", Estudios Intemacionales, NQ64, año XVI, octubre-diciembre 1983, pp. 523-533.

ECONOMIA INTERNACIONAL; TERCER MUNDO; PAISES EN DESARROLLO; CRISIS.

02582 Furtado, Celso. "La crisis financiera internacional y sus consecuencias para América Latina", Estudios Internacionales, N64, año XVI, octubre-diciembre 1983, pp. 534-546.

ECONOMLA INTERNACIONAL; AMERICA LATINA; DEUDA EXTERNA; CRISIS.

02583 Devlin, Robert. "La crisis del sector externo de América Latina: el origen del problema y algunas opciones para enfrentarlo", Estudios Internacionales, №64, año XVI, octubre-diciembre 1983, pp. 547-567. ECONOMIA INTERNACIONAL; AMERICA LATINA; DEUDA EXTERNA.

02584 Buira, Ariel. "México: la crisis de divisas y el programa de ajuste", 
Estudios Internacionales, №64, año XVI, octubre-diciembre 1983, pp. 568-578.

MEXICO; AMERICA DEL NORTE; ECONOMIA INTERNACIONAL; POLITICA ECONOMICA.

02585 Nogueira Batista, Paulo. "Análisis crítico de la programación gubernamental del sector externo en el Brasil", Estudios Internacionales, №64, año XVI, octubre-diciembre 1983, pp. 579-602.

BRASIL; AMERICA DEL SUR; ECONOMIA INTERNACIONAL; DEUDA EXTERNA.

02586 Ferrer, Aldo. "¿Puede Argentina pagar su deuda externa?", Estudios Internacionales, $\mathrm{N}^{2} 64$, año XVI, octubre-diciembre 1983, pp. 603628.

ARGENTINA; AMERICA DEL SUR; ECONOMIA INTERNACIONAL; DEUDA EXTERNA.

02587 Green, Rosario. "Visión y acción de Washington frente a la deuda externa latinoamericana", Estudios Intemacionates, №64, año XVI, octubre-diciembre 1983, pp. 629-663.

ECONOMIA INTERNACIONAL; DEUDA EXTERNA; AMERICA LATINA; ESTADOS UNIDOS; AMERICA DEL NORTE.

02588 Reunión de personalidades sobre la crisis mundial y América Latina: conclusiones, Estudios Intemacionales, N²64, año XVI, octubre-diciembre 1983, pp. 664-668.

DOCUMENTOS; AMERICA LATINA; ECONOMIA INTERNACIONAL; CEPAL; DEUDA EXTERNA; REUNION; CRISIS.

02589 Reunión sobre crisis y deuda en América Latina: conclusiones. Estudios Intemacionales, N64, año XVI, octubre-diciembre 1983, pp. 669-674.

DOCUMENTOS; AMERICA LATINA; ECONOMIA INTERNACIONAL; CEPAL; DEUDA EXTERNA; REUNION; CRISIS.

02590 Jaguaribe, Helio. "Reflexiones sobre la paz mundial", Estudios Internacionales, N65, año XVII, enero-marzo 1984, pp. 4-15. POLITICA MUNDIAL; ARMAMENTISMO; PAZ.

02591 Tomassini, Luciano. "El proceso de transnacionalización y las relaciones externas de los países latinoamericanos", Estudios Internacionales, №65, año XVII, enero-marzo 1984, pp. 16-55.

AMERICA LATINA; POLITICA INTERNAGIONAL; POLITICA MUNDIAL; RELACIONES EXTERIORES.

02592 Varas, Augusto. "De la internacionalización a la transnacionalización en América Latina", Estudios Internacionales, №65, año XVII, enero-marzo 1984, pp. 56-65.

AMERICA LATINA; POLITICA INTERNACIONAL; RELACIONES EXTERIORES. 
02593 Bueno, Gerardo M. "Interdependencia económica: perspectivas desde América Latina", Estudios Internacionales, №65, año XVII, enero-marzo 1984, pp. 66-93.

ECONOMIA INTERNACIONAL; AMERICA LATINA; DEPENDENCIA ECONOMICA; RELACIONES ECONOMICAS INTERNACIONALES.

02594 Bouzas, Roberto. "Estados Unidos y el proceso de transnacionalización en la postguerra", Estudios Internacionales, N65, año XVII, enero-marzo 1984, pp. 94-111.

ESTADOS UNIDOS; AMERICA DEL NORTE; POLITICA INTERNACIONAL; RELACIONES EXTERIORES.

02595 Grabendorff, Wolf. "Las relaciones entre América Latina y Europa Occidental: los actores nacionales y transnacionales, sus objetivos y expectativas", Estudios Internacionales, No65, año XVII, enero-marzo 1984, pp. 112-130.

AMERICA LATINA; EUROPA; POLITICA INTERNACIONAL; COOPERACION INTERNACIONAL; EUROPA OCCIDENTAL; RELACIONES EXTERIORES.

02596 Moneta, Carlos J. "El factor energético (hidrocarburos), en las relaciones internacionales de América Latina", Estudios Intemacionales, №65, año XVII, enero-marzo 1984, pp. 131-159.

AMERICA LATINA; POLITICA INTERNACIONAL; ECONOMIA INTERNACIONAL; RECURSOS ENERGETICOS; PETROLEO; COOPERACION INTERNACIONAL; ENERGIA; RELACIONES EXTERIORES.

02597 Lahera, Eugenio. "La internacionalización del proceso productivo", Estudios Intentacionales, Ne65, año XVII, enero-marzo 1984, pp. 160-166.

ECONOMIA INTERNACIONAL; EMPRESAS TRANSNACIONALES.

02598 Russell, Roberto. "Argentina y la política exterior del régimen autoritario (1976-1983): una evaluación preliminar", Estudios Intemacionales, No66, año XVII, abril-junio 1984, pp. 170-201.

ARGENTINA; AMERICA DEL SUR; POLITICA INTERNACIONAL; POLITICA $Y$ GOBIERNO; RELACIONES EXTERIORES.

02599 Soares, Glaucio Ary Dillon. "El futuro de la democracia en América Latina", Estudios Intemacionales, N66, año XVII, abril-junio 1984, pp. 202-231.

AMERICA LATINA; DEMOCRACIA; POLITICA Y GOBIERNO.

02600 Orrego Vicuña, Francisco. "Políticas internas e influencias externas en el debate sobre derechos humanos en América Latina", Estudios Internacionales, №66, año XVI, abril-junio 1984, pp. 232-246.

AMERICA LATINA; DERECHOS HUMANOS; POLITICA INTERNACIONAL; POLITICA Y GOBIERNO.

02601 Bitar, Sergio. "Los intereses económicos de EE.UU. y su política hacia 
América Latina", Estudios Internacionales, №66, año XVII, abril-junio 1984, pp. 247-256.

ESTADOS UNIDOS; AMERICA DEL NORTE; AMERICA LATINA; ECONOMIA INTERNACIONAL; POLITICA INTERNACIONAL.

02602 Iglesias, Enrique V. "América Latina: crisis y opciones de desarrollo", Estudios Intemacionales, №6, año XVII, enero-marzo 1984, pp. 257-292.

DOCUMENTOS; AMERICA LATINA; DESARROLLO ECONOMICO; CEPAL; ECONOMIA INTERNACIONAL.

02603 Pardo, Arvid. "El espacio oceánico y la humanidad", Estudios Internacionales, N'66, año XVII, abril-junio 1984, pp. 293-306.

DERECHO DEL MAR; ESPACIOS MARITIMOS.

02604 Ferrer, Aldo. "Deuda, soberanía y democracia en América Latina", Estudios Internacionales, №67, año XVII, julio-septiembre 1984, pp. 309-323.

DEUDA EXTERNA; AMERICA LATINA; ECONOMIA INTERNACIONAL; DEMOCRACIA; SOBERANIA.

02605 Armanet Armanet, Pilar. "La seguridad regional: hacia la consolidación de la zona desnuclearizada", Estudios Intemacionales, №67, año XVII, julio-septiembre 1984, pp. 324-336.

POLITICA INTERNACIONAL; AMERICA LATINA; TRATADO DE TLATELOLCO; SEGURIDAD REGIONAL; ZONAS DESNUCLEARIZADAS.

02606 Infante Caffi, María Teresa. "Argentina y Chile: percepciones del conflicto de la zona del Beagle", Estudios Internacionales, No67, año XVII; julio-septiembre 1984, pp. 337-358.

ARGENTINA; CHILE; AMERICA DEL SUR; CONFLICTOS; BEAGLE; POLITICA INTERNACIONAL; RELACIONES BILATERALES.

02607 Jaksic, Iván. "Puerto Rico: los dilemas del status político y el desarrollo dependiente", Estudios Intemacionales, №67, año XVII, julioseptiembre 1984, pp. 359-377.

PUERTO RICO; AMERICA CENTRAL Y CARIBE; ESTADOS UNIDOS; AMERICA DEL NORTE; HISTORIA; POLITICA INTERNACIONAL; DEPENDENCIA.

02608 Barros Charlín, Raymundo. "Comunidad Económica Europea: la incertidumbre compartida", Estudios Internacionales, N267, año XVII, julio-septiembre 1984, pp. 378-400.

COMUNIDAD ECONOMICA EUROPEA; EUROPA; INTEGRACION REGIONAL; INTEGRACION ECONOMICA.

02609 Granda Alva, Germán; García y García Sánchez-Blanco, José Luis. "La cooperación para el desarrollo de las comunidades europeas y sus relaciones con América Latina: un reto para España", Estudios Intemacionales, №67, año XVII, julio-septiembre 1984, pp. 401-417. 
AMERICA LATINA; COMUNIDAD ECONOMICA EUROPEA; ESPAÑA; EUROPA; COMUNIDADES EUROPEAS; COOPERACION INTERNACIONAL; RELACIONES EXTERIORES; COOPERACION REGIONAL.

02610 Martner G., Gonzalo. "América Latina dentro del orden económico mundial", Estudios Intemacionales, №68, año XVII, octubre-diciembre 1984, pp. 420-440.

AMERICA LATINA; ECONOMIA INTERNACIONAL; NUEVO ORDEN ECONOMICO INTERINACIONAL.

02611 Wionczek, Miguel S. "Las desventuras de la ALADI: 1980-1983", Estudios Internacionales, N68, año XVII, octubre-diciembre 1984, pp. 441-458.

INTEGRACION ECONOMICA; INTEGRACION REGIONAL; AMERICA LATINA; ECONOMIA INTERNACIONAL; ALADI.

02612 Salgado, Germánico. "El Grupo Andino: problemas y perspectivas", Estudios Internacionales, №68, año XVII, octubre-diciembre 1984, pp. 459-492.

GRUPO ANDINO; INTEGRACION ECONOMICA; INTEGRACION REGIONAL; ECONOMIA INTERNACIONAL; AMERICA DEL SUR; PACTO ANDINO.

02613 Rosenthal, Gert. "Algunas lecciones de la integración económica en América Latina: el caso de Centroamérica", Estudios Inteniacionales, №68, año XVII, octubre-diciembre 1984, pp. 493-512.

AMERICA LATINA; AMERICA CENTRAL Y CARIBE; INTEGRACION ECONOMICA; ECONOMIA INTERNACIONAL.

02614 Klaveren, Alberto van. "Las nuevas formas de concertación política en América Latina", Estudios Interiacionales, N68, año XVII, octubre-diciembre 1984, pp. 513-536.

AMERICA LATINA; INTEGRACION REGIONAL; PACTO ANDINO; ISLAS MALVINAS; CONCERTACION POLITICA; GRUPO CONTADORA.

02615 Durán, Esperanza. "La solución de Contadora para el logro de la paz en Centroamerica", Estudios Intemacionales, N68, año XVII, octubre-diciembre 1984, pp. 537-547.

AMERICA CENTRAL Y CARIBE; CONFLICTOS; GRUPO CONTADORA; PAZ.

02616 Nohlen, Dieter. "El cambio de régimen político en América Latina: en torno a la democratización de los regímenes autoritarios", Estudios Internacionales, N68, año XVI, octubre-diciembre 1984, pp. 548-575.

AMERICA LATINA; POLITICA Y GOBIERNO; DEMOCRATIZACION; AUTORITARISMO.

02617 Wionczek, Miguel S. "La economía mundial en 1984 y sus perspectivas para el resto de los años ochenta", Estudios Internacionales, No69, año XVIII, enero-marzo 1985, pp. 3-31. 
ECONOMIA INTERNACIONAL; ESTADOS UNIDOS; AMERICA DEL NORTE; EUROPA; TERCER MUNDO; COMERCIO EXTERIOR.

02618 Barros, Alexandre de S. C. "Política internacional en América Latina: seguridad en los primeros años del decenio de 1980 y después", Estudios Intentacionales, N69, año XVIII, enero-marzo 1985, pp. 32-50.

AMERICA LATINA; POLITICA INTERNACIONAL; SEGURIDAD.

02619 Russell, Roberto. "El fenómeno Reagan y América Latina: visiones, obstáculos y perspectivas", Estudios Internacionales, N69, año XVIII, enero-marzo 1985 ; pp. 51-62.

AMERICA LATINA; ESTADOS UNIDOS; AMERICA DEL NORTE; POLITICAINTERNACIONAL; RELACIONES EXTERIORES.

02620 Lagos, Gustavo; Plaza, Oscar. "La actual política exterior norteamericana y su proyección en América Latina", Estudios Intemacionales, N69, año XVIII, enero-marzo 1985, pp. 63-80.

ESTADOS UNIDOS; AMERICA DEL NORTE; AMERICA LATINA; POLITICA INTERNACIONAL; RELACIONES EXTERIORES.

02621 Santa Cruz, Hernán. "La anticooperación internacional y el retorno de las políticas de poder", Estudios Intemacionales, N²69, año XVIII, ènero-marzo 1985, pp. 81-86.

POLITICA MUNDIAL; COOPERACION INTERNACIONAL; PODER.

02622 Moneta, Carlos J. "Fuerzas Armadas y gobierno constitucional después de Malvinas: hacia una nueva relación civil-militar", Estudios Intemacionales, №69, año XVIII, enero-marzo 1985, pp. 110-171. ARGENTINA; AMERICA DEL SUR; FUERZAS ARMADAS; PÓLITICA $Y$ GOBIERNO; ISLAS MALVINAS; POLITICA INTERNACIONAL:

02623 Pérez Llana, Carlos. "La crisis internacional y los países en desarro1lo", Estudios Intemacionales, Ne70, año XVIII, abril-junio 1985, pp. 175-185.

POLITICA INTERNACIONAL; AFRICA; AMERICA LATINA; ASIA; PAISES EN DESARROLLO; POLITICA MUNDIAL; GRISIS.

02624 Marshall, Isabel; Silva, Enrique; Mardones, José Luis. "Proteccionismo y reestructuración en la industria del cobre: las políticas de los productores", Estudios Internacionales, N69, año XVIII, enero-marzo 1985 , pp. 87-109.

ECONOMIA INTERNACIONAL; COBRE; PROTECCIONISMO; ESTADOS UNIDOS; AMERICA DEL NORTE.

02625 Sideri, Sandro. "Europa y América Latina en la crisis mundial", Estudios Intemacionales, Ne70, año XVII, abril-junio 1985, pp. 186220.

EUROPA; AMERICA LATINA; ECONOMIA INTERNACIONAL; CRISIS. 
02626 Tomassini, Luciano. "La economía mundial y América Latina: reflexiones sobre el corto y el mediano plazo", Estudios Internacionales, №70, año XVIII, abril-junio 1985, pp. 221-240.

ECONOMIAINTERNACIONAL; AMERICA LATINA; DESARROLLO ECONOMICO.

02627 Hirst, Mónica. "Las relaciones de Estados Unidos con las potencias medianas en América Latina: los casos de México y Brasil", Estudios Internacionales, №70, año XVIII, abril-junio 1985, pp. 241-269.

ESTADOS UNIDOS; AMERICA DEL NORTE; AMERICA LATINA; MEXICO; BRASIL; AMERICA DEL SUR; POLITICA INTERNACIONAL; ECONOMIA INTERNACIONAL; RELACIONES EXTERIORES.

02628 Selcher, Wayne. "Relaciones entre Brasil y Argentina en la década del 80: de una cautelosa rivalidad a una competencia amistosa", Estudios Internacionales, N270, año XVIII, abril-junio 1985, pp. 270301.

BRASIL; ARGENTINA; AMERICA DEL SUR; POLITICA INTERNACIONAL; ECONOMIA INTERNACIONAL; RELACIONES BILATERALES; RELACIONES ECONOMICAS INTERNACIONALES.

02629 Wilhelmy, Manfred. "¿Es Afganistán un Vietnam para la Unión Soviética?", Estudios Internacionales, Ne70, año XVIII, abril-junio 1985, pp. 302-334.

URSS; EUROPA DEL ESTE; AFGANISTAN; ASIA; POLITICA INTERNACIONAL; CONFLICTOS; RELACIONES EXTERIORES; INTERVENCION - DERECHO INTERNACIONAL.

02630 Jaguaribe, Helio. "Los conflictos cardinales de nuestro tiempo y la posición del Brasil", Estudios Intemacionales, NQ71, año XVIII, julio-septiembre 1975, pp. 337-348,

POLITICA INTERNACIONAL; BRASIL; AMERICA DEL SUR; POUTICA MUNDIAL; CONFLICTOS.

02631 Tella, Torcuato di. "Los procesos políticos en América Latina", Estudios Internacionales, No71, año XVIII, julio-septiembre 1985, pp. 349-369.

AMERICA LATINA; POLITICA Y GOBIERNO.

02632 Delich, Francisco. "De la democracia como necesidad a la democracia como condición", Estudios Intemacionales, N271, año XVIII, julio-septiembre 1985, pp. 370-381.

DEMOCRACIA; POLITICA Y GOBIERNO; AMERICA LATINA.

02633 Matos Mar, José. "Crisis del Estado y desborde popular en el Perú", Estudios Internacionales, No71, año XVIII, julio-septiembre 1985, pp. 382-388.

PERU; AMERICA DEL SUR: POLITICA Y GOBIERNO; CRISIS; MOVIMIENTOS SOCIALES. 
02634 Viñas, Angel. "Coordenadas de la política de seguridad española: análisis y sugerencias", Estudios Internacionales, №71, año XVII, julio-septiembre 1985, pp. 389-421.

ESPAÑA; EUROPA; SEGURIDAD; POLITICA INTERNACIONAL; OTAN.

02635 Grabendorff, Wolf. "La crisis centroamericana: ¿Tiene Europa Occidental un papel en ella?", Estudios Intemacionales, №71, año XVIII, julio-septiembre 1985, pp. $422-439$.

AMERICA CENTRAL Y CARIBE; CONFLICTOS; POLITICA INTERNACIONAL; EUROPA; EUROPA OCCIDENTAL.

02636 Cepeda Ulloa, Fernando. "El proceso de paz en Colombia y la política internacional", Estudios Internacionales, No71, año XVIII, julio-septiembre 1985, pp. 440-450.

COLOMBIA; AMERICA DEL SUR; POLITICA INTERNACIONAL; POLITICA Y GOBIERNO; PAZ.

02637 Maira, Luis. "Los márgenes de hegemonía internacional de Estados Unidos: una visión histórica", Estudios Internacionales, Ne72, año XVIII, octubre-diciembre 1985, pp. 454-477.

ESTADOS UNIDOS; AMERICA DEL NORTE; POLITICA INTERNACIONAL; HISTORIA; AMERICA LATINA; POLITICA MUNDIAL; PODER.

02638 Tavares, María da Çonceiçao. "La recuperación de la hegemonía norteamericana", Estudios Internacionales, N272, año XVIII, octubre-diciembre 1985, pp. 478-505.

ESTADOS UNIDOS; AMERICA DEL NORTE; PODER; ECONOMIA INTERNACIONALi POLITICA INTERNACIONAL.

02639 Bitar, Sergio. "El desconcertante reimpulso de la hegemonía internacional de Estados Unidos", Estudios Intemacionales, No72, año XVIII, octubre-diciembre 1985, pp. 506-527.

ESTADOS UNIDOS; AMERICA. DEL NORTE; POLITICA INTERNACIONAL; POLITICA MUNDIAL; ECONOMIA INTERNACIONAL; PODER.

02640 Bouzas, Roberto. "La evolución de la economía y la política económica norteamericana en 1984/1985", Estudios Intemacionales, No72, año XVIII, octubre-diciembre 1985, pp. 528-575.

ESTADOS UNIDOS; AMERICA DEL NORTE; ECONOMIA INTERNACIONAL; POLITICA ECONOHICA.

02641 Rodríguez Mendoza, Miguel. "América Latina y la nueva legislación comercial de Estados Unidos", Estudios Internacionales, Ne72, año XVII, octubre-diciembre 1985, pp. 576-592.

ESTADOS UNIDOS; AMERICA DEL NORTE; AMERICA LATINA; ECONOMIA INTERNACIONAL; COMERCIO EXTERIOR.

02642 Pelzman, Joseph; Núñez, José. "El crimen más largo: los controles impuestos por los Estados Unidos a la exportación de productos 
textiles", Estudios Internacionales, NN72, año XVII, octubre-diciembre 1985, pp. 593-600.

ESTADOS UNIDOS; AMERICA DEL NORTE; ECONOMIA INTERNACIONAL; COMERCIO EXTERIOR; EXPORTACIONES.

02643 Pérez Llana, Carlos. "Relaciones internacionales y transición política", Estudios Intemacionales, №73, año XIX, enero-marzo 1986, pp. 3-15.

POLITICAINTERNACIONAL; POLITICA Y GOBIERNO; TRANSICION DEMOCRATICA.

02644 Roett, Riordan. "Panorama de las relaciones políticas y la seguridad del área del Atlántico, como consecuencia del trastorno económico", Estudios Intemacionales, №73, año XIX, enero-marzo 1986, pp. 16-36.

SEGURIDAD; ECONOMIA INTERNACIONAL; DEUDA EXTERNA; EUROPA; ESTADOS UNIDOS; AMERICA DEL NORTE; AMERICA DEL SUR; RELACIONES EXTERIORES.

02645 Paiva Abreu, Marcelo de; Fritsch, Winston. "Un estudio sobre la graduación", Estudios Internacionales, №73, año XIX, enero-marzo 1986, pp. 37-75.

ECONOMIA INTERNACIONAL; GATT; BRASIL; AMERICA DEL SUR.

02646 Walker, Ignacio. "Las armas nucleares y el carácter de las relacioncs internacionales", Estudios Intemacionales, №73, año XIX, eneromarzo 1986, pp. 76-97.

POLITICA INTERNACIONAL; ARMAMENTISMO; CONFLICTOS; ARMAS NUCLEARES; RELACIONES EXTERIORES.

02647 Estévez, Jaime. "Crisis de pagos y políticas de ajuste en América Latina", Estudios Intemacionales, N73, año XIX, enero-marzo 1986, pp. 98-117.

AMERICA LATINA; ECONOMIA INTERNACIONAL; DEUDA EXTERNA; POLITICA ECONOMICA.

02648 Berthelot, Ives. "Perspectivas económicas para 1985-1990: algunas inquietudes", Estudios Internacionales, N273, año XIX, enero-marzo 1986, pp. 118-121.

ECONOMLA INTERNACIONAL.

02649 Herrera Lane, Felipe. "Alianza para el Progreso: los postulados y las realizaciones", Estudios Internacionales, N274, año XIX, abril-junio 1986, pp. 125-132.

ALIANZA PARA EL PROGRESO; ESTADOS UNIDOS; AMERICA DEL NORTE; AMERICA LATINA; POLITICA INTERNACIONAL

02650 Lowenthal, Abraham F. "Las relaciones externas de América Latina 
en 1985", Estudios Intemacionales, №74, año XIX, abril-junio 1986, pp. 133-158.

POLITICA INTERNACIONAL; AMERICA LATINA; ESTADOS UNIDOS; AMERICA DEL NORTE; ECONOMIA INTERNACIONAL; RELACIONES EXTERIORES.

02651 Sunkel, Osvaldo. "Las empresas transnacionales en el capitalismo actual: algunos viejos y nuevos temas de reflexión", Estudios Internacionales, №74, año XIX, abril-junio 1986, pp. 159-169.

ECONOMIA INTERNACIONAL; EMPRESAS TRANSNACIONALES; CAPITALISMO.

02652 Ominami, Carlos. "El Tercer Mundo y la economía mundial", Estıdios Internacionales, №74, año XIX, abril-junio 1986, pp. 170-210. ECONOMIA INTERNACIONAL; TERCER MUNDO; RELACIONES NORTE SUR; RELACIONES EXTERIORES.

02653 Bodemer, Klaus. "La política de desarrollo de la administración Reagan: fundamentos ideológicos, estrategias y perspectivas", Estudios Internacionales, N74, año XIX, abril-junio 1986, pp. 211-238. ESTADOS UNIDOS; AMERICA DEL NORTE; POLITICA INTERNACIONAL; TERCER MUNDO; POLITICA MUNDIAL.

02654 Ferguson, Yale H. "Reflexiones sobre el análisis de las políticas externas latinoamericanas", Estudios Intemacionales, N274, año XIX, abril-junio 1986, pp. 239-274.

POLITICA INTERNACIONAL; AMERICA LATINA; POLITICA Y GOBIERNO.

02655. Portales, Carlos. "Sudamérica: seguridad regional y relaciones con Estados Unidos", Estudios Internacionales, №75, año XIX, julio-septiembre 1986, pp. 279-334.

AMERICA DEL SUR; ESTADOS UNIDOS; AMERICA DEL NORTE; POLITICA INTERNACIONAL; SEGURIDAD REGIONAL; RELACIONES EXTERIORES.

02656 Briones, Alvaro. "El Tercer Mundo en la perspectiva latinoamericana", Estudios Internacionales, №75, año XIX, julio-septiembre 1986, pp. 335-370.

TERCER MUNDO; AMERICA LATINA; POLITICA INTERNACIONAL; POLITICA MUNDIAL; ECONOMIA INTERNACIONAL.

02657 Arias, María Fernanda. "Trilateralismo y política norteamericana en la decada del 80: el caso de la administración Reagan", Estudios Internacionales, №75, año XIX, julio-septiembre 1986, pp. 371-391. ESTADOS UNIDOS; AMERICA DEL NORTE; POLITICA INTERNACIONAL; GRANDES POTENCIAS.

02658 Ominami, Carlos. "América Latina y la Tercera Revolución Industrial", Estudios Internacionales, №76, año XIX, octubre-diciembre 1986, pp. 407-419.

AMERICA LATINA; CIENCIA Y TECNOLOGIA; ECONOMIA INTERNACIONAL. 
02910 Instituto de Estudios Internacionales - Biblioteca. "Indice de Estudios Internacionales, Año XXIV, Ne93-96, 1991", Estudios Internacionales Ne97, año XXV, enero-marzo 1992; pp. 154-166.

INDICE

02911 Instituto de Estudios Internacionales - Biblioteca. "Bibliografía: Derecho internacional", Estuidios Intemacionales №99, año XXV, julio-septiembre 1992, pp. 437-445.

DERECHO INTERNACIONAL; BIBLIOGRAFIA.

02912 Infante Caffi, María Teresa. "El derecho internacional como objeto de los estudios internacionales", Estudios Internacionales №99, año XXV, julio-septiembre 1992, pp. 427-436.

DERECHO INTERNACIONAL; RELACIONES INTERNACIONALES - ESTUDIO Y ENSEÑANZA; ESTUDIO Y ENSENAANZA.

02913 Durán, Roberto. "Vigencia del esquema conductualista en los estudios internacionales: su viabilidad en América Latina", Estudios Internacionales Ne99, año XXV, julio-septiembre 1992, pp. 385-404. AMERICA LATINA; RELACIONES INTERNACIONALES - ESTUDIO Y ENSEÑANZA; RELACIONES INTERNACIONALES - TEORIA; METODOLOGIA.

02914 Palmer, David Scott. "Perú 1992: la sorpresa de abril de Fujimori", Estudios Intemacionales N99, año XXV, julio-septiembre 1992, pp. 378-384.

PERU; AMERICA DEL SUR; GOLPES DE ESTADO; POLITICA Y GOBIERNO.

02915 León, Francisco. "Cuba: procesos y dilemas", Estudios Intenacionales N299, año XXV, julio-septiembre 1992, pp. 365-377.

CUBA; AMERICA CENTRAL Y CARIBE; POLITICA Y GOBIERNO; DEUDA EXTERNA; ECONOMIA INTERNACIONAL; REFORMAS; DEMOCRATIZACION; DESARROLLO SOCIAL; POLITICA ECONOMICA.

02916 Schamis, Héctor E. "Política económica conservadora en América Latina y Europa Occidental: las fuentes políticas de la privatización", Estudios Intenacionales №99, año XXV, julio-septiembre 1992, pp. 341-364.

AMERICA LATINA; EUROPA OCCIDENTAL; POLITICA ECONOMICA; CHILE; AMERICA DEL SUR; GRAN BRETAÑA; PRIVATIZACIONES.

02917 Iglesias, Enrique V. "Hacia una agenda económica para los años noventa", Estudios Internacionales No99, año XXV, julio-septiembre 1992, pp. 322-340.

AMERICA LATINA; CRECIMIENTO ECONOMICO; POLITICA ECONOMICA; POLITICA SOCIAL; ESTADO; REFORMAS; INTEGRACION ECONOMICA; ECONOMIA INTERNACIONAL; DESARROLLO SUSTENTABLE; POLITICA INTERNACIONAL. 
tivo", Estudios Intemacionales, NN98, año XXV, abril-junio 1992, pp. 275-313.

TERRORISMO; GUERRILLAS; EUROPA; AMERICA LATINA; VIOLENCIA; NICARAGUA; ALEMANIA REP. FEDERAL.

02811 Rehren, Alfredo J. "El liderazgo encubierto de Eisenhower", Estudios Intemacionales, №98, año XXV, abril-junio 1992, pp. 258-274. ESTADOS UNIDOS; AMERICA DEL NORTE; CHILE; AMERICA DEL SUR; RELACIONES BILATERALES; POLITICAINTERNACIONAL; LIDERES; INTERVENCION - DERECHO INTERNACIONAL; CUBA; AMERICA CENTRAL Y CARIBE; POLITICA Y GOBIERNO.

02812 Gomes Saraiva, Miriam. "Las dos dimensiones de la política exterior de la Comunidad Europea. Sus procesos de formulación y sus difíciles relaciones", Estudios Internacionales, N98, año XXV, abril-junio 1992, pp. 217-257.

COMUNIDADES EUROPEAS; POLITICA INTERNACIONAL; RELACIONES INTERNACIONALES; DERECHO COMUNITARIO; EUROPA; COOPERACION POLITICA; COOPERACION INTERNACIONAL.

02813 Klaveren, Alberto van. "Entendiendo las políticas exteriores latinoamericanas: modelo para armar", Estudios Intemacionales, №98, año XXV, abril-junio 1992, pp. 169-216.

AMERICA LATINA; POLITICA INTERNACIONAL; RELACIONES EXTERIORES; RELACIONES INTERNACIONALES - ESTUDIO Y ENSEÑANZA; DEPENDENCIA; ECONOMIA INTERNACIONAL.

02814 Petras, James. "Estados Unidos y el nuevo equilibrio en América Latina", Estudios Internacionales, Ne8, año II, enero-marzo 1969, pp. 490-518.

AMERICA LATINA; ESTADOS UNIDOS; AMERICA DEL NORTE; POLITICA Y GOBIERNO; POLITICA INTERNACIONAL; INTERVENCION - DERECHO INTEFNACIONAL; CONFLICTOS; DEPENDENCIA; ALIANZA PARA EL PROGRESO.

02815 Millar, T. B. "Los océanos Indico y Pacífico: algunas consideraciones estratégicas, Estudios Intemacionales, №11, año III, octubre-diciembre 1969, pp. 321-351.

OCEANO PACIFICO; OCEANO INDICO; OCEANOPOLITICA; MAR; ESTRATEGIA; SEGURIDAD; POLITICA INTERNACIONAL; POLITICA MUNDIAL.

02840 Diez años de Estudios Internacionales. Estudios Internacionales, Ne40, año X, octubre-diciembre 1977, pp. 3-4.

INSTITUTO DEESTUDIOS INTERNACIONALES; RELACIONESINTERNACIONALES - ESTUDIO Y ENSEÑANZA; CHILE; AMERICA DEL SUR.

02909 Instituto de Estudios Internacionales - Biblioteca. "Indice de Estudios Internacionales, Año XXIII, No89-92, 1990", Estudios Internacionales N993, año XXIV, enero-marzo 1991, pp. 159-173.

INDICE 
"ricana", Estudios Internacionales, Ne48, año XII, octubre-diciembre 1979, pp. 361-371.

AMERICA LATINA; RELACIONES NORTE SUR; POLITICA INTERNACIONAL; DIALOGO NORTE SUR.

02751 Sunkel, Osvaldo; Fuenzalida, Edmundo. "Capitalismo transnacional y desarrollo nacional", Estudios Intemacionales, №44, año XI, octubre-diciembre 1978, pp. 3-27.

CAPITALISMO; DESARROLLO ECONOMICO; ECONOMIA INTERNACIONAL; POLITICA INTERNACIONAL; EMPRESAS TRANSNACIONALES.

02752 Ferrer, Aldo. "La crisis del sistema trilateral y América Latina", Estudios Internacionales, №42, año XI, abril-junio 1978, pp. 3-38.

AMERICA LATINA; POLITICA MUNDIAL; ROLITICA INTERNACIONAL; ECONOMIA INTERNACIONAL; GRANDES POTENCIAS; EUROPA OCCIDENTAL; JAPON; ASIA; ESTADOS UNIDOS; AMERICA DEL NORTE.

02753 Sunkel, Osvaldo. "El desarrollo de la teoría del desarrollo", Estudios Internacionales, №40, año X, octubre-diciembre 1977, pp. 33-46. DESARROLLO ECONOMICO; TEORIA ECONOMICA; ECONOMIA INTERNACIONAL; DEPENDENCIA.

02754 Iglesias, Enrique V. "Transferencia de recursos en el ámbito internacional", Estudios Intemacionales, Ne34, año IX, abril-junio 1976, pp. $42-57$.

ECONOMIA INTERNACIONAL; NUEVO ORDEN ECONOMICO INTERNACIONAL; TERCER MUNDO; COOPERACION ECONOMICA; RELACIONES ECONOMICAS INTERNACIONALES.

02755 Véliz, Claudio; García, Antonio; Vernant, Jacques. "El seminario de Arica", Estudios Intemacionales, №5, año II, abril-junio 1968, pp. 138-150.

AMERICA LATINA; INTEGRACION ECONOMICA; INTEGRACION POLITICA.

02756 Niekerk, Arnold van. "América Latina y las Antillas Neerlandesas", Estudios Intemacionales, N²3, año VI, julio-septiembre 1973, pp. 93-104.

AMERICA LATINA; POLITICA INTERNACIONAL; ANTILLAS NEERLANDESAS; RELACIONES EXTERIORES; AMERICA CENTTAL Y CARIBE.

02809 Instituto de Estudios Internacionales - Biblioteca. "Bibliografía: Relaciones exteriores de América Latina", Estudios Intemacionales, Ne98, año XXV, abril-junio 1992, pp. 314-319.

AMERICA LATINA; RELACIONES EXTERIORES; POLITICA INTERNACIONAL; BIBLIOGRAFIA.

02810 Waldmann, Peter. "Terrorismo y guerrilla: la violencia organizada contra el Estado en Europa y América Latina. Un análisis compara- 
02728 Bodenheimer, Susanne. "La crisis del Movimiento Socialdemócrata en América latina", Estudios Internacionales, №12, año III, eneromarzo 1970, pp. 544-567.

AMERICA LATINA; SOCIALDEMOCRACIA.

02729 Cotler, Julio. "Crisis política y populismo militar en el Perú", Estıdios Intemacionales, $\mathrm{N}^{0} 12$, año III, enero-marzo 1970, pp. 439-488.

FUERZAS ARMADAS; PERU; MILITARISMO; POPULISMO; POLITICA Y GOBIERNO; CRISIS; AMERICA DEL SUR.

02743 Grabendorff, Wolf. "Perspectivas y polos de desarrollo en América Latina", Estudios Intertacionales, No50, año XIII, abril-junio 1980, pp. 252-278.

DESARROLLO ECONOMICO; AMERICA LATINA; POLITICA INTERNACIONAL; ECONOMIA INTERNACIONAL.

02744 Barros Charlín, Raymundo. "Notas sobre Andrés Bello y América Latina", Estudios Internacionales, №57, año XV, enero-marzo 1982, pp. 104-124.

AMERICA LATINA; BELLO, ANDRES; INTEGRACION REGIONAL.

02745 Klaveren, Alberto van. "La cooperación política curopea: realidades y desafíos de un modelo de concertación externa", Estudios Intemacionales, No83, año XXI, julio-septiembre 1988, pp. 327-353.

COMUNIDADES EUROPEAS; EUROPA; INTEGRACION REGIONAL; INTEGRACION ECONOMICA; POLITICA INTERNACIONAL; CONCERTACION POLITICA.

02746 O'Connell, Arturo. "La coordinación de los deudores latinoamericanos: el consenso de Cartagena y el Grupo de los Ocho", Estudios Internacionales, NNo83, año XXI, julio-septiembre 1988, pp. 373-385. DEUDA EXTERNA; ECONOMIA INTERNACIONAL; AMERICA LATINA; GRUPO DE LOS OCHO; CONCERTACION POLITICA.

02747 Griffith-Jones, Stephany. "El crecimiento de la banca multinacional, los mercados de euromonedas y los países de la periferia", Estudios Internacionales, N44, año XI, octubre-diciembre 1978, pp. 71-87. ECONOMIA INTERNACIONAL; BANCOS; EMPRESAS TRANSNACIONALES.

02748 Jaguaribe, Helio. "Autonomía periférica y hegemonía céntrica", Estudios Internacionales, N46, año XII, abril-junio 1979, pp. 91-130. POLITICA MUNDIAL; HISTORIA; GRANDES POTENCIAS; ESTADOS UNIDOS; AMERICA DEL NORTE; URSS; EUROPA DEL ESTE.

02749 Levine, Flavián. "¿Economía o economía política?", Estudios Internacionales, Ne47, año XII, julio-septiembre 1979, pp. 231-246. CIENCIAS SOCIALES; ECONOMIA; TEORIA ECONOMICA.

02750 Botero, Rodrigo. "La Comisión Brandt: una perspectiva latinoame- 
POLITICA INTERNACIONAL; AMERICA LATINA; RELACIONES NORTE SUR; ECONOMIA INTERNACIONAL; PAISES ARABES; RELACIONES EXTERIORES.

02720 Khalil, Ismael. "La promoción de las relaciones entre Estados latinoamericanos y árabes", Estudios Interiacionales, NN84, año XXI, octubre-diciembre 1988, pp. 451-461.

POLITICA INTERNACIONAL; AMERICA LATINA; ECONOMIA INTERNACIONAL; PAISES ARABES; RELACIONES ECONOMICAS INTERNACIONALES; RELACIONES EXTERIORES,

02721 Tulchin, Joseph S. "Los Estados Unidos y América Latina en la década del 60", Estudios Intemacionales, No84, año XXI, octubre-diciembre 1988, pp. 462-497.

ESTADOS UNIDOS; AMERICA DEL NORTE; AMERICA LATINA; POLITICAINTERNACIONAL; RELACIONES EXTERIORES.

02722 Tomassini, Luciano. "El análisis de la política exterior", Estudios Internacionales, Ne84, año XXI, octubre-diciembre 1988, pp. 498559 .

AMERICA LATINA; POLITICA INTERNACIONAL; RELACIONES EXTERIORES.

02723 Tomassini, Luciano. "Introducción al estudio de las nuevas formas de concertación latinoamericana", Estudios Intentacionales, №83, año XXI, julio-septiembre 1988, pp. 310-326.

AMERICA LATINA; CONCERTACION POLITICA; INTEGRACION REGIONAL; GRUPO DE LOS OCHO; GRUPO CONTADORA.

02724 Green, Rosario. "Nuevas formas de concertación regional en América Latina: el Grupo de los Ocho", Estudios Internacionales, Ne83, año XXI, julio-septiembre 1988, pp. 354-372.

AMERICA LATINA; CONCERTACION POLITICA; GRUPO DE LOS OCHO; POLITICA INTERNACIONAL; INTEGRACION REGIONAL.

02725 Peña, Félix. "Concertación latinoamericana: arquitectura de integración e ingeniería de negocios", Estudios Internacionales, №83, año XXI, julio-septiembre 1988, pp. 386-424.

AMERICA. LATINA; INTEGRACION REGIONAL; INTEGPACION ECONOMICA; CONCERTACION POLITICA; POLITICA INTERNACIONAL.

02726 Torres-Rivas, Edelberto. "Desarrollo, integración y dependencia en Centroamérica", Estudios Internacionales, N¹2, año III, enero-marzo 1970 , pp. $489-511$.

DESARROLLO ECONOMICO; INTEGRACION REGIONAL; DEPENDENCIA; AMERICA CENTRAL Y CARIBE; INTEGRACION ECONOMICA.

02727 Tomassini, Luciano. "La misión imposible del presidente Nixon", Estudios Intemacionales, №12, año III, enero-marzo 1970, pp. 512543.

ESTADOS UNIDOS; POLITICA MUNDIAL; AMERICA DEL NORTE. 
02699 Heine, Jorge. "Latinos y antillanos: Las relaciones entre América Latina y el Caribe en los noventa", Estudios Internacionales, №87, año XXII, julio-septiembre 1989, pp. 298-307.

AMERICA LATINA; AMERICA CENTRAL Y CARIBE; RELACIONES EXTERIORES; POLITICA INTERNACIONAL.

02707 Sierralta, Hernán. "La estructura de poder del BID", Estudios Internacionales, №82, año XXI, abril-junio 1988, pp. 141-156.

ECONOMIA INTERNACIONAL; BID; AMERICA LATINA.

02708 Paimer, David Scott. "Actores y factores en las relaciones contemporáneas de los Estados Unidos y América Latina", Estudios Internacionales, №82, año XXI, abril-junio 1988, pp. 157-172.

ESTADOS UNIDOS; AMERICA LATINA; AMERICA DEL NORTE; POLITICAINTERNACIONAL; RELACIONES EXTERIORES.

02709 Roett, Riordan. "Perspectivas para el Plan Arias en El Salvador y Guatemala", Estıdios Intemacionales, Ne82, año XXI, abril-junio 1988, pp. 173-183.

AMERICA CENTRAL Y CARIBE; EL SALVADOR; GUATEMALA; CONFLICTOS; POLITICA Y GOBIERNO.

02710 Perina, Rubén M.; Ramírez, Norma A. "La importancia de América Latina en el sistema internacional en la década de los ochenta: un ensayo bibliográfico", Estudios Internacionales, Ne82, año XXI, abriljunio 1988, pp. 184-205.

AMERICA LATINA; POLITICA INTERNACIONAL; BIBLIOGRAFIA.

02711 Edwards, Ernesto. "América Latina y la economía mundial", Estudios Internacionales, N282, año XXI, abril-junio 1988, pp. 206-253.

AMERICA LATINA; ECONOMIA INTERNACIONAL; DEUDA EXTERNA; COMERCIO EXTERIOR.

02712 Primer Seminario Regional sobre Diplomacia Económica: las politicas económicas de los países industrializados y su impacto en América Latina: síntesis de los debates. Estudios Intemacionales, №82, año XXI, abril-junio 1988, pp. 254-281.

DOCUMENTOS; ECONOMIA INTERNACIONAL; AMERICA LATINA; CIENCIA Y TECNOLOGIA; GATT; DEUDA EXTERNA; PAISES DESARROLLADOS; POLITICA ECONOMICA.

02718 Jaguaribe, Helio. "La relación Norte-Sur", Estudios Intemacionales, N284, año XXI, octubre-diciembre 1988, pp. 425-438.

RELACIONES NORTE SUR; TERCER MUNDO; DESARROLLO ECONOMICO.

02719 Fleixa Lima, Paulo de Tarso. "Perspectivas de las relaciones entre América Latina y los países de la Liga de los Estados Arabes", Estudios Internacionales, N84, año XXI, octubre-diciembre 1988, pp. 439-450. 
SEGURIDAD; ESTRATEGIA; ESTADOS UNIDOS; AMERICA DEL NORTE; URSS; AMERICA LATINA; OCEANO PACIFICO; EUROPA DEL ESTE.

02685 Grabendorff, Wolf. "La política nuclear y de no proliferación de Brasil", Estudios Internacionales, Ne80, año XX, octubre-diciembre 1987, pp. 520-568.

BRASIL; AMERICA DEL SUR; ENERGIA NUCLEAR; ARMAMENTISMO; POLITICA INTERNACIONAL; CONTROL DE ARMAMENTOS.

02686 Muñoz, Heraldo. "El escenario mundial hacia el año 2000", Estudios Internacionates, N281, año XXI, enero-marzo 1988, pp. 3-14. POLITICA MUNDIAL; FUTUROLOGIA.

02687 Peña, Félix. "La cumbre latinoamericana de Acapulco: transformación económica, democratización y cooperación internacional", Eshudios Intemacionales, №81, año XXI, enero-marzo 1988, pp. 15-22. AMERICA LATINA; POLITICA INTERNACIONAL; GRUPO DE LOS OCHO; COOPERACION INTERNACIONAL; DEMOCRATIZACION; REUNIONES CUMBRES; POLITICA ECONOMICA.

02688 Bitar, Sergio. "América Latina en el nuevo mapa de la economía mundial", Estudios Internacionales, Ne81, año XXI, enero-marzo 1988, pp. 23-44.

ECONOMIAINTERINACIONAL; AMERICA LATINA; ESTADOS UNIDOS; AMERICA DEL NORTE; COMUNIDAD ECONOMICA EUROPEA; EUROPA; JAPON; ASIA.

02689 Mols, Manfred. "ASEAN luego de la tercera reunión cumbre", Esttdios Intemacionales, №81, año XXI, enero-marzo 1988, pp. 45-60. ASEAN; POLITICA INTERNACIONAL; INTEGRACION ECONOMICA; INTEGRACION REGIONAL.

02690 Pardo, Rodrigo; Tokatlian, Juan Gabriel. "Teoría y práctica de las relaciones internacionales: el caso de Colombia", Estudios Internacionales, Ne81, año XXI, enero-marzo 1988, pp. 94-135.

COLOMBIA; AMERICA DEL SUR; RELACIONES INTERNACIONALES; POLTICA INTERNACIONAL; RELACIONES EXTERIORES.

02691 Moneta, Carlos J. "Corea del Sur y los países asiáticos de reciente industrialización (PARI) en el contexto de los cambios del sistema económico mundial. Reflexiones para América Latina", Estudios Intemacionales, Ne81, año XXI, enero-marzo 1988, pp. 61-93.

ASIA; ECONOMIA INTERNACIONAL; AMERICA LATINA; REFORMAS; COREA, REPUBLICA DE; NIC's.

02695 Russell, Roberto; Hirst, Mónica. "Democracia y política exterior los casos de Argentina y Brasil", Estudios Intemacionales, N280, año XX, octubre-diciembre 1987, pp. 442-490.

DEMOCRACIA; POLITICA INTERNACIONAL; ARGENTINA; BRASIL; AMERICA DEL SUR; POLITICA Y GOBIERNO. 
nidad Económica Europea y América Latina", Estudios Intemacionales, №79, año XX, julio-septiembre 1987, pp. 321-327.

COMUNIDAD ECONOMICA EUROPEA; EUROPA; AMERICA LATINA; ECONOMIA INTERNACIONAL; COOPERACION ECONOMICA; RELACIONES ECONOMICAS INTERNACIONALES.

02677 Lafer, Celso. "Las nuevas dimensiones de la política externa brasileña", Estudios Internacionales, №79, año XX, julio-septiembre 1987, pp. 328-341.

BRASIL; AMERICA DEL SUR; POLITICA INTERNACIONAL; POLITICA Y GOBIERNO; RELACIONES EXTERIORES.

02678 Valdivieso Eguiguren, Sergio. "El tema antártico en las Naciones Unidas", Estıdios Internacionales, №79, año XX, julio-septiembre 1987, pp. 342-351.

ANTARTICA; NACIONES UNIDAS.

02679 Portales, Carlos. "Democracia y derechos humanos en la política exterior del Presidente Reagan", Estudios Intemacionales, N79, año XX, julio-septiembre 1987, pp. 352-378.

ESTADOS UNIDOS; AMERICA DEL NORTE; DEMOCRACIA; DERECHOS HUMANOS; POLITICA INTERNACIONAL.

02680 Wilhelmy, Manfred. "La evolución de la multipolaridad", Estudios Intemacionales, №79, año XX, julio-septiembre 1987, pp. 379-401. POLITICA MUNDIAL; ESTADOS UNIDOS; AMERICA DEL NORTE; EUROPA; CHINA; ASIA; JAPON; PAISES NO ALINEADOS.

02681 Muñoz, Heraldo. "El estudio de las políticas exteriores latinoamericanas: temas y enfoques dominantes", Estudios Intemacionales, N\$80, año XX, octubre-diciembre 1987, pp. 406-434.

AMERICA LATINA; POLITICA INTERNACIONAL; RELACIONES INTERNACIONALES.

02682 Pardo, Rodrigo; Tokatlian, Juan Gabriel. "Política internacional, paz interna e interés nacional", Estudios Internacionales, N80, año XX, octubre-diciembre 1987, pp. 435-441.

POLITICA INTERNACIONAL; ESTADO; POLITICAY GOBIERNO; PAZ.

02683 Wilhelmy, Manfred; Fermandois Huerta, Joaquín. "La Cancillería en la futura política exterior de Chile", Estudios Intemacionales, No80, año XX, octubre-diciembre 1987, pp. 491-505.

CHILE; AMERICA DEL SUR; POLITICA INTERNACIONAL; DIPLOMACIA; MINISTERIO DE RELACIONES EXTERIORES.

02684 Varas, Augusto. "Percepciones estratégicas del Pacífico Sur", Estudios Internacionales, №80, año XX, octubre-diciembre 1987, pp. 506-519. 
de la Carta de 1985", Estudios Internacionales, №77, año XX, eneromarzo 1987, pp. 70-87.

OEA; SISTEMA INTERAMERICANO; REFORMAS.

02668 Barros Charlín, Raymundo. "Trayectoria y agenda de ALADI", Estudios Internacionales, №77, año XX, enero-marzo 1987, pp. 88-101. ALADI; INTEGRACION REGIONAL; INTEGRACION ECONOMICA; AMERICA LATINA.

02669 Muñoz, Heraldo. "Las causas del auge y la declinación del Sistema Interamericano de Seguridad: una perspectiva latinoamericana", $E S-$ tudios Internacionales, №77, año XX, enero-marzo 1987, pp. 102-113. SISTEMA INTERAMERICANO; SEGURIDAD; AMERICA LATINA; ESTADOS UNIDOS; AMERICA DEL NORTE.

02670 Tomassini, Luciano. "Elementos para el análisis de la política exterior", Estudios Intemacionales, №78, año XX, abril-junio 1987, pp. 125-157.

POUITICA INTERNACIONAL; RELACIONES INTERNACIONALES.

02671 Boisier, Sergio. "Notas en torno al desarrollo de regiones fronterizas en América Latina", Estudios Intemacionales, №78, año XX, abriljunio 1987, pp. 158-191.

AMERICA LATINA; FRONTERAS; DESARROLLO; INTEGRACION REGIONAL.

02672 Tulchin, Joseph S. "La Guerra de las Malvinas: un conflicto inevitable que nunca debió haber ocurrido", Estudios Internacionales, №78, año XX, abril-junio 1987, pp. 192-209.

ISLAS MALVINAS; AMERICA DEL SUR; CONFLICTOS; ARGENTINA; SEGURIDAD; ESTRATEGIA; GUERRA.

02673 Pinochet de la Barra, Oscar. "Negociaciones antárticas de Chile en un mundo cambiante", Estudios Internacionales, N278, año XX, abriljunio 1987, pp. 210-222.

ANTARTICA; CHILE; AMERICA DEL. SUR; NEGOCIACIONES; POLITICA MUNDIAL.

02674 Pomerlau, Claude. "El problema de las relaciones Iglesia-Estado en México", Estudios Internacionales, No78, año XX, abril-junio 1987, pp. 223-241.

MEXICO; AMERICA DEL NORTE; IGLESIA CATOLICA; POLITICA Y GOBIERNO.

02675 Bianchi, Andrés; Devlin, Robert; Ramos, Joseph. "El proceso de ajuste en América Latina 1981-1986", Estudios Internacionales, №79, año XX, julio-septiembre 1987, pp. 272-320.

ECONOMIA INTERNACIONAL; AMERICA LATINA; DEUDA EXTERNA; POLITICA ECONOMICA.

02676 Iglesias, Enrique V. "Nuevas formas de cooperación entre la Comu- 
02659 Irigoin, Jeannette. "El espacio: ¿Patrimonio común de la humanidad?" Estudios Internacionales, №75, año XIX, julio-septiembre 1986, pp. 392-404.

ESPACIO EXTERIOR; DERECHO ESPACIAL; CIENCIA Y TECNOLOGIA; DERECHO INTERNACIONAL.

02660 Pérez, Carlota. "Las nuevas tecnologías: una visión de conjunto", Estudios Internacionales, №76, año XIX, octubre-diciembre 1986, pp. 420-459.

CIENCIA Y TECNOLOGIA; TECNOLOGIA.

02661 Lorino, Philippe. "La Comunidad Económica Europea en la competencia tecnológica mundial", Estudios Intemacionales, №76, año XIX, octubre-diciembre 1986, pp. 460-486.

COMUNIDAD ECONOMICA EUROPEA; EUROPA; CIENCIA Y TECNOLOGIA; POLITICA INTERNACIONAL; TECNOLOGIA.

02662 Sagasti, Francisco R. "Perspectivas futuras de la ciencia y la tecnología en América Latina", Estudios Intemacionales, N²76, año XIX, octubre-diciembre 1986, pp. 487-512.

CIENCIA Y TECNOLOGIA; AMERICA LATINA; POLITICA INTERNACIONAL.

02663 Bitar, Sergio. "Las políticas económicas de los países desarrollados. Consecuencias para América Latina", Estudios Intemacionales, №76, año XIX, octubre-diciembre 1986, pp. 513-530.

ECONOMIA INTERNACIONAL; AMERICA LATINA; PAISES DESARROLLADOS; POLITICA ECONOMICA.

02664 Varas, Augusto. "De la competencia a la cooperación militar en América Latina", Estudios Intemacionales, №77, año XX, eneromarzo 1987, pp. 3-18.

FUERZAS ARMADAS; AMERICA LATINA; POLITICA INTERNACIONAL; SEGURIDAD; COOPERACION REGIONAL; POLITICA MILITAR.

02665 Armanet Armanet, Pilar. "La zona desnuclearizada latinoamericana en la perspectiva de la cooperación regional", Estudios Internacionales, N277, año XX, enero-marzo 1987, pp. 19-38.

AMERICA LATINA; ARMAMENTISMO; TRATADO DE TLATELOLCO; POLITICA INTERNACIONAL; ZONAS DESNUCLEARIZADAS; COOPERACION REGIONAL.

02666 Mercado Jarrín, Edgardo. "Perspectivas de los acuerdos de limitación de desarme en América Latina y el Caribe", Estudios Internacionales, №77, año XX, enero-marzo 1987, pp. 39-69.

ARMAMENTISMO; SEGURIDAD; AMERICA LATINA; POLTICA INTERNACIONAL; PERU; AMERICA DEL SUR; AMERICA CENTRAL Y CARIBE; DESARME.

02667 Orrego Vicuña, Francisco. "La búsqueda de un nuevo papel para la Organización de los Estados Americanos: el Protocolo de Reformas 
de la Carta de 1985", Estudios Intemacionales, №77, año XX, eneromarzo 1987, pp. 70-87.

OEA; SISTEMA INTERAMERICANO; REFORMAS.

02668 Barros Charlín, Raymundo. "Trayectoria y agenda de ALADI", Estudios Internacionales, №77, año XX, enero-marzo 1987, pp. 88-101. ALADI; INTEGRACION REGIONAL; INTEGRACION ECONOMICA; AMERICA LATINA.

02669 Muñoz, Heraldo. "Las causas del auge y la declinación del Sistema Interamericano de Seguridad: una perspectiva latinoamericana", Estudios Intemacionales, №77, año XX, enero-marzo 1987, pp. 102-113. SISTEMA INTERAMERICANO; SEGURIDAD; AMERICA LATINA; ESTADOS UNIDOS; AMERICA DEL NORTE.

02670 Tomassini, Luciano. "Elementos para el análisis de la política exterior", Estudios Intemacionales, N\$78, año XX, abril-junio 1987, pp. 1.25-1.57.

POLITICA INTERNACIONAL; RELACIONES INTERNACIONALES.

02671 Boisier, Sergio. "Notas en torno al desarrollo de regiones fronterizas en América Latina", Estudios Intemacionules, N878, año XX, abriljunio 1987, pp. 158-191.

AMERICA LATINA; FRONTERAS; DESARROLLO; INTEGRACION REGIONAL.

02672 Tulchin, Joseph S. "La Gucra de las Malvinas: un conflicto inevitable que nunca debió haber ocurrido", Estudios Internacionales, N278, año XX, abril-junio 1987, pp. 192-209.

ISLAS MALVINAS; AMERICA DEL SUR; CONFLICTOS; ARGENTINA; SEGURIDAD; ESTRATEGIA; GUERRA.

02673 Pinochet de la Barra, Oscar. "Negociaciones antárticas de Chile en un mundo cambiante", Estudios Internacionales, N278, año XX, abriljunio 1987, pp. 210-222.

ANTARTICA; CHILE; AMERICA DEL SUR; NEGOCIACIONES; POLITICA MUN. DIAL.

02674 Pomerlau, Claude. "El problema de las relaciones Iglesia-Estado en México", Estudios Intemacionales; N78, año XX, abril-junio 1987, pp. 223-241.

MEXICO; AMERICA DEL NORTE; IGLESIA CATOLICA; POLITICA Y GOBIERNO.

02675 Bianchi, Andrés; Devlin, Robert; Ramos, Joseph. "El proceso de ajuste en América Latina 1981-1986", Estudios Internacionales, No79, año XX, julio-septiembre 1987, pp. 272-320.

ECONOMIA INTERNACIONAL; AMERICA LATINA; DEUDA EXTERNA; POLITICA ECONOMICA.

02676 Iglesias, Enrique V. "Nuevas formas de cooperación entre la Comu- 
nidad Económica Europea y América Latina", Estudios Intemacionales, №79, año XX, julio-sepliembre 1987, pp. 321-327.

COMUNIDAD ECGNOMICA EUROPEA; EUROPA; AMERICA LATINA; ECONOMIA INTERNACIONAL; COOPERACION ECONOMICA; RELACIONES ECONOMICAS INTERNACIONALES.

02677 Lafer, Celso. "Las nuevas dimensiones de la política cxterna brasileña", Estudios Intemacionales, No79, año XX, julio-scptiembre 1987, pp. 328-341.

BRASIL_; AMERICA DEL SUR; POLITICAINTERNACIONAL; POLITICA Y GOBIERNO; RELACIONES EXTERIORES.

02678 Valdivieso Eguiguren, Sergio. "El tema antártico en las Naciones Unidas", Estudios Internacionales, $N^{8} 79$, año XX, julio-septiembre 1987, pp. 342-351.

ANTARTICA; NACIONES UNIDAS.

02679 Portales, Carlos. "Democracia y derechos humanos en la política exterior del Presidente Reagan", Estudios Intemacionales, №79, año $\mathrm{XX}$, julio-septiembre 1987, pp. 352-378.

ESTADOS UNIDOS; AMERICA DEL NORTE; DEMOCRACIA; DERECHOS HUMANOS; POLITICA INTERNACIONAL.

02680 Wilhelmy, Manfred. "La evolución de la multipolaridad", Estudios Internacionales, Ne79, año XX, julio-scptiembre 1987, pp. 379-401. POLITICA MUNDIAL; ESTADOS UNIDOS; AMERICA DEL NORTE; EUROPA; CHINAA; ASIA; JAPON; PAISES NO ALINEADOS.

02681 Muño\%, Heraldo. "El estudio de las políticas exteriores latinoamericanas: temas y enfoques dominantes", Estudios Intemacionales, Ne80, año XX, octubre-diciembre 1987, pp. 406-434.

AMERICA LATINA; POLITICA INTERNACIONAL; RELACIONES INTERNACIONALES.

02682 Pardo, Rodrigo; Tokatlian, Juan Gabriel. "Política internacional, paz interna c interés nacional", Estudios Intemacionales, Ne80, año XX, octubrc-diciembre 1987, pp. 435-441. POLITICA INTERNACIONAL; ESTADO; POLITICA Y GOBIERNO; PAZ.

02683 Wilhelmy, Manfred; Fermandois Huerta, Joaquín. "La Cancillería en la futura política cxterior de Chile", Estudios Intemacionales, №80, año XX, octubre-dicicmbre 1987, pp. 491-505.

CHILE; AMERICA DEL SUR; POLITICA INTERNACIONAL; DIPLOMACIA; MINISTERIO DE RELACIONES EXTERIORES.

02684 Varas, Augusto. "Percepciones estratégicas del Pacílico Sur", Estudios Intemacionales, No80, año XX, octubre-diciembre 1987, pp. 506-519. 
SEGURIDAD; ESTRATEGIA; ESTADOS UNIDOS; AMERICA DEL NORTE; URSS; AMERICA LATINA; OCEANO PACIFICO; EUROPA DEL ESTE.

02685 Grabendorf, Wolf. "La política nuclear y de no proliferación de Brasil", Estudios Internacionales, N80, año XX, octubre-diciembre 1987, pp. 520-568.

BRAS!L; AMERICA DEL SUR; ENERGIA NUCLEAR; ARMAMENTISMO; POLITICA INTERNACIONAL; CONTROL DE ARMAMENTOS.

02686 Muñoz, Heraldo. "El escenario mundial hacia el año 2000", Estadios Internacionales, Ne81, año XXI, enero-marzo 1.988, pp. 3-1.4. POLITICA MUNDIAL; FUTUROLOGIA.

02687 Peña, Félix. "La cumbre latinoamericana de Acapulco: transformación económica, democratización y cooperación internacional", Esildios Intemacionales, N281, año XXI, cnero-marzo 1988, pp. 15-22. AMERICA LATINA; POLITICA INTERNACIONAL; GRUPO DE LOS OCHO; COOPERACION INTERNACIONAL; DEMOCPATIZACION; REUNIONES CUMBRES; POLITICA ECONOMICA.

02688 Bitar, Sergio. "América Latina en el nucvo mapa de la cconomía mundial", Estudios Intemacionales, N\$81, año XXI, enero-marzo 1988 , pp. 23-44.

ECONOMIA INTERNACIONAL; AMERICA LATINA; ESTADOS UNIDOS; AMERICA DEL NORTE; COMUNIDAD ECONOMICA EUROPEA; EUROPA; JAPON; ASIA.

02689 Mols, Manfred. "ASEAN luego de la tercera reunión cumbre", Estudios Inlemacionales, Ne81, año XXI, enero-marto 1988, pp. 45-60. ASEAN; POLITICA INTERNACIONAL; INTEGRACION ECONOMICA; INTEGRACION REGIONAL.

02690 Pardo, Rodrigo; Tokatlian, Juan Gabricl. "Tcoría y práctica de las relaciones internacionales: el caso de Colombia", Estudios Internacionales, N81, año XXI, encro-marzo 1988, pp. 94-135.

COLOMBIA; AMERICA DEL SUR; RELACIONES INTERNACIONALES; POLITICA INTERNACIONAL; RELACIONES EXTERIORES.

02691 Moneta, Carlos J. "Corea del Sur y los países asiáticos de recicnte industrialización (PAR) en el contexto de los cambios del sistema económico mundial. Reflexiones para América Latina", Estudios Internacionales, N81, año XXI, encro-marzo 1988, pp. 61-93.

ASIA; ECONOMIA INTERNACIONAL; AMERICA LATINA; REFORMAS; COREA, REPUBLICA DE; NIC's.

02695 Russell, Roberto; Hirst, Mónica. "Democracia y polílica exterior los casos de Argentina y Brasil", Estudios Intemacionales, $\mathrm{N}^{\circ} 80$, año XX, octubre-diciembrc 1987, pp. 442-490.

DEMOCRACIA; POLITICA INTERNACIONAL; ARGENTINA; BRASIL; AMERICA DEL SUR; POLITICA Y GOBIERNO. 
02699 Hcine, Jorge. "Latinos y antillanos: Las relaciones entre América Latina y el Caribe en los noventa", Estudios Intemacionales, Ne87, año XXII, julio-septiembre 1989, pp. 298-307.

AMERICA LATINA; AMERICA CENTRAL Y CARIBE; RELACIONES EXTERIORES; POLITICA INTERNACIONAL.

02707 Sierralta, Hernán. "La estructura de poder del BID", Estudios Internacionales, N'82, año XXI, abril-junio 1988, pp. 141-156. ECONOMIA INTERNACIONAL; BID; AMERICA LATINA.

02708 Palmer, David Scott. "Actores y factores en las relaciones contemporáneas de los Estados Unidos y América Latina", Estudios Intemacionales, Ne82, año XXI, abril-junio 1988, pp. 157-172.

ESTADOS UNIDOS; AMERICALATINA; AMERICA DEL NORTE; POLITICAINTERNACIONAL; RELACIONES EXTERIORES.

02709 Roett, Riordan. "Perspectivas para el Plan Arias en El Salvador y Guatemala", Estudios Intemacionales, Ne82, año XXI, abril-junio 1988, pp. 173-183.

AMERICA CENTRAL Y CARIBE; EL SALVADOR; GUATEMALA; CONFLICTOS; POLITICA Y GOBIERNO.

02710 Perina, Rubén M.; Ramírcz, Norma A. "La importancia de América Latina en el sistema internacional en la década de los ochenta: un ensayo bibliográfico", Estudios Intemacionales, Ne82, año XXI, abriljunio 1988, pp. 184-205.

AMERICA LATINA; POLITICA INTERNACIONAL; BIBLIOGRAFIA.

02711 Edwards, Ernesto. "América Latina y la economía mundial", Estudios Intemacionales, No82, año XXI, abril-junio 1988, pp. 206-253.

AMERICA LATINA; ECONOMIA INTERNACIONAL; DELDA EXTERNA; COMERCIO EXTERIOR.

02712 Primer Seminario Regional sobre Diplomacia Económica: las politicas económicas de los países industrializados y su impacto en América Latina: sintesis de los debates. Estudios Internacionales, No82, año XXI, abril-junio 1988, pp. 254-281.

DOCUMENTOS; ECONOMIA INTERNACIONAL; AMERICA LATINA; CIENCIA Y TECNOLOGIA; GATT; DEUDA EXTERNA; PAISES DESARROLLADOS; POLITICA ECONOMICA.

02718 Jaguaribe, Helio. "La relación Norte-Sur", Estudios Intemacionales, Ne84, año XXI, octubre-diciembre 1988, pp. 425-438.

RELACIONES NORTE SUR; TERCER MUNDO; DESARROLLO ECONOMICO.

02719 Fleixa Lima, Paulo de Tarso. "Perspectivas de las relaciones entre América Latina y los países de la Liga de los Estados Arabes", Estudios Internacionales, №84, año XXI, octubre-diciembre 1988, pp. $439-450$. 
POLITICA INTERNACIONAL; AMERICA LATINA; RELACIONES NORTE SUR; ECONOMIA INTERNACIONAL; PAISES ARABES; RELACIONES EXTERIORES.

02720 Khalil, Ismael. "La promoción de las rciaciones entre Estados latinoamericanos y árabes", Estudios Intenacionales, N984, año XXI, octubrc-diciembre 1988, pp. 451-461.

POLITICA INTERNACIONAL; AMERICA LATINA; ECONOMIA INTERNACIONAL; PAISES ARABES; RELACIONES ECONOMICAS INTERNACIONALES; RELACIONES EXTERIORES.

02721 Tulchin, Joseph S. "Los Estados Unidos y América Latina en la década del $60^{n}$, Estudios Intemacionales, N284, año XXI, octubre-diciembrc 1988 , pp. $462-497$.

ESTADOS UNIDOS; AMERICA DEL NORTE; AMERICA LATINA; POLITICAINTERNACIONAL; RELACIONES EXTERIORES.

02722 Tomassini, Luciano. "El análisis de la política extcrior", Estudios Internacionales, Ne84, año XXI, octubre-diciembre 1989, pp. 498559.

AMERICA LATINA; POLITICA INTERNACIONAL; RELACIONES EXTERIORES.

02723 Tomassini, Luciano. "Introducción al estudio de las nuevas formas de concertación latinoamericana", Estudios Intentacionoles, N83, año XXI, julio-septicmbre 1988, pp. 310-326.

AMERICA LATINA; CONCERTACION POLITICA; INTEGRACION REGIONAL; GRUPO DE LOS OCHO; GRUPO CONTADORA.

02724 Green, Rosario. "Nuevas formas de concertación regional en América Latina: cl Grupo de los Ocho", Estudios Intemacionales, No83, año XXI, julio-septiembre 1988, pp. 354-372.

AMERICA LATINA; CONCERTACION POLITICA; GRUPO DE LOS OCHO; POLITICA INTERNACIONAL; INTEGRACION REGIONAL.

02725 Peña, Félix. "Concertación latinoamericana: arquileclura de integración e ingeniería de negocios", Estudios Intemacionales, N!83, año XXI, julio-septiembre 1988, pp. 386-424.

AMERICA LATINA; INTEGRACION REGIONAL; INTEGRACION ECONOMICA; CONCERTACION POLITICA; POLITICA INTERNACIONAL.

02726 Torres-Rivas, Edelberto. "Desarrollo, integración y dependencia en Centroamérica", Estudios Intemacionales, No12, año Ill, encro-marzo 1970, pp. 489-511.

DESARROLLO ECONOMICO; INTEGRACION REGIONAL; DEPENDENCIA; AMERICA CENTRAL Y CARIBE; INTEGRACION ECONOMICA.

02727 Tomassini, Luciano. "La misión imposible del presidente Nixon", Estudios Internacionales, $\mathrm{N}^{\mathrm{0}} 12$, año III, enero-marzo 1970, pp. 512543.

ESTADOS UNIDOS; POLITICA MUNDIAL; AMERICA DEL NORTE. 
02728 Bodenheimer, Susanne. "La crisis del Movimiento Socialdemócrata en Amćrica latina", Estudios Internacionales, No12, año III, eneromarzo 1970, pp. 544-567.

AMERICA LATINA; SOCIALDEMOCRACIA.

02729 Cotler, Julio. "Crisis política y populismo militar en el Perú", Estudios Intemacionales, №12, año III, cnero-marzo 1970, pp. 439-488.

FUERZAS ARMADAS; PERU; MILITARISMO; POPULISMO; POLITICA Y GOBEERNO; CRISIS; AMERICA DEL SUR.

02743 Grabendorff, Woll. "Perspectivas y polos de desarrollo en América Latina", Estudios Intemacionales, №50, año XIII, abril-junio 1980, pp. 252-278.

DESARROLLO ECONOMICO; AMERICA LATINA; POLITICA INTERNACIONAL; ECONOMIA INTERNACIONAL.

02744 Barros Charlín, Raymundo. "Notas sobre Andrés Bello y América Latina", Estudios Intemacionales, N57, año XV, cnero-marzo 1982, pp. 104-124.

AMERICA LATINA; BELLO, ANDRES; INTEGRACION REGIONAL.

02745 Klaveren, Alberto van. "La cooperación política curopea: realidades y desafíos de un modelo de concertación externa", Estudios Intemacionales, N983, año XXI, julio-septiembre 1988, pp. 327-353.

COMUNIDADES EUROPEAS; EUROPA; INTEGRACION REGIONAL; INTEGRACION ECONOMICA; POUITICA INTERNACIONAL; CONCERTACION POLITICA.

02746 O'Conncll, Arturo. "La coordinación de los deudores latinoamericanos: el consenso de Cariagena y el Grupo de los Ocho", Estudios Intemacionales, No83, año XXI, julio-septiembre 1988, pp. 373-385. DEUDA EXTERNA; ECONOMIA INTERNACIONAL; AMERICA LATINA; GRUPO DE LOS OCHO; CONCERTACION POLITICA.

02747 Griffith-Jones, Stephany. "El crecimiento de la banca multinacional, los mercados de curomonedas y los paises de la periferia", Estudios Intentacionales, $N^{\circ} 44$, año XI, octubre-dicicmbre 1978, pp. 71-87. ECONOMIA INTERNACIONAL; BANCOS; EMPRESAS TRANSNACIONALES.

02748 Jaguaribe, Helio. "Autonomía periférica y hegemonia céntrica", Estudios Intemacionales, №46, año XII, abril-junio 1979, pp. 91-130. POLITICA MUNDIAL; HISTORIA; GRANDES POTENCIAS; ESTADOS UNIDOS; ÁMERICA DEL NORTE; URSS; EUROPA DEL ESTE.

02749 Levine, Flavián. "iEconomía o economía política?", Estudios Internacionales, N47, año XII, julio-septiembre 1979, pp. 231-246. CIENCIAS SOCIALES; ECONOMIA; TEORIA ECONOMICA.

02750 Botero, Rodrigo. "La Comisión Brandt: una perspectiva latinoame[658] 
ricana", Estudios Internacionales, No48, año XII, octubre-diciembre 1979, pp. 361-371.

AMERICA LATINA; RELACIONES NORTE SUR; POLITICA INTERNACIONAL; DIALOGO NORTE SUR.

02751 Sunkel, Osvaldo; Fuenzalida, Edmundo. "Capitalismo transnacional y desarrollo nacional", Estudios Intemacionales, N44, año XI, octubre-diciembre 1978, pp. 3-27.

CAPITALISMO; DESARROLLO ECONOMICO; ECONOMIA INTERNACIONAL; POLITICA INTERNACIONAL; EMPRESAS TRANSNACIONALES.

02752 Ferrer, Aldo. "La crisis del sistema trilateral y América Latina", Estudios Internacionales, Ne42, año XI, abril-junio 1978, pp. 3-38. AMERICA LATINA; POLITICA MUNDIAL; POLITICA INTERNACIONAL; ECONOMIA INTERNACIONAL; GRANDES POTENCIAS; EUROPA OCCIDENTAL; JAPON; ASIA; ESTADOS UNIDOS; AMERICA DELL NORTE.

02753 Sunkel, Osvaldo. "El desarrollo de la teoría del desarrollo", Estudios Internacionales, N40, año X, octubre-diciembre 1977, pp. 33-46.

DESARROLLO ECONOMICO; TEORIA ECONOMICA; ECONOMIA INTERNACIONAL; DEPENDENCIA.

02754 Iglesias, Enrique V. "Transferencia de recursos en el ámbito internacional", Estudios Intemacionales, Ne34, año IX, abril-junio 1976, pp. $42-57$.

ECONOMIA INTERNACIONAL; NUEVO ORDEN ECONOMICO INTERNACIONAL; TERCER MUNDO; COOPERACION ECONOMICA; RELACIONES ECONOMICAS INTERNACIONALES,

02755 Véliz, Claudio; García, Antonio; Vernant, Jacques. "El seminario de Arica", Estudios Intentacionales, NQ5, año II, abri1-junio 1968, pp. 138-150.

AMERICA LATINA; INTEGRACION ECONOMICA; INTEGRACION POLITICA.

02756 Niekerk, Arnold van. "América Latina y las Antillas Necrlandesas", Estudios Internacionales, No23, año VI, julio-septiembre 1973, pp. 93-104.

AMERICA LATINA; POLITICA INTERNACIONAL; ANTILLAS NEERLANDESAS; RELACIONES EXTERIORES; AMERICA CENTRAL Y CARIBE.

02809 Instituto de Estudios Internacionales - Biblioteca. "Bibliografía: Relaciones exteriores de Amćrica Latina", Estudios Intemacionales, NN98, año XXV, abril-junio 1992, pp. 314-319.

AMERICA LATINA; RELACIONES EXTERIORES; POLITICA INTERNACIONAL; BIBLIOGRAFIA.

02810 Waldmann, Peter. "Terrorismo y guerrilla: la violencia organizada contra el Estado en Europa y América Latina. Un análisis compara- 
tivo", Estudios Intemacionales, N98, año XXV, abril-junio 1992, pp. 275-313.

TERRORISMO; GUERRILLAS; EUROPA; AMERICA LATINA; VIOLENCIA; NICARAGUA; ALEMANIA REP. FEDERAL.

02811 Rehren, Allredo J. "El liderazgo encubierto de Eisenhower", Estudios Intentacionules, NQ98, año XXV, abril-junio 1992, pp. 258-274. ESTADOS UNIDOS; AMERICA DEL NORTE; CHILE; AMERICA DEL SUR; RELACIONES BILATERALES; POLITICAINTERNACIONAL; LIDERES; INTERVENCION - DERECHO INTERNACIONAL; CUBA; AMERICA CENTRAL Y CARIBE; POLITICA Y GOBIERNO.

02812 Gomes Saraiva, Miriam. "Las dos dimensiones de la política extcrior de la Comunidad Europea. Sus procesos de formulación y sus difíciless relaciones", Estudios Internacionales, N98, año XXV, abril-junio 1992, pp. 217-257.

COMUNIDADES EUROPEAS; POLITICA INTERNACIONAL; RELACIONES INTERNACIONALES; DERECHO COMUNITARIO; EUROPA; COOPERACION POLITICA; COOPERACION INTERNACIONAL.

02813 Klaveren, Alberto van. "Entendiendo las políticas exteriores latinoamericanas: modcio para armar", Estudios Internacionales, Ne98, año XXV, abril-junio 1992, pp. 169-216.

AMERICA LATINA; POLITICA INTERNACIONAL; RELACIONES EXTERIORES; RELACIONES INTERNACIONAL.ES - ESTUDIO Y ENSEÑANZA; DEPENDENCIA; ECONOMIA INTERNACIONAL.

02814 Petras, Jamcs. "Estados Unidos y el nuevo equilibrio en América Latina", Estudios Intenacionales, NeS, año II, cnero-marzo 1969, pp. 490-518.

AMERICA LATINA; ESTADOS UNIDOS; AMERICA DEL NORTE; POLITICA Y GOBIERNO; POLITICA INTERNACIONAL; INTERVENCION - DERECHO INTEFNACIONAL; CONFLICTOS; DEPENDENCIA; ALIANZA PARA EL PROGRESO.

02815 Millar, T. B. "Los ocćanos Indico y Pacífico: algunas consideraciones cstratégicas, Estudios Intemacionales, № 11 , año III, octubre-diciembre 1969, pp. 321-351.

OCEANO PACIFICO; OCEANO INOICO; OCEANOPOLITICA; MAR; ESTRATEGIA; SEGURIDAD; POLITICA INTERNACIONAL; POLITICA MUNDIAL.

02840 Diez años de Estudios Internacionales. Estudios Intemacionales, N40, año X, octubrc-dicicmbre 1977, pp. 3-4.

INSTITUTO DE ESTUDIOS INTERNACIONALES; RELACIONES INTERNACIONALES - ESTUDIO Y ENSENAANZA; CHILE; AMERICA DEL SUR.

02909 Instituto de Estudios Internacionales - Biblioteca. "Indice de Estudios Internacionales, Año XXIII, Ne89-92, 1990", Estudios Intemacionales No93, año XXIV, encro-marzo 1991., pp. 159-173. INDICE 
02910 Instituto de Estudios Internacionales - Biblioteca. "Indice de Estudios Internacionales, Año XXIV, Ne93-96, 1991.", Estudios Intemacionales №97, año XXV, enero-marzo 1992, pp. 154-166.

INDICE

0291.1 Instituto de Estudios Internacionales - Biblioteca. "Bibliografía: Derecho internacional", Estudios Internacionales №9, año XXV, julio-scptiembre 1992, pp. 437-445.

DERECHO INTERNACIONAL; BIBLIOGRAFIA.

02912 Infante Cafli, María Tercsa. "El derecho internacional como objeto de los estudios intcrnacionales", Estudios Internacionales No99, año XXV, julio-septiembre 1992, pp. 427-436.

DERECHO INTERNACIONAL; RELACIONES INTERNACIONALES - ESTUDIO Y ENSENNANZA; ESTUDIO Y ENSEÑANZA.

02913 Durán, Roberto. "Vigencia del esquema conductualista en los estudios internacionales: su viabilidad en América Latina", Estudios Intenacionales No99, año XXV, julio-septiembre 1992, pp. 385-404. AMERICALATINA; RELACIONES INTERNACIONALES - ESTUDIO Y ENSEÑANZA; RELACIONES INTERNACIONALES - TEORIA; METODOLOGIA.

02914 Palmer, David Scott. "Perú 1992: la sorpresa de abril de Fujimori", Estudios Intemacionales N\$99, año XXV, julio-septicmbre 1992, pp. 378-384.

PERU; AMERICA DEL SUR; GOLPES DE ESTADO; POLITICA Y GOBIERNO.

02915 León, Francisco. "Cuba: procesos y dilemas", Estudios IntentacionaIes Ne99, año XXV, julio-septicmbre 1992, pp. 365-377.

CUBA; AMERICA CENTRAL Y CARIBE; POLITICA Y GOBIERNO; DEUDA EXTERNA; ECONOMIA INTERNACIONAL; REFORMAS; DEMOCRATIZACION; DESARROLLLO SOCIAL; POLITICA ECONOMICA.

02916 Schamis, Hector E. "Política cconúmica conservadora en América Latina y Europa Occidental: las fuentes políticas de la privatización", Estadios Internacionales $\mathrm{N}^{\mathrm{9} 99}$, año XXV, julio-septiembre 1992, pp. 341-364.

AMERICA LATINA; EUROPA OCCIDENTAL; POLITICA ECONOMICA; CHILE; AMERICA DEL SUR; GRAN BRETAÑA; PRIVATIZACIONES.

02917 Iglesias, Enrique V. "Hacia una agenda económica para los años noventa", Estudios Intemacionales $\mathrm{N}^{299}$, año XXV, julio-septiembre 1992, pp. 322-340.

AMERICA LATINA; CRECIMIENTO ECONOMICO; FOLITICA ECONOMICA; POLITICA SOCIAL; ESTADO; REFORMAS; INTEGRACION ECONOMICA; ECONOMIA INTERNACIONAL; DESARROLLO SUSTENTABLE; POLITICA INTERNACIONAL. 